\title{
SYNCHRONOUS ONLINE PEER TUTORING VIA VIDEO CONFERENCING TECHNOLOGY: AN EXPLORATORY CASE STUDY
}

\section{by}

Christopher David Smith

\author{
A dissertation \\ submitted in partial fulfillment \\ of the requirements for the degree of \\ Doctor of Education in Educational Technology \\ Boise State University
}

August 2018 
Christopher David Smith SOME RIGHTS RESERVED

\section{(c) () (2) (2)}

This work is licensed under a Creative Commons Attribution-Noncommercial-

Share Alike 3.0 License. 


\title{
BOISE STATE UNIVERSITY GRADUATE COLLEGE
}

\section{DEFENSE COMMITTEE AND FINAL READING APPROVALS}

\author{
of the dissertation submitted by
}

Christopher David Smith

Dissertation Title: Synchronous Online Peer Tutoring Via Video Conferencing Technology: An Exploratory Case Study

Date of Final Oral Examination: $\quad 25$ April 2018

The following individuals read and discussed the dissertation submitted by student Christopher David Smith, and they evaluated his presentation and response to questions during the final oral examination. They found that the student passed the final oral examination.

Patrick R. Lowenthal, Ph.D.

Chareen Lee Snelson, Ed.D.

Dazhi Yang, Ph.D.
Chair, Supervisory Committee

Member, Supervisory Committee

Member, Supervisory Committee

The final reading approval of the dissertation was granted by Patrick Lowenthal, Ph.D., Chair of the Supervisory Committee. The dissertation was approved by the Graduate College. 


\section{DEDICATION}

I dedicate this dissertation to my wife Caroline, our two children Savannah and Maggie, and my late mother-in-law Peggy Kirby. Caroline, Savannah, and Maggie have been there to love and support me every step of the way throughout my doctoral studies. While my mother-in-law Peggy was called to her heavenly home much too early and is not here to witness the final part of this academic journey, when she was with us, she was always very supportive and encouraged me every step of the way.

This work is also dedicated to my parents, Thornton and Vera, who have always encouraged me to work hard, study, and accomplish my goals. They provided me a strong foundation upon which I have been able to use to pursue my personal, academic, and professional dreams. 


\section{ACKNOWLEDGEMENTS}

First and foremost, I would like to thank God for granting me the wisdom, motivation, and support to pursue this academic program and fulfill the dissertation requirements. Without his guidance and blessings, this academic achievement would not have been possible.

Secondly, I would like to thank Dr. Patrick Lowenthal for serving as the chairman of my dissertation committee and for the supervision and guidance he provided throughout this academic journey. I would also like to thank Dr. Dazhi Yang and Dr. Chareen Snelson for serving on my committee and helping to guide this study through the proposal, data collection, and final defense process. Together, all three members of my committed helped to increase the academic rigor and relevance of this study. Dr. Lowenthal and Dr. Yang were excellent with identifying gaps in my research and methodologies and making suggestions for closing those gaps to strengthen the study. Dr. Snelson helped guide me through the creation of a video analysis guide and with pinpointing specific first and second cycle coding strategies which really helped with the data analysis process.

Third, I would also like to thank Old Dominion University for allowing me to work with their Peer Educator Program administrators to conduct this study. Jennifer Grimm (Director) and Taia Reid (Assistant Director) were both instrumental throughout the dissertation process. When I first reached out to Jenn, she immediately began responding to my requests for information about the possibility of pursuing this study 
through ODU. She regularly responded to my emails, held meetings with school administrators to ensure all necessary permissions were granted, identified the pool of participants and talked to them about participating in the study, and helped to set up the in-person interviews. Taia was also just as fast to respond to email requests which included helping me to locate additional statistical and demographic data and finalizing the in-person interview schedule. Taia made time in her schedule to personally show me around the Peer Educator Program space on campus, provided me with a dedicated area for conducting the participant interviews, and introduced me to the peer tutors. This study would not have been possible without the efforts of Jennifer and Taia. I will be forever grateful for the assistance they provided throughout the entire year and a half long process.

Finally, I would like to thank my parents, Thornton and Vera Smith, my wife Caroline, and our two daughters Savannah and Maggie for their continued encouragement and support. My parents instilled the importance of hard-work and dedication in me from a very young age and have been encouraging me through every step of my academic adventures. Caroline has supported me academically and emotionally throughout this program and the other post-secondary degrees and certificates I have earned during the ten years we have been together. Savannah and Maggie have provided an abundance of joy, laughter, love, and inspiration that helped me to get through even the toughest of times. 


\begin{abstract}
The objective of this study was to analyze the lived experiences of peer tutors who provide synchronous online tutoring services, at a large, accredited, public, four-year university located in the Middle Atlantic Region of the United States. An exploratory qualitative case study approach was used to conduct this study. The case chosen for this study consisted of a single holistic case that was both descriptive and intrinsic.

Participants of the study consisted of students who were hired by the chosen university to serve as peer tutors as well as students that utilize the online peer tutoring service. Data collection and analysis for this study included semi-structured individual interviews and observations. Findings from this study were used to help improve and further expand the use of synchronous online peer tutoring in higher education.
\end{abstract}

Keywords: synchronous online tutoring, peer tutoring, video conferencing 


\section{TABLE OF CONTENTS}

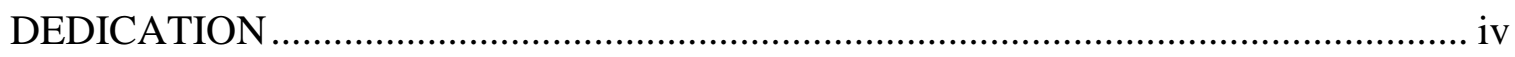

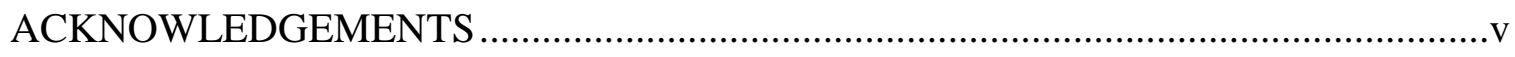

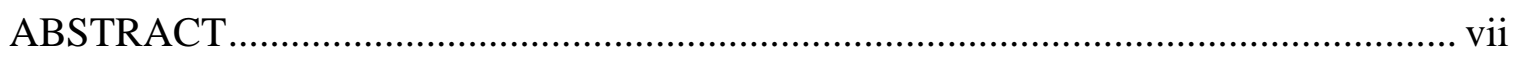

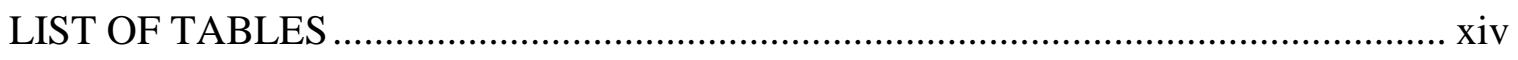

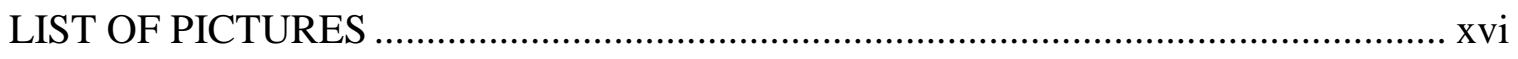

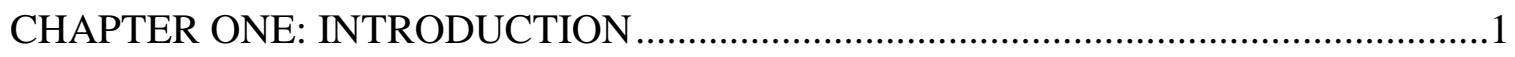

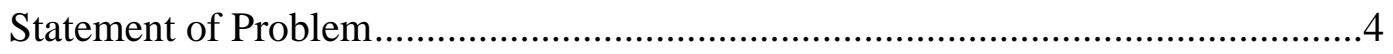

Access to Academic Support Services.......................................................5

Delivery of Online Tutoring Services......................................................6

Commercial Synchronous Online Tutoring Programs..................................

Online Tutoring Environment Experiences ...............................................

Need for Further Research ......................................................................10

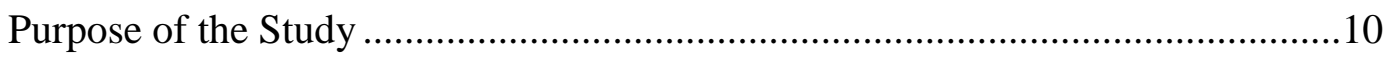

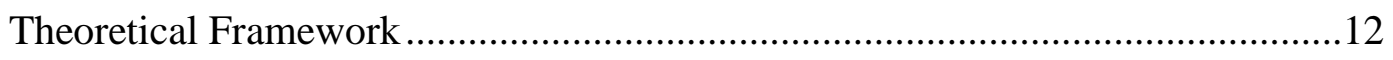

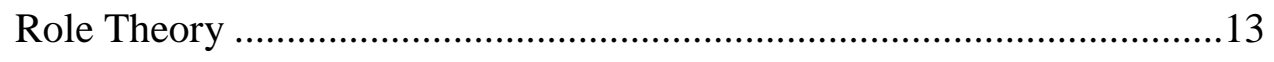

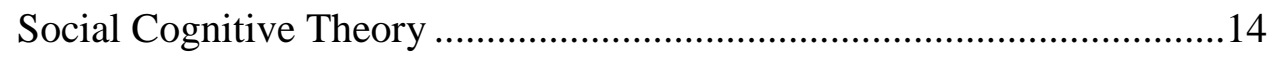

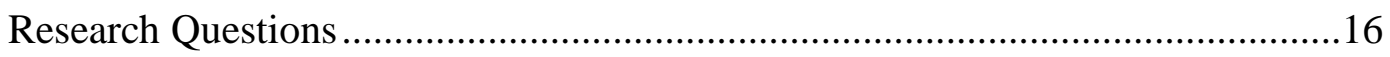

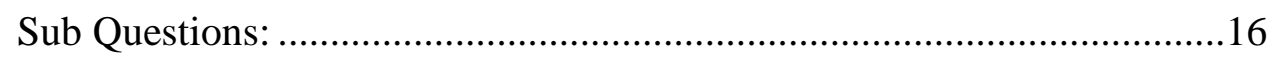

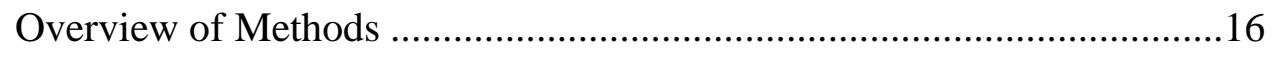




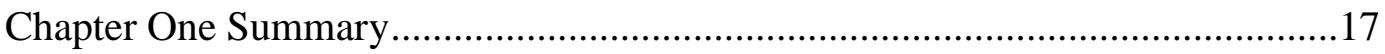

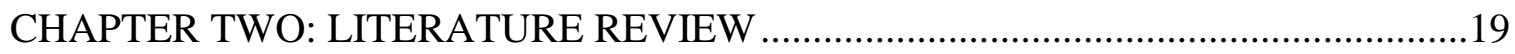

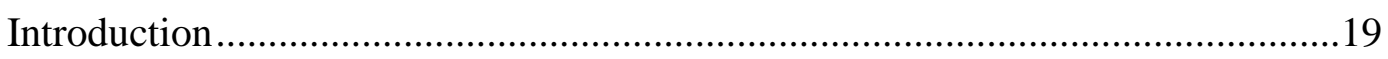

College-Readiness, Academic Preparedness, and Persistence …………...............19

Effects of Academic Unpreparedness .......................................................21

Remedial and Developmental Courses ..........................................................22

Constraints of Remedial or Developmental Programs................................23

Tutoring as an Academic Support Strategy .......................................................24

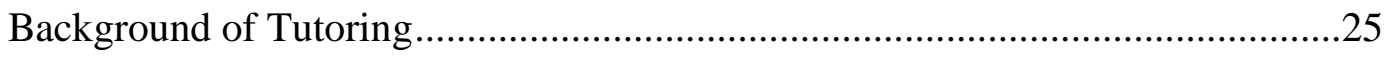

Purpose and Benefits of Tutoring ………………….....................................26

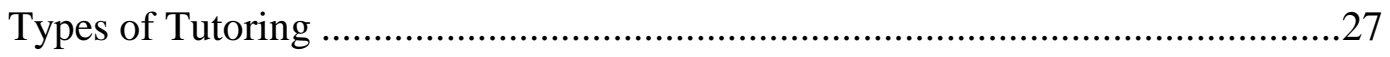

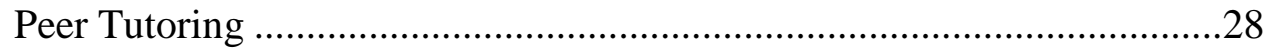

Professional Tutoring .........................................................................28

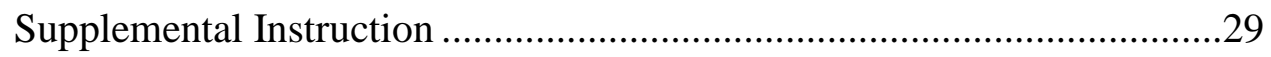

Peer Tutoring as an Academic Support Strategy ................................................30

Peer Tutoring- Definition and History ........................................................30

Peer Tutor and Tutee Interaction .............................................................32

Benefits of Peer Tutoring ............................................................................3

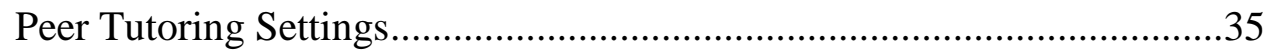

Selecting and Training Peer Tutors.............................................................38

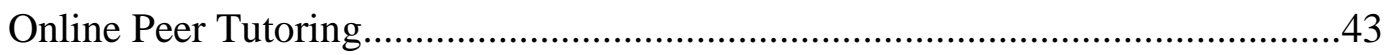

Online Peer Tutoring as a Support Strategy for Blended and Face-to-Face

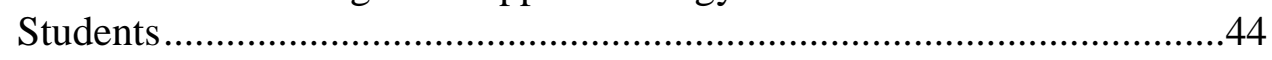

Advantages of Online Peer Tutoring ........................................................45 
Asynchronous versus Synchronous Online Peer Tutoring

Video Conferencing Technology for Providing Synchronous Online

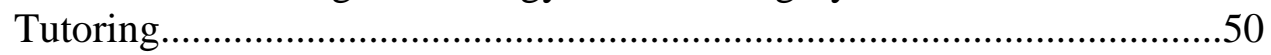

Synchronous Virtual Classrooms .....................................................51

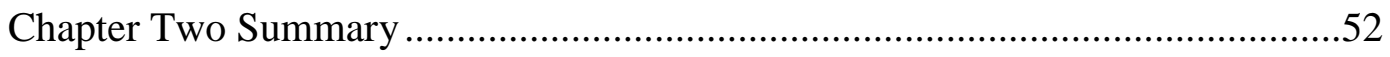

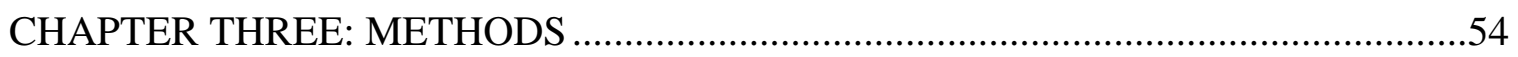

Research Methods ..................................................................................... 54

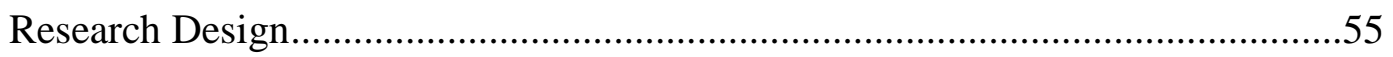

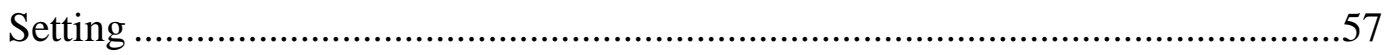

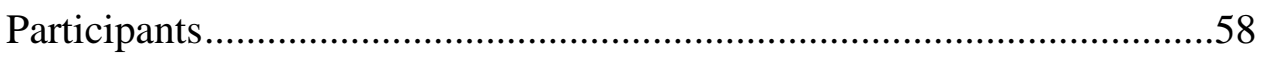

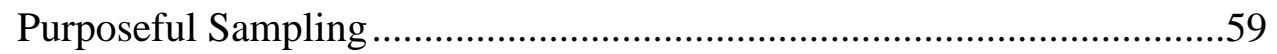

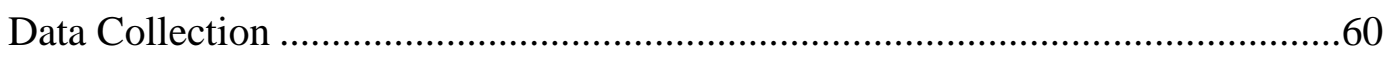

Semi-Structured Interviews ..........................................................61

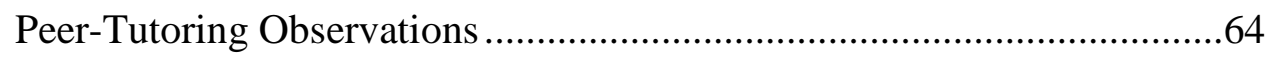

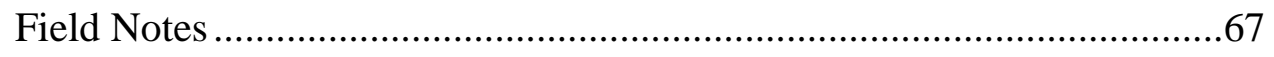

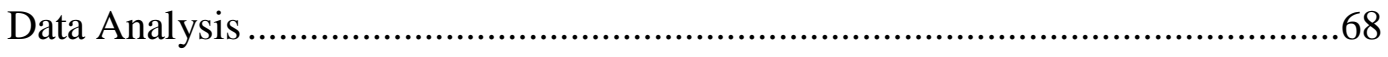

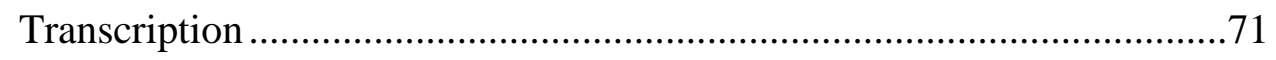

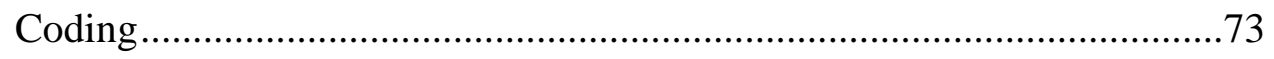

Credibility, Trustworthiness, Consistency, and Rigor ................................... 85

Chapter Three Summary ........................................................................ 90

CHAPTER FOUR: RESULTS ........................................................................ 91

Central Questions:.....................................................................91

Sub Questions: ..............................................................................91

The Synchronous Online Peer Tutoring Program at Old Dominion University....92 
The Physical Tutoring Space

The Virtual Tutoring Space …………………………….......................98

Scheduling Online Peer Tutoring Sessions ...............................................102

Peer tutor Demographic and Descriptive Data …….........................................103

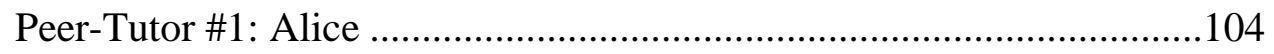

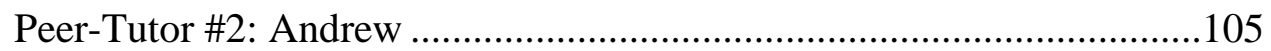

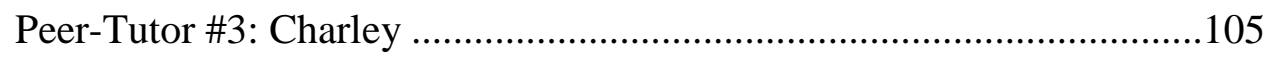

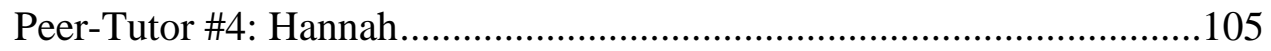

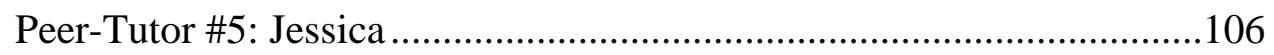

Peer-Tutor \#6: Justin .............................................................................106

Peer-Tutor \#7: Mark .............................................................................107

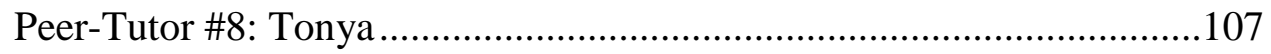

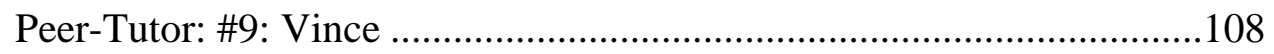

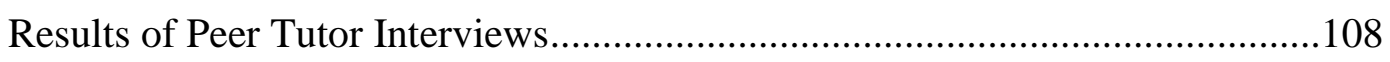

Interview question \#1. Why did you decided to become a peer tutor and did you know you were going to have to provide online peer tutoring services when you first accepted the position? .........................................108

Interview question \#2. Please describe a time when the synchronous tutoring session went well and then a time when it went bad...................110

Interview question \#3. Would you recommend participation in this program to your friends? Why or why not?

Interview question \#4. How do you know you are helping the students?

Interview question \#5. How do you adjust your instructional practices when you have determined that the tutee is not comprehending the subject matter?. 
Interview question \#6. What suggestions for overall improvements to the synchronous online peer tutoring program do you have?

Results for Peer Tutoring Observations

Observation question \#1. How did the peer tutor initially identify the topic to be discussed in the peer tutoring session? What questions were asked?

Video Recording Analysis Question \#1 Summary

Observation question \#2. What questions do the tutees ask throughout the session? How do the peer tutors respond to those questions?

Observation question \#3. What strategies do peer tutors use to assess the tutee's understanding of each topic? Do they provide similar practice questions or problems for the tutee to complete? If so, what resources are used to find the practice items?

Observation question \#4. What additional processes or concepts were observed that appear to be relevant to answering the research questions? What observations related to the research questions were surprising? What, if anything, appeared to be missing from the sessions?

Summary of Observation Results 166

Synthesis of Results

Research question \#1. How do peer tutors interact with their tutees in the synchronous online tutoring environment?.

Research question \#2. How do peer tutors determine if the tutee comprehends the content being discussed?.

Research question \#3. How do peer tutors change their instructional practice when it is perceived that the tutee does not comprehend the content being discussed?....

Chapter Four Summary

CHAPTER FIVE: DISCUSSION

Sub-Questions

Assertions 
Research Question \#1: How do peer tutors interact with their tutees in the synchronous online tutoring environment?

Research Question \#2: How do peer tutors determine if the tutee comprehends the content being discussed?

Research Question \#3: How do peer tutors change their instructional practices when it is perceived that the tutee does not comprehend the content being discussed?

Limitations .223

Scheduled Synchronous Online Peer Tutoring Sessions That Occur ......223

The Number of Peer Tutors Who Provide Online Peer Tutoring Services .225

The Willingness of Tutees to Participate in The Study .........................226

Issues with Webex Recordings of Online Peer Tutoring Sessions .227

Recommendations for Practice

Recommendations for Future Research

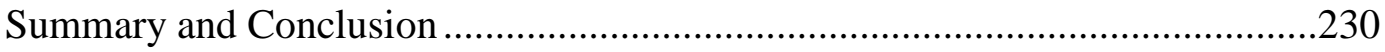

Perceptions Associated with Peer Tutor Training …............................230

Increasing Technical Support for Peer Tutors and Their Tutees .231

Improving Scheduling and Preparation for Peer Tutors 


\section{LIST OF TABLES}

Table 2.1 CRLA Peer Tutoring Training Program Certification Requirements ....... 40

Table 2.2 CRLA Peer Tutoring Training Program Training Topics.......................... 41

Table 3.1 Interview Question Guide for Peer Tutor Semi-Structured Interviews .... 63

Table 3.2 Alignment of Questions to be Answered During Observation Data

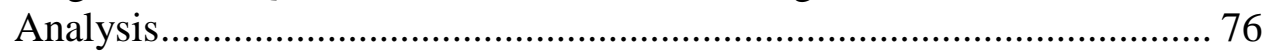

Table 3.3 Sample of In Vivo Coding Table Used to Organize Observation Data.... 78

Table 3.4 Sample of Focused Coding Table Used to Complete Second Cycle Coding 81

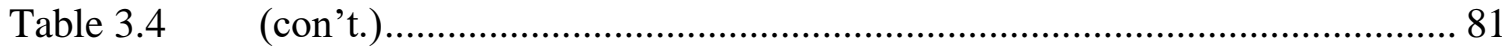

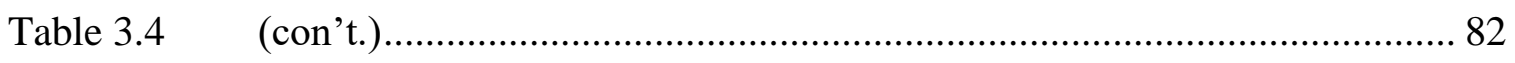

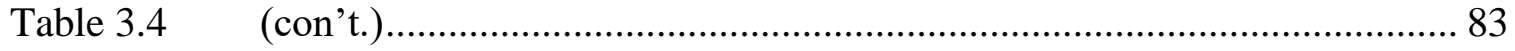

Table 3.5 Codes That Emerged During Constant Comparison Analysis................... 84

Table 4.1 Statistical Data for ODU Online Peer Tutoring Program ......................... 93

Table 4.2 Statistical Data for Peer Education Peer Tutoring Program ..................... 94

Table 4.3 Sharing Features Available Through Cisco’s WebEx Meeting Center Application.......................................................................................... 99

Table 4.4 WebEx's Communication Tools............................................................. 101

Table 4.5 Peer Tutor Demographic Data Based on the Spring 2017 Academic

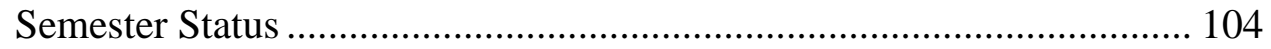

Table 4.6 Breakdown of Screen Share Feature Usage, Type of Tutoring Session, and Amount of Time to Start Addressing the First Tutee Concern................ 134 
Table 4.7 Summary for Themes of Questions Asked Throughout the Observed Tutoring Sessions ............................................................................. 139

Table 4.8 Alignment of Interview and Observation Questions to Research SubQuestions.................................................................................... 167

Table 5.1 Research Questions and Assertions .................................................... 201 


\section{LIST OF PICTURES}

Picture 1. Images of Journaling/Field Notes Added During the Observation Transcription Process ................................................................................ 70

Picture 2. Images of Transcribed Audio Recording ............................................... 72

Picture 3. Images of Pre-Coding Process on Two Different Audio Transcripts ....... 75

Picture 4. Images of First Cycle In-Vivo Coding for Observation Transcript .......... 79

Picture 5. Example Journaling and Field Notes from Semi-Structured Interview.... 89

Picture 6. Images of Peer Tutoring Center............................................................... 97

Picture 7. Screenshot of Tutee Using the WebEx Screen Share Feature to Share a Computer Science Program from the PuTTy software with his tutee .... 100

Picture 8. Screenshot of the WebEx Whiteboard Feature Used by Mark to Solve a Sample Proportion Problem

Picture 9. Screenshot of Microsoft Paint Being Used as a Whiteboard by Hannah to Solve a Sample Proportion Problem ....................................................... 155

Picture 10. Screenshot of Microsoft Notepad being used as a whiteboard by Alice to Demonstrate the Connection Between the Header, Client, and Implementation Codes in a Computer Program. 156

Picture 11. Screenshot of a Physical Whiteboard Mounted on the Wall Being Used by Alice to explain the fminbnd function 157

Picture 12. Screenshot of the Statistics How website used by Hannah to Explain the Binomial Distribution Formula.

Picture 13. Screenshot of a Google Image Used by Mark to Explain the Level of Confidence Formula.

Picture 14. Screenshot of an Internal Page on the ODU Computer Science Website Used by Jessica to Explain Wild Cards in Computer Programming ....... 159 
Picture 15. Screenshot of Computer Programming Code from a Sample Program that was Previously Developed by Alice to Explain Classes, Pointers, and link

lists.

Picture 16. Screenshote of MATLab Software Vince Used to Explain the fminbnd Function

Picture 17. Screenshot of Justin Attempting to Share a Page from the Textbook with his Tutee by Holding the Gap in Place in Front of the Computer's Webcam 163 


\section{CHAPTER ONE: INTRODUCTION}

Academic preparedness continues to be a common problem experienced by many two-year and four-year colleges and universities across the United States. For instance, the National Assessment of Educational Progress (NAEP) is used to determine if graduating $12^{\text {th }}$ grade students are college and career ready based on student achievement in reading and mathematics (Fields, 2014). In 2013, only $39 \%$ of $12^{\text {th }}$ graders nationally scored at or above the 163-point threshold in mathematics set by the NAEP, and only $38 \%$ scored at or above the 302-point threshold in reading (Fields, 2014). Therefore, based on the NAEP, approximately two thirds of all graduating $12^{\text {th }}$ graders throughout the United States are not academically prepared for college level mathematics and reading courses. The level to which students are academically prepared to successfully complete college-level coursework is most commonly referred to as college readiness. Three of the most heavily researched and relied upon data markers used to measure college readiness in the United States include: cumulative high school grade point average, combined mathematics and verbal SAT scores, and ACT composite scores (McClarty \& Gaertner, 2015).

To address academic preparedness shortfalls, many colleges and universities began offering a variety of remedial courses and services (Bettinger \& Long, 2009). According to Shaw and Skomsvold (2015), nearly 33 percent of all first- and second-year students who were enrolled in bachelor degree programs between 2011 and 2012 (29 percent of those at 4-year institutions and 41 percent at 2-year institutions) had to 
complete at least one remedial course. Remedial or developmental courses provide academically underprepared students with extra support in targeted areas of reading, writing, and mathematics to help them with completing college-level work assignments and to succeed in college (Bailey, Jeong, \& Cho, 2010).

Typically, remediation programs consist of a series of courses that count toward a student's overall grade point average but not toward graduation requirements (Bettinger, Boatman, \& Long, 2013). The courses in these remedial programs often must be successfully completed before students can enroll in college-level courses (Bettinger \& Long, 2009). Unfortunately, not all students are able to pass the remedial courses in which they are enrolled. According to Chen (2016), only about 59 percent of students enrolled at public 4-year institutions successfully completed the remedial courses they attempted, 25 percent completed some but not all of their remedial courses, and 15 percent did not complete any of the remedial courses in which they enrolled. When students fail to successfully complete their remedial courses, students, institutions, and taxpayers are emotionally and financially negatively impacted. Lower self-esteem, greater frustration, additional tuition costs, and lost earning potential are all factors that have been associated with higher dropout rates for students who have been required to enroll in remedial or developmental programs (Amos, 2011). According to Bettinger, Boatman, and Long (2013), delivering remedial instruction during the 2007-2008 academic year totaled $\$ 3.6$ billion in student tuition and institutional instructional costs; the average taxpayer cost per student for delivering remediation was between $\$ 2,020$ and $\$ 2,531$ in four-year colleges. Because of these negative consequences, researchers have 
begun to question the short- and long-term effects of remedial education programs (Amos, 2011).

One alternative to remedial programs involves the development of learning assistance centers at colleges and universities (Gerlaugh, Thompson, Boylan, \& Davis, 2007; Perin, 2004; Stern, 2001; VanLehn, 2011). Learning assistance centers are designed to support the entire heterogeneous mix of students learning in both developmental courses and college-level courses (Perin, 2004). Learning assistance centers offer various services including: academic tutoring, computer-based learning, assessment, advisement, and counseling (Stern, 2001). Out of these services, research has shown that tutoring services are among the more popular academic success strategies being implemented (Gerlaugh et al., 2007). One reason for the increased popularity of tutoring services is that students can receive targeted instruction on individual topics of concern rather than being required to complete mandatory remedial courses (Perin, 2005). One benefit of tutoring services is that they allow students to receive additional academic support while simultaneously enrolling and progressing through college-level courses. Students who have chosen to take advantage of tutoring services have been shown to demonstrate improved persistence and retention, higher academic achievement, and increased graduation rates (Rheinheimer, Grace-Odeleye, Francois, \& Kusorgbor, 2010).

The two most common forms of tutoring offered on college and university campuses are professional and peer tutoring (Gerlaugh et al., 2007). Professional tutoring services are provided by individuals who are either licensed teachers or certified subject matter experts (Berliner, 2004). Peer tutors, on the other hand, are currently enrolled 
students providing tutoring services (Saunders, 1992; Topping, 1996). Generally, peer tutors must have already completed the courses with a B or higher in the subject area in which they provide tutoring services ("International Tutor Training Program Certification Requirements", 2015). Because peer tutors do not already hold a degree and are not credentialed at the same level as professional tutors, they do not cost institutions as much as professional tutors (Chi, 2006).

\section{Statement of Problem}

Distance education enrollments in higher education have continued to grow while face-to-face enrollments have declined. From 2013 to 2014, the number of students that took at least one distance education course increased to $3.9 \%$, while the number of students not taking distance education courses dropped from 434,236 to 390,815 during the same timespan (Allen, Seaman, Poulin, \& Straut, 2016). According to the Southern Association of Colleges and Schools Commission on Colleges (SACSCOC), distance education is defined as a "formal educational process in which most of the instruction (synchronous or asynchronous interaction between students and instructors and among students) in a course occurs when students and instructors are not in the same place" (Southern Association of Colleges and Schools Commission on Colleges, 2011, p. 128). One of the more popular and modern forms of distance education, online learning, promotes the idea of "any time - any place" learning (Moore \& Kearsly, 1996). Unlike more traditional forms of distance education that relied on print-based correspondences, broadcast television or radio, videocassettes or DVDs, and/or stand-alone educational software programs, online learning is defined as a form of distance education where 
instruction is delivered completely using the Internet, and students and instructors are not required to be present at the same time and place (Anderson, 2008).

\section{Access to Academic Support Services}

While the convenience of being able to learn anytime, anyplace, has led to increased online enrollments, online learners have also reported feelings of being disconnected from vital student and academic support services such as library resources and tutoring services (Burns, Cunningham, \& Foran-Mulcahy, 2014). To address the disconnect that can occur between online learners and traditional on-campus students, SACSCOC, the accrediting agency for degree-granting higher education institutions in the southern United States, developed a specific set of guidelines that colleges and universities under their purview are expected to follow. Within those guidelines, institutions are required to make available to distance education students the same student, academic, and administrative support services that are available traditional oncampus students (Southern Association of Colleges and Schools Commission on Colleges, 2011).

Tutoring is one of the academic support services that is discussed within the SACSCOC distance education guidelines. Because of the comparable student and academic services requirement put in place by SACSCOC (as part of the reaffirmation process for all colleges and universities serviced by the reginal organization) many institutions have begun exploring ways for offering tutoring services online (Park \& Kim, 2016). 


\section{$\underline{\text { Delivery of Online Tutoring Services }}$}

Initially, online tutoring services in higher education were delivered asynchronously primarily using email and discussion boards. Those services often took the form of writing centers where tutees would email written papers to tutors who would later respond with feedback (Palmquist, 2003). One advantage that has been associated with delivering online tutoring services asynchronously is that tutors can provide written feedback that is more thorough, (e.g. it can include more in-depth comments) (Breuch \& Racine, 2000). However, researchers found that active participation (Einon, 2010) and effective communication (Price, Richardson, \& Jelfs, 2007) can be difficult to achieve in asynchronous online tutoring environments.

Technological advancements in online communication services, such as the expansion of broadband connectivity and the emergence of collaborative Web 2.0 technologies (Corrigan, 2012) along with interactive technology like improved videoconferencing capabilities (Anderson, 2008), have enabled institutions to experiment with offering synchronous online tutoring programs (Kear, Chetwynd, Williams, \& Donelan, 2012). Synchronous online tutoring sessions are conducted using video conferencing technology which supports real-time interaction using audio, video, and text (Wu, Lin, \& Yang, 2013). Additional synchronous technologies include chat rooms, instant messaging tools, and web conferencing solutions that include interactive whiteboards along with advanced audio and video capabilities (Parker \& Martin, 2010). Synchronous technologies allow tutors to be flexible in the delivery of their instruction using text, white board overlays, video, audio, and print materials (Vasquez \& Slocum, 2012). 


\section{Commercial Synchronous Online Tutoring Programs}

Initially, many colleges and universities used commercial online tutoring programs like Smarthinking, Upswing, Tutor.com, NetTutor, etc. to provide synchronous online tutoring (Britto \& Rush, 2013; Chediak, 2005; University of North Dakota, 2004). One common feature that popularized each of those programs is the availability of tutoring services 24 hours a day and 7 days a week (De Fazio \& Ketenon, 2012). Traditional face-to-face tutoring services are only offered during normal business hours, which are generally Monday through Friday day and night. The main difference between these commercial online tutoring programs is the level of education required for the tutors providing the tutoring services. For instance, Smarthinking promotes a tutoring pool that consists of educators and other professionals with an average of nine years of experience, many of which have earned advanced degrees beyond the baccalaureate level (Britto \& Rush, 2013; Turrentine \& MacDonald, 2006). This type of commercial online tutoring program neglects to take advantage of the additional benefits often gained when students or peers provide the tutoring services (Park \& Kim, 2016). One of the main benefits that is missed is the concept of learning by teaching. Topping (1996) found that “just preparing to be a peer tutor has been proposed to enhance cognitive processing in

the tutor - by increasing attention to and motivation for the task, and necessitating review of existing knowledge and skills" (p. 324). Using outside peer tutors that are available through commercial tutoring solutions negate that advantage. Upswing, another commercial online tutoring solution, also offers professional tutoring services, however, Upswing provides institutions with the option of using internal tutors currently employed by the institution. NetTutor is a commercial online tutoring solution that generally uses 
tutors from the local institution (Turrentine \& MacDonald, 2006). This option allows colleges and universities to take advantage of the time, money, and training that has already been invested in tutoring programs, however, institutions incur additional costs associated with providing the service. According to Berg (2009), commercial online tutoring programs can cost institutions up to and sometimes even more than $\$ 35-50$ per hour.

Some colleges and universities have started to take a step back to analyze and compare the cost and benefits associated with using commercial online tutoring services. For example, a study conducted by Doherty and Atkinson (2004) found that adoption and utilization of commercial tutoring services to be lower than expected. The results of studies like these have driven some institutions to consider ways to reduce the financial cost associated with providing commercial tutoring solutions (Turrentine \& MacDonald, 2006). Some higher education institutions, for instance, have begun to develop and pilot their own internal online peer tutoring programs using the technology tools (e.g. WebEx) and tutors that they already have at the institution. Old Dominion University, the host institution for this study, made a similar decision between the 2014 and 2015 academic semesters. In 2014 they received some grant funding that allowed them to begin offering online tutoring through SmartThinking, however, as the grant funding was running out in 2015, an internal evaluation revealed that low adoption and usage rates did not warrant the use of institutional funds to support commercial tutoring services. Once SmartThinking was no longer an option, Old Dominion began researching how they could offer online tutoring services using only internal technology (WebEx videoconferencing solution) and internal peer tutors. The result was a synchronous online 
peer tutoring program that uses videoconferencing technology to deliver tutoring services. The programs adoption and usage rates have continued to grow since it began in the fall of 2015. More information on the specific details and the context of the program are provided in Chapters 2 and 3.

$\underline{\text { Online Tutoring Environment Experiences }}$

While both asynchronous and synchronous online tutoring have both been shown to have a positive impact on student learning (Thurston, Duran, Cunningham, Blanch, \& Topping, 2009; Tsuei, 2012), there is little understanding of how peer tutors and their tutees experience online tutoring environments (Wu, Lin, \& Yang, 2013). Some research has reported positive effects of integrating peer tutoring into institutional academic success programs (Bowman-Perrott, Davis, Vannest, Williams, Greenwood, \& Parker, 2013) along with using synchronous video conferencing technologies for connecting students separated by distance (Rehn, Maor, \& McConney, 2016). Kear et al. (2012) found that videoconferencing technology enabled tutors to interact with and engage tutees academically in ways that could not always be replicated in face-to-face sessions. However, those findings were based solely on the experiences of professionally trained teachers and teacher-trainees who were already skilled in providing distance education rather than investigating the experiences of peer tutors. Therefore, this case study examined the perceptions and experiences of peer tutors who utilize videoconferencing technology to provide synchronous online tutoring services in a four-year university setting. 


\section{$\underline{\text { Need for Further Research }}$}

Enrollments in online courses and programs continue to rise in colleges and universities throughout the United States. Meanwhile, students enrolling in those online courses and programs continue to struggle with achieving the same level of access to vital student and academic support services such as library resources and tutoring services that traditional on-campus students receive. Higher education accrediting agencies, like SACSCOC, have noticed this disconnect and have added additional guidelines into the accreditation process to ensure colleges and universities are addressing any deficiencies. Institutions began by offering asynchronous online tutoring services using internal resources or synchronous online tutoring services through commercial third-party solutions to address these deficiencies. However, delayed response times in the asynchronous environments and increased additional cost and the loss of academic benefits caused many colleges and universities to rethink how they offer online tutoring services. Some of these institutions have begun experimenting with using video conferencing technology already available through the home institution and internally employed peer tutors to develop in-house synchronous online tutoring programs. However, very little research has been conducted on the affordances and constraints of synchronous online peer tutoring programs, especially from the perspective and experiences of the peer tutors who provide the peer tutoring services.

\section{Purpose of the Study}

The purpose of this exploratory qualitative case study was to gain an in-depth understanding of 1) the overall synchronous online tutoring experience from the perspective of the peer tutor, 2) the types of interactions that occur during the tutoring 
sessions, 3) the instructional strategies peer tutors employ to check for understanding, and 4) what instructional strategy adjustments are made by peer tutors when the tutee comprehension appears to be lacking. As advances in technology have made real-time communication tools more affordable, synchronous instruction has increased in popularity (e.g. Barron et al., 2005; Cao, Griffin, \& Bai, 2009; Chen, Chen, \& Tsai, 2009; Hrastinski, 2008; Xenos, Avouris, Stravinoudis, \& Margaritis, 2009). Research suggests that synchronous technologies in distance education can increase student-to-student interactions (Cao, Griffin, and Bai, 2009) and provide a more humanistic feel to communication (Loch \& Reuschle, 2008). Two-way video conferencing has been found to be the most popular solution for faculty who chose to integrate synchronous activities into their lessons (Hsiao \& Huang, 2012).

Video conferencing, or web conferencing as it is frequently referred to, can provide a close alternative to face-to-face learning (see Barron et al., 2005; Wu, Lin, \& Yang, 2013). According to Wu, Lin, and Yang (2013), "synchronous video conferencing supports spontaneous interaction, immediate feedback and social presence involving audio, video and text" (p. 53). After studying a series of live video conference interactions between 227 Taiwanese students and a native English speaker, Wu and Marek (2010) concluded that the delivery method showed promising results for building confidence and improving students' academic ability. Therefore, based on the previously reported successes for using synchronous video conferencing technologies to improve online learning opportunities, the researcher investigated the lived experiences of peer tutors using synchronous video conferencing technology to provide online peer tutoring services. The results of this study offer guidance and support for other institutions of 
higher education who have developed, are currently developing, or plan to develop similar internal synchronous online peer tutoring programs using video conferencing technology and peer tutoring personnel that are already available within each host institution.

\section{Theoretical Framework}

Theories are developed to explain, predict, understand, and extend previous knowledge surrounding a phenomenon or set of phenomena (Swanson \& Chermack, 2013). Individual or groups of theories are combined with additional concepts relevant to a topic being researched to form a theoretical framework (Lederman \& Lederman, 2015). A theoretical framework provides a deeper explanation about the theories behind the problem being researched and help to further explain why the research problem being investigated exists (Swanson \& Chermack, 2013). The theoretical framework for this exploratory study includes various aspects associated with role theory and social cognitive theory. Role theory has been utilized by researchers to address the responsibilities and expectations of both the tutee and the tutor as they interact in the tutoring environment (Powell, 1997). Students who choose to serve as peer tutors essentially agree to leave their daily role of student to assume the role of a teacher or mentor. Role theory is used to describe various societal roles such as the role of a teacher and the specific rights, duties, and expectations that are associated with the role rather than the individual assuming a specific role (Biddle, 1986). To be effective tutors, once peer tutors assume the role of a teacher, they then must understand a variety of theories that are involved with the process of teaching, including Bandura's (1988) social 
cognitive theory. The following section will provide further insight into how role theory and social cognitive theory are addressed in peer tutoring programs.

$\underline{\text { Role Theory }}$

Linton (1945) described roles as rights, duties, expectations, and standards for behavior attached to specific social positions as defined by various cultural norms. Roles do not remain stagnant, rather they evolve as changes occur within a society over time (Turner, 1990). An individual can hold multiple roles within a society or organization (Rothbell, 1991), and each role that one plays involves a learned behavior (Solomon, Surprenant, Czepiel, \& Gutman, 1985). Expectations for roles are comprised of the privileges, duties, and obligations that are associated with social position (Sarbin \& Vernon, 1968). To successfully meet those expectations, assuming a new role requires the person playing that role to take into consideration the actions and behaviors of other individuals or groups of people who are associated with the role being assumed (Solomon et al., 1985).

Role theory (Biddle, 2013), focuses on the ability of the initial role player (peer tutor) to predict the behavior of other role players (tutees) to adjust his or her (peer tutor) own behaviors to accommodate the needs of the tutees (Mead, 1935; Rose, 1962). Weitz (1981) used an example of a salesman to describe this concept. This process relies heavily upon the role player being able to identify and react to various social and facial cues as they are expressed by other associated role players (Solomon et al., 1985). According to Weitz, a salesman who adapts his behaviors and strategies to meet the needs of his customers will be more successful than one who does not make the proper adaptations. One concept was investigated in this study involved understanding how peer 
tutors determine if their tutees are comprehending the concepts being discussed and how teaching strategies are adapted to address areas of possible confusion. Synchronous tools, such as audio and video capabilities, available through video conferencing technology that was used by the peer tutors in this study allowed for more intimate social interactions between the tutor and the tutee (Hou \& Wu, 2011; Hrastinski, 2008). This provided further insight to how peer tutors perceive their roles and utilize key aspects of role theory to gauge tutee understanding and make modifications to their own instructional practices to address any deficits or misunderstandings that might surface.

\section{$\underline{\text { Social Cognitive Theory }}$}

In the 1970 s, Bandura introduced the concept of social learning theory which began a paradigm shift from a behavioral focus to a cognitive learning focus (Bandura, 1977). The social learning theory introduced by Bandura in 1977, focused on the influence that social modelling has on human motivation (Luszczynska \& Schwarzer, 2005). Eventually, Bandura (1986) introduced the social cognitive theory that involved a triangular reciprocal causation model in which behavior, cognitive, and emotional events interact together simultaneously. According to Bandura, (1988), one of the key elements associated with social cognitive theory relevant to this study is modeling which involves; the use of modelling lessons or activities to build competency mastery, stronger selfconfidence, and increased self-motivation.

According to social cognitive theory, motivation and confidence for solving larger more complex problems comes because of witnessing the modelling of smaller subproblems being solved (Luszczynska \& Schwarzer, 2005). The process of developing new competencies begins with the use of modelling, which involves breaking down 
complex skills into smaller subskills (Bandura, 1988). Once individuals begin to comprehend the smaller subskills, they are then able to develop more complex problemsolving strategies (Bandura, 1997). For modelling to be effective, the trainer or peer tutor must share general rules and strategies for solving problems rather than simply providing specific responses or answers (Bandura, 1988). As trainees, or in the case of this study tutees, perfect their skills, informative feedback is required along the way to validate that the work being done is correct.

Trainees are more apt to grasp and implement modeled strategies when they feel they share similarities with the person modeling the strategies versus when the models are very different from the individual being trained (Bandura, 1988). Similar results have been presented in research comparing the results of professional tutoring services to peer tutoring services. Topping (1996) found the interactions that occur between peers in a tutoring environment to be qualitatively different than those between a teacher and a student, and that the two approaches involved different affordances and constraints. According to Fantuzzo, Dimeff, and Fox (1989), greater combined cognitive gains have been achieved between the peer tutor and the tutee when academically average peer tutors are used as opposed to peer tutors whose academic intellectual skills and talents are closer to that of professional teachers. Scruggs and Osguthorpe (1986) and Ashman and Elkins (1990) found these types of peer tutoring situations to also be academically beneficial for the tutors. 


\section{Research Questions}

The central research question that guided this study was, "How do peer tutors describe the lived experience of using video conferencing technology to provided synchronous online tutoring services?"

$\underline{\text { Sub Questions: }}$

a) How do peer tutors interact with their tutees in the synchronous online tutoring environment?

b) How do peer tutors determine if the tutee comprehends the content being discussed?

c) How do peer tutors change their instructional practices when it is perceived that the tutee does not comprehend the content being discussed?

$\underline{\text { Overview of Methods }}$

An exploratory case study approach was used to investigate the perceptions and experiences of peer tutors providing synchronous online tutoring services via video conferencing technology. The study employed a single case approach and drew participants from a pool of twelve peer tutors who had already provided online tutoring services at Old Dominion University prior to and during the 2017 spring academic semester. The primary method of data collection was semi-structured interviews. During the interviews, participants were asked to explain what led them to participate in the program, examples of when sessions went well and when they did not, whether participants would recommend the program to friends, how tutee understanding is measured, how instructional practices are adjusted to meet student needs, and about suggested improvements for the program. Along with the interviews, the researcher also 
observed previous synchronous online peer tutoring sessions to identify additional data and further validate responses recorded during the interviews. Data collected during the interviews and observations was recorded, transcribed, and coded by the researcher. The researcher provided study participants with copies of the thematically organized interpretations along with text versions of the interview transcriptions and notes from the video reviews to use member-checking for improving trustworthiness, consistency, and credibility to the study findings. Additional details about the methods that were used for this study can be found in Chapter 3 .

\section{Chapter One Summary}

Colleges and universities throughout the United States continue to seek out possible instructional support solutions for addressing the increasing number of students enrolling in higher education who are academically unprepared to independently complete college-level work. Additionally, as online course and program enrollments are on the rise at the same higher education institutions due to expanded distance education course and program offerings, administrators are faced with figuring out how to provide those online students with student, academic, and administrative support services that are comparable to the same services that are offered in-person to students on campus. Tutoring has been shown to be a more academically, emotionally, and economically viable solution compared to original attempts to offer remedial or developmental programs. Face-to-face professional and peer tutoring programs have been shown to have a positive impact on student persistence, retention, and graduation rates, however, reaching the same level of success with online tutoring programs has proven to be a challenge for many institutions. While several commercial online tutoring programs 
currently exist to address this issue, they require additional financial resources to implement and utilize peer or professional tutors who are not vetted or employed by the host institution. Therefore, some colleges and universities have begun to experiment with utilizing previously purchased videoconferencing technology along with currently employed peer tutors to develop their own synchronous online peer tutoring programs. This study sought to gather details on the perceptions and experiences of peer tutors who provide synchronous online peer tutoring services to provide guidance and support for other institutions of higher education who have developed, are currently developing, or plan to develop similar internal online peer tutoring programs. 


\section{CHAPTER TWO: LITERATURE REVIEW}

\section{Introduction}

As colleges and universities throughout the United States have increased distance education offerings, many have struggled with finding solutions to provide academic and student support services for their online students that are comparable to the face-to-face services that are available to on-campus students. One specific solution that has started gaining more attention is the use of video conferencing technology by peer tutors to provide synchronous online peer tutoring services. The objective of this exploratory case study research was to gain an in-depth understanding of the online tutoring experience from the perspective of the peer tutor.

The following literature review provides further insight into accountability concerns of college-readiness and academic preparedness that many four-year colleges and universities are facing, the history of peer tutoring and how the service might serve as a possible academic support solution. Additionally, this literature review discusses the need for further research to be conducted on how to more effectively make quality peer tutoring services available in an online environment.

\section{College-Readiness, Academic Preparedness, and Persistence}

In the modern era of accountability, colleges are being judged not just by the number and types of students they enroll, but also on whether those students they graduate are prepared to work in the field in which they were trained (Kisker, 2015). Unfortunately, many colleges and universities have found that an increasing number of 
the students that are accepted, especially high school graduates, are underprepared in terms of college-readiness and academic preparedness (Fields, 2014). Armstrong, Arnold, and $\mathrm{Lu}$ (2012) defined "college readiness" as "a student's capacity to enroll in the first year, earn passing grades in courses, and persist to his or her educational goals" (p. 1). Hughes, Gibbons, and Mynatt (2013), on the other hand, defined academic unpreparedness as students who perform below college standards in math, reading comprehension, or writing skills. According to a 2004 report published by the National Center for Education Statistics, only 26.8 percent of graduating high school seniors had completed high level coursework (Chen, Tasoff, \& Wu, 2010). Chen, Tasoff, and Wu defined high level coursework as English, Algebra II and two higher math courses, three years of science, two years of social studies, and two years of a foreign language. In a separate study, Greene and Winters (2005) found that only about 34 percent of high school graduates were identified as being college ready. Additionally, the American College Test (ACT, 2011) reported that based on the four college-readiness benchmarks associated with the examination, only about one out of every four high school graduates across the United States were sufficiently academically prepared for college-level work in the primary subjects. The four benchmarks include English Composition, College Algebra, Biology, and social sciences. English Composition, College Algebra and Biology are included because they represent the first credit-bearing courses that are most commonly taken by first-year college students, and reading achievements have been associated with academic achievements in credit-bearing social sciences courses (Maruyama, 2012). 


\section{Effects of Academic Unpreparedness}

The struggles associated with academic underpreparedness have been linked to lower self-esteem, greater frustration, and higher college drop-out rates (Bettinger \& Long, 2009; Radford, Berkner, Wheeless, \& Shepherd, 2010). Because of lower numbers of students successfully graduating from college with a degree, higher education persistence rates have come under scrutiny in recent years. Decreasing retention rates and lower grade point averages (GPAs) have caused college presidents and administrators to put additional pressure on faculty to increase success in both academic areas for institutions and their graduates to be prepared for today's competitive market (Lau, 2003). When institutions are not able to retain and graduate students, the consequences are two-fold. Lower retention rates have been shown to negatively impact the institutions reputation and financials (Leone \& Tian, 2009).

\section{$\underline{\text { Retention and Persistence }}$}

The numbers associated with retention and graduation rates in higher education have been the focus of many publications. In a study that focused on first-year to secondyear retention rates in colleges and universities, ACT Inc. (2011) found that only about 67 percent of first-year college students returned to the same institution for their second year. A separate study, conducted by Knapp, Kelly-Reid, and Ginder (2011), found that only about 55.5 percent of students entering four-year institutions were graduating within six years, and that statistic dropped down to 29.2 percent for students graduating from two-year colleges within three years. One of the main contributing factors that has been directly tied to student persistence is academic preparedness (Bridges, Buckley, Hayek, Kinzie, \& Kuh, 2011). Porter and Polikoff (2012), identified three quantitative data points 
that are often used to quantify academic preparedness: standardized test scores, grade point averages, and the type of course work completed in high school. To improve retention and graduation rates and address the lack of academic preparedness issue, many postsecondary institutions have started offering a variety of remedial and developmental courses (Bettinger, Boatman, \& Long, 2013).

\section{Remedial and Developmental Courses}

Remedial courses, or developmental courses as they are often referred to by many institutions, refer to a series of courses that are offered to underprepared students to increase their ability to be successful at completing college-level work (Bailey, Jeong, \& Cho, 2010). Students are generally placed in developmental reading, writing, and/or math courses based on the results of academic placement testing (Goldstein \& Perin, 2008). Approximately 92 percent of postsecondary institutions use some form of standardized placement exam as markers for determining which students will be enrolled in remedial or developmental courses when they first arrive on campus (Greene, Lewis, \& Parsad, 2003). COMPASS and Accuplacer are two of the most common nationally standardized placement tests that are used by community colleges, state colleges, and public universities throughout the United States to assess mathematical skills, reading comprehension, and basic writing skills (Kaplan, 2014). Traditionally, placement tests are required for all students applying and enrolling in institutions of higher education for the first time (Tan, 2013). The number of students enrolled in remedial or developmental programs continues to increase (Adelman, 2005). According to Parker, Barrett, and Bustillos (2014), approximately 76 percent of higher education institutions offer developmental education. Bailey (2009) found that more than one-third of first-time 
college students are enrolled in English and/or mathematics remedial courses. Of those students, approximately $25 \%$ who are required to complete three or more developmental courses leave the institution after their first year (Adelman, 2005).

\section{Constraints of Remedial or Developmental Programs}

One of the reasons drop-out rates are so high, for students who are required to complete remedial courses, is the organizational and delivery structure for many developmental education programs. Generally, developmental courses are offered for credit and count toward a student's overall grade point average; however, they do not count toward graduation requirements and must be completed before students can enroll in college-level major courses (Bettinger, Boatman, \& Long, 2013). Greene, Lewis, and Parsad (2003) found that more than four-fifths of postsecondary institutions nation-wide require the successful completion of remediation before students can enroll in courses required for their major, and most of those institutions identify the specific courses that are part of the prerequisites. Because of these factors, Jenkins (2011) found that developmental or remedial course requirements often result in extending the length of time it takes students to complete degrees which in turn brings about a lower probability of degree completion. The additional time needed to complete developmental and remedial course requirements also often results in a negative financial impact on students because they end up paying more tuition and are prevented from earning the incomes associated with each degree sought (Bettinger, Boatman, \& Long, 2013).

To address the concerns associated with negative impact that some developmental education programs are having on student success and retention, many higher education institutions have begun to explore alternative interventions for addressing academic 
shortfalls, such as summer bridge programs, learning assistance centers, and academic counseling (Bettinger, Boatman, \& Long, 2013). Academic leaders and educators are beginning to address concerns related to developmental education through shortening the time spent in remedial courses, integration programs that combine basic skill attainment with college-level coursework, and supplemental programs such as tutoring or advising (Rutschow \& Schneider, 2012).

\section{Tutoring as an Academic Support Strategy}

Due to decreases in student enrollment and state and federal funding, increased competition between institutions for student enrollment, along with the pressure from college administrators, faculty, and students to ensure academic success, many institutions have turned to offering a variety of tutoring services (Leone \& Tian, 2009). Tutoring has gained popularity as a more effective academic support strategy than requiring students to complete developmental or remedial courses. Unlike developmental and remedial courses that require completion based on academic placement testing scores, tutoring services are completely voluntary and provide additional academic support to the entire college or university student body (Bettinger, Boatman, \& Long, 2013; Chaney, 2010; Perin, 2004; Barefoot, Gardner, \& Upcraft, 2004). In one study, Slavin (1987) found providing tutoring services to be an effective strategy for helping students to understand more difficult academic content and increase motivation. The following sections of this review of the literature will provide further insight into the history, benefits, and types tutoring services that are most commonly found in higher education. 


\section{Background of Tutoring}

The word tutor originated from the Latin Tueri, which means "one who protects, guards, and cares for" (Rapoport, Yair, \& Kahane, 1989, p. 16). Tutoring is an action that relies not only on tutor(s) working with other individuals or small groups of people to achieve specific academic goals, but also involves developing personal, trusting, and caring connections between the tutor and the tutee (Nelson-Royes, 2015). VanLehn (2011) defined tutoring as a process where someone who is more informed about a topic, concept, or problem provides academic assistance in the form of coaching to others who are less knowledgeable about the topic. The person(s) who are more knowledgeable about a topic are referred to as the tutor and the person(s) seeking additional academic support are referred to as tutees (Bray, Farlowe, \& Shumow, 2002; De Backer, Van Keer, \& Valcke, 2012). According to Nelson-Royes (2015), tutors can consist of one or more educators, paraprofessionals, classmates, other students, or volunteers who "deliver instruction that promotes independence and empowerment" (p. 24).

Tutoring has a lengthy history in higher education. Prior to the start of the $19^{\text {th }}$ century, many early European colleges and upper-class families relied on tutoring as their primary form of instruction, which was a trend that continued into the $19^{\text {th }}$ and early $20^{\text {th }}$ centuries across Europe and the United States (Gordon \& Gordon, 1990). Tutors were hired, in early $18^{\text {th }}$ century America, throughout many southern colonies to teach Latin, grammar, arithmetic, English, and Euclidean geometry to the sons of the wealthy plantation owners (Rippa, 1997). Initially, tutoring services were primarily available to elite families where the children were spared from having to participate in manual plantation labor. However, as more formalized educational institutions began forming in 
the late 19th and early 20th centuries, tutoring services became more readily available to the masses through schools, colleges, universities, libraries, churches, communities, and other public and private institutions (Nelson-Royes, 2015). Tutoring services have continued to grow and expand in popularity as an effective means of supplemental instruction in higher education (Gaustad, 1993; Bray, Farlowe, \& Shumow, 2002). In many modern colleges and universities, tutoring services continue to play a vital role in providing academic support to general student populations (Gerlaugh et al., 2007; Rheinheimer et al., 2010). Financially, the tutoring industry grew by more than ten times its value in 2001 to an estimated value of somewhere between $\$ 5$ billion and $\$ 7$ billion a year in 2011 (Sullivan, 2011).

\section{Purpose and Benefits of Tutoring}

The purpose of tutoring today is to provide remediation for students who encounter academic difficulties or to expand students' academic abilities to develop successful independent learners (Nelson-Royes, 2015). During the tutoring sessions, tutors, who are generally more knowledgeable about the specific academic content being addressed, are responsible for supporting and directing the learning process through active scaffolding, questioning, and explaining (Chi \& Roscoe, 2008). Scaffolding, based on Vygotsky's Zone of Proximal Development Theory, involves tutors assessing the tutees prior knowledge, removing the difficult tasks, and building from the most basic steps to the more challenging concepts until tutee understanding increases and independent mastery is achieved (Wood, Bruner, \& Ross, 1976; Vygotsky, 1978).

The benefits of tutoring have been widely reported in the literature (Cohen, Kulik, \& Kulik, 1982; Nelson-Royes, 2015; Rheinheimer et al., 2010). Cohen, Kulik, and 
Kulick (1982) conducted a meta-analysis of the findings from 65 independent school tutoring program evaluations and found that tutoring programs have had a positive effect on tutee academic performance and attitudes. More recently, Rheinheimer et al. (2010) found persistence, academic achievement, retention, and degree attainment to be some of the most commonly reported indirect benefits of tutoring services. According to NelsonRoyes (2015), social interactions between tutors and tutees has resulted in higher levels of student engagement and more positive educational experiences. Other researchers have reported that tutoring can enhance subject matter mastery, boost academic self-efficacy, and increase persistence and retention rates (Astin, 1998; Pascarella \& Terenzini, 2005). Research on undergraduate persistence, retention, and graduation rates has revealed that tutoring programs have played crucial roles in improving students' sense of social and academic integration (Astin, 1993; Bean \& Eaton, 2001; Pascarella \& Terenzini, 2005; Tinto, 2000).

\section{Types of Tutoring}

A review of the literature identified three primary types of tutoring commonly used in higher education (Almarzouqi \& Mynard, 2006; Chi, 2006; Rheinheimer et al., 2010). Peer and professional tutoring are two of the more commonly used academic support strategies, however, some higher education institutions have also experimented with a type of tutoring known as supplemental instruction (Burns, 2006; National Center for Supplemental Instruction, 1997; Nelson-Royes, 2015; Rheinheimer et al., 2010). The following section of this literature review will provide a more in-depth comparison of the three tutoring types. 


\section{Peer Tutoring}

Peer Tutoring is a type of tutoring that involves pairing more advanced learners who have already demonstrated mastery of a process or skill with less advanced learners who have not yet to master the same knowledge (Saunders, 1992; Topping, 1996). According to Falchikov (2001) and Topping (2005), peer tutoring is a form of cooperative learning that involves students working among peers in pairs or small groups to help and support each other with acquiring new knowledge and skills. Almarzouqi and Mynard (2006) defined peer tutoring simply as a system in which students help each other to learn, and in turn learn by teaching. Utley, Mortweek, and Greenwood (1997) described peer tutoring as "a class of practices and strategies that employ peers as oneon-one teachers to provide individualized instruction, practice, repetition, and clarification of concepts" (p. 9). Although Utley and colleagues limited their definition of peer tutoring to involve only one-on-one type scenarios, the academic support strategy can also be utilized in small group settings. Peer tutors are charged with facilitating learning by helping to understand and apply information (Moust \& Schmidt, 1995).

\section{Professional Tutoring}

Professional Tutoring services involve the use of either recent college graduates, current and retired teachers, and/or other types of subject matter experts (Chi, 2006). Many benefits have been linked to the use of professionally trained experts for providing tutoring services which include: an increased ability to choose more appropriate instructional strategies to use, generating better, faster, and more accurate problem solutions, having faster and more accurate pattern recognition capabilities, and have more accurate self-monitoring skills (Berliner, 2001, 2004; Chi, 2006). However, Chi (2006) 
also cited several constraints that have been associated with using experts to provide professional tutoring services such as: over confidence and inflexibility which can cause the tutor to overlook smaller details that are perceived to be less relevant, trouble breaking more complex subject-matter down into smaller pieces of information, and limited to expertise in a single domain.

\section{$\underline{\text { Supplemental Instruction }}$}

Supplemental instruction is another type of academic assistance program that has been classified as a type of peer tutoring. However, unlike typical peer tutoring sessions, supplemental instruction is a totally different type of academic intervention strategy. Arendale (1994) defined supplemental instruction as "a student academic assistance program that increases academic performance and retention through its use of collaborative learning strategies" (p. 1). Rheinheimer et al. (2010) described supplemental instruction as an academic support strategy that employs trained leaders who are generally upper-class students to serve as facilitators or tutors. Unlike the remedial nature of tutoring services, supplemental instruction identifies high-risk courses rather than at-risk students. The high-risk courses most commonly addressed through supplemental instruction include courses that typically have a 30 percent or higher rate of D of F final course grades and/or withdrawals (Martin, Lorton, Banc, \& Evans, 1977). Supplementary instructional involves regularly scheduled, out-of-class, peer-facilitated sessions that provide students with an opportunity to discuss and process course information. The sessions are open to everyone in the course on a voluntary basis (Hodges \& White, 2001). Traditionally, supplemental instructors attend course meetings alongside the students enrolled in the courses and take their own notes, read the 
textbooks, and provide more in-depth academic content explanations to tutees through small group help sessions (Arendale, 1994; Burmeister, 1995; Eig, 1997). Research has shown supplemental instruction to have a positive impact on short-term persistence rates, between first and second year students, while improving the passing grades of students enrolled in some of the more difficult courses in higher education like mathematics and sciences courses (Davenport, Good-Majah, Johnson, Schollaet, \& Visor, 1995; Pascarella \& Terenzini, 2005). Academic and social integration have also been identified as elements that have been positively impacted by supplemental instruction and are crucial to the academic performance of undergraduate students (Rheinheimer et al., 2010). Empirically, supplemental instruction has been shown to be a successful academic assistance strategy that has demonstrated increases in student grades and persistence along with decreases in failure rates for students enrolled in higher education (Dawson, van der Meer, Skalicky, \& Cowley, 2014). Unfortunately, when supplemental instruction is available, it only supports a very select set of courses such as higher-level science, technology, engineering and mathematics courses (Hizer, Shultz, \& Bray, 2017).

\section{Peer Tutoring as an Academic Support Strategy}

\section{Peer Tutoring- Definition and History}

Tutoring services have traditionally been provided by peers or professional tutors who have been hired by colleges and universities on a per-subject knowledge basis (Nelson-Royes, 2015; Rheinheimer et al., 2010). While professional tutoring has been shown to be beneficial (Burns, 2006), the primary focus of this study was peer tutoring services. The basic concept of students teaching other students has been around for thousands of years (Bell, 1808; Gardner, Nobel, Hessler, Yawn, \& Heron, 2007; 
Topping, 1998; Wagner, 1990). Ancient Greek civilizations utilized a form of peer tutoring at the Athenian Academy where select students like Aristotle were tutored (Gardner et al., 2007).

One of the more popular early cases of peer tutoring being used in a school setting as an educational strategy dates to Dr. Andrew Bell in the late 1700's. Dr. Bell, who has been identified as one of the innovators of peer tutoring (Topping, 1998), had actually spent time working as a tutor while attending St. Andrews University, and went on to spend additional time serving as a professional tutor after graduating in 1774 (Blackie, 2004). Bell served as the school superintendent for Egmore Military Male Asylum in Madras, India from 1789-1796. He reportedly first got the idea of using peers to tutor other students after witnessing older students teaching younger students to write by tracing letters in the sand on a beach (Bowyer-Bower, 1954). The Asylum was originally formed through a collaboration between the governor and his council to support and educate 100 distressed male orphans of the European military (Bell, 1797, 1808). Bell (1797) described the orphaned males as being poorly and improperly trained in the areas of reading and writing and inferior to the rest of society. Government officials appointed Bell as the superintendent of the Asylum with the expectation that he would transform the orphans into good scholars, men, Christians, and members of society (Bell, 1797). While serving as the superintendent Bell attempted to implement a few new educational ideas; however, he was met with strong resistance by many faculty within the academy (Topping, 1988). So, he turned to having some of the students experiment with the new ideas. Through this experimentation, Bell noticed the power and potential of students teaching other students (Bell, 1808; Topping, 1988). He later coined the phrase the 
"System of Tuition" (Bell, 1808, p. ix) to describe this method of teaching and instruction. He believed that the system should be an essential educational strategy for every institution (Bell, 1797). Apparently, many other educational leaders agreed with Bell's viewpoint as the system was later implemented in over 12,000 schools that served more than 346,000 children across England, Wales, Ireland, and other British colonies around the world (Blackie, 2004).

$\underline{\text { Peer Tutor and Tutee Interaction }}$

As peer tutors and their tutees begin to interact, relationships are formed and those relationships are initially responsible for determining the success of peer tutoring sessions (Poellhuber, Chomienne, \& Karsenti, 2008). Situations in which those relationships between the peer tutor and the tutee have been built upon trust and mutual respect have yielded higher levels of cooperation and have therefore been more successful overall (Cobb, 2000). In one study, Stephen, O’Connel, and Hall (2008) found that tutees reported that the ability of and level to which the peer tutors could establish and maintain a positive rapport was an important measure of effectiveness in peer tutoring programs. One important aspect associated with forming a positive rapport between the peer tutor and the tutee is the peer tutors' ability to listen as a tutee describes his or her specific academic challenges. Cobb (2000) found that the peer tutors' ability to listen to the tutees, to gain an understanding of the specific academic challenges, was essential to the process of being able to customize the tutoring sessions to meet tutees' academic needs. When peer tutors could listen and accurately address the specific academic needs of each individual tutee, both the peer tutor and the tutee reported higher levels of confidence, self-esteem, and academic skills (Barton-Arwood, Jolivette, \& Massey, 2000). 
Consequently, Lazerson (1980) found that breakdowns in the formation of strong relationships led to tutee's failure to progress.

\section{$\underline{\text { Student-To-Student Interaction }}$}

Developing strong relationships between peer tutors and their tutees relies heavily upon the interactions that occur between the two types of students (Stephen, O'Connel, \& Hall, 2008). Those connections are recognized in the literature as student-to-student interactions. Moore (1989) described the concept of student-to-student as interaction that occur between individual pairs of students or among students working in small groups. According to Moore and Kearsley (1996), student-to-student interactions have contributed to higher levels of student satisfaction and learning. Student-to-student interaction has also been shown to address social, professional, and emotional problems related to geographical separation in educational settings (e.g., Kellog \& Smith, 2009; Swan, 2003). Additional benefits that have been linked to positive student-to-student interaction include increased tutee confidence (Rovai, 2001), student retention (Williams, Duray, \& Reddy, 2006), and greater academic gains (Bowman-Perrott et al., 2013).

\section{Benefits of Peer Tutoring}

Peer tutoring has yielded positive results across multiple subject areas, specialized classroom settings, and participant group sizes. Because of implementing Bell's method of peer tutoring, the following benefits were reported for peer tutoring services: (a) the strategy helped slower students to keep up with their classmates, (b) tutors and tutees established good educational habits, and (c) all involved parties often went on to become good students and achieve success (Goodlad, 1998). Bell (1808) found that as students progressed and advanced from one class to the next, tutees became tutors, tutors became 
more social, tutors became mentors for their tutees, and tutors learned academic material much better through teaching it. Based on Bell's success with the "System of Tuition", William Bentley Fowle opened the first school in Boston based on the instructional strategy and further concluded the following: (a) peer tutors who shared similar age ranges related to each other better than with teachers, (b) tutors tended to be more compassionate and considerate when working with tutees, (c) students reported feeling more comfortable when receiving tutoring services from their peers, and (d) many tutees reported feelings of being afraid of failing and being intimidated when receiving tutoring services from teachers (Dabkowski, 2000).

Research has shown positive increases in cognitive, metacognitive, affective, and social outcomes for both the tutors and the tutees who participate in peer tutoring sessions (e.g. Falchikov, 2001; Topping, 2005). Furthermore, Chi and Roscoe $(2007,2008)$ found that peer tutoring sessions had a positive influence on the metacognitive skill of reflective knowledge-building. De Backer, Van Keer, and Valcke (2012) also identified comprehension-monitoring and more in-depth explanations as additional metacognitive benefits associated with peer tutoring sessions. Peer tutoring sessions have also led to increases in the ability for tutors and tutees to generate more higher-level questions and responses which has correspondingly contributed to increased metacognitive awareness. A study conducted by Bloom and his colleagues at the University of Chicago, found that the average student who utilized peer tutoring services scored about two standard deviations above the average of the control class or $98 \%$ better than students in the control environment (Bloom, 1984). 


\section{$\underline{\text { Special Populations }}$}

Certain special populations within education have also reported similar cognitive, social, and emotional benefits that have been associated with peer tutoring programs. Through a synthesis of the literature, Okilwa and Shelby (2010) found that students with or without identified disabilities as well as non-native and native English students all demonstrated positive results when participating in peer tutoring programs. The synthesis involved 12 peer-reviewed articles that investigated special education students in Grades 6 through 12 who received peer tutoring services in language arts, math, science, and social studies. Special education students represented in the studies chosen were part of separate special education classrooms or participated in general education classrooms through inclusion. Although special education students who were included in general education classrooms received peer tutoring from students without identified disabilities, and the students that were in separate special education classrooms received similar services from other students with disabilities, both settings yielded improved academic performances in all subjects studied (Okilwa \& Shelby, 2010). Therefore, peer tutoring programs have been shown to be successful among diverse populations of students within a variety of educational settings.

\section{$\underline{\text { Peer Tutoring Settings }}$}

Peer tutoring can either occur in one of two settings: one-to-one or in small groups. One commonality between both settings is that they can each be delivered faceto-face or online (e.g. using learning management systems, specifically designed tutoring software, or video conferencing technology). This section of the literature review will 
further define each specific setting for peer tutoring along with some of the affordances and constraints that have been associated with each method.

\section{One-to-One Tutoring}

In typical tutoring settings, peer tutoring occurs on a one-to-one basis (Ehly \& Larsen, 1980; Roscoe \& Chi, 2007). One-on-one peer tutoring is more commonly referred to as reciprocal peer tutoring in the literature. Reciprocal peer tutoring is unique in that it is promotes a high degree of student interaction and mutual support (Blanc, DeBuhr, \& Martin, 1983) that promotes a sense of community among tutors and tutees (Hawkins, 1980). Fantuzzo, Riggo, Connelly, and Dimeff (1989) found that because peer tutors and their tutees often face similar academic stressors, the success of tutoring sessions depends on mutual assistance and support from both parties involved. Reciprocal peer tutoring has also been shown to decrease some of the stress associated with academic performance. As previously stated earlier in this literature review, Bell (1808) found that among several benefits that have been associated with peer tutoring, when tutoring occurs in a one-to-one environment, the tutor often ends up serving as a mentor for the tutee which has been shown to provide additional psychological and emotional benefits to tutees.

\section{Cross-Age Tutoring}

The term cross-age tutoring refers to a specific type of one-on-one or reciprocal tutoring_environment in which the peer tutor providing the tutoring services is older and/or in a higher-grade level than the student being tutored (Robinson, Scholfield, \& Steers-Wentel, 2005). According to Tansy and de Barona (1996), cross-age tutoring is often used when additional challenges are at play such as learning disabilities, behavioral 
issues, or when students are lacking in motivation. Cross-age tutoring has been shown to increase academic performance and self-esteem (Topping, Peter, Stephens, \& Whale, 2004) without requiring additional staff support or resources (Wright \& Cleary, 2006). This form of peer tutoring has been shown to contribute to increased self-esteem in mathematics (Topping, Campbell, Douglas, \& Smith, 2003), fluency in scientific language (Topping, Peter, Stephen, \& Whale, 2004), thinking skills (Topping \& Bryce, 2004), and literacy (Paquette, 2008). However, negative results have been reported with cross-age peer tutoring when the age difference between the tutor and tutee is too large (Robinson et al., 2005).

\section{$\underline{\text { Small Group Tutoring }}$}

The most common form of small group peer tutoring involves a single tutor providing tutoring services to two or more tutees. Through small group tutoring, the tutor actively engages with the tutees to provide high level feedback and guidance that targets each individual student's overall level of understanding and learning strategy (Anderson, 1997; Biggs, 2011; Hellstrom, Johannesson, Karlsson, \& Thorbiornson, 2007). Hellstrom et al. (2007) described a common scenario of a small group peer tutoring session in which the peer tutor sat at a table situated between two different tutees and all three participants worked collaboratively to solve a series of mathematical problems. This type of scenario allows the tutor to identify each individual tutee level of understanding on a per topic or concept basis and allows both tutees to learn from each other's mistakes. Therefore, small group tutoring sessions are most effective when the tutees receiving services are attempting to solve similar problems within common concepts. Martin and Zajchowski (1993) found small group peer tutoring sessions to be appropriate and beneficial in all 
subjects where there is a strong focus on solving problems such as science, technology, engineering, and mathematics courses. While the collaborative nature of small group peer tutoring has been shown to be beneficial, one of the greatest challenges associated with the tutoring method is finding a common time in which the entire group involved can meet for the tutoring session (Hellstrom et al., 2007). Group size is another important issue that deserves consideration when providing small group tutoring services.

Depending on the complexity of the topic being discussed, having too many tutees in one group has the possibility of creating additional confusion and frustration. Hellstrom et al. (2007) suggested limiting small group tutoring to four to six students.

\section{$\underline{\text { Selecting and Training Peer Tutors }}$}

One of the primary organizations that has been responsible for providing guidelines for selecting peer tutors and designing and evaluating peer tutor training programs is the College Reading and Learning Association (CRLA). Founded by a group of reading specialists in the United States, CRLA has established a set of standards for accrediting new peer tutor programs which include: certified (Level I), advanced (Level II), and mastered (Level III) (Boylan, 2002). Once the requirements for each level of certification are met, colleges must apply for accreditation, CRLA reviews the applications, accredits the peer tutoring programs as Level I, II, or III based on how much tutoring time and training the peer tutors have completed (Boylan, 2002). Furthermore, after each tutor completes the required amount of training and tutoring service, he or she is individually recognized and certified at the appropriate level by CRLA (Deese-Roberts, 2003). The following sub-sections will provide further insight into how peer tutors are selected and then trained based on the guidelines established by CRLA members. 


\section{$\underline{\text { Selecting Peer Tutors }}$}

There are three main criteria that are traditionally used for selecting peer tutors in higher education which include: they must currently be a student at the same institution, have already successfully completed the academic courses they will be providing services for, and must be recommended by campus staff or faculty member ("International Tutor Training Program Certification Requirements," 2015). The CRLA guidelines state that peer tutors must have at least a 3.0 Grade Point Average (GPA), must go through an interview or application process with the coordinator or supervisor of the peer tutoring program, and must have at least two references from a faculty member, program coordinator, or college counselor ("International Tutor Training Program Certification Requirements," 2015). The participants in this study fit within the CRLA guidelines for selecting quality peer tutors.

\section{$\underline{\text { Training Peer Tutors }}$}

While peer tutors generally excel academically in the subjects in which they were hired to tutor, they do not always have teaching experience and therefore often lack the necessary instructional strategies for helping tutees learn the content (Falchikov, 2001). MacDonald (2000) suggested that peer tutors should be properly trained on various study skills strategies so that they can then share those strategies with their tutees. Boylan (2002) stated that colleges must provide peer tutors with best practices and researchbased strategies to share with tutees for peer tutoring programs to be effective. Furthermore, Boylan, Bliss, and Bonham (1997) found that students who received peer tutoring services from a program in which the peer tutors were specifically trained showed increases in academic success and retention in college. 
CRLA has established three distinct levels for peer tutor training, each of which recommends different best practice strategies that peer tutors must understand for the host institution's peer tutoring program to be accredited. One commonality between all three levels of the CRLA certification is that at least 10 hours of instructional training are required (see Table 2.1).

\section{Table 2.1 CRLA Peer Tutoring Training Program Certification Requirements}

\begin{tabular}{|c|c|c|}
\hline CRLA Level & Training Time & $\begin{array}{c}\text { Previous Peer Tutoring } \\
\text { Experience }\end{array}$ \\
\hline Level 1 & $\begin{array}{l}10 \text { hours of training of which at least } \\
6 \text { hours must be supervised, live, and } \\
\text { in real-time, prior to providing any } \\
\text { peer tutoring services }\end{array}$ & $\begin{array}{l}25 \text { hours of required } \\
\text { tutoring service }\end{array}$ \\
\hline Level 2 & $\begin{array}{l}10 \text { additional hours of which at least } \\
4 \text { hours must be supervised, live, and } \\
\text { in real-time }\end{array}$ & $\begin{array}{l}50 \text { hours of required } \\
\text { tutoring service }\end{array}$ \\
\hline Level 3 & $\begin{array}{l}10 \text { additional hours of which at least } \\
2 \text { hours must be supervised, live, and } \\
\text { in real-time }\end{array}$ & $\begin{array}{l}75 \text { hours of required } \\
\text { tutoring service }\end{array}$ \\
\hline
\end{tabular}

The greatest difference between the three levels of CRLA peer tutor training certification are the training topics (see Table 2.2) and the minimum amount of prior tutoring experience (see Table 2.1) that is required ("ITTPC Certification Requirements", 2015). 
Table 2.2 CRLA Peer Tutoring Training Program Training Topics

\begin{tabular}{|c|c|c|}
\hline Level 1 & Level 2 & Level 3 \\
\hline $\begin{array}{l}\text { A minimum of } 8 \text { of the } \\
\text { following topics should be } \\
\text { covered: } \\
\text { - definition of tutoring } \\
\text { and tutoring } \\
\text { responsibilities } \\
\text { - basic tutoring } \\
\text { guidelines } \\
\text { - techniques for } \\
\text { successfully beginning } \\
\text { and ending a tutor } \\
\text { session } \\
\text { - adult learners, learning } \\
\text { theory, and/or learning } \\
\text { styles } \\
\text { - assertiveness and/or } \\
\text { handling difficult } \\
\text { students } \\
\text { - role modeling } \\
\text { - setting goals and/or } \\
\text { planning } \\
\text { - communication skills } \\
\text { - active listening and } \\
\text { paraphrasing } \\
\text { - referral skills } \\
\text { - study skills } \\
\text { - critical thinking skills } \\
\text { - compliance with the } \\
\text { ethics and philosophy } \\
\text { of the tutor program, } \\
\text { sexual harassment, } \\
\text { and/or plagiarism } \\
\text { - modeling problem } \\
\text { solving }\end{array}$ & $\begin{array}{l}\text { In addition to the topics } \\
\text { covered in Level } 1, \text { a } \\
\text { minimum of } 4 \text { of the } \\
\text { following topics should be } \\
\text { covered: } \\
\text { - review of Level } 1 \text { topics } \\
\text { - use of probing questions } \\
\text { - Brain Dominance } \\
\text { Learning } \\
\text { - cultural awareness, } \\
\text { inter-cultural } \\
\text { communications, } \\
\text { diversity, and/or special } \\
\text { needs students } \\
\text { - identifying and using } \\
\text { resources } \\
\text { - tutoring in specific skill } \\
\text { and/or subject areas } \\
\text { - assessing or changing } \\
\text { study behaviors }\end{array}$ & $\begin{array}{l}\text { In addition to the topics } \\
\text { covered in Level } 1 \text { and } 2 \text {, } \\
\text { a minimum of } 4 \text { of the } \\
\text { following topics should be } \\
\text { covered: } \\
\text { - review of Level } 1 \text { And } \\
\text { Level } 2 \text { topics } \\
\text { - self-regulated } \\
\text { learning, brain } \\
\text { learning, and/or } \\
\text { memory } \\
\text { - how to tutor/deal with } \\
\text { target populations } \\
\text { - the role of learning } \\
\text { centers in higher } \\
\text { education } \\
\text { - structuring the } \\
\text { learning experience } \\
\text { - training and } \\
\text { supervising other } \\
\text { tutors } \\
\text { - group management } \\
\text { skills }\end{array}$ \\
\hline
\end{tabular}


The training can be completed through either face-to-face workshops or discussions or through online multi-user virtual environments (e.g. Second Life). Once the training has been completed, then the individual peer tutors who have been properly trained can begin working towards the 25 hours of required tutoring service.

Old Dominion University, the host institution for this study, has earned a Level 3 CRLA certification. At a minimum, all 12 study participants that were selected for this study have received a minimum of 10 hours of targeted training on effective tutoring strategies and have also provided a minimum of 25 hours of face-to-face peer tutoring services.

\section{$\underline{\text { Peer Tutor Responsibilities }}$}

For peer tutoring sessions to be successful, peer tutors should be well equipped and prepared with a variety of effective instructional strategies (MacDonald, 2000). Being prepared can involve reviewing a tutee's class notes to recommend certain study strategies (Reid \& Moore, 2008). Gabriel (2008) recommended that peer tutors demonstrate how to create quality note cards to help students study and remember key concepts. Reid and Moore (2008) found that providing examples of good time management strategies and study skills early in the tutoring session and continuing to utilize those strategies throughout future sessions had a positive impact on tutee achievement.

Peer tutors are expected to use various forms of formative and summative assessment strategies to assess tutee understanding to adapt instruction and enhance learning (Herppich, Wittwer, Nuckles, \& Renkl, 2014). Formative assessment data is gathered by an instructor, or peer tutor in the case of this study, and then used to adapt 
instructional practices (Shepard, Hammerness, Darling-Hammond, \& Rust, 2005). Summative assessment is used not improve learning rather it is used to measure student learning at the end of instruction (e.g. Shavelson et al., 2008). Peer tutors ask their tutees various questions to determine what the tutee does and does not know (Cromley \& Azevedo, 2005). This information can then later be used to holistically assess tutee understanding after the peer tutoring session has concluded (Black \& William, 2009).

For peer tutoring programs to be successfully, colleges and universities must carefully select and train all peer tutors. CRLA provides higher education institutions with specific guidelines for what institutions should require academically for students seeking employment as peer tutors and how those peer tutors should be trained. Research has shown that higher levels of success have been reported in peer tutoring programs that require peer tutors have high academic achievement and rigorous training on effective peer tutoring instructional strategies. Knowledge gained through peer tutoring sessions provides peer tutors with the skills and confidence to formatively assess tutee understanding, adapt instruction, and then assess overall learning at the end of each peer tutoring session.

\section{Online Peer Tutoring}

To increase enrollments at minimal cost, many modern higher education institutions have begun to intentionally focus on building and growing their distance education programs. For instance, in 2014 a total of 2.85 million students took all their classes at a distance and 2.97 million took some, but not all, courses at a distance (Allen et al., 2016). To support increasing numbers of online students, many colleges have started to explore the idea of providing online synchronous tutoring services as an 
academic support strategy (Huang \& Liu, 2015; Jopling, 2012). Online tutoring involves personalized learning support provided via the Internet and includes audio, video, or text communication between the e-tutor and the e-tutee (Flowers, 2007). While the positive rewards of face-to-face peer tutoring programs have been extensively documented, Evans and Moore (2013) found studies on computer-aided peer tutoring programs to be less common.

Online Peer Tutoring as a Support Strategy for Blended and Face-to-Face Students Initially, online tutoring programs were developed to support the increasing number of students enrolling in distance education courses and programs in higher education (Huang \& Liu, 2015; Jopling, 2012). However, students enrolled in blended and traditional face-to-face courses have begun to take advantage of online peer tutoring services (Richardson, 2012). Sansone, Ligorio, and Buglass (2016) conducted a study to determine how the role of e-tutor was performed and perceived by 12 students who enrolled in a blended university course. Throughout the course of the study, participants took turns playing the role of an e-tutor. Playing the role of e-tutor involved monitoring and supporting discussions, encouraging everyone to participate, keeping discussions on topic, and guiding progress while reinforcing deadlines. The researchers found that students were more actively engaged in participating in the course and interacting with the content when they were tasked with the responsibility of playing the role of e-tutor. Furthermore, prior to serving as an e-tutor, most student discussion posts were emotional, supportive, and collaborative, however, the became more supportive, collaborative, and educational or more content-oriented when students began serving as e-tutors. 


\section{Advantages of Online Peer Tutoring}

A few advantages have been associated with offering peer tutoring services online (Vasquez, Forbush, Mason, Lockwood, \& Gleed, 2011). Beth-Marom, Saporta, and Caspi (2005) found that delivering tutoring online provided additional flexibility in instructional materials, geographic delivery, and the time of day in which tutoring services could be provided. Additionally, peer tutors and their tutees do not have to use additional resources (e.g., time and money toward commuting to and from rural areas) to receive tutoring services (Jung, Gaylon-Keramidas, Collins, \& Ludlow, 2006).

Online tutoring involves the use of a variety of interactive modes, such as textbased chats or discussions and video conferencing. Text-based discussions more commonly occur in an asynchronous setting and offer the tutor and the tutee the convenience and flexibility in the areas of time and place (Hara, Bonk, \& Angeli, 2000). This scenario is especially true with students who struggle to coordinate all aspects of their personal, school, and work lives (Wu, Lin, \& Yang, 2013). Using video conferencing, peer tutors and their tutees can hear each other and share a variety of resources including visual aids in real-time (Jennings \& Bronack, 2001). Online communication that occur in real-time is referred to as synchronous.

\section{$\underline{\text { Asynchronous versus Synchronous Online Peer Tutoring }}$}

Most early research on online education has focused on courses that predominantly or solely use asynchronous, text-based, communication (de Freitas \& Neumann, 2009; Kear et al., 2012). This is largely because asynchronous web-based online instruction used to be the most widely adopted delivery method for distance education (Persad \& Lewis, 2008). However, the use of synchronous communication 
tools in online education is increasing because of its ability to promote more in-depth real-time dialog between students in distance courses (Hrastinski, 2008). Furthermore, synchronous online tutoring offers additional advantages which include: (a) access to skilled tutors regardless of a students' geographic boundaries, (b) available during school hours or outside of school hours, and (c) can be accessed from virtually any location (e.g., home, school, or other locations). Synchronous instruction involves real-time interaction between the instructor and students where both are situated in the same online space, at the same time, to communicate and engage in instructional activities, whereas situations in which the interactions take place at different times in the same space are referred to as asynchronous instruction (Horton, 2006; Hrastinkski, 2008; Hsiao \& Huang, 2012; Salmon, 2012; Schuster \& Finkelstein, 2006).

\section{Asynchronous Tutoring}

E-mail, discussion boards, wikis, and video/audio recordings are tools that are used in asynchronous tutoring (Hsiao \& Huang, 2012). The use of asynchronous tutoring within the learning environment can foster in-depth learning and critical thinking because students have more time to process information (Bonk \& King, 1998; Duffy, Dueber, \& Hawley, 1998; Hiltz, Coppola, Rotter, Turroff \& Benbunan-Fich, 1999). However, some research has shown that asynchronous communication can lead to feelings of isolation resulting from a delay in response time (Branon \& Essex, 2001; Ory \& Bullock, 1997; Vonderwell, 2003). Swann (2010) also found that some students have found it difficult to discuss or understand learning issues without seeing and hearing other people.

Many colleges and universities began offering their online peer tutoring programs via asynchronous technologies. The most common form of asynchronous online tutoring 
program was and still is used to provide tutees with additional writing support; in this type of online peer tutoring program, tutees submit drafts or final versions of their written content to a peer tutor (e.g., through a discussion forum, or other form of asynchronous technology) and then must wait for the peer tutor to provide feedback on the writing later and time. Unfortunately, participation rates for asynchronous online tutoring programs have remained low due to communication issues. After interviewing tutors and tutees who participated in an asynchronous online tutoring program, Childs (2012), identified the following reasons for low adoption of the program: (a) tutors and tutees often found it difficult to explain certain concepts using online written expression, (b) time delays between then work was submitted, reviewed, and then sent back made it difficult measure progression, and (c) additional time was often needed to clarify specific points. These constraints have led to lower adoption rates for students at colleges and universities that offer asynchronous peer tutoring support in writing. Therefore, some institutions have begun to experiment with different options for offering synchronous peer tutoring.

\section{$\underline{\text { Synchronous Peer Tutoring }}$}

Kear et al., (2012) suggested one possible solution for addressing the drawbacks associated with asynchronous learning environments is the use of synchronous online communication. Synchronous communication technologies can include the use of chat room, instant messaging, and video conferencing technologies (Finkelstein, 2006). Researchers have identified several benefits of synchronous communication. Loch and Reushle (2008) suggested that audio and video conferencing technologies can positively impact social presence and can give online communication more of a human feel. According to Park and Bonk (2007), the benefits of using synchronous video 
conferencing communication include: the ability to provide immediate feedback, an exchange of multiple perspectives, enhanced dynamic interactions between participants, strengthened social presence, and increased emotional support. Cao, Griffin, and Bai (2009) also found that synchronous instruction has also been shown to effectively increase student interaction.

After investigating a series of synchronous video conference interactions between Taiwanese students and a native English speaker, Wu and Marek (2010) found that synchronous communication led to improved student confidence and improved academic abilities. Through integrating additional synchronous tools (e.g., whiteboards, document sharing, and audio/video capabilities) that are built into most common video conferencing solutions, Chen, Wang, Wu, and Levy (2008) found in another study that tutees tended to be more engaged in listening, speaking, and writing about the content being covered and other research has shown that synchronous learning experiences also led to increased communication between the tutor and the tutee (Pattillo, 2007).

While additional affordances are brought about using synchronous communication technologies, the delivery method does have a few constraints that have been presented in previously published research. Technical difficulties, poor audio and video quality, limited bandwidth, outside distractions, and the lack of physical human interaction are some of the constraints that have been associated with using more complex interactive tools for providing synchronous online tutoring services (Knipe \& Lee, 2002; Wilkinson \& Hemby, 2000).

Peer tutors who provide online tutoring services using synchronous technologies must be properly trained on how to address the various technical issues that might occur 
during each tutoring session (Guichon, 2009). Develotte, Guichon, and Vincent (2010) found that technical issues that interfere with communication between the peer tutor and the tutee in a synchronous learning environment, can lead to increased anxiety in both the tutor and the tutee. Therefore, institutions should include technical troubleshooting and adaptation strategies in their initial peer tutor training programs to better prepare peer tutors to "adapt dynamically to changing circumstances" (Clancey, 1995, p. 49).

The Need for Additional Preparation Time and Practice

Synchronous online tutoring requires tutors to possess a new skill set to provide learners not only with content knowledge but also with emotional and technical support (Angelova \& Zhao, 2016). Kear et al. (2012) conducted a study to further understand peer tutor perspectives of using web conferencing tools to deliver synchronous online tutorials. During the study, six tutors invited their students to participate in supplementary online tutoring sessions via Elluminate video conferencing technology. One concept that emerged from the qualitative data that while they had previously prepared a variety of instructional materials and resources for the face-to-face tutoring sessions, nearly all those materials had to be revised or replaced for the tutoring sessions to be successful in an online environment. This required additional preparation, planning, and training for tutors to complete. While the tutors that participated in this study were provided with several different training videos and handouts on how to interact via Elluminate videoconferencing technology, several of the tutors reported that they had to conduct a few practice sessions with friends or family members to start to feel comfortable with interacting in the online tutoring environment. 
$\underline{\text { Video Conferencing Technology for Providing Synchronous Online Tutoring }}$

Traditionally, face-to-face tutoring sessions have accounted for the most widely used methods for delivering tutoring services. However, due to technological advancements, many colleges and universities have begun experimenting with different forms of synchronous online peer tutoring programs either through third-party web-based software or through in-house video conferencing systems (Stickler \& Hampel, 2007). Desktop video conferencing (DVC), a feature available in many commercial e-tutoring packages, combines audio and video hardware with Internet-based software on a personal computer (Furr \& Ragsdale, 2002) to create an interactive synchronous environment between students and instructors (Mize, 1996). Common DVC applications include a whiteboard, video and audio conferencing, chat rooms, file sharing, and remote desktop screen sharing.

A few commercial web-based e-tutoring solutions such as SmartThinking, Tutor.com, and eTutoring.org have been marketed to higher education institutions in recent years. Two common advantages most commercial e-tutoring software solutions promote are the usage of shared pools of vetted tutors pulled together from a variety of higher education institutions and 24 hours a day, 7 days a week availability of tutoring services. However, when shared pools of tutors from outside institutions are used, the advantage of in-house peer tutors benefiting from learning by teaching is lost (Sternberg, 1985). In a study conducted by Annis (1983), three groups of female college students were analyzed: one in which students simply read the assigned material, a second group read and developed a plan to teach fellow students, and the final group had to read and teach the material to a peer. The results of that study showed that the students who taught 
other students gained more content-specific and generalized cognitive knowledge than the students who prepared to teach or who were taught by their peers and that peer tutoring appears to have the potential to increase all levels of student learning.

While multiple studies have shown the positive effects of integrating peer tutoring into developmental education programs (Bowman-Perrott et al., 2013), the use of digital video conferencing to enable oral and visual interaction between distance education students and tutors has been underrepresented in the literature (Wang, 2004).

\section{$\underline{\text { Synchronous Virtual Classrooms }}$}

Rockinson-Szapkiw and Walker (2009) coined the term synchronous virtual classrooms (SVC) to describe classrooms that use web conferencing or e-conferencing technologies to provide real-time instruction. The ability for multiple users to conduct meetings and seminars, lead discussions, make presentations and demonstrations, and other educational functions are some of the affordances of SVCs (Martin \& Parker, 2014). While the communication tools available differ from one SVC solution to another, most allow participants to share files, have an interactive whiteboard for instructors and students to write and draw, include text chats to interact through words and emoticons, and audio and video chats that allow for interaction through the use of webcams, microphones, and telephones along with the ability to record and archive sessions as their main feature (Martin \& Parker, 2014; McBrien, Cheng, \& Jones, 2009). Of all the available features in most SVCs, Martin, Parker, and Deale (2012) found that using the recording feature to archive sessions, which includes recording presentations in advance or recording live presentations, to be one of the most widely used features because it allows students to review the content and self-identify any missed information or 
misconceptions that might have occurred during the initial presentation. LaPointe, Greysen, and Barrett (2004) found that the audio and video capabilities of SVCs help to break down barriers between cultural differences and to build collaborative communities. Furthermore, Martin, Parker, and Deale (2012) analyzed the communication that occurs in SVCs and found definite signs of enhanced interaction.

\section{Chapter Two Summary}

In summary, a review of the research has shown peer tutoring to be an effective academic support strategy both for the tutor and for the tutee. While various forms of peer tutoring have been occurring for centuries, the concept of synchronous online peer tutoring services that utilize video conferencing technologies have just recently emerged in the past decade. The emergence of synchronous online peer tutoring was brought about because of the increasing demand on institutions of higher education to offer more online courses and programs to meet needs of students who are not able to attend classes on campus through traditional seated classes due to time, disabilities, or other limiting factors. The use of an institution's internal peer tutors has been shown to bring about additional cognitive benefits for the peer tutors and has led to additional social and emotional benefits for the tutees. Tutees benefit when internal peer tutors are used to provide synchronous online peer tutoring services because the internal peer tutors tend to be more familiar with the specific instructors who teach the subject matter being addressed and with institutional policies and procedures in general. Although several benefits of having on internal synchronous online peer tutoring program have already been revealed through a review of the literature, the one component that seems to under researched is the perceptions of the peer tutors who providing synchronous tutoring 
services in an online environment that utilizes video conferencing technologies for delivering instruction. This study sought to fill in that gap and identified additional affordances or constraints peer identified concerning the synchronous online tutoring methodology that has been chosen. 


\section{CHAPTER THREE: METHODS}

\section{Research Methods}

Research has demonstrated the positive impact of peer tutoring services in higher education (Blackie, 2004; Chi \& Roscoe, 2008; De Backer, Van Keer, \& Valcke, 2012; Topping, 2005). As a result, institutions have experimented with different ways to offer peer tutoring at a distance. While some research has focused on the student experience, as a tutee, using online peer tutoring (Stickler \& Hampel, 2007), there is very little, if any, research focused on the peer tutors experience of providing online peer tutoring $(\mathrm{Wu}$, Lin, \& Yang, 2013). The overall goal of this study was to better understand the synchronous online tutoring experience from the peer tutor's perspective, including the types of interactions and instructional strategies used during online tutoring sessions. More specifically, this study sought to answer the following overarching research question: How do peer tutors experience video-based synchronous online tutoring services? Along with the following sub-questions:

a) How do peer tutors interact with their tutees in the synchronous online tutoring environment?

b) How do peer tutors determine if the tutee comprehends the content being discussed?

c) How do peer tutors change their instructional practices when it is perceived that the tutee does not comprehend the content being discussed? 
This chapter describes the research methodology used to conduct this study. The chapter includes a description of the research methods and design, the study population, criteria for defining and procedures for selecting the study sample, design, development, reliability and validity of the questions for the semi-structured interviews, data collection, and data analysis.

\section{Research Design}

An exploratory qualitative case study research design was used to explore and describe the experiences of peer tutors and specifically answer the research questions. Mariano (1990) explains that qualitative approaches to research primarily focus on providing inductive and descriptive accounts of the perceptions, meanings, and lived experiences of the individuals or groups being studied. Qualitative studies allow researchers to "study things in their natural settings, to make sense of, or interpret, phenomena in terms of the meaning people bring to them" (Denzin \& Lincoln, 2011, p.3). Creswell (2012) explained that qualitative research studies are used to explore and further investigate a central phenomenon within a context. Since the purpose of this study was to investigate the experiences of students who provide synchronous online peer tutoring services using video conferencing software (central phenomenon), this study fit within the guidelines outlined in both definitions. Interview data collected during this study was used to further investigate the perceptions and lived experiences of the peer tutors and the observations were used to study the peer tutors in their natural settings. To truly capture the experiences of the peer tutors in their natural settings, archived screen recordings of peer tutoring sessions that had already occurred were reviewed to gather the observation data for this study. The benefit of using a qualitative case study approach is 
that it ensures a issue is explored in-depth from multiple angles rather than through a single lens which allows the researcher to uncover and understand multiple aspects associated with the issue being studied (Baxter \& Jack, 2008).

This exploratory qualitative study used a case study approach to further investigate the experiences of peer tutors as they used video conferencing software to provide synchronous online tutoring services. Yin (2012) described a case as a "bounded entity such as a person, organization, behavioral condition, event or other social phenomenon (Yin, 2012, p.6). Old Dominion University offers one holistic online peer tutoring service that is available to all undergraduate students on campus. So, it does not matter if a student is enrolled in a nursing, engineering, or business degree program, they all go through the same main Peer Educator Program to register for online peer tutoring services. The boundaries for the case in this study were that all peer tutors attended and served students at the same university as their tutees, all peer tutors and their tutees were undergraduate students, and the participants had specifically provided or were providing synchronous online peer tutoring before and during the time this study was conducted.

Case studies can use either a single case or multiple cases. This study used a single case approach. According to Yin (2014) one of the five rationales for a single case approach is that the case represents an extreme or unusual situation or case. The case in this exploratory qualitative study was not extreme, however, the specific method for providing synchronous online peer tutoring services used by Old Dominion University was unusual. Initially, a Google search for "online peer tutoring programs" revealed several colleges and universities in the south-eastern region of the United States were attempting to offer various forms of online peer tutoring services to their students. 
Unfortunately, most of those programs either used commercial third-party software which used outside peer tutors to provide online tutoring or they only offered asynchronous online writing tutoring services. Florida Atlantic University and Old Dominion University appeared to be the only two higher education institutions in the south-eastern United States who were using internal peer tutors and video conferencing software to offer synchronous online peer tutoring services. Of the two programs identified, Old Dominion University was the only institution that responded to a request to participate in this study. Based on those circumstances, this study fit within the unusual case rationale for a single case study approach.

\section{Setting}

This study took place at Old Dominion University (ODU) during the 2017 spring academic semester. ODU is a large, accredited, public, four-year university located in the Middle Atlantic Region of the United States. ODU first gained independent institution status in 1962 and later earned university status in 1969. It is accredited by the Southern Association of Colleges and Schools Commission on Colleges to award baccalaureate, masters, education specialist, and doctoral degrees. The university currently has approximately 24,672 students, of which 20,101 are undergraduate students and 4,571 are graduate students. Internationally, there are 1,092 students enrolled from 105 different countries. Out of 168 bachelors', master's, and doctoral programs available to students, more than 100 programs are offered via distance education through the institution's online campus.

ODU's accreditor, the Southern Association of Colleges and Schools Commission on Colleges and Schools, requires institutions who offer distance and correspondence 
education to provide appropriate academic support services to online students that are comparable to the support services offered to on campus students (SACSCOC, 2011, p. 7). To provide tutoring services to distance education students, ODU originally began offering online peer tutoring services through SmartThinking, which is a third-party software package that utilizes shared pools of peer tutors from around the globe. However, after experiencing a lack of student usage and a reduction in financial resources, ODU investigated more affordable alternatives for providing peer tutoring services to online students. As a result, the institution developed an internal system online peer tutoring service using Cisco's WebEx video conferencing software. The service was first made available to students as part of a pilot study that began in the fall of 2015. During the pilot, the online peer tutoring services were only offered to a small group of students enrolled in specific online programs.

Although the initial pilot study was limited to a small percentage of the student body, an evaluation of the online peer tutoring services yielded positive results.

Subsequently, based on the success of the pilot, the online peer tutoring services program was expanded and offered to all students enrolled in online programs or courses in the spring of 2016. Then in the Fall 2016 semester, the program was expanded to include all students regardless of instructional delivery format.

\section{$\underline{\text { Participants }}$}

The Old Dominion University Peer Educator Program administrators identified a total of twelve individual peer tutors who conducted synchronous online peer tutoring sessions during the Fall 2016 academic semester. Of those twelve, three did not return as peer tutors for the Spring 2017 academic semester. Of the remaining nine peer tutors who 
provided online tutoring services in the fall of 2016 and again in the spring of 2017 , all nine volunteered to participate in this study. Each of the nine peer tutors who agreed to participate in the study were interviewed, however, observations were only conducted on six of the nine tutors. Two of those peer tutors are still currently providing online peer tutoring services while one of the three has since obtained employment in the professional field in which he is majoring. The interviews and observations will be described in more detail later in this chapter.

\section{Purposeful Sampling}

Purposeful sampling is a nonrandom technique widely used in qualitative research for the identification and selection of information-rich cases for the most effective use of limited resources (Palinkas, Horwitz, Green, Wisdom, Duan, \& Hoagwood, 2015; Tongco, 2007). Purposeful sampling involves selecting individuals or groups of individuals based on a phenomenon of interest (Creswell \& Clark, 2011). In more simplistic terms, purposeful sampling involves the researcher specifically choosing participants based on similar lived-experiences and their willingness to participate (Lewis $\&$ Sheppard, 2006; Tongco, 2007). The researcher purposely selected all nine returning peer tutors as participants for this study to get the most diversity among experiences in the program as possible.

When deciding to purposeful sample participants, it is imperative that the researcher learns about the specific population being studied to efficiently select knowledgeable and reliable informants (Snedecor, 1939). One way that researchers can do this is by asking for assistance from members associated with the specific community being studied to strategically select possible participants (Tongco, 2007). Thus, the 
researcher met with ODU online peer tutoring program administrators multiple times to plan out specific details for this study. Through those meetings, the program administrators shared biographical and statistical data about each of the 9 possible participants with the researcher. This data is public knowledge and readily available through the Old Dominion University website.

Allen (1971) recommended that researchers develop a set of well-defined qualifications when using purposeful sampling to select participants for a study. As a result, two specific criteria were identified for purposefully selecting participants for this study. The main criteria was to select as many of the peer tutors who has provided online peer tutoring services in at least one previous semester as possible. As an incentive, online peer tutoring program administrators at ODU agreed to allow participants to take part in the study during the hours in which the peer tutors were getting paid to provide tutoring services. Therefore, participating in the study did not require additional time outside of work and school. The second criteria was to try to capture viewpoints from as many different subject areas as possible.

\section{Data Collection}

When conducting qualitative research, the researcher, who is the primary data collector, is responsible for developing protocols for recording captured data as the study proceeds (Creswell, 2012, 2013). Creswell (2013) described the immersive role the researcher plays in qualitative research as "locating the observer in the world" (p. 43). Qualitative studies require the researcher to decide what types of data collection strategies to be used, what types of data to be collected for each strategy, and how the captured data is going to be recorded, stored, and thematically interpreted (Creswell, 
2012; Merriam, 2009). Therefore, qualitative studies require the researcher to contextually interpret the meanings of events, actions and expressions rather than simply accepting them as 'given' or 'self-evident' (Have, 2004). Those detailed and descriptive interpretations are then presented in the form of written words and pictures rather than as numbers and hard statistical data (Merriam, 2009).

\section{$\underline{\text { Semi-Structured Interviews }}$}

To investigate the lived experiences of peer tutors, semi-structured interviews were conducted with peer tutors. There are three main types of interviews that can be used when conducting qualitative research studies: unstructured, semi-structured, and structured. Each of the three types of interview lie on a continuum: (a) unstructured interviews require the researcher to have a clear plan, however, the researcher has little control over how participants will answer, (b) semi-structured interviews require the researcher to develop a guide with specific questions and topics that must be covered but allows the researcher the freedom to decide what order the questions are asked and to insert additional probes when necessary, and (c) structured interviews require the researcher to develop a fixed set of questions and to ask all study participants the same questions in the same order (Harrell \& Bradley, 2009). The biggest difference between semi-structured and structured interviews involves the researchers' freedom to insert additional probing questions into the interviews based on participant responses whereas structured interviews limit the researcher to providing a previously scripted response or definition (Fowler, 2002).

Semi-structured interviews allow researchers to dig deep beneath initial appearances to gain a holistic in-depth understanding of the concept being studied 
(Wengraf, 2001). Thus, semi-structured interviews were conducted in this study because they would allow the researcher to gain a rich, in-depth understanding of multiple experiences described by each peer tutor participant. Further, semi-structured interviews, according to Bernard (2002), are extremely useful when the researcher most likely will only get one chance to interview the study participants. In this study, the researcher had one week to visit ODU and interview the participants due to limitations associated with the timeline for when synchronous online peer tutoring services were available during the 2017 spring academic semester.

Interviews have been shown to be an effective method for collecting qualitative data because they encourage study participants to talk about their personal feelings, opinions, and experiences (Mack et al., 2005). The researcher coordinated with the online peer tutoring program administrators to schedule face-to-face interviews with each of the peer tutors who agreed to participate in the study. The interviews were conducted on the campus of Old Dominion University over the course of a one-week period during the 2017 spring academic semester. The interviews were recorded. During the interviews, the researcher also took field notes in a journal.

Interview questions are usually open-ended, general, and focused on understanding the central phenomenon in the study (Creswell, 2013). Interview questions are traditionally refined and revised through pilot studies (Creswell, 2013) However, due to limited one-time access to possible participants and the unique nature of the program being studied, a pilot study was not possible. However, the interview questions were carefully constructed to align with the research questions guiding this study. Table 3.1 
provides a rationale for each question and how each question aligns with the research question.

Table 3.1 Interview Question Guide for Peer Tutor Semi-Structured Interviews

\begin{tabular}{|c|c|c|c|}
\hline \multicolumn{2}{|r|}{$\begin{array}{l}\text { Semi-structured interview } \\
\text { questions }\end{array}$} & Rationale & \multirow{2}{*}{$\begin{array}{l}\text { Alignment of Research } \\
\text { Questions } \\
\text { a) How do peer tutors } \\
\text { describe the lived } \\
\text { experience of using } \\
\text { video conferencing to } \\
\text { provide synchronous } \\
\text { online tutoring services? }\end{array}$} \\
\hline a) & $\begin{array}{l}\text { Why did you decide to } \\
\text { become a peer tutor } \\
\text { and did you know you } \\
\text { were going to have to } \\
\text { provide }\end{array}$ & $\begin{array}{l}\text { a) For ODU peer tutors, } \\
\text { participation in the } \\
\text { synchronous online } \\
\text { peer tutoring program } \\
\text { was originally optional. }\end{array}$ & \\
\hline b) & $\begin{array}{l}\text { Please describe a time } \\
\text { when the synchronous } \\
\text { tutoring session went } \\
\text { well and then a time } \\
\text { when it went bad. }\end{array}$ & $\begin{array}{l}\text { b) For ODU peer tutors, } \\
\text { participation in the } \\
\text { synchronous online } \\
\text { peer tutoring program } \\
\text { was originally optional. }\end{array}$ & $\begin{array}{l}\text { b) How do peer tutors } \\
\text { interact with their tutees } \\
\text { in the synchronous } \\
\text { online environment? } \\
\text { How do peer tutors } \\
\text { determine if the tutee } \\
\text { comprehends the content } \\
\text { being discussed? }\end{array}$ \\
\hline c) & $\begin{array}{l}\text { Would you recommend } \\
\text { participation in this } \\
\text { program to your } \\
\text { friends? Why or why } \\
\text { not? }\end{array}$ & $\begin{array}{l}\text { c) The previous question } \\
\text { sought to identify } \\
\text { individual situations in } \\
\text { which a session did or } \\
\text { did not go well. This } \\
\text { question will further } \\
\text { expand on that concept } \\
\text { to get a more summative } \\
\text { overview of how the } \\
\text { peer tutor feels about the } \\
\text { entire program based on } \\
\text { lived-experiences. }\end{array}$ & $\begin{array}{l}\text { c) How do peer tutors } \\
\text { describe the lived } \\
\text { experience of using } \\
\text { video conferencing } \\
\text { technology to provide } \\
\text { synchronous online } \\
\text { tutoring services? }\end{array}$ \\
\hline & $\begin{array}{l}\text { How do you know if } \\
\text { you are helping the } \\
\text { students? }\end{array}$ & $\begin{array}{l}\text { d) Success in peer tutoring } \\
\text { programs hinge on } \\
\text { whether the peer tutors } \\
\text { can accurately assess the } \\
\text { needs of the tutees they } \\
\text { serve and how those } \\
\text { needs are addressed. } \\
\text { This question will } \\
\text { provide further insight }\end{array}$ & $\begin{array}{l}\text { d) How do peer tutors } \\
\text { determine if the tutee } \\
\text { comprehends the content } \\
\text { being discussed? }\end{array}$ \\
\hline
\end{tabular}


into what teaching approaches are being utilized by each peer tutor during the tutoring session.

e) How do you adjust your instructional practices when you have determined that the tutee is not comprehending the subject matter?

f) What suggestions for overall improvements to the synchronous online peer tutoring program do you have? e) The previous question focused on determining how peer tutors assess the needs of their tutees. This question is focused on determining how peer tutors change their teaching approaches to accommodate the changing needs of the tutees. This question also seeks to identify what teaching approaches are being used.

f) While the peer tutors were previously asked to identify affordances and constraints of participating in the program, however the peer tutors were not provided the opportunity to provide suggestions for addressing times in which the sessions might not have gone well. This question is primarily focused on soliciting further information about technology, but might e) How do peer tutors change their instructional practices when it is perceived that the tutee does not comprehend the content being discussed? f) How do peer tutors describe the lived experience of using video conferencing technology to provide synchronous online tutoring services?

\section{$\underline{\text { Peer-Tutoring Observations }}$}

Recordings of the peer tutoring sessions were reviewed and analyzed to validate information provided by the peer tutors during the face-to-interviews and identify any 
additional concepts that might not have been discussed in the initial interviews. The researcher wrote field notes, in the form of a journal, while initially reviewing the recording of each session and then subsequently thematically coded the recorded observations. The researcher only observed peer tutors that he had previously interviewed.

Observation is one of the key tools for collecting data in qualitative research (Creswell, 2013, p. 106). Using all five senses, sight, hearing, touch, smell, and taste, observation allows the researcher to gather valuable data for scientific purposes about a specific phenomenon in a field (Angrosino, 2007). Creswell described four main types of observations that can occur which include complete participant, participant as observer, nonparticipant/observer as participant, and complete observer. To maintain the integrity of the actual tutoring sessions, the researcher took on the role of a complete observer. In a complete observer role, Creswell (2013) explains that "the researcher is neither seen nor noticed by the people under the study" (p. 167). As a complete observer, the researcher could review recorded sessions without interrupting the training or tutoring that was taking place. To keep the online peer tutoring sessions as authentic as possible, the researcher did not actually participate in the tutoring sessions nor observe the sessions in person. Instead, the researcher reviewed recordings of the actual tutoring sessions. The purpose for conducting observations as a complete observer was to maintain authenticity throughout the tutoring sessions. Bell (1808) and Topping (1998) found that students who seek out peer tutoring over other forms of tutoring do so because their peers seem to be less intimidating than instructors or subject-matter experts. Adding the researcher into the live online peer tutoring sessions as a third person had the potential to 
negatively impact the interactions between the tutees and their peer tutors. Secondly, placing the researcher in the live online peer tutoring sessions would also have caused additional scheduling conflicts. Old Dominion University students who wish to participate in the synchronous online peer tutoring program must have completed a registration form in advance. Sometimes, students register for online sessions on the same day that the sessions occur. There is no way of knowing who the tutees are until they have registered for a session. Once they have registered, the researcher would then have to obtain permission for participation in the study from the tutee prior to the start of the session. Obtaining this permission for sessions that were requested and scheduled on the same day would have been nearly impossible. The agreement with ODU was that the Peer Educator Program administrators would reach out to individual tutees after the online tutoring sessions had occurred via email to request permission for participation in this study. The researcher had no direct contact with any of the tutees who agreed to participate.

One of the main disadvantages that has often been associated with relying on data collected through participant observation is that it is very difficult to focus on the act of observing while trying to write down everything that is important (Mack et al., 2005). By reviewing recordings of the actual synchronous online peer tutoring sessions, the researcher was able eliminate this disadvantage. The researcher reviewed the recordings, in their entirety, multiple times which increased the reliability and validity of the observation data.

Observational data provided the researcher with a way to further triangulate data collected during the one-on-one interviews. According to Mack et al. (2005), "data 
obtained through participant observation serve as a check against participants' subjective reporting of what they believe and do" (p. 13). Meyer (2001) also added that observation can increase the rigor of a study when it is combined with other data collection methods. Observation data also helped the researcher to identify possible discrepancies that might arise between what the peer tutor participants say in the individual interviews and casual conversation and what they do (Pettigrew, 1990). Data collected through the observations in this study was used to identify any additional teaching approaches that were used by the peer tutors that were not captured during the semi-structured interviews. The observational data assisted the researcher with identifying any additional technology issues that were not addressed through the interviews.

\section{Field Notes}

Field notes in the form of a reflective journal were kept by the researcher during the semi-structured interviews and observation. Creswell (2013) discussed the concept of collecting and recording observation field notes as popular forms of recording information in narrative research, ethnographies, and case studies. Marshall and Roseman (1995) highlighted the importance of observing and recording participant actions to capture body language and other non-verbal cues that might not otherwise be identified through reviewing audio recordings of the sessions. Field notes are also valuable in the event the participant asks the researcher to turn off the audio recordings at any point during the interview process (Mack et. al., 2005). Data captured on the field notes included reactions to questions, facial expressions, emotions, intonation, and any additional nonverbal cues that might be displayed to get a more holistic description of the peer tutor's perspective. Following the suggestions of Mack et al. (2005), field notes were 
collected and recorded on the semi-structured interview question guide created by the researcher; specific notations were included to distinguish clearly between participant and researcher comments.

\section{Data Analysis}

Qualitative data analysis, according to Creswell (2013), involves a three-step process which includes: preparing the data for analysis, organizing the data into themes through a process known as coding, and descriptively representing the thematically coded data through charts, tables, or a discussion. While the three steps might seem straight forward and simple, Patton (2002) discussed just how daunting discriminating the massive amounts of data found in interview transcripts and field note file can be. Agar (1980) suggested that researchers should read through and immerse themselves in each interview transcript in its entirety several times before attempting to thematically code the data. Furthermore, Creswell (2013) suggested the researcher should add notes or memos to the margins of the transcripts, field notes, or photographs during their initial read through of the documents. Given this, I chose to transcribe the recordings of the interviews and the observations (i.e., the recordings of past sessions) myself. This allowed me to follow Agar and Creswell's recommendations and immerse myself in the data. Picture 1 provides an example of some of the field notes that were added as the observations were transcribed. Basic observation details were noted in parenthesis directly within the transcripts. One example of a basic observations that was noted using this method can be seen in lines 326 and 327 in Picture 1. The notation, "Moves head directly in front of the screen very closely and stares into the screen anxiously" was added to emphasize the difficulty both the peer tutor and the tutee were having as they 
both attempted to share printed text content using their respective computer webcams. In some instances, additional, more detailed, explanations were added to further describe the context of certain situations and those notes were added to the margins using the commenting feature in Microsoft Word. An example of this can be seen in lines 331 and 332 and the comment in the right margin that extends out from those lines in Picture 1. The notation, "Another tutor begins a face-to-face tutoring session on the other side of the room. His voice can be heard in this session." was an observation made by the researcher while reviewing the previously recorded peer tutoring session. The fact that additional tutors can be heard providing tutoring services in the background meant that the peer tutor was providing online peer tutoring services from within the main open Peer Tutoring Center rather than from within the dedicated Distance Tutoring Room. This inference was made by the researcher based on the in-person interviews with each of the participants that were conducted within the same main open Peer Tutoring Center. 
Session Recording Breakdown

Tuesday March 21, 2017

323 Tutee- No, there's no R1 anywhere.

324 Tutor- Ok, so what's the next formula after the A-BQ2-2BQ? (49:39)

Tutee- Q1 equals $1 / 2(\mathrm{~A}-\mathrm{C} 1-\mathrm{BQ} 2)$

Tutor- Can you show me that? I'm sorry. (Moves head directly in front of the screen very closely

and stares into the screen anxiously)

Tutee- (Holds handwritten notes up in front of the camera as was seen earlier)

Tutor- Hold on one second. (No sound) Alright thank you!

SILENCE- (Loud ding on computer at 51:00 mark. No sounds so far. Might be timer for first

session)- (Another tutor begins a face-to-face tutoring session on the other side of the room. His voice can be heard in this session)

Tutor- I think your teacher left out a formula without distributing the half. I believe that's all

that's going on there. (staring intently at other computer screen) because every where else I'm

looking has the terms split up, but they have divided by 2 underneath them as opposed to your

notes which have the half outside the parenthesis on one side. So I think you were looking at

distributing the half next.

Tutee- Well it has over here, the reaction function for Firm 1. (Holds a new note up to the screen

from the far right side of the same page of notes)

Tutor- Ok, I got it. (Appears to be doing something on the desk and then begins looking at and

using the other computer screen. Later begins flipping through the textbook.)

Lots of silence (Break in action)- around 53:00-

Tutor-Sorry, I'm comparing your teachers formula to what I'm looking at in the book. (55:42)

Tutee- Oh, ok.

Tutor- Like your exactly sure you got the math right when you copied it down?

Tutee- I mean, anything is possible, but I would hope so. But if I didn't, that might have been my

whole problem this whole time.

Tutor- Ok, so I'm seeing in the book it has you're A-BQ2-2BQ one equals $\mathrm{C} 1$ and then it solves

the equation in terms of $\mathrm{Q} 2$, so we get a formula which looks similar to what you have but

um..(57:19- tried to hold the textbook up to the camera to point out the sample problem in the

book) Can you read that at all?

Tutee- Um. Maybe if you put it a little closer

Tutor- What we're doing is Q1...want me to take a picture and send it to you? Can I just like

type in your phone number so I can just text you?

\section{Picture 1. Images of Journaling/Field Notes Added During the Observation Transcription Process}

In this study, three main types of data were analyzed: semi-structured interviews, observations, and field notes. Each participant was asked to sign two different consent forms prior to the start of the face-to-face interviews and the observations. On the first form, the participants were asked to consent to having the audio recorded during the faceto-face interview sessions. The second form was used to obtain consent for allowing the researcher to review previously recorded online peer tutoring sessions. Old Dominion University Peer Educator Program administrators already require each online peer tutoring session to be recorded and archived using the tools and features available in the WebEx video conferencing software. Therefore, permission to record the sessions was not necessary, only permission to review the previously recorded sessions was needed. 
Two different versions of the second form were created. One version was designed for the peer tutors and a second version was used to obtain permission from the tutee that was receiving the tutoring services. For the session recording to be made available to the researcher for viewing and analysis, both the peer tutor and their tutee must have consented to having the tutoring session screen recorded and for that recording to be shared with the researcher via a secure URL. Once all necessary consent forms were completed and returned to the researcher, the face-to-face interviews began. The following sections describes how each type of data was transcribed, thematically coded, and checked for reliability and validity.

\section{Transcription}

After the interviews were conducted, the researcher transcribed each individual interview session word-for-word. After each of the interviews were fully transcribed, the researcher went back through to denaturalize the data (Halcomb \& Davidson, 2006) by removing words such as "uh", "um", or "ah" that do not hold any significant meaning to the overall purpose of the study. To protect confidentiality and promote privacy, the use of any specific names of program administrators, peer tutors, or tutees were removed and replaced with pseudonyms such as Administrator A, Peer Tutor B, and/or Tutee C.

Picture 1 provided an example of a transcribed observation recording. Line numbers and time codes were added throughout the transcribed document to assist quoting specific content from the observation and help to help the researcher with locating items later in the data analysis process. Time codes were only added to the observation transcripts to organize the depth of information that came from transcribing entire hour long synchronous online peer tutoring session recordings. Picture 2 provides an example of 
one of the transcribed interview audio recordings. Line numbers and time codes were not used in the audio transcription documents. Instead, the audio recording transcripts were broken down by each question that was asked and the responses that were recorded for each question. Once the audio from the interviews had been transcribed, the researcher read through each transcript while replaying the recordings to double-check for accuracy. The researcher often had to return to specific events and actions in the video recordings or observation data, which made the line numbers and time codes vital

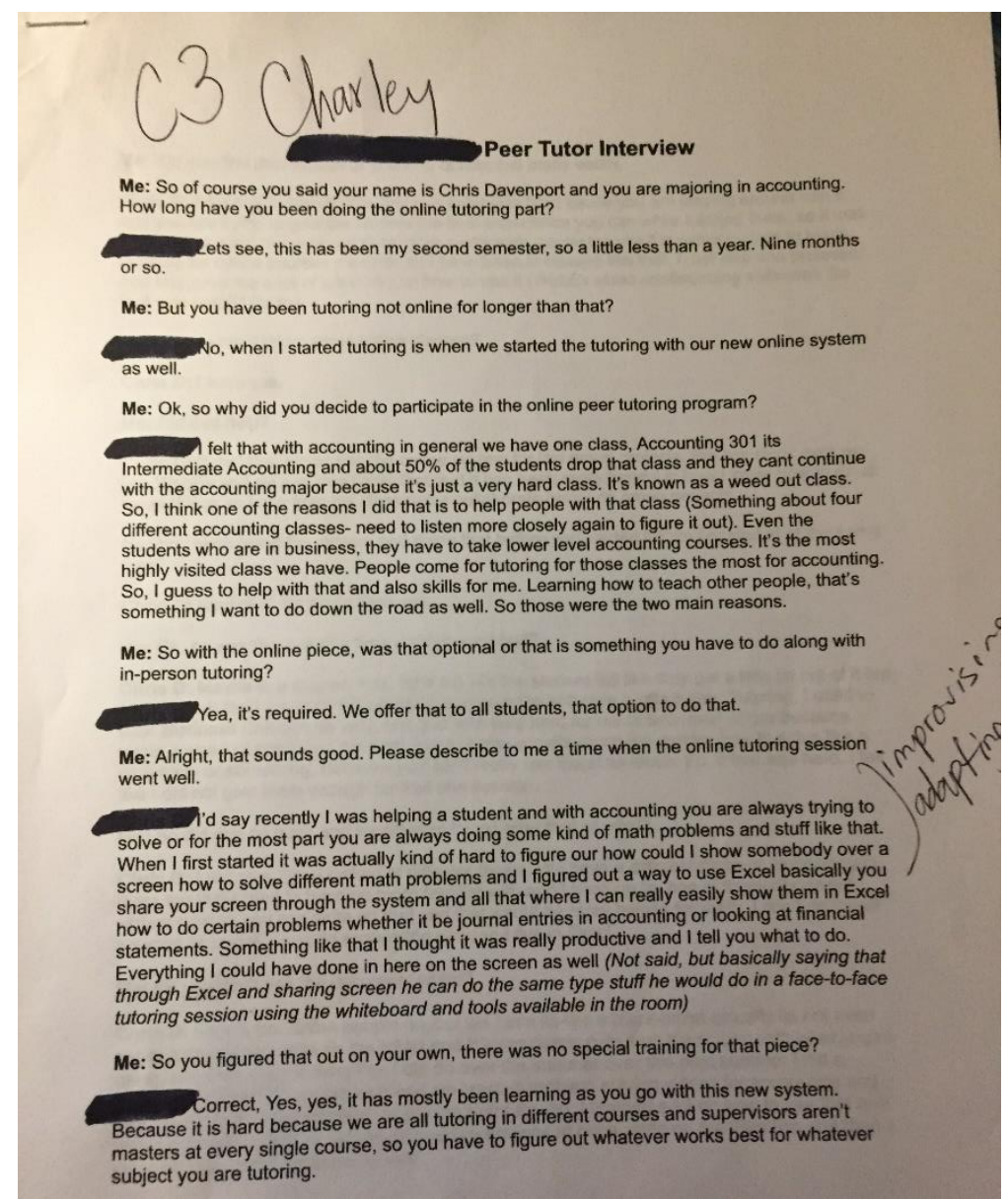

\section{Picture 2. Images of Transcribed Audio Recording}

The peer tutoring observations were also transcribed word-for-word by the researcher. Pseudonyms were used to replace actual names when necessary. The names 
chosen during the interview transcriptions were matched up to the names used during the observation transcription process. Those names were randomly assigned by the researcher and only the researcher knows which peer tutor each pseudonym represents. $\underline{\text { Coding }}$

Coding qualitative data involves identifying big ideas, commonly referred to as themes or topics, and then connecting those big ideas to all data pertaining to the big ideas (Richards \& Morse, 2007). Thematic coding transforms large amounts of original data recorded in transcripts, field notes, documents, images, interest pages, and audio or video recordings into something that is more meaningful and easy to digest (Rivas, 2012). The coding process is cyclical in that it requires the researcher to pass the data through multiple cycles to identify categories, themes, and concepts, grasp meaning, and/or build theory (Saldana, 2009). Codes are applied and reapplied to "permit the data to be segregated, grouped, regrouped, and relinked to consolidate meaning and explanation" (Grbich, 2007, p. 21). Analyzing data through coding allows the researcher to search for patterns in the data and to identify additional explanations of why the patterns exist (Bernard, 2002).

The researcher began the coding process through pre-coding the data during the interview transcription process. Pre-coding involves bolding significant quotes or passages as participant responses are transcribed (Boyatzis, 1998). Additionally, during the pre-coding process, the researcher placed brackets around any preliminary words or phrases that seemed important. Bracketing is used during the pre-coding process to mark potential key topics or codes since pre-coded data might not be completely accurate (Saldana, 2009). To keep the original, pre-coded, and final code data organized, the 
researcher created one electronic document for each individual participant that included a three-column table. The first column of the table included the raw data, the second column contained the preliminary codes, and the third column the final codes. All precoding for this research study was manually recorded by the researcher. The researcher then manually entered the data into a Microsoft Word Document to create and organize the actual final codes. This allowed the researcher to apply multiple codes to a single passage or sequential passages, code smaller passages within larger passages, and insert additional descriptive memos related to specific blocks of data or specific codes (Saldana, 2009). Picture 3 provides an example of the pre-coding process that was used. Once the transcription process had been completed, the researcher then went back through each transcript to highlight, circle, and bracket specific phrases or sentences that stood out. Additional notes were made in the margins of the printed transcripts to further highlight exact statements and/or to more summarize the researcher's interpretations of each peer tutors' responses. Eventually, the comments in the margins were revisited and grouped into categories that were later used to help identify the themes for this study as can be seen in Picture 3. Four different items were highlighted in green. The four items that were highlighted in green all involved different aspects of whiteboards. In the example transcript on the left in Picture 3, the peer tutor was talking about using Microsoft Paint as a whiteboard software while the peer tutor on the right talked about using the build in whiteboard tool in WebEx. Although the peer tutor on the left did not specifically mention whiteboards in his response at the top of the document on the page on the left, he later explained that he uses Paint as a whiteboard tool in his last response at the bottom of the same page. 


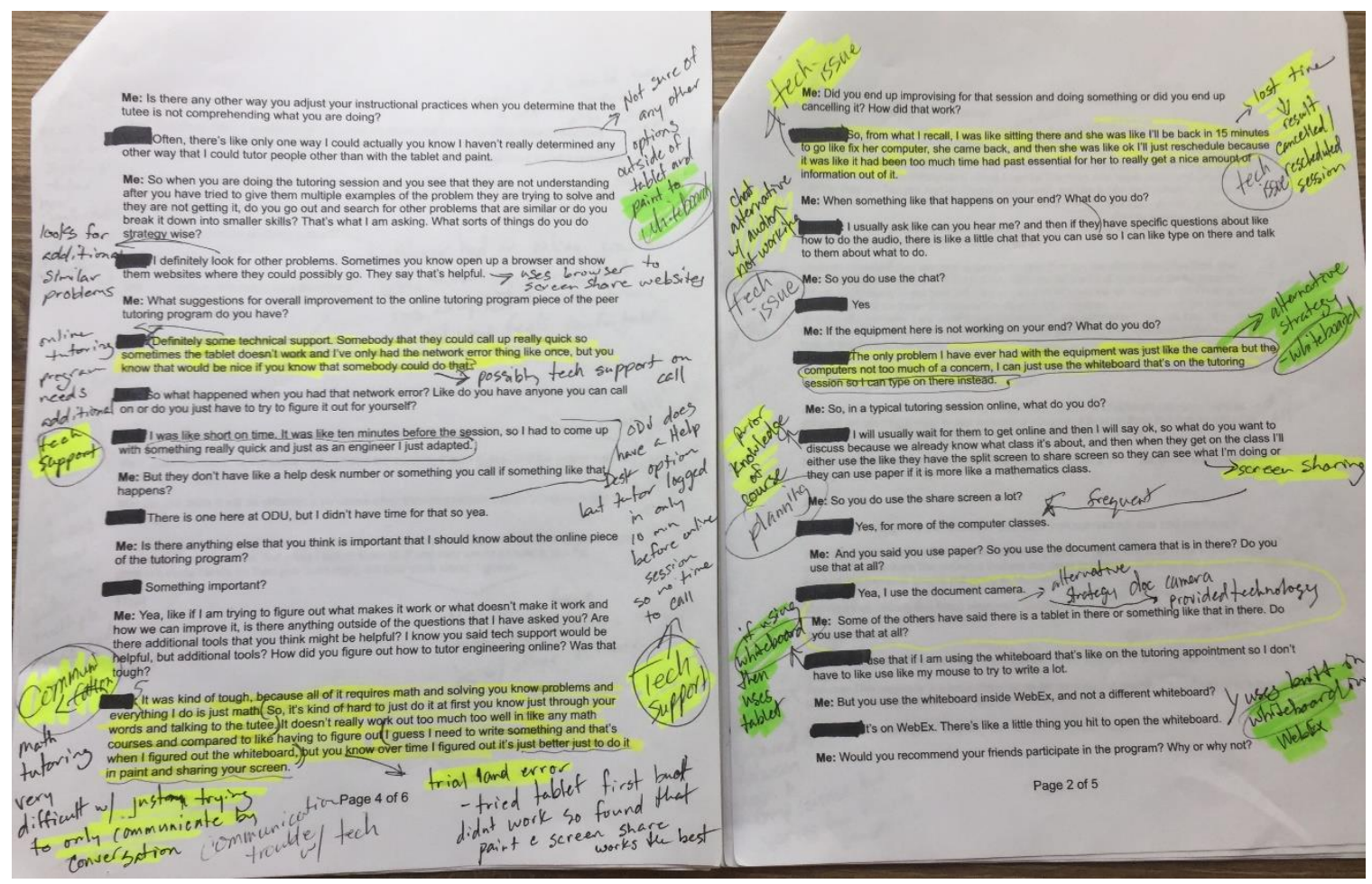

\section{Picture 3. Images of Pre-Coding Process on Two Different Audio Transcripts}

Coding the peer tutoring observations differed from the process of coding interview data. Unlike coding interviews, that are often aligned with key constructs or research questions, in observational research, most of the coding and analysis work occurs simultaneously as the data is gathered (Vogt, Gardner, Haeffele, \& Vogt, 2014). While researchers generally seek to capture participant interview responses in their entirety, not everything witnessed through observational research is beneficial to the intended purpose of a study. Therefore, prior to conducting observations, Vogt et. al., (2014) suggests researchers should identify a specific set of common questions that should be used to guide each observation and to assist with deciding what data to record and what data to discard. Table 3.2 provides a list of the questions that were used to guide the recording of observation data and how each question aligns to the research questions guiding this study. 
Table 3.2 Alignment of Questions to be Answered During Observation Data Analysis

\author{
Observation question to be answered Alignment of Research Questions
}

a) How did the peer tutor initially identify the topic to be discussed in the peer tutoring session? What questions were asked?

b) What questions do the tutees ask throughout the session? How do the peer tutors respond to those questions?

c) What strategies do peer tutors use to assess the tutee's understanding of each topic? Do they provide similar practice questions or problems for the tutee to complete? If so, what resources are used to find the practice items?

d) What additional processes or concepts were observed that appear to be relevant to answering the research questions? What observations related to the research questions were surprising? What if anything appeared to be missing from the sessions?

a) How did the peer tutor initially identify the topic to be discussed in the peer tutoring session? What questions were asked?

b) How do peer tutors interact with their tutees in the synchronous online environment? How do peer tutors determine if the tutee comprehends the content being discussed?

c) How do peer tutors determine if the tutee comprehends the content being discussed? How do peer tutors change their instructional practices when it is perceived that the tutee does not comprehend the content being discussed?

d) How do peer tutors describe the lived experience of using video conferencing technology to provide synchronous online tutoring services? How do peer tutors determine if the tutee comprehends the content being discussed? How do peer tutors change their instructional practices when it is perceived that the tutee does not comprehend the content being discussed?

While analyzing the observational data, only responses or actions that answered the predetermined observational questions were transcribed or described in detail exactly as they occurred. Once the previously recorded synchronous online peer tutoring sessions were reviewed and the researcher had captured the necessary information to answer the observation questions, the thematic coding process began. Pre-coding of recorded observational data occurred through the same process that was used to pre-code the interview transcripts. Bold text was used to highlight all significant quotes or passages 
and brackets were used to mark preliminary codes or themes that were identified by the researcher. A new version of the same three column table that was used to record and organize pre-coding data during the interview process was created to record and organize the raw data, preliminary codes, and final codes captured through the observational research process.

\section{First Cycle Coding Methods}

While the pre-coding process helps to initially identify preliminary key concepts or topics, the actual coding of qualitative data occurs through a two-cycle process. The researcher used In Vivo coding as the First Cycle coding method. In Vivo coding has been referred to as "Literal Coding" or "Verbatim Coding" (Saldana, 2009), because it is used to capture the actual terms and phrases used by individual study participants (Strauss, 1987). Since the overarching purpose of this exploratory study was to capture the lived experiences of peer tutors as they interact with and provide tutoring services to tutees in a synchronous online environment, In Vivo coding was used to prioritize and honor the peer tutor's voices. Codes created through In Vivo coding were derived from “impacting nouns, action-oriented verbs, evocative word choices, clever or ironic phrases, similes and metaphors, etc.” (Saldana, 2009, p. 75). In Vivo coding provides researchers with a way to reduce the amount of data being analyzed and provides an additional check to ensure that what is most significant to participants is what is being analyzed (Charmaz, 2006). Unfortunately, this method of First Cycle coding can limit the researcher's perspective of the data which could limit the identification of more conceptual or theoretical views of the phenomenon being studied (Saldana, 2009), Therefore, the use of a Second Cycle coding method is necessary. 
In Vivo coding was first used to pull out a complete list of the individual questions that each peer tutor asked throughout the online peer tutoring sessions that were reviewed. To organize and gather this information, a three-column table was created on a Microsoft Word document. Table 3.3 provides an example of the table that was used for In Vivo coding. Items listed on this table were pulled directly from the observation transcripts. No data was added to the third column during the first cycle of coding. Data was added to the third column of Table 3.3 during the second cycle coding process.

Table 3.3 Sample of In Vivo Coding Table Used to Organize Observation Data

\begin{tabular}{|c|c|}
\hline Original Text from Transcript & In Vivo Code \\
\hline $\begin{array}{l}\text { “And it looks like you're just...it's a } \\
\text { directory, so that's what he is saying. You }\end{array}$ & $\begin{array}{l}\text { "So, do you know how to use a wild } \\
\text { card?" }\end{array}$ \\
\hline just can't do it. Cause you gave it like this & \\
\hline project folder, and you can't directly search a & \\
\hline project folder like that $(2: 07)$ and you need to & \\
\hline use a wildcard. So, do you know how to use & \\
\hline a wildcard? (2:11) & \\
\hline $\begin{array}{l}\text { "Ok, let me see if I can find something in } \\
\text { these notes with wildcards. (Jessica shares } \\
\text { her screen with her tutee. She has a website } \\
\text { loaded that shows how to use a wildcard in } \\
\text { common commands from the ODU computer } \\
\text { science website) Can you see my screen?" } \\
(2: 51)\end{array}$ & "Can you see my screen?" \\
\hline
\end{tabular}

While using the In Vivo method for the first cycle of coding, the researcher chose to include some additional conversations and notations of actions observed by each peer tutor to add additional context as seen in Table 3.3 and Picture 4. The additional context 
was then used to assist with the second cycle of coding. Picture 4 provides an example of quotes that were pulled from the transcripts and the tutee responses to those questions and comments. Table 3.3 shows how the passages were transformed into In Vivo codes during the first cycle of coding. The white space under the word Theme on the right side of the document was later used by the researcher to write additional notes and to start creating categories from the In Vivo codes during the second cycle of the coding process.

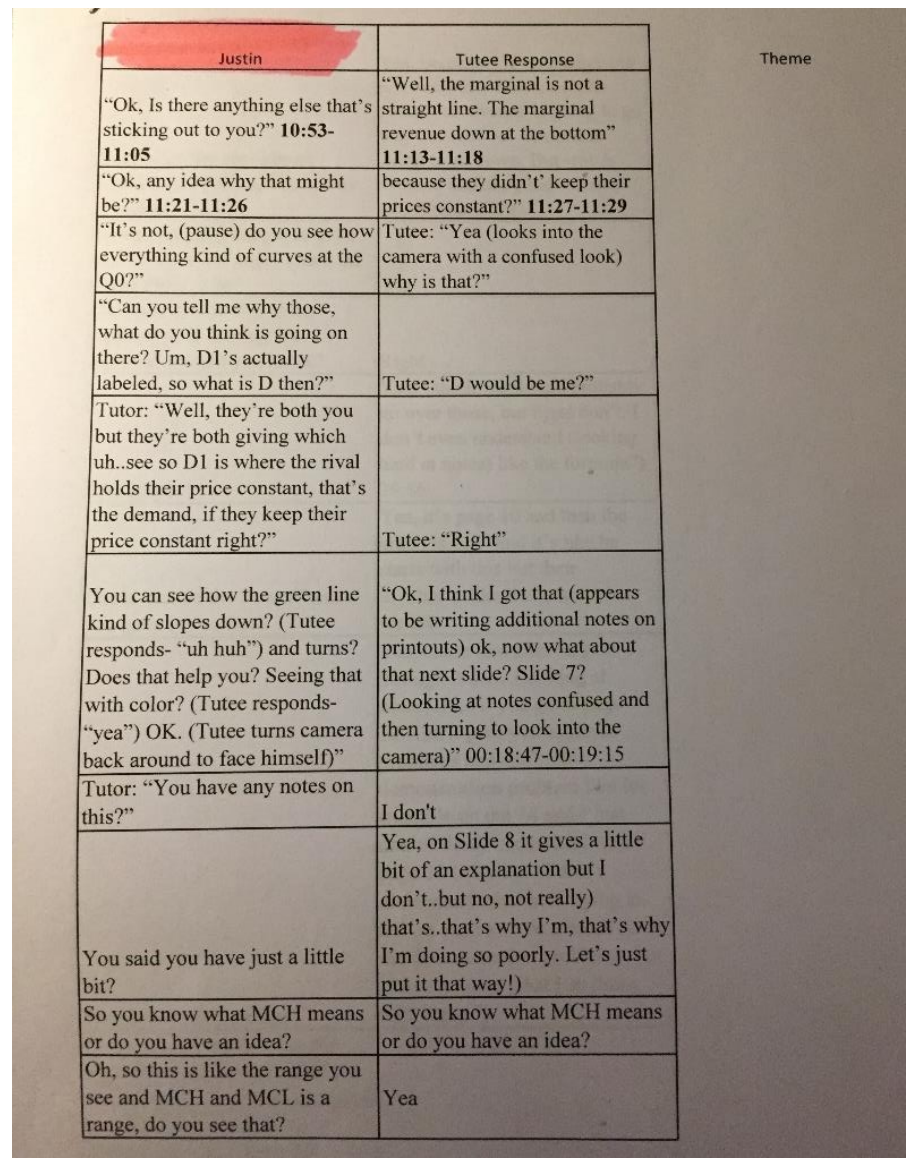

\section{Picture 4. Images of First Cycle In-Vivo Coding for Observation Transcript}

\section{$\underline{\text { Second Cycle Coding Methods }}$}

Second Cycle coding methods involve more advanced strategies for re-organizing and re-analyzing the data codes created through First Cycle methods (Saldana, 2009). This process involves analyzing codes created during First Cycle coding to group codes 
that are similar in concept and re-evaluate or eliminate codes that may appear to be marginal or redundant (Lewins \& Silver, 2007). Second Cycle coding is essentially used to develop "categorical, thematic, conceptual, and/or theoretical organization from the array of First Cycle codes" (Saldana, 2009, p. 149). The Second Cycle coding method used to code data was Focused Coding. Focused Coding involves identifying "the most frequent or significant codes" (Saldana, 2015, p. 264) to recognize code frequencies and relationships to build categories around them. Through Focused Coding, the researcher regroups previously created codes and their original words or phrases into a new categorically or thematically organized document. Glaser (1978) emphasized that codes should not be forced into pre-conceived categories during the reorganization and categorization of codes that occurs during the Focused Coding process. One strategy recommended by Rubin and Rubin (1995) to address this is to create an organizational outline of the categories and subcategories to organize the different clusters of codes. In this study, the researcher used the strategy recommended by Rubin and Rubin to organize and restructure all codes identified during the first cycle and second cycles processes.

Once the first cycle of coding had been completed, the researcher when went back through the In Vivo codes to categorize the codes by themes using the Focused Coding method. Table 3.4 provides an example of the progression that occurred between the first and second cycle of coding and the theme that emerged. Table 3.4 also provides an explanation for each grouping specifically related to the groups that were created during the Focused Coding process. The Focused Coding code groups are displayed in the center column of Table 3.4 . 


\section{Table 3.4 Sample of Focused Coding Table Used to Complete Second Cycle Coding}
In Vivo Codes
Focused Coding
Explanation of Grouping
(Groups)

\section{Table 3.4 (con't.)}

\begin{tabular}{|c|c|c|}
\hline In Vivo Codes & $\begin{array}{l}\text { Focused Coding } \\
\quad \text { (Groups) }\end{array}$ & Explanation of Grouping \\
\hline $\begin{array}{l}\text { Does it make a little } \\
\text { more sense? Binomial } \\
\text { and why? }\end{array}$ & \multirow[t]{5}{*}{ Checking for clarity } & $\begin{array}{l}\text { In the first example, the peer tutor } \\
\text { had already confirmed the tutee } \\
\text { had the correct answer but wanted }\end{array}$ \\
\hline $\begin{array}{l}\text { Ok, so what does the } \\
\text { formula look like }\end{array}$ & & $\begin{array}{l}\text { to ensure the tutee knew how why } \\
\text { it was the correct answer. }\end{array}$ \\
\hline $\begin{array}{l}\text { once you put in all the } \\
\text { numbers? }\end{array}$ & & \multirow{2}{*}{$\begin{array}{l}\text { In the second example, the peer } \\
\text { tutor was having the tutee read the } \\
\text { problem formula back after } \\
\text { inserting all the numbers to ensure } \\
\text { all numbers had been inserted into } \\
\text { the proper locations. }\end{array}$} \\
\hline $\begin{array}{l}\text { So here is something } \\
\text { really important } \\
\text { because you said you } \\
\text { were confused about }\end{array}$ & & \\
\hline $\begin{array}{l}\text { character arrays, } \\
\text { right? }\end{array}$ & & $\begin{array}{l}\text { In the third example, the peer } \\
\text { tutor was confirming the correct } \\
\text { topic of confusion before moving } \\
\text { forward. }\end{array}$ \\
\hline $\begin{array}{l}\text { So, what is a } \\
\text { directory? }\end{array}$ & \multirow[t]{3}{*}{ Defining a term } & \multirow{2}{*}{$\begin{array}{l}\text { In the first two examples, the peer } \\
\text { tutor was essentially asking their } \\
\text { respective tutees to define } \\
\text { directories and files. }\end{array}$} \\
\hline $\begin{array}{l}\text { What makes a file a } \\
\text { file? }\end{array}$ & & \\
\hline $\begin{array}{l}\text { Ok, so what are the } \\
\text { rules to a binomial? } \\
\text { As far as you } \\
\text { understand? }\end{array}$ & & $\begin{array}{l}\text { The third example was a little } \\
\text { tricky. At first, the word "rules" } \\
\text { almost insinuates the question is } \\
\text { more about a process. However, } \\
\text { the peer tutor was asking what } \\
\text { makes a binomial a binomial like } \\
\text { the question in the second } \\
\text { example. Therefore, the In Vivo } \\
\text { code was categorized as defining } \\
\text { a term. }\end{array}$ \\
\hline
\end{tabular}


Table 3.4 (con't.)

\begin{tabular}{|c|c|c|}
\hline In Vivo Codes & $\begin{array}{l}\text { Focused Coding } \\
\text { (Groups) }\end{array}$ & Explanation of Grouping \\
\hline $\begin{array}{l}\text { Ok, first of all, do you } \\
\text { understand how the } \\
\text { process works? } \\
\text { How many } \\
\text { assignments have you } \\
\text { done for this class? }\end{array}$ & Establishing a baseline & $\begin{array}{l}\text { In the first example, rather than } \\
\text { having the tutee describe the } \\
\text { process the peer tutor was asking } \\
\text { the tutee if how the process works } \\
\text { was understood to determine if a } \\
\text { review was necessary. } \\
\text { In the second question, the peer } \\
\text { tutor was very familiar with the } \\
\text { course and knowing how many } \\
\text { projects had been submitted how } \\
\text { far into the course the student was } \\
\text { and how much he should have } \\
\text { known at that specific point. The } \\
\text { tutee response was used to } \\
\text { determine if a review was needed. }\end{array}$ \\
\hline $\begin{array}{l}\text { Is it in a book? A } \\
\text { textbook or } \\
\text { something? } \\
\text { The question is, what } \\
\text { is the probability the } \\
\text { whole batch will be } \\
\text { accepted? } \\
\text { Extra step taken by } \\
\text { peer tutors to double- } \\
\text { check to ensure the } \\
\text { tutees were } \\
\text { understanding the } \\
\text { content that was } \\
\text { presented }\end{array}$ & General & $\begin{array}{l}\text { In the first example, the peer tutor } \\
\text { was just trying to determine where } \\
\text { the problem in question could be } \\
\text { found to see if he had access to } \\
\text { that specific problem. } \\
\text { In the second example, the peer } \\
\text { tutor was essentially asking the } \\
\text { tutee to repeat part of the problem. } \\
\text { Both questions were clerical in } \\
\text { nature, therefore, they were } \\
\text { categorized as general. }\end{array}$ \\
\hline
\end{tabular}


Table 3.4 (con't.)

\begin{tabular}{|c|c|c|}
\hline In Vivo Codes & $\begin{array}{l}\text { Focused Coding } \\
\text { (Groups) }\end{array}$ & Explanation of Grouping \\
\hline $\begin{array}{l}\text { So, do you know how } \\
\text { to use a wildcard? } \\
\text { Ok, so how would } \\
\text { you put it into a } \\
\text { formula? }\end{array}$ & Understanding a Process & $\begin{array}{l}\text { While the first example could } \\
\text { have been answered with a yes or } \\
\text { no response, the peer tutor was } \\
\text { really asking her tutee to explain } \\
\text { how wildcards work. This was } \\
\text { done through a series of questions, } \\
\text { but the example provided here } \\
\text { started that chain of questions. } \\
\text { In the second example, the peer } \\
\text { tutor was basically saying, you } \\
\text { have all the numbers you need and } \\
\text { the formula you need to put them } \\
\text { into, so how do you set that up. } \\
\text { To set the formula up correctly, } \\
\text { the tutee had to understand a } \\
\text { process. }\end{array}$ \\
\hline
\end{tabular}

During the second cycle of coding, words, phrases, and questions that were identified during the first cycle of coding were grouped together in larger overarching themes.

\section{Constant Comparison Analysis}

Along with the first and second cycle coding process that was used for the data analysis phase of this study, constant comparison analysis took place from the very beginning of the data collection process. When using constant comparison analysis as a coding strategy, codes can emerge deductively, inductively, or abductively. (Leech \& Onwuegbuzie, 2007). In the case of this study, codes emerged inductively meaning they came out of the data as it was collected and analyzed. Constant comparison analysis was used to bring the data gathered through the semi-structured interviews, observations, and journaling together into one main data set for analysis and synthesis. 
Constant comparison analysis involves the researcher initialing reading through the data and then later going back to underline important phrases in the data (important phrases have been underlined in the excerpt below) (Leech \& Onwuegbuzie, 2007).

That depends too. If they are looking at it and they just look confused on the assumption their video is working. Then that might be like a cue to maybe go back and see what they need help with. Then their voice too. Like if they said if they get it but they sound like they don't, that might be another indicator.

Table 3.5 provides a list of codes that were generated for each underlined phrase. During that process, earlier codes that were created were checked to determine if there was already an existing code.

\section{Table 3.5 Codes That Emerged During Constant Comparison Analysis}

\begin{tabular}{ll}
\hline \multicolumn{1}{c}{ Phrases } & \multicolumn{1}{c}{ Code for Each Phrase } \\
\hline Looking at it and they just looked confused & Visual cues \\
Assumption their video was working & Technology issues \\
Might be a cue & Visual cues \\
Go back and see what they need help with & Checking for prior knowledge \\
& Scaffolding \\
Their voice too & Audio cues \\
$\begin{array}{l}\text { If they said they get it but they sound like they } \\
\text { don't, that might be another indicator }\end{array}$ & Audio cues \\
\hline
\end{tabular}

The codes identified through constant comparison analysis of the interview notes, journal entries, and interview transcripts were then combined with the second cycle codes that were generated from the observation data to identify the major findings for each research question. 


\section{Credibility, Trustworthiness, Consistency, and Rigor}

One of the main concerns associated with the reliability and validity of reporting qualitative research findings is that most qualitative researchers work alone in the field, they focus more on the findings rather than how they were achieved, and are limited in terms of processing information (Miles \& Huberman, 1994). This qualitative case study relied on a single researcher to collect, transcribe, code, and analyze the data in a similar setting to the described by Miles and Huberman (1994). Therefore, extra precautions were taken by the researcher to address the issues described.

The term rigor, in qualitative research, is used for "establishing consistency of the study methods over time and provides an accurate representation of the population studied" (Thomas \& Magilvy, 2011, p. 151) which provides a means for conducting similar studies with different research samples. Lincoln and Guba (1985) first addressed the rigor as a method of establishing trustworthiness in qualitative research studies by addressing the question, "How can an inquirer persuade his or her audiences (including self) that the findings of an inquiry are worth paying attention to, worth considering of?" (p. 290). As a result, Lincoln and Guba (1985) developed a four-component model of trustworthiness in qualitative research that consists of (a) credibility, (b) transferability, (c) consistency or dependability, and (d) confirmability.

\section{Credibility}

In qualitative research studies, credibility refers to the ability of outside individuals, who have had similar experiences to the phenomenon that was studied, to relate to the interpretations of participants' experiences as presented in the study findings (Thomas \& Magilvy, 2011). Krefting (1991) described the concept of credibility by 
stating that "a qualitative study is considered credible when it presents an accurate description or interpretation of human experience that people who also share the same experience would immediately recognize" (p. 218).

The main strategy used by the researcher to establish credibility in this study was member checking. Member checking describes a process in which the researcher provides participants with various findings and interpretations developed throughout the course of the study to check for credibility and validity (Miles \& Huberman, 1994). Lincoln and Guba (1985) considered member checking to be "the most critical technique for establishing credibility" (p. 314). Stake (1995) suggested that study participants should be actively engaged in the study as directors and participants who analyze rough drafts of the researchers work to provide additional credibility and share "critical observations or interpretations" (p. 115).

\section{$\underline{\text { Transferability }}$}

One of the main objectives of this study was to provide other colleges and universities with suggestions for building synchronous online peer tutoring programs. To accomplish this objective, the researcher was interested in the concept of transferability. In qualitative research, transferability is defined as "how one determines the extent to which the findings of an inquiry have applicability in other contexts or with other subjects/participants" (Lincoln \& Guba, 1985, p. 290). Thomas and Magilvy (2011) suggested one strategy for addressing transferability in qualitative studies is for the researcher to provide extremely detailed descriptions of the population studied by providing rich descriptions of the demographics and geographic boundaries of the study. To address transferability, the researcher provided thorough descriptions of all the 
operational policies and procedures that have been put in place for the synchronous online peer tutoring by Old Dominion University including how tutees sign up for tutoring services, what is involved in scheduling the tutoring sessions, how are peer tutors selected, trained, and evaluated, and any other key factors that might add to the transferability of the study.

\section{Dependability}

Dependability, in qualitative studies, essentially refers to the ability of an outside researcher, who was not involved in the original study, to retrace and comprehend the path of decisions that were made by the researcher. Thomas and Magilvy (2011) described the process of creating an audit trail for establishing dependability of a study which includes providing a detailed description of (a) the purpose of the study, (b) how study participants were selected, (c) the data collection process and timeline, (d) the data coding process, (e) final interpretations and research findings; and (f) how credibility for the study was established. The researcher in this study used written analytic memos to assist with establishing dependability for this study. According to Saldana (2009), the purpose of writing analytic memos is to "document and reflect on: your coding process and code choices, how the process of inquiry is taking shape; and the emergent patterns, categories and subcategories, themes, and concepts in your data - all possibly leading toward theory" (p. 32). Information written in the analytic memos are discussed in Chapter 4.

\section{Confirmability}

Confirmability is the result of the researcher being open and reflective as interviews are conducted and the study unfolds. One strategy recommended by Thomas 
and Magilvy (2011) for adding confirmability to a qualitative study involves the researcher writing or audio recording field notes immediately after conducting each individual interview or observation to address personal feelings, insights, and biases. The researcher scheduled an additional 10 to 15 minutes after each of the semi-structured interviews to record these field notes in a digital journal. This type of reflective practice allows researchers to gain a more holistic process of the entire study to develop new insights, establish confirmability of the research, and provide outside researchers with a sense of trust in the credibility and applicability of the study findings (Johns, 2009). 


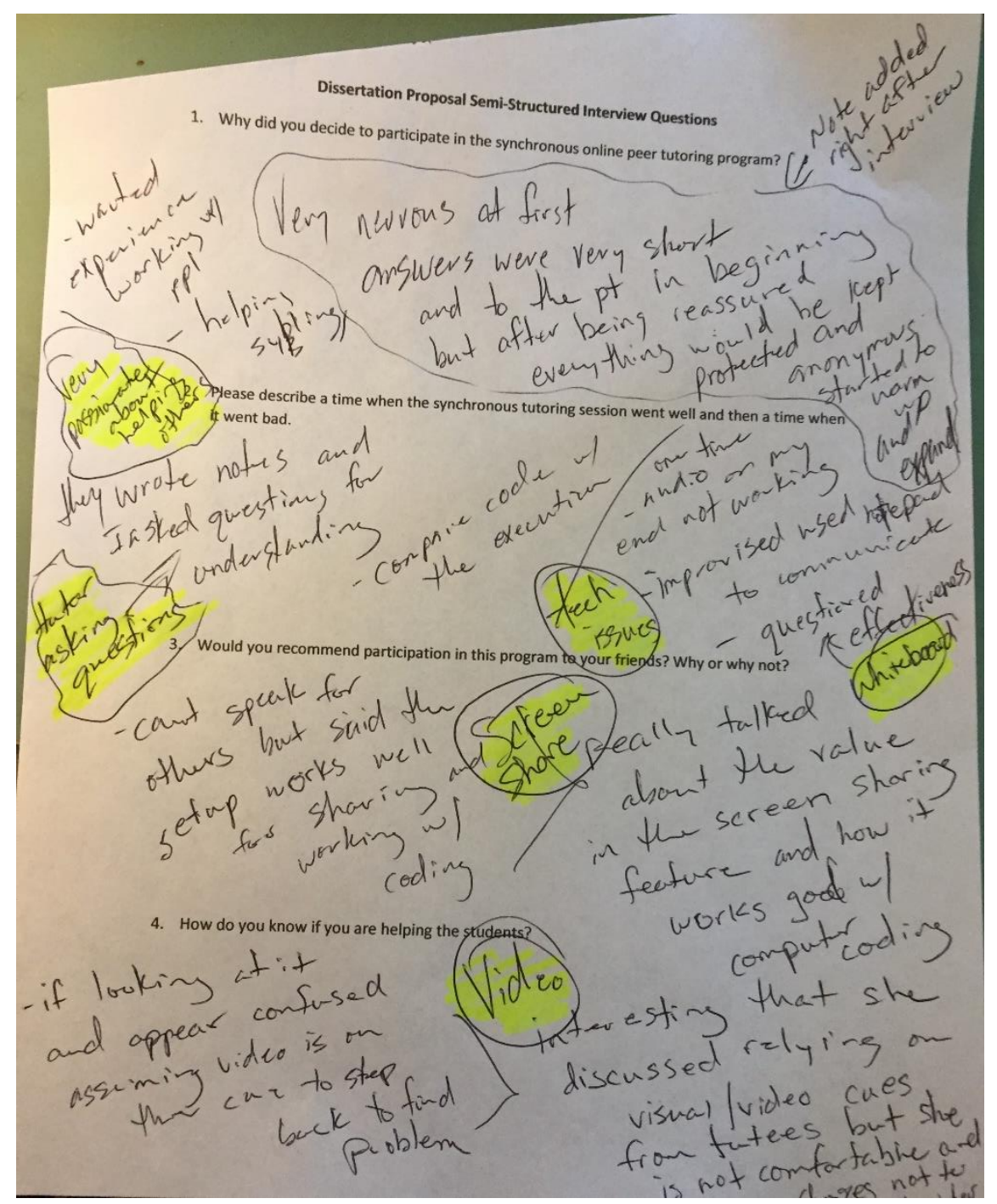

\section{Picture 5. Example Journaling and Field Notes from Semi-Structured Interview}

A question guide like the one shown in Picture 5 was used throughout the course of each semi-structured interview to record the journaling experience. I recorded the notes on the left side of the page using a similar strategy that person on an interview committee might do during a job interview. Once each interview concluded, I read through the notes I had taken with each study participant to check for accuracy. When they had agreed with the information I shared, the interview was officially over. I then spent approximately 10 minutes going back through the notes and reflecting on the items that I found interesting 
related to each question that was asked. Notes taken during the post-interview journaling process can be seen on the right side of Picture 5. Finally, I quickly summarized each item noted by creating some very generic initial codes which, in the example in Picture 5, included helping others, asking questions, tech issues, screen sharing, whiteboards, and video usage.

\section{Chapter Three Summary}

This exploratory case study employed multiple qualitative data collection and analysis strategies to gain insight into the lived-experiences of peer tutors providing synchronous online peer tutoring services via video conferencing technology. Data was collected through face-to-face semi-structured interviews, observations of recorded synchronous online peer tutoring sessions, and field notes. The data was then analyzed and thematically coded by the researcher. Once the initial analysis and coding process was completed, the researcher shared the written transcripts with each peer tutor through a process known as member checking which further assisted with validating the data. Once provided with the transcripts, peer tutors were asked to check the documents for accuracy before providing any additional comments that might not have been captured through the transcribed interviews. Finally, the field note data recorded by the researcher during the interviews and observations were added into the thematic analysis. The results of this study are reported in Chapter 4. 


\section{CHAPTER FOUR: RESULTS}

This exploratory case study explored the lived experiences of peer tutors who use video conferencing technology to provide synchronous online tutoring services for students enrolled in a four-year university. The following research questions guided this study.

\section{Central Questions:}

How do peer tutors experience video-based synchronous online tutoring services?

\section{$\underline{\text { Sub Questions: }}$}

a) How do peer tutors interact with their tutees in the synchronous online tutoring environment?

b) How do peer tutors determine if the tutee comprehends the content being discussed?

c) How do peer tutors change their instructional practices when it is perceived that the tutee does not comprehend the content being discussed?

The results from semi-structured interviews and observations of peer tutors who provide synchronous online tutoring services at Old Dominion University are presented in this chapter. Participants described specific instances in which the online peer tutoring sessions did and did not go well, identified instructional strategies that are used to determine if the tutees comprehend the material being presented, explained the steps they took to address any misconceptions or confusion, and provided suggestions for improving 
the synchronous online peer tutoring program. Pseudonyms were assigned to each tutor by the researcher to maintain confidentiality and anonymity. Prior to describing the themes that emerged during the data analysis phase of the study, detailed descriptions of the online peer tutoring program at Old Dominion University will be described. Descriptions of the physical and virtual spaces in which each of the tutoring sessions occur will also be explained.

\section{The Synchronous Online Peer Tutoring Program at Old Dominion University}

As discussed in Chapter 3, Old Dominion University (ODU) has been utilizing their own peer tutors to provide synchronous online peer tutoring services to undergraduate students since the fall of 2015. Each semester since the initial pilot study in 2015, the synchronous online peer tutoring program at ODU has continued to show increased usage. Table 4.1 shows the final statistical usage data for the Spring 2017 and Fall 2017 academic semesters.

The number of scheduled synchronous online peer tutoring sessions increased from 62 in the Spring 2017 semester to 197 scheduled online peer tutoring session in the Fall 2017 semester. Despite an increase in the number of online tutoring session noshows from 16 in Spring 2017 to 70 in Fall 2017 and an increase in the number of online appointments cancelled by the student from 18 in Spring 2017 to 95 in Fall 2017, the number of online tutoring visits that occurred increased from 28 in Spring 2017 to 32 in Fall 2017. Along with an increase in the number of synchronous online peer tutoring sessions that occurred, the number of courses supported increased from 12 to 21 , the number of tutors with online sessions increased from 9 to 13 , and the number of students 
who received online peer tutoring increased from 16 to 26 between the Spring 2017 and Fall 2017 semesters.

Table 4.1 Statistical Data for ODU Online Peer Tutoring Program

\begin{tabular}{llc}
\hline Data point & Fall 2017 & Spring \\
& & 2017 \\
\hline Scheduled Online Tutoring Visits & 197 & 62 \\
Online Tutoring Visits that Occurred & $32(16 \%)$ & $16(26 \%)$ \\
Online No-Shows & $70(35 \%)$ & $18(29 \%)$ \\
Online Appointments Cancelled by the & $95(48 \%)$ & 12 \\
Student & & 9 \\
Courses Supported & 21 & 16 \\
Tutors with Online Sessions & 13 & \\
Students who Received Online & 26 & \\
\hline
\end{tabular}

Overall, the peer tutoring program which includes both online and in-person sessions experienced the same positive trend from the Spring 2017 semester to the Fall 2017 semester. Table 4.2 shows the statistical usage data for both the in-person and online tutoring programs at ODU. 
Table 4.2 Statistical Data for Peer Education Peer Tutoring Program

\begin{tabular}{|c|c|c|}
\hline \multirow[t]{2}{*}{ Data point } & Fall 2017 & Spring \\
\hline & \multicolumn{2}{|c|}{2017} \\
\hline Scheduled Tutoring Visits & 1378 & 805 \\
\hline \multirow[t]{2}{*}{ Tutoring Visits that Occurred } & $735(55 \%)$ & 526 \\
\hline & \multicolumn{2}{|c|}{$(45 \%)$} \\
\hline \multirow[t]{2}{*}{ No-Shows } & $257(19 \%)$ & 104 \\
\hline & \multicolumn{2}{|c|}{$(13 \%)$} \\
\hline \multirow[t]{2}{*}{ Appointments Cancelled by the Student } & $386(28 \%)$ & 175 \\
\hline & \multicolumn{2}{|c|}{$(22 \%)$} \\
\hline Unique Courses Supported & 60 & 50 \\
\hline Tutors with Sessions & 21 & 20 \\
\hline Students who Received Tutoring & 344 & 242 \\
\hline
\end{tabular}

From Spring 2017 to Fall 2017, the number of tutoring visits that occurred increased from 526 to 735 , the number of unique courses supported increased from 50 to 60 , the number of tutors with sessions increased from 20 to 21 , and the number of students who received tutoring services increased from 242 to 344 .

According to the ODU Peer Educator Program website, a total of 70 unique academic courses were available for both in-person and online peer tutoring sessions in the Fall 2017 semester. Based on the statistical data reported by ODU which is presented in Table 5, peer tutoring sessions occurred for 60 of the possible 70 courses for which it was offered. An exact list of the 60 academic courses was not available at the time of writing of this dissertation, however, the ODU Peer Educator Program website indicated 
that the supported courses included multiple levels of: Accounting, Biology, Anatomy and Physiology, Ecology, Evolution, Genetics, Business Analytics, Statistics, Criminology, Computer Programming, Economics, Electrical Technology, French, Geography, Mechanical and Aerospace Engineering, Calculus, Organizational Management, Oceanography, Earth Science, Philosophy, Ethics, Physics, Psychology, and Spanish. Each of the courses listed were supported through both in-person and online tutoring sessions.

Located on the first floor of the Perry Library, which is referred to as the Learning Commons, the Peer Educator Program Tutoring room is part of the Student Success Center. A separate room within the Peer Educator Program Tutoring room called the Distance Tutoring Room that has specifically been set up for the peer tutors to use when conducting the synchronous online peer tutoring sessions. Since the online tutoring sessions rely on synchronous video conferencing technology, the setting for this study also includes a virtual space which utilizes WebEx video conferencing software. The next two sub-sections will provide additional descriptive information about both the physical and virtual space in which the synchronous online peer tutoring services are provided. The Physical Tutoring Space

The Peer Tutoring Center is in the Learning Commons area of the Perry Library. Formally referred to as the Peer Educator Program Tutoring Room, the physical tutoring space consists of a single open-concept room that is sectioned off in the back-left corner of the Learning Commons in the Perry Library (see Picture 6). There are approximately eight group tables located in the center of the room that hold four students each and cubical spaces with computers along two of the four walls (see Picture 6). The back wall 
has several roll-away whiteboards. A receptionist, who is responsible for signing inperson tutees in and out of the tutoring center, is located beside the entrance to the Peer Educator Program Tutoring Room. Online peer tutoring sessions are scheduled through a third-party software tool that will be described later in this chapter. That scheduling software is used to track the attendance of the online tutee.

Depending on individual availability of the peer tutors, multiple in-person tutoring sessions might be going on at the same time in the open tutoring space. While the open concept of the physical space allows peer tutors and tutees to move around freely as they interact, it does cause additional noise disruptions when more than one tutoring session is occurring at the same time. The in-person interviews that were conducted for this study occurred in the open tutoring space while other in-person tutoring sessions were taking place. Although the live in-person tutoring sessions did add some additional noise, they did not appear to distract the peer tutors as they participated in the semi-structured interviews for this study.

The Distance Tutoring Room, approximately the size of a medium-sized closet, is in the corner of the Peer Educator Program Tutoring room (see Picture 6). The Distance Tutoring Room contains a single long table with a desktop computer, document camera, and Wacom tablet (Picture 6). Wacom tablets are hardware input devices that have a hard plastic, touch-sensitive drawing surface that transfers movements from a pen or stylus to a computer monitor. The hard-plastic surface is generally blank and does not include a display that shows what the user writes or draws. Instead of displaying on the tablet, anything written on the Wacom tablet is displayed directly on the computer screen. It generally takes some time to get used to being able to coordinate writing on the device 
and to understand where the contents will be displayed on the monitor. Once users get comfortable with how the content is displayed, using the Wacom tablet can become as natural as using a pen or pencil on paper. The Distance Tutoring Room also contains two rolling chairs, an Emergency Response Kit, and two fans (Picture 6). The fans have been added to the Distance Tutoring Room because the tutees found that the room gets very hot in the summer time since it is closed off from the air conditioning system. There is a small whiteboard that is mounted on the wall directly behind the chair that sits in front of the desktop computer. The size of the whiteboard is slightly larger than the monitor to the desktop computer which is approximately 19 to 22 inches wide and slightly shorter than those dimensions.

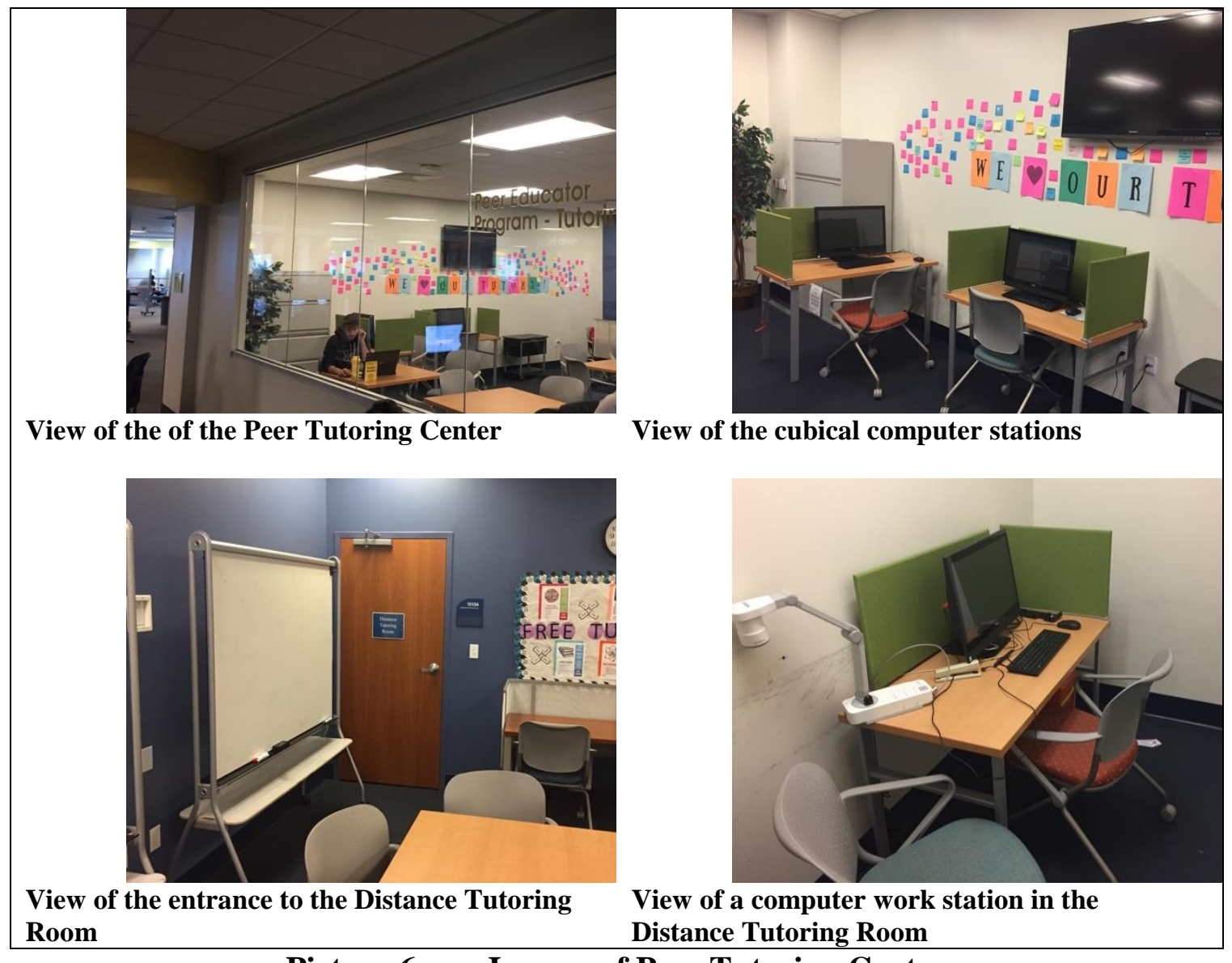

Picture 6. Images of Peer Tutoring Center 
Due to the small size of the Distance Tutoring Room and the availability of only a single computer work station, only one peer tutor can conduct a synchronous online peer tutoring session from that room at a time. If more than one online peer tutoring session is scheduled at a specific time, the other peer tutors must conduct his or her session from inside the larger, open Peer Educator Program Tutoring room. Some of the peer tutors that were interviewed for this study suggested that they preferred to work in the Peer Educator Tutoring room versus the Distance Tutoring Room when conducting online tutoring sessions, because they liked having access to the larger rolling whiteboards. Unfortunately, by doing so, the peer tutors lose access to the document camera and the Wacom tablet that are available in the online tutoring room. Several of the peer tutors that were interviewed for this study mentioned that they do not use any of the extra tools. Other peer tutors reported that they tried to use the additional technology tools before, but they could not get the tools to work.

\section{The Virtual Tutoring Space}

ODU uses Cisco’s WebEx video conferencing software for online peer tutoring sessions. There are four different applications within the WebEx suite which include the Meeting Center, Training Center, Event Center, and the Support Center. ODU uses the Meeting Center application for the synchronous online peer tutoring program. WebEx Meeting Center provides peer tutors access to five unique features that can be used to share content with tutees (see Table 4.3). Those features include application, file, screen, and web browser sharing along with a whiteboard tool. Table 4.3 provides some specific details on what tutees see when each sharing feature is used and includes some possible uses for each feature. 
Table 4.3 Sharing Features Available Through Cisco's WebEx Meeting Center Application

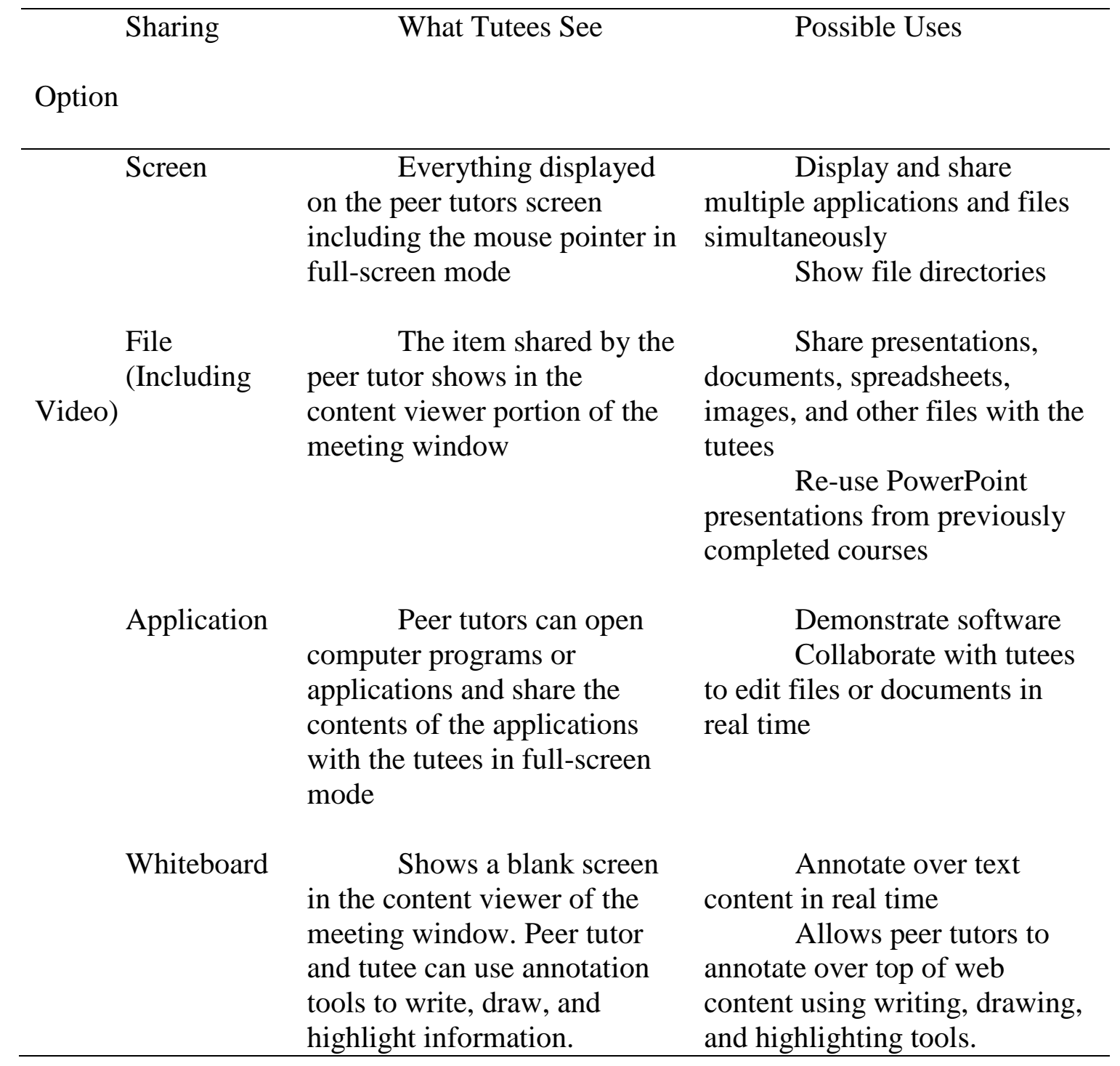

It is important to note that only the screen sharing and the whiteboard tool-thus, only two of the five features of WebEx's Meeting Center application (see Table 4.3) -were observed in this study. Some peer tutors were observed sharing files such as additional PowerPoint presentations from previously completed courses and additional content such as coding from computer programming projects, websites, and even software applications. However, each of those additional items were shared through the 
screen share feature and not through the file, application, or web browser sharing features. By sharing content through the screen share feature instead of the file, application, or web browser sharing features provided by WebEx, only the peer tutors could interact with the content being displayed on the screen. Tutees could see what was being shared, but could not actively take control of the mouse or annotate content. Picture 7 shows an example of an application — in this case, PuTTy which is a SSH and Telnet client—being used to share files outside of WebEx. In this example, the peer tutor was assisting her tutee with writing, testing, and debugging computer programming code using the Microsoft Windows Command Prompt window. Only one of the six peer tutors who were observed had their tutee share his screen.

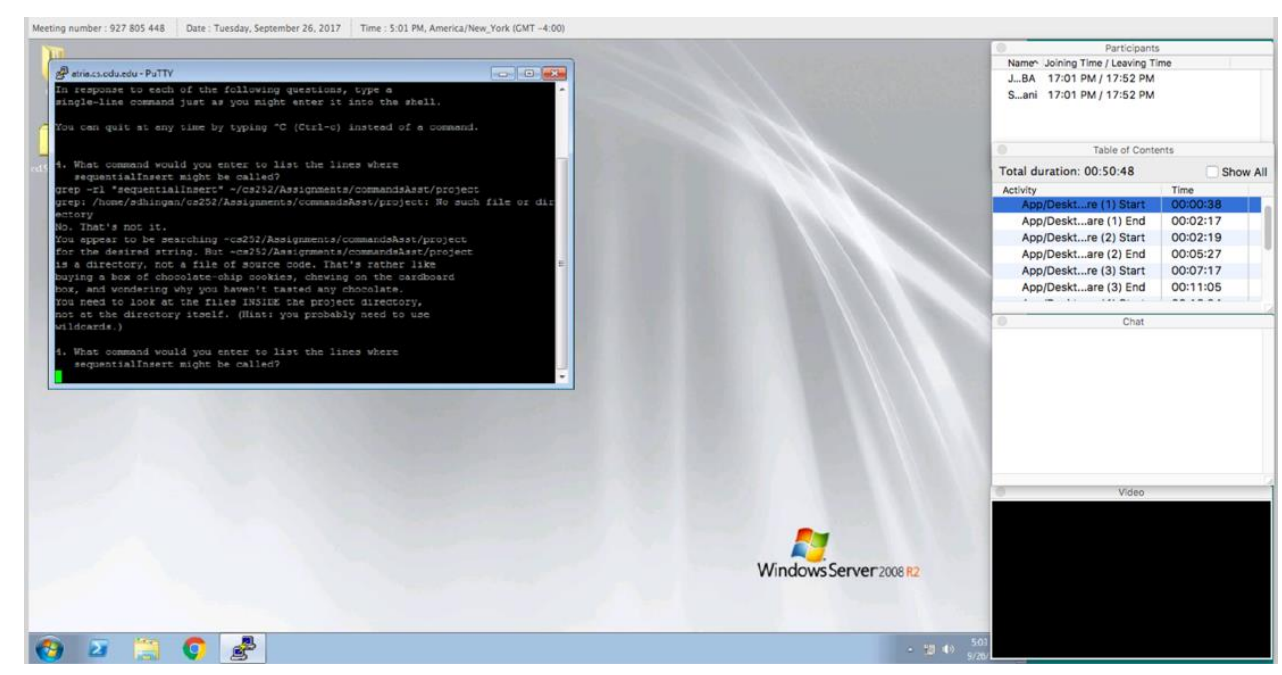

Picture 7. Screenshot of Tutee Using the WebEx Screen Share Feature to Share a Computer Science Program from the PuTTy software with his tutee

Along with sharing features, the WebEx Meeting Center application also has four communication tools. Thus, peer tutors using WebEx can communicate with their tutees through audio, video, text chat, and/or polls. Table 4.4 briefly describes the four communication tools. 
Table 4.4 WebEx's Communication Tools

\begin{tabular}{ll}
\hline \multicolumn{1}{c}{ Communication Tool } & \multicolumn{1}{c}{ How it Works } \\
\hline Audio & $\begin{array}{l}\text { The audio tool enables two or more users to talk to each } \\
\text { other as they might on a telephone. This requires the } \\
\text { users to have a microphone and speakers. }\end{array}$ \\
Video & $\begin{array}{l}\text { The video tool enables two or more users to talk and see } \\
\text { each other while they talk. This tool requires that users } \\
\text { This tool requires a web camera or an external video } \\
\text { camera. }\end{array}$ \\
Text chat & $\begin{array}{l}\text { The text tool enables users to communicate through } \\
\text { written text or what is sometimes called text-based } \\
\text { synchronous communication (i.e., chatting). }\end{array}$ \\
Polls & $\begin{array}{l}\text { The pool tool enables a host of a WebEx meeting (in this } \\
\text { case the peer tutor) to ask questions in a polling format. }\end{array}$ \\
\hline
\end{tabular}

As described in the Table 4.4, all synchronous online tutoring session participants (peer tutors and tutees) are required to have a microphone for audio communication during the peer tutoring sessions. In the interviews for this study, some of the peer tutors described situations where either the peer tutor or the tutee was not able to get his or her audio working for one reason or another. In those instances, most of peer tutors resorted to using some form of a virtual whiteboard tool for text-based communication, but stated that interacting through text only made it hard to understand whether the tutees were comprehending the material being discussed. However, one peer tutor described a situation in which he had spent so much time trying to get the audio connected that he and the tutee mutually decided to reschedule the session because of the amount of time that was lost. There was only one instance out of the six observations that text chat feature was observed being used. In that specific instance, the peer tutor used the chat window to type her username for accessing a specific computer programming software, so the tutee could see the username protocol needed to authenticate the software. There 
were only two peer tutors who chose to turn their video cameras on and in those two sessions, the tutees also chose to turn their video cameras on. None of the peer tutors were observed using the polling tool with their tutees.

\section{$\underline{\text { Scheduling Online Peer Tutoring Sessions }}$}

ODU uses a product called Student Success Collaborative-Campus (SSCCampus) to manage the online peer tutoring sessions. SSC-Campus is a multi-purpose web-based predictive analytics advising platform developed by the Educational Advisory Board. SSC-Campus is used by ODU to schedule and manage both advising and tutoring appointments. ODU named the tutoring scheduling and management feature of SSCCampus MyTutor and the advising scheduling and management feature as MyAdvisor.

All online tutoring sessions are scheduled ahead of time via the MyTutor application. ODU has integrated MyTutor into their single sign-on student portal. Once students sign in through the ODU student portal to schedule an online tutoring appointment they click the MyTutor link on the Applications Menu on the right side of the student portal homepage. Students then click the Schedule a Tutoring Services appointment button and are prompted to choose the specific course for which they are seeking help via a drop-down menu of course, choose a time for the session, and then whether they would like an in-person or online appointment. An additional advantage of the integration of the MyTutor application with the ODU student portal is that each individual student's courses schedule is built into the tutoring session scheduling tool. So, students registering for online tutoring appointments can easily locate and choose the specific course for which they are seeking assistance. The time slots that are available per academic course are pre-programmed based on each individual tutor's availability. Once 
a tutoring session has been scheduled, both the tutor and the tutee receive an automated confirmation email for the session. If the tutee chose an online session, additional information is included in the confirmation email with instructions on how to access the virtual tutoring session through the WebEx software.

ODU has rules on when and how students sign up for peer tutoring. For instance, students who register for a tutoring appointment are asked to contact the Peer Educator Program within two hours of a scheduled peer tutoring session. Cancellations made less than two hours before a scheduled appointment are considered "no-shows"; also, if a student is more than fifteen minutes late to a session, the student is considered a "noshow." "No-shows" are recorded and tracked by the MyTutor application. If a student misses two appointments in a 30-day time span, that student is barred from registering for future appointments until they set up a personal meeting with the Director or Assistant Director of the Peer Educator Program. Peer tutoring sessions are scheduled for 50 minutes and scheduling back-to-back sessions is not permitted. Each student is allotted two appointments per week per course.

\section{Peer tutor Demographic and Descriptive Data}

Nine undergraduate students who serve as online peer tutors for Old Dominion University agreed to participate in this study. All nine of those peer tutors participated in the interview portion of this study. However, online peer tutoring recordings were not able to be obtained for three of the nine peer tutors that were interviewed. As a result, only six of the nine peer tutors were observed. Table 4.5 provides a brief overview of the demographic data for each of the nine participants. Each participant will be described in 
more detail in the following section. To maintain confidentiality and anonymity, the researcher has assigned each peer tutor a pseudonym.

Table 4.5 Peer Tutor Demographic Data Based on the Spring 2017 Academic Semester Status

\begin{tabular}{|c|c|c|c|c|}
\hline Peer Tutor & Gender & Major & Subjects Tutored & $\begin{array}{c}\text { Semesters } \\
\text { Tutoring }\end{array}$ \\
\hline $\begin{array}{l}\text { Peer-tutor \#1: } \\
\text { Alice }\end{array}$ & Female & Business Analytics & $\begin{array}{l}\text { Information } \\
\text { Technology }\end{array}$ & 2 \\
\hline $\begin{array}{l}\text { Peer-tutor \#2: } \\
\text { Andrew }\end{array}$ & Male & $\begin{array}{l}\text { Mechanical } \\
\text { Engineering with } \\
\text { minor in Actuarial } \\
\text { Math }\end{array}$ & $\begin{array}{l}\text { Lower level Physics, } \\
\text { Calculus }\end{array}$ & 1 \\
\hline $\begin{array}{l}\text { Peer-tutor \#3: } \\
\text { Charley }\end{array}$ & Male & Accounting & $\begin{array}{l}\text { Accounting and } \\
\text { Business Calculus }\end{array}$ & 2 \\
\hline $\begin{array}{l}\text { Peer-tutor \#4: } \\
\text { Hannah }\end{array}$ & Female & $\begin{array}{l}\text { Business Analytics } \\
\text { and Management }\end{array}$ & $\begin{array}{l}\text { Introduction to } \\
\text { Statistics }\end{array}$ & 2 \\
\hline $\begin{array}{l}\text { Peer-tutor \#5: } \\
\text { Jessica }\end{array}$ & Female & Computer Science & Computer Science & 3 \\
\hline $\begin{array}{l}\text { Peer-tutor \#6: } \\
\text { Justin }\end{array}$ & Male & $\begin{array}{l}\text { Accounting and } \\
\text { Business Analytics }\end{array}$ & Accounting & 2 \\
\hline $\begin{array}{l}\text { Peer-tutor \#7: } \\
\text { Mark }\end{array}$ & Male & Accounting & $\begin{array}{l}\text { Accounting, } \\
\text { Business Statistics, } \\
\text { Introduction to } \\
\text { Statistics }\end{array}$ & 2 \\
\hline $\begin{array}{l}\text { Peer-tutor \#8: } \\
\text { Tonya }\end{array}$ & Female & $\begin{array}{l}\text { Biochemistry with a } \\
\text { minor in Spanish }\end{array}$ & $\begin{array}{l}\text { Biology, Chemistry, } \\
\text { and Spanish }\end{array}$ & 2 \\
\hline $\begin{array}{l}\text { Peer-tutor \#9: } \\
\text { Vince }\end{array}$ & Male & $\begin{array}{l}\text { Mechanical } \\
\text { Engineering }\end{array}$ & $\begin{array}{l}\text { Mechanical } \\
\text { Engineering }\end{array}$ & 2 \\
\hline
\end{tabular}

Peer-Tutor \#1: Alice

Alice was a Computer Information and Business Analytics major. At the time of the interview, Alice had been providing online peer tutoring services for two semesters. She had previous experience tutoring her siblings and enjoys helping others. Alice was 
observed providing computer programming tutoring services on the topic of classes, pointers, and link lists. Alice was apprehensive about the video communication tool; thus, she always chose not to turn on her video camera during the tutoring sessions.

\section{Peer-Tutor \#2: Andrew}

Andrew was a mechanical engineering major, minoring in Actuarial Mathematics. He had just started providing online tutoring services at the beginning of the Spring 2017 semester, so Andrew had less than a semester of experience at the time of the interview. Andrew stated that his love for playing and coaching lacrosse along with his passion for helping others were factors that influenced his decision to become a peer tutor. Although he did begin the Fall 2017 as an online peer tutor, he chose to leave the program shortly after the start of the semester after being hired for a professional job in his field of study. As a result, Andrew was interviewed but not observed.

\section{Peer-Tutor \#3: Charley}

Charley was an accounting major. He was just finishing his second semester of employment in the online peer tutoring program at the time of his interview. Charley's passion for the field of accounting and his desire to learn how to teach other people were the two main factors that influenced his decision to become a peer tutor the most. An online peer tutoring session recording could not be obtained for Charley. Charley was interviewed, however, an online peer tutoring session recording was not able to be obtained for him, so he was not observed.

\section{Peer-Tutor \#4: Hannah}

Hannah was a double Business Analytics and Business Management major. She was completing her third full semester of providing synchronous online peer tutoring at 
the time of her interview. Hannah's passion for teaching and helping others influenced her peer tutoring the most. She was observed providing statistics tutoring on the topics of binomial distributions to a female student. Like Alice, Hannah too was very apprehensive about turning on the video camera and having her online peer tutoring sessions recorded. She chooses not to use the video camera communication tool in WebEx when providing online tutoring services.

\section{Peer-Tutor \#5: Jessica}

Jessica was a computer science major. She was in the process of completing her third full academic semester of providing synchronous online peer tutoring when she was interviewed. Jessica's primary influences for peer tutoring came from her desire to help people and from excelling in the courses in her academic major. She was observed providing computer programming tutoring on the topic of wildcards to a male student. Jessica also decided not to have her video camera on during the observed tutoring session.

\section{Peer-Tutor \#6: Justin}

Justin was double majoring in Accounting and Business Analytics. He was completing his second full academic semester of providing online tutoring services when his interview occurred. Justin's desire to help others influenced his decision to become a peer tutor. He was observed providing economics tutoring on several topics such as competitive pricing and supply and demand to a female student. Justin was the first peer tutor observed who chose to turn is computer's video camera on during the observed synchronous online peer tutoring session. His tutee also had her computer's video camera 
turned on and connected to WebEx throughout the duration of the online peer tutoring session.

Peer-Tutor \#7: Mark

Mark was an Accounting major. Mark first enrolled at ODU as a Biology major and changed to a Criminal Justice major before eventually becoming an Accounting major. Because of the three different majors he has had during his tenure at ODU, he is certified and provides online training in business analytics, regular statistics, economics, and biology along with accounting. At the time of his interview, Mark was finishing his second full semester of providing online peer tutoring services. His main influence on providing peer tutoring services is the enjoyment he gets from helping others. Mark was observed providing mathematical tutoring on calculating sample proportion to a female student. He did not have his video camera feed active during the tutoring session and neither did his tutee.

Peer-Tutor \#8: Tonya

Tonya was a female Biochemistry major who was also minoring in Spanish. Tonya provides online tutoring in biology, chemistry, and Spanish. She was in the process of completing her second full semester in the online peer tutoring program at the time of her interview. Tonya's passion for the academic content in her major along with the joy she feels from helping others have been influential on her in-terms of the peer tutoring program. Tonya was interviewed, however, an online peer tutoring session recording was not able to be obtained for her, so she was not observed. 


\section{Peer-Tutor: \#9: Vince}

Vince was a male Mechanical Engineering major. He was just finishing up his second full semester of service in the online peer tutoring program at the time his interview occurred. Unlike the other eight study participants who shared similar influential factors such as the desire to help others and passion for subject-area content on their peer tutoring services, Vince stated that his motivation to become a peer tutor came from an email advertising for peer tutors at a time he did not currently have a job. Vince was observed providing mathematical tutoring to two different female tutees in the same synchronous online peer tutoring session.

\section{Results of Peer Tutor Interviews}

Nine peer tutors were asked six open-ended questions. The questions were designed to provide further insight into the lived experiences of each of the peer tutors. The results from each of these interview questions are reported in the following section. Interview question \#1. Why did you decided to become a peer tutor and did you know you were going to have to provide online peer tutoring services when you first accepted the position?

The two main reasons students decided to become peer tutors were because they enjoyed helping others and because they were passionate about the academic courses in their field of study. For instance, Peer tutor \#1 Alice stated that she "often helps her siblings answer tough questions without giving away the answers," and "when she took programming, she could see other people in the class were struggling," so she wanted to help them as well. Peer tutor \#2 Andrew shared the following:

"I am pretty good at lacrosse and I coach that for youth leagues and what not and the same goes for tutoring and I have practiced all this content and done 
well in school and helped myself and so if I can, I would like to help others with my skills that I have"

Alice and Andrew shared similar passions for helping others. Peer tutor \# 3 Vince had the most unique answer to the question about his decision to become a peer tutor. His response was, "Well, I saw an ad on my email and you know I thought why not! Pretty much I didn't have a job back then. I had just quit my job from fast food and found this opportunity."

In response to the second part of the question, Peer tutor \#4 Hannah helped to clarify that in fact the decision of whether a peer tutor wants to provide online tutoring services is no longer an option and is now part of the peer tutoring position. She said, "I knew about it and usually you had to sign up if you wanted to do it, but then basically anyone that is a peer tutor now has to do it." Jessica said, "pretty much we were told we do online and we do in-person" referring to the two types of tutoring services each of the peer tutors are expected to provide. Justin said he knew about the requirement for providing online peer tutoring services because he had used the service in one of his previous courses. He said, "I knew. I was comfortable with it because I used the program in one of my classes before." Andrew also knew about the requirement ahead of time and was comfortable like Justin, he said, “They mentioned that there was online, but it didn't seem that it was a very big factor and I didn't give it any special attention." Unlike Andrew and Justin, Mark said he did not know about the online service requirement until he was sitting in the peer tutoring training course over the summer. He said, "I did not! They were kind of like at the tutor training over the summer you guys are going to be doing online training too. I think it was like a one-hour training module on it." Tonya talked about how she was apprehensive about how the instruction would be received 
when she found out about the requirement. She said, "I was like ok, that's different. I was just like are they going to understand what I am trying to tell them? Just kind of like the communication barrier I guess." Vince said he was not aware of the requirement ahead of time, he said, "I just thought it was going to be in here (referring to in-person peer tutoring in the Peer Educator Program Tutoring room). So, I think it was kind of new back then."

$\underline{\text { Interview question \#2. Please describe a time when the synchronous tutoring session }}$ went well and then a time when it went bad.

All nine peer tutors who were interviewed indicated that most of their online peer tutoring sessions have seemed to have gone well. The main factor that each of the nine participants used to determine if a session went well was if the technology, hardware, software, and network, worked. Interestingly, one of the most common responses for when a session went well had to do with the peer tutors figuring out on their own how to use the WebEx screen sharing feature to interact with their tutees. Apparently, this was either not well covered or not understood by the peer tutors after having completed the online portion of the peer tutor training program. Another factor that the peer tutors used for determining the level of success for online tutoring sessions was preparedness. This included their own level of preparedness along with how well the tutees were prepared for each online tutoring session. The following section will provide specific examples of the five themes that emerged from interview question 2. Two of those themes, screen sharing success and peer tutor and tutee success were associated with online peer tutoring sessions that went well. The remaining three themes, technical issues, technology tools, and background interruptions were tied to sessions that did not go well. 


\section{Theme 2.1: Screen Sharing Success}

The first theme that emerged from interview question 2 was that peer tutors reflected on the first time the figured out how to share their computer screen in WebEx with their tutees. Three of the nine peer tutors who were interviewed shared similar responses about figuring out how to share their screen in response to the question about a time when an online tutoring session went well.

Peer tutor \#3 Charley provided details about a math tutoring session he had recently conducted in which he figured out how to share his screen and use Microsoft Excel to help students in Accounting. He said,

"Recently, I was helping a student with Accounting. You know you are always trying to solve some kind of math problems or stuff like that in Accounting. When I first started, it was actually kind of hard to figure out how I could show somebody over a screen how to solve different math problems. Then I figured out how to share my screen through the system (referring to WebEx) where I can show tutees how do certain problems in Excel like journal entries in Accounting of financial statements"

The example Charley shared did not start out as a session that went well.

However, through experimentation and trial and error, he figured out how to use the screen share feature in WebEx to share his screen. Once he knew how to share his screen, he was then able to use Microsoft Excel to provide more specific examples of calculations and journal entries for financial statements. Charley's measurement for success was being able to interact with his tutee through Excel to provide Accounting remediation. Like Charley, Peer tutor \# 7 Mark also described the moment when he first discovered the option to use the WebEx screen sharing feature to interact with his tutee through Microsoft Excel. He said, "That was really helpful too, because we didn't have a camera at the time, so I couldn't really show them anything on a piece of paper." Peer 
tutor \#9 Vince described the "ah ha" moment he had when he first discovered he could share is screen and use Microsoft Paint to draw and write freely on the screen. To describe that moment, he said, "I first used the tablet and the programs whiteboard to draw stuff but that didn't really work out. Then I discovered I could share my screen and just open up paint to draw freely." In a follow-up question about what tool he was using to draw in Paint, he said that he had been using the Wacom tablet that is available in the Distance Tutoring Room.

Charley, Mark, and Vince all three described the first time they learned how to share their screen and used that as examples to explain situations in with their online peer tutoring sessions had gone well. In all three examples, the peer tutors were referring to the sessions going well for themselves, they were not referring to sessions going well for their tutees. All three peer tutors felt they were better able to communicate and interact with their tutees after figuring out how to share their screens.

Theme 2.2: Peer Tutor and Tutee Preparedness

The level to which the peer tutors and their tutees were prepared for each online peer tutoring session emerged as the second theme for interview question 2 . Peer tutor \#4 Hannah specifically talked about tutee preparation when describing when peer tutoring sessions did or did not go so well. She said, "If they come prepared with a lot of questions, then I know they are ready to get help, but if they can't give me an example of what they want to discuss then it's a bit more of a concern." Hannah also talked about tutees asking questions as a measure of preparedness. She said, "Usually, if they are asking questions and they are questions about the topic and understanding the concept, then I know they are prepared to get help." Both items Hannah mentioned are key to the 
success of any peer tutoring session regardless of whether it takes place in-person or synchronously online. Unfortunately, one of the downsides to peer tutoring is that some tutees show up to the tutoring sessions expecting to hand assignments over to the peer tutor to get answers and step-by-step directions rather than taking ownership of the concepts being discussed. Avoiding the trap of providing answers rather than checking for tutee understanding is something that is highly emphasized in the peer tutor training program at Old Dominion University.

Peer tutor \#1 Alice talked about a different type of preparedness. The preparedness she was describing in her response was her own preparedness. While Alice did not specifically mention preparation in the example she provided for when a session went well, the response she gave required preparation on her part to be successful. Alice described how she helped a student in a computer programming tutoring session. She said, "Since the programs are relatively short, I would compare the code with the execution to explain what each line did and if they were still confused I would go back and try to reword it." The computer programs that Alice was referring to were programs she herself had written and saved in the previous academic courses she had completed. Alice preferred to use sample computer programs to explain more complex programming questions. Having a variety of example computer programs readily available required preparation ahead of time on Alice's part. To be able to do so, she had to have the programs saved and organized in a way that she could easily find them as questions arose throughout each peer tutoring session. 


\section{Theme 2.3: Technical Issues}

The main theme that emerged from the second part of the question was technical issues and how they have impacted specific online peer tutoring sessions that have occurred in the past. In response to the second part of the question, Alice described a specific online tutoring session where she had to improvise with communication due to technical issues. She said,

"I didn't think this one went well only because for some reason the audio was...on my part the mic wasn't working. So, I had to improvise and use notepad on the side and type in what I wanted to say. So, I am not sure how well I conveyed the information to the student, but I did my best at it anyway."

The technical difficulties that Alice and her tutee experienced caused Alice to question her own level of effectiveness for the specific online peer tutoring session she described. Only being able to communicate with her tutee through text rather than audio prevented Alice from being able to feed off audio cues that are often used to assess if the tutees are understanding various concepts in synchronous online peer tutoring sessions.

Peer tutor \#2 Andrew shared a different situation in which he did not have the best online tutoring experience because of technical difficulties. He said, "The main issue was technical problems. I couldn't get the camera to come on and I asked someone else and they couldn't figure it out either." He then talked about how he sometimes uses Skype to tutor some of his friends on the side and how he holds paper notes and other print content up to the computers camera to share them with the person he is tutoring. However, during the session in which he was describing, he did not have access to a camera. He said, "I didn’t have a camera in here which was very troublesome." Andrew relies on the functionality of the computer's built in camera to share printed materials with his tutees. Without the use of his camera, he did not know how else to share content 
with his tutee. Since there is not a computer scanner readily available to the online peer tutors, Andrew's only remaining option was to use his audio to describe each item in as much detail as possible with no visual representation of the concepts.

Peer tutor \#5 Jessica also described a technical issue she had experienced with her computer's camera, but on top of the camera issue, the tutees audio or microphone were not working as well. In that instance, the tutee spent approximately fifteen minutes trying to find an alternative microphone option, but was unsuccessful. Jessica said, "The camera wasn't working for me and her audio wasn't working so she went to get a different microphone. After about fifteen minutes, the tutee just said I will just reschedule." Hannah identified a different type of technology issue that she has come across in a couple of her online peer tutoring sessions. She stated that, "The only issues that usually arise are when they can't share their screen and if I can't see the problem they're working on it's more difficult."

Peer tutor \#4 Hannah, Peer tutor \#5 Justin, and Peer tutor \#9 all also described various types of technology issues that had occurred when describing a time when an online peer tutoring session went bad. Hannah did not give a specific example, she just stated that had not really experienced any other issues with the technology not working. Justin described a time when the audio was not coming through the computer clearly, so he had to use text to communicate with his tutee. Vince had the worst.

Vince was the only peer tutor who described a situation in which he had experienced total network failure and was unable to get the computer in the Distance Tutoring Room to connect to the network. On top of the network connection issue, he also said the Wacom tablet was missing. When asked how he responded to the situation 
he said, "I used my own laptop and carried a real whiteboard in front of me to physically do it. That was uncomfortable, and the tutee had a hard time actually seeing what it was."

\section{Theme 2.4: Technology Tools}

Another theme that emerged from the discussion that was focused on describing a time when an online peer tutoring session did not go well was determining what technology tools to use based on specific course content. Peer tutor \#3 Charley discussed how he found it particularly difficult to tutor students in Business Calculus courses online. He said, "Tutoring. I used to tutor Business Calculus as well, and that was very hard for me to tutor over online because it was confusing to show somebody on the system how to solve a derivative of something." Furthermore, he added, “...because you can't really use Excel as much, so I felt like I did not give them enough for that one session." Charley questioned his own effectiveness in the session he described because he was not sure what tools to use to best convey the messages he was trying to share with his tutee. He talked about the unique and complex nature of some of the formulas and functions that are used in calculus courses and how Microsoft Excel was not able to handle the higher-level calculations.

Peer tutor \#7 Mark talked specifically about a few online peer tutoring sessions he had conducted before he finally learned how to use WebEx to share his screen. Prior to learning how to screen share, Mark also had issues with trying to determine what tools worked best for him to provide online peer tutoring in mathematics and Accounting courses. Before he figured out how to use the screen sharing feature in WebEx, he was trying to write out journal entries for Accounting using the whiteboard feature. When describing the specific situation, Mark said, 
"I don't know if you know there is a little whiteboard feature in there. I tried to draw stuff out or tried to write Accounting journal entries and thinks like that in there. I could do it, but it was really confusing. I was even confused putting it on there. The tools they have in there I don't think were geared for some subjects like math or Accounting."

In a follow up question, Mark was asked what hardware tool he was using to draw on the whiteboard and he said, "I was using the mouse. They have one of those tablets that you can write on, but that was really inaccurate and really hard to write on." He suggested that maybe he could do better with the tablet if he practiced, but at the time he was not able to use the tool. Learning how to share his screen helped solve some of the problems Mark described, but he did state that he does still struggle at times with trying to determine the best technology options for sharing some content.

\section{Theme 2.5: Background Interruptions}

The final theme for interview question 2 was not as prevalent as only two of the nine peer tutors who were interviewed discussed the topic of background interruptions. One additional issue that arose in a couple of the participant interviews was background noise. Peer tutor \#4 Hannah talked about having issues with noise in the background coming from the tutee. She said, "It's pretty rare, but sometimes there is an issue with noise in their background (referring to the tutee).” Peer tutor \#8 Tonya described a specific online tutoring session in which she had a lot of trouble hearing the tutee because of background noise that came from the tutee having her child with her during the tutoring session. Tonya said, "My first online tutoring appointment, it was ok, but the person had a kid, so it was like they were going back and forth with the kid and stuff in the background while we were trying to talk." Background noise was the only real issue that Tonya had experienced in any of her online tutoring sessions. In the two examples 
provided, both Hannah and Tonya explained how the background interruptions took away from instructional time and disrupted the flow of the online peer tutoring sessions. Interview question \#3. Would you recommend participation in this program to your friends? Why or why not?

This interview question confused most of the participants. They did not know whether the question was focused on students participating in the program as tutees or if it was referring to students applying to become online peer tutors. They were also unsure if the question was referring to the online peer tutoring program rather than the in-person aspect of tutoring. All nine participants asked the researcher to clarify the question. Once they were provided with some additional clarification, most of them answered the question. However, their responses turned into more of a comparison between in-person and online tutoring which was not the purpose of this study and therefore results focused on that topic are not reported.

Peer tutor \#1 Alice reflected how synchronous online peer tutoring sessions offer benefits to the tutees. She was one of the only participants able to immediately provide a response without needing further clarification. Alice responded by saying,

"I can't vouch for other subjects because like I said, mine was coding, so I do suggest that because with the share screen function, you could show a code that you're using as well as execute it because it's all on the computer. You don't have to write anything. So, like I said, I can't really say anything about other subjects, but for programming I would suggest yea."

Peer tutor \#7 Mark and Peer tutor \#9 both responded to interview question 4 by talking about students who might be considering becoming peer tutors. Mark felt that it depended on who the peer tutor was as to if he would recommend them to become a peer tutor. He said, "I think it really depends on the tutor. I know I had a learning curve with it 
(referring to synchronous online tutoring), and a few other tutors had a learning curve with it so I just think the tutors need more training before they can really do well." In his statement, Mark was referring to students who might be thinking about becoming peer tutors but also mentioned that his thoughts could also apply to tutees. Vince's response was also aimed at students that might possibly be considering becoming peer tutors. He said, "Definitely. I would definitely warn them about the online tutoring, so they would be prepared for that with all the possible hardware errors and what not." Mark and Vince both discussed the need to be more open about the online tutoring requirement that comes with the decision to work as a peer tutor at Old Dominion University. At the beginning of their interviews, the two peer tutors mentioned that they were not aware of the online tutoring requirement prior to making the decision to work as peer tutors for ODU. Interview question \#4. How do you know you are helping the students?

Two main themes emerged from the peer tutor's responses. First, the peer tutors rely heavily on a variety of auditory and visual cues to determine if they are helping the students. The second theme that emerged was that some of the peer tutors still struggle to truly determine if they are successfully helping their tutees. The following section will provide more specific details on the two themes that emerged from interview question 4.

\section{Theme 4.1: Visual and Audio Cues}

Audio cues were the most common and frequently used strategy peer tutors identified for determining if the tutoring session is helpful since all peer tutors and tutees are required to have working microphones and audio throughout the course of each online tutoring session. While audio is required for all, the use of the computer's video camera is not. Two of the nine peer tutors interviewed prefered not to have their face on 
camera during the online peer tutoring sessions, therefore, they chose not to use the video function.

Peer tutor \#1 Alice talked about how she has had to use both options. She said,

"That depends. If they are looking at it and they just look confused on the assumption that their video is working. Then that might be like a cue to maybe go back and see what they need help with. Then their voice too. Like if they said they get it but they sound like they don't, that might be another indicator."

Alice was one of the peer tutors who was very apprehensive about using the video feature to show herself in WebEx. She mentioned that she was not comfortable with the ODU Peer Educator Program requirement that states all online peer tutoring sessions are to be recorded and achieved within WebEx and she was nervous about participating in this study. Alice said that she is slowly becoming more comfortable with having to be recorded and after being reassured about participant anonymity and confidentiality she said she did not have a problem with participating in this study. While Alice herself is apprehensive about turning on her own video camera, she did state that she sometimes relies on the visual cues from tutee video footage to help assess tutee understanding.

Peer tutor \#2 Andrew had a similar response about watching and listening for video and audio cues. He said, "One time they had a camera and I didn't, so it was a lot easier for me to watch what they were doing and usually body language is a really easy one to use." On top of that he added, "What they are saying is also another way. If someone is like yea, yea, yea, yea, they say yea too many time, that's usually a red flag." Andrew also described a situation in which the tutee did not have a video camera and that the tutee rarely said anything during the session. He said, "I was completely unaware of what she was doing. Every now and then she would chime in and say something otherwise I just trusted she was keeping up." 
Peer tutor \#4 Hannah just simply said, "You can definitely tell if they get what you are trying to say and understand what you are actually trying to portray to them. They kind of have this "ah-ha" moment." She did not explain whether she was relying on video or audio cues to recognize the "ah-ha" moment.

Peer tutor \#5 Justin uses a questioning strategy to determine if his tutees are understanding the concepts being discussed as well. He said, "Really. Open-ended questions. If they have an idea of what you are talking about, they will be able to answer open-ended questions on the topic." Justin also discussed how he intentionally avoids giving the tutees multiple choice questions to answer when trying to assess a tutees level of understanding. He then went on to provide a specific example of a time in which he successfully used this strategy in a synchronous online peer tutoring session to identify the tutees misunderstanding. After asking the tutee a series of open-ended questions and having the tutee explain several key concepts in his/her own words, Justin said he figured out that the tutee had been putting the percentages into the formula wrong. Instead of entering a .10 in the formula to represent $10 \%$, the tutee was using the decimal .01 , which is $1 \%$ instead of $10 \%$. Once the peer tutor figured that out, he/she successfully solved the problem.

Peer tutor \#6 Jessica uses a strategy that involves directly asking tutees if they understand each concept and then asks the tutee to solve a similar problem if he or she says yes. Jessica said, "I will ask them do you understand this and then I'll ask them a question afterwards that is very similar. If they get it they obviously understood the topic, if not, then not so much." When asked where those additional questions or problems 
come from, her response was, “...for math, I'll get example problems out of the book or for computer science I'll show them websites that are good for future reference."

Peer tutor \#8 Tonya uses a series of "why" questions to help her assess tutee understanding. She also gives the tutees examples and asks the tutees to verbally explain what is known about how to approach the example. Tonya said, "I'll ask them why and then have them explain to me why. I give them an example and have them talk me through the example by telling me what they know." As the tutees are explaining the examples, she likes to occasionally throw some trick questions into the mix to really determine how well the tutee understands the concepts.

\section{Theme 4.2: Struggling Identifying When Being Successful}

Two of the nine peer tutors who were interviewed for this study stated that they are still unsure at times with identifying when they are being successful. Peer tutor \#3 Charley said he still really struggled with trying to determine if his tutees are really understanding the material he presents, especially when he works in Excel. He mentioned that he still relies heavily on verbal feedback from the tutee. Charley said, “...because I am still at the point where the student is watching me do the problem in Excel. I haven't gotten to the point where the student will be able to solve the problem online too and show me."

Peer tutor \#9 Vince also struggled with trying to determine if the tutee is understanding the content in the online peer tutoring sessions. He did say that he will often ask the tutees questions and try to get them to explain some things by going through each step of the process or problem, but that does not always provide the most accurate picture of understanding. Vince commented by saying, "I can't really see if they are 
doing it on a piece of paper and all. I guess that's like the shortcoming in the program." Mark did not say specifically that he struggles with determining whether the tutee is understanding each concept, but he did not provide any specific strategies. Basically, he just said, "Usually, they will give me good feedback and say you helped me a lot, you explained it a lot." Mark really did not have much to say about any kind of instructional strategy that he uses.

Interview question \#5. How do you adjust your instructional practices when you have determined that the tutee is not comprehending the subject matter?

Three main themes, scaffolding, study skills and learning styles, and supplementary tools and resources, emerged from interview question 5. The main instructional strategy described by five of the nine peer tutors who participated involved some type of scaffolding. Although the peer tutors were not specifically familiar with the academic term, they all described some form of breaking complex steps down into smaller more basic content to build up to solving bigger more complex problems. Two of the nine peer tutors who explained how they used information they learned in the peer tutor training on study skills and learning styles to help their tutees. Finally, the remaining two peer tutors described how they use supplementary websites, software, and hardware tools to provide additional explanations for their tutees. The following section will provide additional details on the three themes that emerged from interview question 5.

\section{Theme 5.1: Scaffolding}

One strategy that peer tutors are trained to use when they have determined their tutees are not comprehending the concepts being discussed is scaffolding. Scaffolding is 
an instructional practice where the tutors break down larger, more complex topics into their basic elements and then work with their tutees to build confidence and knowledge in small steps to solve the complex problems. Peer tutor \#1 described how she uses "IF" statements to scaffold content for her tutees. When asked how she adjusts her instructional practice after determining that the tutee does not appear to be grasping the content being discussed, Alice said, "I would basically try covering the topic or portions of the topic at a time so for control structures or "IF" statements, I would start off with a simple "IF" statement and if they get it then I move on to the next "IF" statement. When that does not work, she said, "I go back to see if I can break it down further. Maybe add additional comments or other similar examples to it that could be applied outside the general concept." Alice uses scaffolding to break down larger more complex computer program into individual lines of code or this case, she broke apart each of the if statements in a computer program she was sharing. She asks her tutee a series of questions about each individual line to assess tutee understanding.

Peer tutor \#2 Andrew described the process that he uses to help student better understand the content being discussed by providing a very detailed response. He said, "I'll usually try to drop back one or two steps and then say, ok, so this is where we started, we knew this, this was true, you agree with me, you know how we got to where we were and they are like yea and I will say ok. So, how do we get to the next step and they will sit there and think about it for a minute. Then I throw out a couple of ideas like we could try this process or we could tray that method and wait until they kind of draw a conclusion in their head."

Andrew went on to say that students must understand the concepts in their own time and their own way. He reflected on how he learned the material which involved solving practice problems and watching YouTube videos. He concluded his response by 
saying, "So, I tried to guide people down the same path of discovery that I went on, but just make it a little more efficient."

Peer tutor \#6 Justin was another peer tutor who discussed using scaffolding techniques. He said, "I break things down into smaller pieces, ask open-ended questions, and then ask them (the tutees) to explain the concept." When asked what this approach looks like, he said he starts by asking the tutee to recall as much as he or she can about what was presented in class and then asks, “...ok, now that you have explained that, here is a similar problem, if you were to apply that concept, how would you approach this?"

Peer tutor \#4 Hannah uses sort of a reverse scaffolding strategy by asking the tutee to break down the steps and explain where he or she is having trouble. She said, "Usually, I quit trying to explain something and ask them specifically, what step is it that is making you struggle?" Hannah did say that sometimes that strategy does not work, so she, "has to hold the tutees hand and walk them through each step."

Peer tutor \#9 Tonya uses a similar strategy with her tutees. Tonya's approach is to, “...give them an example and then have them talk me through it. When they get stuck, I will explain it more and then we move on through the rest of the example." Once the tutee can explain the entire concept, Tonya said she likes to give the tutee a second similar question just to reemphasize the concept.

\section{Theme 5.2: Study Skills and Learning Styles}

Another theme that emerged from Research Question 5 was study skills and learning styles. Like scaffolding, peer tutors are trained on a variety of study skills and learning styles share and interact with their tutees. Peer tutor \#3 Charley and Peer tutor \#5 Jessica described how they have used and discussed the information provided in the 
training on study skills and learning styles with their tutees. Charley didn't really focus on scaffolding as an instructional strategy for helping students who did not appear to be understanding the material. Instead, he said that he talks to the tutees about learning styles and study habits. Charley's comment was, "You know I ask them the way they study or how they learn because you know we go through training on that." He said he would have conversations with his tutees and that he tries to help the students solve the problems in diverse ways.

Jessica also discussed trying to identify tutee learning styles in her response to the question. She said,

"I'll try and explain it in a different way because of different learning styles so different people might need to see a visual or compare it to something that makes sense to them. I usually just try to identify what kind of learning style they use."

Jessica explained that they learned about the learning styles approach during the peer tutoring training they received prior to being able to provide peer tutoring services.

\section{Theme 5.3: Supplementary Tools and Resources}

The peer tutors also use a variety of supplementary tools and resources. All six peer tutors who were observed demonstrated the act of sharing supplementary tools and resources. Some of the peer tutors only shared additional websites that might be helpful while others shared more subject specific content. The following section will provide further insight into the types of supplementary tools and resources that were used during the observed online peer tutoring sessions. 
Peer tutor \# 7 Mark did not identify an instructional strategy that he uses once he has determined the tutee does not seem to be comprehending the material. Instead, he responded by saying, "Usually if I can't show them on the WebEx whiteboard or on the tools in there I guess I will go with share my screen and pull up some other different website or pull up Excel where it is more visual." Of course, Mark was also the peer tutor who did not really provide any detail as to what instructional strategies he uses to gauge tutee comprehension in the previous question. Although a couple follow up questions were provided during Mark's interview to solicit more detailed responses to both questions, the extra questions did not really yield any additional valuable data.

Peer tutor \#9 Vince had a similar response to Mark. He first said that his main approach was to use the Wacom tablet and Microsoft Paint to write and draw out solutions to provide extra instruction. After some additional questioning, he added, "I definitely look for other problems. Sometimes I open up a browser and show them websites where they could possibly go. They say that's helpful." Other than providing additional supplementary materials and drawing things out, Vince did not really describe a specific instructional strategy that he uses with the tutees.

Interview question \#6. What suggestions for overall improvements to the synchronous online peer tutoring program do you have?

When asked about future improvements for the online peer tutoring program multiple, peer tutors broke the question down into two parts. First, they talked about ways the program could be improved for the tutees and then they talked about ways the program could be improved for the peer tutors. The reoccurring theme that came out of their responses to both parts of the question involved the need for additional technical 
training. Some of the peer tutors suggested developing training handouts for tutees to use when trying to access the online tutoring sessions in WebEx and others recommended variations of a peer tutor training peer tutor program.

\section{Theme 6.1: Improvements for Tutees}

In response to how the program could be improved for the tutees, Peer tutor \#1 Alice talked about possibly finding a way to improve the directions that are provided to tutees on how to get logged in and get started in WebEx. She said, "Maybe you could help train the students. Sometimes they have had trouble getting on WebEx. Maybe if the steps were divided into steps instead of lumped up in a paragraph, that might help." The paragraph Alice referred to is a small set of basic directions that are sent to each tutor once they register for an online peer tutoring session. The email notification which is automatically generated by the WebEx software provides the information needed to log into the session, but does not provide any extra instructions to help address any technical issues that might occur along the way when getting logged in and started.

Peer tutor \#3 Charley expanded on Alice's idea. He suggested that ODU might need to put together "step-by-step instructions on how to get into WebEx really quick." Jessica also recommended putting together some sort of tutorial to share with the tutees ahead of time. She suggested that a tutorial that explained how online tutoring works would help to address the biggest hurdle which is usually technical difficulties. According to Jessica, “... a lot of the students have never used the online tutoring or WebEx before, so they don't understand how it all works.” Justin, Mark, Tonya, and Vince did not provide any suggestions for improvements to the online peer tutoring program for tutees. 
Peer tutor \#2 Andrew felt the program needed to be publicized more around campus so that other students know that online peer tutoring is available. He said,

'I feel like it's not publicized enough, and if it is, that people don't know what it is. I will tell people that we have online tutoring and they ask how they can find it. People don't really know how to set it up. Honestly, I don't really know how to set up online tutoring either. I just know when someone signs up for online tutoring it will tell me."

Andrew explained that there have been some pamphlets and other promotional materials distributed in the past and information about online peer tutoring is posted on the ODU website, but students do not always pay attention information presented and posted in those locations. He talked about how he has shared the information with is classmates in the past and served as a recruiter for the program.

\section{Theme 6.2: Improvements for Tutees}

In response to how the program could be improved for the peer tutors, Peer tutor \#1 Alice suggested finding a way to improve the training on how to better communicate an interact with tutees in the online tutoring environment. She said, "I think it's hard to get used to it because of the distance and only having a computer screen to communicate with them." Alice further elaborated on her statement by saying, "So, we get trained on how to us it, but you don't actually use it and practice until someone actually makes an appointment. So, maybe if there was better training for it I suppose."

Peer tutor \#2 Andrew also felt that improvements needed to be made to the online peer tutoring program training. His suggestion was to have, "an experimental trial run kind of thing where I would tutor my boss or something like that just, so she can help me. Like sit right next to me and we both have our computers up to walk through using 
WebEx." He said the WebEx training they received was a PowerPoint presentation with screen shots on each slide and that they were told where to click on each screen.

Peer tutor \#3 Charley too felt like some additional training needed to be put together for the peer tutors on how to tutor in their core subjects. He suggested, "We've got to find a way to have better training for our tutors to learn ways that they can show students how to tutor in their own course subjects whether we get it from Cisco, the company that we get it from (WebEx), or ODU.” To build on Charley's response,

Peer tutor \#5 Jessica suggested finding a way to allow new peer tutors to view online tutoring sessions conducted by other peer tutors to help learn how to use everything. She responded by saying, "Most of the time, I think it's just understanding the tools that are associated with it, not so much the concepts that you are teaching." Jessica said she basically just jumped into the online tutoring sessions and relied heavily on her computer skills to help her figure out how to make everything work. Furthermore, she stated that other peer tutors who are not computer majors might not experience the same success.

Peer tutor \#6 Justin just wanted to see some additional directions made available for how to use the supplemental hardware equipment that is available in the Distance Tutoring Room. According to Justin, "I just go in there a couple times a semester and that's not enough time to get familiar with all the equipment." The equipment he was referring too was the Wacom tablet and stylus, the document camera, and he also mentioned an iPad being available but that he had never used it before. When asked more about the iPad, he responded by saying that it does not stay in the Distance Tutoring 
Room all the time, but it is available in another cabinet in the Peer Education Program Tutoring room.

Peer tutor \# 7 Mark suggested having current peer tutors who have already provided online tutoring sessions put together the additional directions that Justin described. Mark's idea was to, “...have the tutors now, even the tutors leaving, start writing guides on how they tutor their classes online with some tips for the next incoming peer tutor to kind of pick up on." He really felt that the initial peer tutoring training was good to show peer tutors how to tutor in general, but that something more detailed on how to tutor in specific subjects online was needed.

Alex felt another issue that needed to be addressed to improve the program was for ODU to regularly test and update the equipment in the Distance Tutoring Room. He said, "They definitely need to make sure the equipment is up to date. I am in here for eight hours a day and I have not seen anyone go in that room for at least two weeks." He talked about how the camera would not work when he last tried to provide online tutoring services with that equipment. Vince felt that it would also help if the peer tutors had a technology support service they could call when a piece of the technology is not working to get some additional assistance. His comment was, "Definitely some technical support. Someone to call up really quick cause sometimes the tablet doesn't work, and I've only had the network error one time, but you know it would be nice to have someone help there." The network error he was referring to was a situation he described earlier in his interview where the computer in the Distance Tutoring Room would not connect to the Internet and therefore he could not access WebEx for the tutoring session. When describing the situation, he said that he pulled in another online peer tutor from the Peer 
Educator Tutoring Room to see if the other peer tutor could help him, but neither of them were successful. So, that session ended up having to be rescheduled.

Tonya had a completely different response to the question about improvements that need to be made to the online peer tutoring program from the perspective of the peer tutors. She discussed the need for soliciting additional information from the tutees about the topics that are going to be discussed in each online tutoring session. Tonya talked about how it takes so much time in the beginning of the session just to drill down and determine what the tutee needs help with. She said, "In the beginning it just takes so much time away from helping students...we spend 10 minutes trying to figure out what they need help with when that 10 minutes could be me helping them with something." Her suggestion was to, make the additional comments field on the online peer tutoring session scheduling form a mandatory field or provide somewhere that requires tutees to provide more details about the upcoming session.

\section{Results for Peer Tutoring Observations}

Four questions were created to assist with analyzing the peer tutoring session recordings that were used for observation data. The four questions were created and aligned to the research questions used to frame this study. The following section will provide further detail about each of the four observation questions, the research questions they were aligned to, and the themes that were identified for each question.

Observation question \#1. How did the peer tutor initially identify the topic to be discussed in the peer tutoring session? What questions were asked?

In four of the six synchronous online peer tutoring recordings that were reviewed, the recordings were started after some initial conversation had already occurred. The 
WebEx software does not automatically record each video conferencing session. Peer tutors must remember to turn the recording feature on at the beginning of each online tutoring session. Fortunately, the peer tutors who did not remember to press the record button before the tutoring session started recognized and corrected their mistake within the first minute or two of the session. So, while the initial introductions were not captured in the recordings, enough of the getting started conversations and processes were present in the recordings to allow video recording analysis question one to be answered.

\section{Theme 1.1: Participant Screen Sharing}

After reviewing all six online tutoring session recordings, one major theme emerged from the data related to video recording analysis question one. That theme was knowing how to effectively use the WebEx software. More specifically, knowing how to allow or direct the tutees to share their computer screens with the peer tutor versus only the peer tutors being able to share the screen. If the tutee could share his or her screen influenced the amount of time it took each peer tutor to initially identify the tutee needs and establish a starting point. Table 4.6 provides an overview of how the screen sharing feature was used, what types of questions or problems were asked, how long it took for each peer tutor to begin addressing the first tutee concern, the total length of the session, and the percentage of session time it took to get started in each online peer tutoring session recording that was reviewed. 
Table 4.6 Breakdown of Screen Share Feature Usage, Type of Tutoring Session, and Amount of Time to Start Addressing the First Tutee Concern.

\begin{tabular}{lcccccc}
\hline $\begin{array}{c}\text { Peer } \\
\text { Tutor } \\
\begin{array}{c}\text { Pseudo } \\
\text { Name }\end{array}\end{array}$ & $\begin{array}{c}\text { Shared } \\
\text { Screen } \\
\text { with } \\
\text { Tutee }\end{array}$ & $\begin{array}{c}\text { Tutee } \\
\text { Shared } \\
\text { Screen } \\
\text { with tutor }\end{array}$ & $\begin{array}{c}\text { General } \\
\text { Question } \\
\text { (GQ) or } \\
\text { Specific } \\
\text { Problem } \\
\text { (SP) }\end{array}$ & $\begin{array}{c}\text { Amount } \\
\text { of Time } \\
\text { to Start }\end{array}$ & $\begin{array}{c}\text { Total } \\
\text { Time for } \\
\text { Session }\end{array}$ & $\begin{array}{c}\text { Percentage } \\
\text { of Time to } \\
\text { Start }\end{array}$ \\
\hline Alice & Yes & No & GQ & N/A & $59: 02$ & N/A \\
Andrew & N/A & N/A & N/A & N/A & N/A & N/A \\
Charley & N/A & N/A & N/A & N/A & N/A & N/A \\
Hannah & Yes & No & SP & $4: 10$ & $45: 18$ & $9.2 \%$ \\
Jessica & Yes & Yes & SP & $1: 13$ & $50: 48$ & $2.4 \%$ \\
Justin & No & No & GQ & N/A & $49: 06$ & N/A \\
Mark & Yes & No & SP & $6: 20$ & $27: 41$ & $22.9 \%$ \\
Tonya & N/A & N/A & N/A & N/A & N/A & N/A \\
Vince & Yes & No & SP & $6: 11$ & $50: 47$ & $12: 2 \%$ \\
\hline
\end{tabular}

Only one of the six peer tutors observed knew how to assist her tutee with sharing his screen in WebEx. There were two sessions in which the tutees were asking questions on general topics versus questions on specific problems. Peer tutor \#1 Alice and Peer tutor \#6 Justin did not have their respective tutees share their screens, however, their tutees were asking more broad questions rather than asking about specific problems. For instance, Alice's tutee was asking about how pointers and link lists work in computer programming. Her tutee said, "What I'm having issues with right now is pointers and link lists. So, I'm trying to have a better understanding of them and how they work." $(0: 50)$. In Justin's session, his tutee was asking for a more detailed explanation of the notes that she had taken and that her instructor had shared with the class. They were discussing oligopolies and duopolies. Oligopolies and duopolies are business terms that refer to two 
different type of market shares. A numerical value for starting time could not be calculated for these two sessions due to the nature of the revolving conversation that took place around the specific topics that were being discussed. The remaining three peer tutors, Peer tutor \# 4 Hannah, Peer tutor \#7 Mark, and Peer tutor \#9 Vince, did not have their tutee's share the computer screen and those tutees were asking specific questions. Sessions in which specific questions were being asked and tutees were not able to share computer screens tended to take longer to get started.

Peer Tutor \#5 Jessica was the only peer tutor who knew how to have her tutee share his screen. Within the first minute of the tutoring session, Jessica was already asking her tutee, "Do you know how to share your screen on here?" (0:49). The tutee did not know how to share his screen, but Jessica was able to guide him through that process and had the tutee sharing his screen within the first minute and seven seconds of the online tutoring session. In just over a minute, the peer tutor had her tutee sharing his screen and was already reading the problem in question from the tutee's shared screen to identify the tutee's needs and establish a starting point. Jessica read the tutee's screen and then said, "Yes, so it looks like you grep something, and usually you're choosing a file?" (1:13). The tutee agreed with the peer tutor's assessment of the problem and the two began working to find a solution.

The main difference that was witnessed when the peer tutor had his or her tutee share their screen was the amount of time it took to identify the tutee's needs and establish a starting point for the sessions. In the three sessions where the peer tutors did not know how to have the tutees share their screens and the tutees were asking specific questions, additional questions and conversations had to occur between the peer tutor and 
the tutee to identify the main problem and to get started. On average, these three sessions took anywhere from $10 \%$ to as much as almost $23 \%$ of the total tutoring session time just to get started compared to Jessica who took less than $3 \%$ of her observed synchronous online peer tutoring session to get started (Table 9). The three peer tutors who fit into this category each began the tutoring sessions by having their respective tutees read the question or problem out loud. This process added extra time, because often the problems were very long or complex and required the peer tutors to ask their tutees to repeat several steps of the problem multiple times before the initial problem-solving process could begin. On average, it took the peer tutors approximately three to seven minutes to establish a starting point in the sessions where the peer tutors were assisting the tutees with solving specific problems and the tutees were not able to share their screen.

Hannah spent the first two minutes of her online tutoring session trying to figure out the best way to gain access to the problem her tutee needed help with. Two minutes and forty-one seconds into the online tutoring session Hannah asked her tutee, "Ok, can you maybe? Is the problem short enough that you can just read it or?" (2:41). The tutee agreed, and it took another two minutes for the tutee to share the first problem with Hannah. Finally, Hannah asked, "Ok, so what are the rules to a binomial? As far as you understand?” (4:15). Each time Hannah and her tutee reached another problem, they spent on average four to seven minutes simply trying to communicate the problem with each other.

Mark also spent some additional time trying to identify the specific problem his tutee needed help with. Just over five minutes into the session, he asked his tutee, "What's your problem and I can go back and check? $(5: 11)$. When he asked, "What's 
your problem...?" Mark was asking the tutee to reread the specific problem they were working on out loud again, so he could determine the next step to be taken in the problem-solving process. It took Mark over six minutes to fully understand the problem his tutee was trying to read out loud. Finally, Mark said, "Ok, so what this is...can you get P hat from that?" $(6: 20)$. On top of taking almost six and a half minutes to officially begin addressing the tutees initial concerns, Mark's computer had technical difficulties when the session was originally scheduled to start. As a result, the total length of time for his session was limited to only twenty-seven minutes versus the standard fifty-minute session. So, Mark ended up spending approximately one-fifth of his entire time just trying to understand the specific problem the tutee needed assistance with.

Vince spent the first minute and a half of his peer tutoring session trying to clarify what version of the textbook his two tutees were using in their course. The last name of the author for the textbook he was asking the tutees about was Choppra. The tutees could not understand what the peer tutor was trying to ask. They asked, "Do we have what?" (0:54). Vince responded by saying, "Which book do you have?" (0:57). One of the two tutees then said, "Hold on. I wish I could share my screen with you because we have it as like a PDF form." (1:04). Similar conversation continued between the peer tutor and the two tutees for the next four and a half minutes. Finally, after exhausting several possibilities for sharing the specific problem, the second tutee said, "I'd say, just turn your computer around and show him my screen since he can seem my video and I have it up on my screen" (5:53). The two tutees had the PDF document loaded on a second computer that was connected to a flat screen TV on the other side of the room. They were using the webcam from the first tutees computer to show the text from the PDF that was 
being displayed on the TV. Although the display was a little blurry at first, the peer tutor was finally able to identify the problem and the initial problem-solving process began over six minutes into the online tutoring session. Vince finally said, "Alright, I think I got it down. Now, do you know how to use fminbnd?" (6:27). A similar trend continued throughout the course of the tutoring session each time a new problem was introduced to the peer tutor.

\section{Video Recording Analysis Question \#1 Summary}

The method by which the peer tutors used to initially identify the topic to be discussed in the online peer tutoring sessions that were observed was affected by if the peer tutors knew how to help the tutees share their screen. In sessions where the tutees had more general questions about a topic, the session time was not impacted as much. However, in the sessions where the tutees were asking more direct more complex questions, a lot of valuable tutoring time was lost as the tutees struggled to share long word problems with the peer tutors using only audio. Out of six peer tutors who were observed only one of the six knew how to have her tutee share his screen. As a result, the initial problem was identified within the first two minutes of the online tutoring session which helped to maximize the amount of time that was spent on solving problems. Observation question \#2. What questions do the tutees ask throughout the session? How do the peer tutors respond to those questions?

After reviewing the synchronous online peer tutoring session recordings, five main themes emerged for the types of questions the peer tutors ask their tutees. The five themes included: a) checking for clarity, b) definition question, c) establishing baseline knowledge, d) general questions, and e) understanding a process. Table 4.7 provides the 
five themes that emerged from the video recording analysis question two, the total number of questions for each category across all six observations, and an example question from each theme.

Table 4.7 Summary for Themes of Questions Asked Throughout the Observed Tutoring Sessions

\begin{tabular}{|c|c|c|}
\hline Category & $\begin{array}{l}\text { Number of } \\
\text { Questions }\end{array}$ & Example \\
\hline General Questions & $103(44.5 \%)$ & $\begin{array}{l}\text { Peer tutor \#9 Vince asked, "Do } \\
\text { you see the whiteboard in the } \\
\text { middle? (31:00), Justin asked, } \\
\text { "You said a minus what? } \\
\text { (46:25), and Mark asked, "What } \\
\text { else did you have to go over? } \\
\text { (24:04) }\end{array}$ \\
\hline Checking for Clarity & $73(31.6 \%)$ & $\begin{array}{l}\text { Peer tutor \#4 Hannah asked, "So, } \\
\text { if I were to ask a student if they } \\
\text { liked rap music and they said } 5 \text {, } \\
\text { does that person saying } 5 \text { affect } \\
\text { the next person's answer? } \\
(6: 59) "\end{array}$ \\
\hline Understanding a Process & $29(12.5 \%)$ & $\begin{array}{l}\text { Peer tutor \#9 Vince asked, } \\
\text { "When the rate of change is } \\
\text { zero, what happens to a } \\
\text { function? Do you remember } \\
\text { that?" (29:51) }\end{array}$ \\
\hline $\begin{array}{l}\text { Establishing Baseline } \\
\text { Knowledge }\end{array}$ & $16(6.9 \%)$ & $\begin{array}{l}\text { Peer Tutor \#1 Alice asked, "Ok, } \\
\text { first of all, do you understand } \\
\text { how the process works?" }(0: 55)\end{array}$ \\
\hline Definition question & $10(4.3 \%)$ & $\begin{array}{l}\text { Peer tutor \#5 Jessica asked, } \\
\text { "What is a directory?" (25:36) }\end{array}$ \\
\hline
\end{tabular}

Theme 2.1: General Questions

The general category included questions that did not involve checking for clarity, establishing baseline knowledge, or understanding a process. Table 4.7 provides examples of three diverse types of questions that were included in the general category. The first question, "Do you see the whiteboard in the middle?" (31:00). which came from reviewing Peer tutor \#9 Vince's online tutoring session recording was simply an attempt 
made by the peer tutor to determine if the tutee was seeing what was being shared on the screen. Peer tutor \#1 Alice asked a similar general question when she asked her tutee, “Ok, so do you see the screen, or do I need to zoom?" (2:20). The second general question example in Table 4.7 came from Peer tutor \# 6 Justin. He asked his tutee, "You said A minus what?" (46:25). In that example, for some reason he had trouble hearing or understanding the previous comment that had been made by the tutee, so he had to have the tutee repeat her previous statement. There were several other similar examples in which the peer tutors asked general questions to clarify comments their tutees had made. At one point, Peer tutor \#4 Hannah had to ask her tutee, "What was that? (28:23) because it was difficult to understand what the tutee had just finished saying. It was very difficult to understand in the recording as well. The third type of general questions provided in the examples in Table 11 were questions that were either asked to begin the session or end the session. The example in Table 11 came from Peer tutor \#7 Mark as he was trying to wrap up his tutoring session. He asked his tutee, "What else do you have to go over?" (24:02). Hannah provided an example at the beginning of her tutoring session when she was trying to welcome her tutee to the tutoring session. She asked her tutee, "Samantha? Hey Samantha, how are you?" (0:30). Hannah’s tutee's name was not Samantha, the tutee's real name as replaced with a pseudo name assigned by the researcher to protect confidentiality and anonymity. The general questions were necessary throughout the course of each tutoring session to kick off the sessions, provide additional understanding of comments made by the tutees, and wrap each session up. 


\section{Theme 2.2: Checking for Clarity Questions}

The second largest category, $31.6 \%$ of 231 questions that were asked, was the checking for clarity category. Two main phrases that were present in several of the checking for clarity questions were, "Do you understand?" or "Does that make sense?" In both examples, the peer tutors would explain a certain concept or problem to their tutees and then would ask the question to clarify whether the tutee understood the concept clearly. Aside from the example checking for clarity question provided in Table 4.7, Peer tutor \#1 Alice asked her tutee, "Do you understand what is happening here?" (3:45) and Jessica asked her tutee, "Does that make sense?" (3:33). In Alice's example, she had just finished explaining what functions were and how they how they fit within the client code. Once she finished explaining the topic, she then asked her tutee if what she understood what was going on. Her tutee responded by saying, "Yea, you're basically saying what the functions are and then your client code is basically plugging those functions in there and then your header..." (3:55). Alice could tell, based on her tutee's response, that he had understood the concept, so Alice was able to move forward to the next step in the process. Jessica had just finished explaining to her tutee what wildcards were and how they worked when she asked her clarifying question. The tutee responded by asking, "So in the slash and the dot, can you put anything, and it will search the?" (3:41). Based on her tutees response of answering a question with another question, Peer tutor \# 5 Jessica could determine that her tutee had not fully grasped the concept that had been presented. So, Jessica immediately began trying to explain the same concept in a slightly different way. Eventually the tutee could understand, and Jessica was able to move forward in the tutoring session. 


\section{Theme 2.3: Understanding a Process Questions}

The third largest category was the understanding a process category. Questions in the understanding a process category were different than the checking for clarity questions because process questions led the tutee to explain the concepts rather than the peer tutors providing the explanations. One of the most frequently-used words found in the understanding a process question was the word "how". Peer tutor \#6 Justin asked his tutee, "Ok, so how do they get from that to the reaction function?" (41:57). His tutees response was, “I don’t know. I have not a clue. Um. Yea, I don't know.” (42:05). From that response, Justin could determine that he needed to find another way to explain the concept because he immediately knew the tutee did not understand what was being discussed. Peer tutor \# 9 Vince asked his tutee, "How do you find the maximum of a function?" (29:27). His tutee responded, “God, I don't know, that was five years ago." (29:32). Again, like in Justin's example, Vince knew right away that he was going to have to provide some additional clarification on the topic because the tutee did not know what he was talking about. Sometimes the understanding a process questions were asked in a format that required only a yes or no answer. Peer tutor \#5 Jessica asked her tutee, “Do you know how to use a wildcard?" (2:11). Her tutee did respond with, "No", but then he went on even further to say, "I do not. I was looking at it and I couldn't really understand it, so I looked at it online and I was still confused.” (2:19). Just as Justin and Vince had to go back and provide additional explanations on the subject, Jessica had to do the same. Through asking the tutees questions that fit within the understanding a process category, the peer tutors were often able to directly assess each tutee's level of 
understanding and either move forward to the next concept or drop back to provide some additional base knowledge.

\section{Theme 2.4: Establishing a Baseline Questions}

The fourth largest category was the establishing a baseline category. In most instances, a lot of the questions that were classified within the establishing baseline category were asked at the beginning of the sessions when the peer tutors were trying to establish starting points for each session. At the beginning of his session, Peer tutor \#9 Vince asked his tutee, "Do you have a specific topic about functions where you have a question? (0:36). Together, his two tutees responded by saying, "Yea, so here we are. We don't know. We've also been doing matrices and operations." (0:41) Vince's tutees not only let him know that they did not know enough about functions to identify a specific question that they had, but they also provided him with two additional topics in which they need help with. Their response helped Vince determine where to begin with his tutoring session. Not all questions in the establishing a baseline category were found at the beginning of the session. Just over halfway into her session, Peer tutor \#5 Jessica asked her tutee a series of questions to help establish a baseline of knowledge. She asked her tutee, "What in the name tells you whether it is a directory or a file?" (29:40), "So what is at the end of a file?" (29:52), and "Right, so what do they all have in common right there?" (30:02). Each time, her tutee responded with another question. He said, "Like the ending? Like what type of file is it?", “.txt or .h?”, and .h?”. Jessica was not only using questions to establish a baseline of knowledge but also to help guide the tutee through the process of understanding on a topic. 


\section{Theme 2.5: Definition Question}

The final question category was definition question. Out of 231 total questions that were asked by the peer tutors, only ten $(4.3 \%)$ of those questions were categorized as definition question. None of the six peer tutors that were observed used more than ten definition question type questions in a single session and one of the peer tutors, Peer tutor \#9 Vince, did not use a single definition question in his online peer tutoring session that was reviewed. There were only a few specific situations that arose which required the peer tutors to determine if the tutees understood the meaning of a term or concept. Peer tutor \#1 Alice provided a specific example of a definition question when she asked her tutee, "Do you know what a character array is? Or an array in a program?" (11:20). Her tutee responded by saying, "Yea, I kind of understand... so it would be a list of letters, right?" Two specific triggers in the tutees response let Alice know that her tutee still did not fully understand the concept. First, there was a good bit of hesitation between the first half and the second half of the tutees response. Second, the tutee answered a question with another question. So, the peer tutor knew she needed to go back and explain things differently and with more detail. Peer tutor \#6 Justin asked his tutee, "Do you know what MCH stands for and means?" (23:45). His tutee responded, "I know it means marginal cost of something. Of Firm H” Ok, I'm thinking it means Marginal Cost High and MCL?” (23:56). Based on his tutee's response, Justin could tell his tutee had a partial understanding of the concept, but needed further clarification before she would be able to move forward in the synchronous online peer tutoring session.

Overall, the tutees really responded well to the peer tutor's questions. There were several times when questions from all five categories were asked that could have been 
answered with a "yes" or "no" response, however, in almost every instance the tutees added some additional details to their responses so that the peer tutors would be able to better determine where the real confusion was coming from. The peer tutors were very attentive to each tutee's responses the questions that were asked and adapted well when the tutees appeared to be confused about a concept.

Observation question \#3. What strategies do peer tutors use to assess the tutee's understanding of each topic? Do they provide similar practice questions or problems for the tutee to complete? If so, what resources are used to find the practice items?

After reviewing all six online tutoring session recordings, three main strategies used by the peer tutors to assess the tutee's understanding of each topic were observed. Those strategies included listening for audio cues, watching for visual cues, and asking additional probing questions. All six peer tutors who were observed were constantly seen and heard reacting to audio cues provided by the tutees throughout the course of each tutoring session. Each of the six peer tutors also asked their tutees a variety of openended and yes-no type questions to assess tutee understanding during the online peer tutoring sessions. Only two of the six peer tutors, Peer tutor \#5 Justin and Peer tutor \#9 Vince, could use visual cues provided by their tutees because the peer tutor and tutee webcam video feeds were turned on and active throughout the entire length of both tutoring sessions.

The six peer tutors were also observed using a variety of resources to identify similar practice problems for their tutees to complete throughout the course of each online peer tutoring session that was reviewed. Some of those practice problems came from course handouts, notes, and textbooks from previously completed courses, others 
came from a variety of websites, and some came from questions the peer tutors made up off the top of their head based on prior knowledge of a topic.

\section{Theme 3.1: Audio Ques}

In synchronous online tutoring sessions where the video features are not used, peer tutors must rely heavily on audio cues to assess understanding. All peer tutors are required to have audio input devices connected to their computers and operational throughout each online peer tutoring session per Old Dominion University Peer Educator Program policies. However, the use of video input devices is optional. Four of the six peer tutors who were observed, Peer tutor \#1 Alice, Peer tutor \#4 Hannah, Peer tutor \#5 Jessica, and Peer tutor \#7 Mark, chose not to activate their webcams during the online peer tutoring sessions that were reviewed. Two of those four, Alice and Hannah, specifically mentioned that they were apprehensive about using their video in the online tutoring sessions, therefore, they stated that the intentionally choose not to use the WebEx video feature.

Sometimes, the audio cues provide by the tutees are more obvious than others. One of the obvious audio clue examples occurred in Alice's online tutoring session. She asked her tutee, "Do you know how to add a header and cpp file?" (5:25). Her tutee responded by saying, "Well I do, but you can show me again just to review this because I have an idea but..." (5:34). The obvious part was when the tutee specifically told Alice he would like her to review the process for adding the two files along with the hesitation and silence that followed the "but" at the end of the statement. Another example of when the audio cues were obvious was when the tutees responded to the peer tutor questions by asking another question. After explaining to her tutee how wildcards work in computer 
programming, Jessica asked her tutee, “Does this make sense?” (3:33). He responded by saying, "So like...(hesitates) the slash and the dot, you can put anything...(hesitates) and it will search that?" $(3: 45)$. Aside from the two pauses in the tutees response, the fact that he was asking an additional question alerted Jessica that the tutee did not completely understand the concept. As a result, she spent the next few minutes of the tutoring session focusing more on how wildcards work. In the two examples provided, along with many other similar examples that were witnessed through the recordings, the peer tutors had to be actively engaged in listening to each tutee throughout the entire course of each online peer tutoring session. All six peer tutors appeared to be very attentive and reacted immediately with additional support when these moments occurred in the session recordings that were reviewed.

Peer tutors also relied on words of affirmation when assessing tutee understanding. During Hannah's observed session, she spent some time explaining the concept of binomials to her tutee before asking the question, "So does this make a little more sense? A binomial and why?" (8:15). The tutee responded by saying, "Yea, definitely!" (8:17). Besides the direct confirmation in words, Hannah could also determine from the inflection used that the tutee really understood the concept of binomials. Another similar example of this occurred in Mark's observed session. Mark was explaining how to use a Z-table when calculating sample proportion problems when he said, "You calculate how far each of the two are away from .07 and then you go with the one that is closer to .07" (10:02). His tutee immediately responded by saying, "Oh, I gotcha!" (10:05). Just like in the previous example, the excitement in the tutee's voice 
along with her words of affirmation confirmed to the peer tutor that the tutee understood the concept.

\section{Theme 3.2: Visual Cues}

The WebEx software provides a moveable and collapsible window where video from the participants is displayed during each online video conferencing session. As each participant in the virtual meeting speaks, WebEx automatically focuses video attention on the person who is speaking. So, if both the peer tutor and the tutee have their video showing, the video focus shifts back and forth as each individual participating in the session speaks. Users do not have to do anything special to turn the auto switching of video focus on, that feature is something that is automatically enabled by WebEx by default. In sessions where both the peer tutor and the tutee had their webcams turned on, visual cues such as facial expressions and physical actions of the tutees could be used to assess tutee understanding. When the tutees webcam footage was displayed, the peer tutor could see every movement the tutee made in front of the camera. Peer tutor \#6 Justin and Peer tutor \#9 Vince were the only two peer tutors observed who used the WebEx video feature during their synchronous online tutoring sessions.

There were several instances throughout the synchronous online peer tutoring session that occurred between Justin and his tutee where visual cues alerted Justin that the tutee was confused and did not understand the concept being presented. Nineteen minutes into the session, the tutee was seen holding her hand over her mouth and looking very confused while Justin was attempting to locate and share additional supplementary resources on the topic being discussed. A few seconds later, when they transferred their attention to the next slide in the presentation, the tutee showed a very puzzled look on her 
face as she shuffled through her notes (19:40). Justin could tell by watching the tutee's actions that the tutee was not understanding what they were reviewing. As a result, Justin located an additional PowerPoint presentation that he had saved from when he had completed the same course the tutee was enrolled in and shared it with the tutor via email. The two then began reviewing the supplementary material. There were a few additional times throughout the tutoring session where the tutee appeared very defeated. In those instances, Justin remained very calm, and provided additional descriptive examples to his tutee.

Vince chose to turn on his video, however, his camera was pointed at a physical whiteboard in the room the entire time. While you could not see Vince's facial expressions and physical actions throughout the course of the observed online tutoring session, you could see physical expressions and actions of both tutees. Unlike the other five synchronous online peer tutoring sessions that were reviewed, Vince had two tutees who participated in his session. The tutee who scheduled the online session was the same tutee who connected her computer to WebEx to join the session. The controlled most of the conversation throughout the entire session while the second tutee, a classmate of the first tutee, primarily served in a bystander role. Vince's tutee appeared very stressed throughout the entire tutoring session. She stated that she had scheduled the tutoring session about an hour and a half before she was scheduled to take a major test in the course and that she had scheduled the online tutoring session specifically to help prepare for the test. There were several instances throughout the course of the online tutoring session where the tutee was observed dropping her head and/or rolling her eyes into the camera. Eight minutes into the session, Vince said, "It could show an actual function like 
this like this one. See this right here?" (referring to content he had highlighted on a webpage he had screen shared) (8:10). In this example, the second tutee was the one who spoke up to confirm she understood what Vince had just described. Meanwhile, the first tutee could be seen rolling her eyes and pulling her hair in front of the camera while saying to the second tutee, "You were asking me to help you on this f---ing test, you are going to be helping me." (8:37) Based on both visual and verbal cues, Vince could immediately determine that the tutee was confused. As a result, he switched over to and example problem in the MATLab software to provide additional clarification on the topic.

\section{Theme 3.3: Probing Questions}

The peer tutors were observed using a variety of probing questions as formative assessment tools to constantly assess what the tutees appeared to and did not appear to know. Two different questioning strategies were used by the peer tutors to check for understanding in the synchronous online peer tutoring sessions that were observed. The two types of probing questioning strategies that were used included questions that could have been answered with a simple yes or no answer and open-ended questions.

\section{$\underline{\text { Yes and No Questions }}$}

Peer tutors are often trained to use specific probing question strategies rather than more generalized questions that might be answered with a yes or no response in their peer tutor training sessions. However, there were specific instances throughout each observed online peer tutoring session where yes and no type questions were appropriate. These types of questions were most commonly used when the peer tutor was directly asking their tutee questions that were aimed at clarifying understanding. For example, Peer tutor 
\#9 Vince asked his tutees, "Do you know how to use the fminbnd?" (6:32) The first tutee responded by saying, "No, so what is that? What is fminbnd?" (6:36) Although answering the question only required a yes or no response, the tutee went a step farther to directly explain to Vince specifically what specific concept she did not understand. Most of the time when a yes or no question was asked, the tutees followed their yes or no responses with additional statements or questions that allowed the peer tutor to better understand the specific areas of confusion. There were several times where the tutees responded by saying yes, yea, right, or uh huh to verify understanding. One example of this occurred in Peer tutor \#7 Mark's session. He asked his tutee, "Is that 15.9 percent? (16:24) and she responded, "Yea") (16:24). Mark then asked, "Ok, so you're putting it into a decimal, right?" (16:29) and his tutee responded, "Right" (16:31). In that example, Mark obtained a quick response from the tutee that confirmed understanding and was able immediately move on to the next step in the problem-solving process.

\section{Open-ended Questions}

Open-ended questions require tutees to provide more detailed descriptions and responses. The peer tutors were trained on how to use open-ended questioning strategies in the online peer tutoring sessions to more accurately assess tutee understanding. Some of the peer tutors who were observed used this strategy more than others. Peer tutor \#1 Alice, Peer tutor \#7 Mark, and Peer tutor \#9 Vince did not use any open-ended questions in their observed online tutoring sessions. Peer tutor \#4 Hannah, Peer tutor \#5 Jessica, and Peer tutor \#6 Justin each used diverse types of open-ended questions in their observed online tutoring sessions to assess tutee understanding. One example of an openended question was heard in Hannah's session. She asked her tutee, "Ok, so what are the 
rules to a binomial? As far as you understand?” (4:15). The tutee responded by saying, “As far as I understand, it means that there are only two possible outcomes?" (4:32). Based on the tutee's response, Hannah determined that the tutee understood what the rules of binomials were. Hannah confirmed the correct response by saying, "Yes, that is correct!" (4:40). Jessica provided another example of the open-ended questioning strategy when she asked her tutee, "How do you know which file you're looking for?" (22:40). He responded by saying, "I am looking for sequential insert in a file, so how would I know what file to type in? (22:53). While the tutee could explain what he was looking for, he could not explain how to find it. Based on that response, Hannah then began breaking down the concept into smaller pieces by talking about how to search the files in the folder. When discussing the topic of marginal revenue, Justin asked his tutee, “Ok, any idea why that might be?" (11:26) and she responded correctly by saying, "Because they didn't keep their prices constant" (11:29). Justin confirmed the tutee's response and the two moved on to the next topic of concern.

\section{Theme 3.4: Supplemental Resources}

The six peer tutors who were observed used a variety of supplementary resources and tools to reinforce concepts throughout each online peer tutoring session. Supplementary resources that were used included websites, special software, presentations, notes, and textbooks from previous courses. Tools that were used included Microsoft Notepad and Microsoft Paint which were both used as virtual whiteboard alternatives, webcams, a physical whiteboard, the WebEx whiteboard, cell phones, and email. This section provides detailed descriptions of the various supplementary resources 
and tools that the tutees used to reinforce learning in the observed online peer tutoring sessions.

\section{$\underline{\text { Whiteboards }}$}

Whiteboards were the most common tool that was used by peer tutors during the observed online peer tutoring sessions. Four of the six peer tutors used some form of a whiteboard to share visual information with their tutees, however, none of the four used the same type of whiteboard. One tutee used the WebEx whiteboard tool (Picture 9), one used Microsoft Paint as a whiteboard tool (Picture 10), another used Microsoft Notepad as a whiteboard tool (Picture 11), and the final tutee used had his computer's webcam pointed a physical whiteboard that was hanging on the wall in the tutoring room (Picture 12). Three of the four peer tutors used the whiteboards to calculate mathematical calculations and the fourth used the whiteboard to share sample computer code she came up with off the top of her head.

Mark used the WebEx whiteboard feature (Picture 9) to type out a sample problem as his tutee read the problem out loud. He did use either of the writing or drawing tools that are built into the WebEx whiteboard tool, instead, he used his keyboard and the text tool to type everything. Once he had written the important parts of the problem, he then began to walk through each step of the process with the tutee and the two worked together to solve the sample proportion problem. Peer tutor \#7 Mark had several technical issues throughout the course of his tutoring session which caused a major delay between the time he would say something and when the actual text would appear on the whiteboard. His tutee made several comments about the slowness 
throughout the session, but the two worked through the issue and connectivity problem eventually went away.
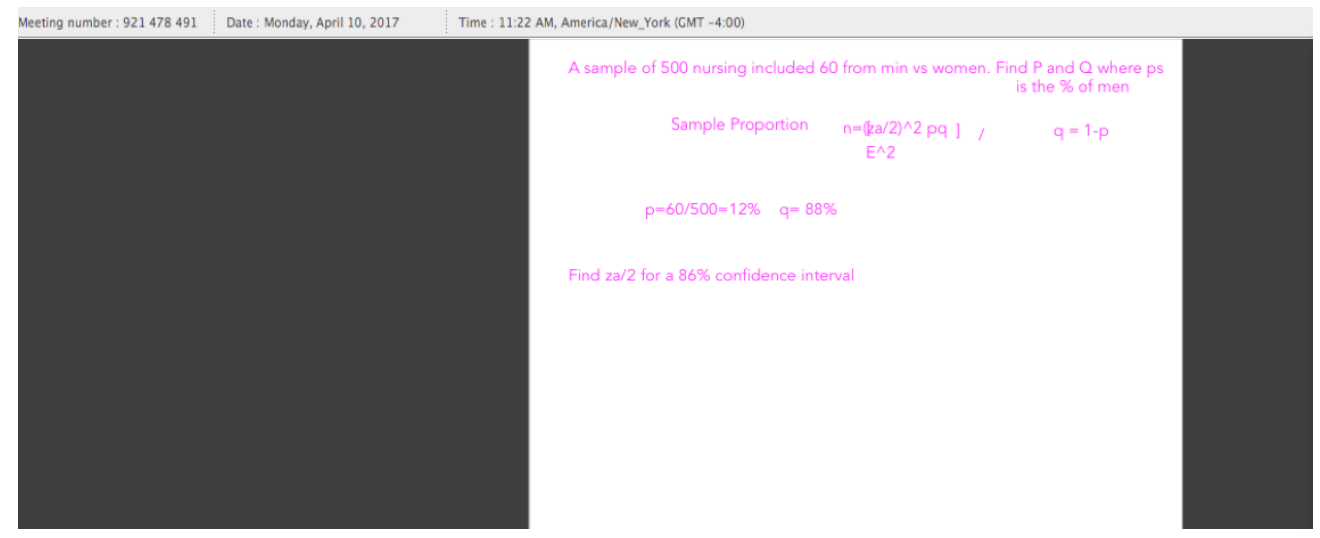

\section{Picture 8. Screenshot of the WebEx Whiteboard Feature Used by Mark to Solve a Sample Proportion Problem}

Peer tutor \#4 Hannah opened a blank Microsoft Paint window (Picture 9) to demonstrate how to solve standard deviation calculations. Using her mouse rather than a stylus or a pen, she first wrote out the original formula and then she began replacing the variables with actual numbers. Once Hannah had all the numbers written in the correct places in the formula, she then asked the tutee to calculate the final answer. Hannah calculated the answer as well so when the tutee responded, Hannah could confirm the correct answer. Paint was only used that one time for a period of approximately three minutes. 


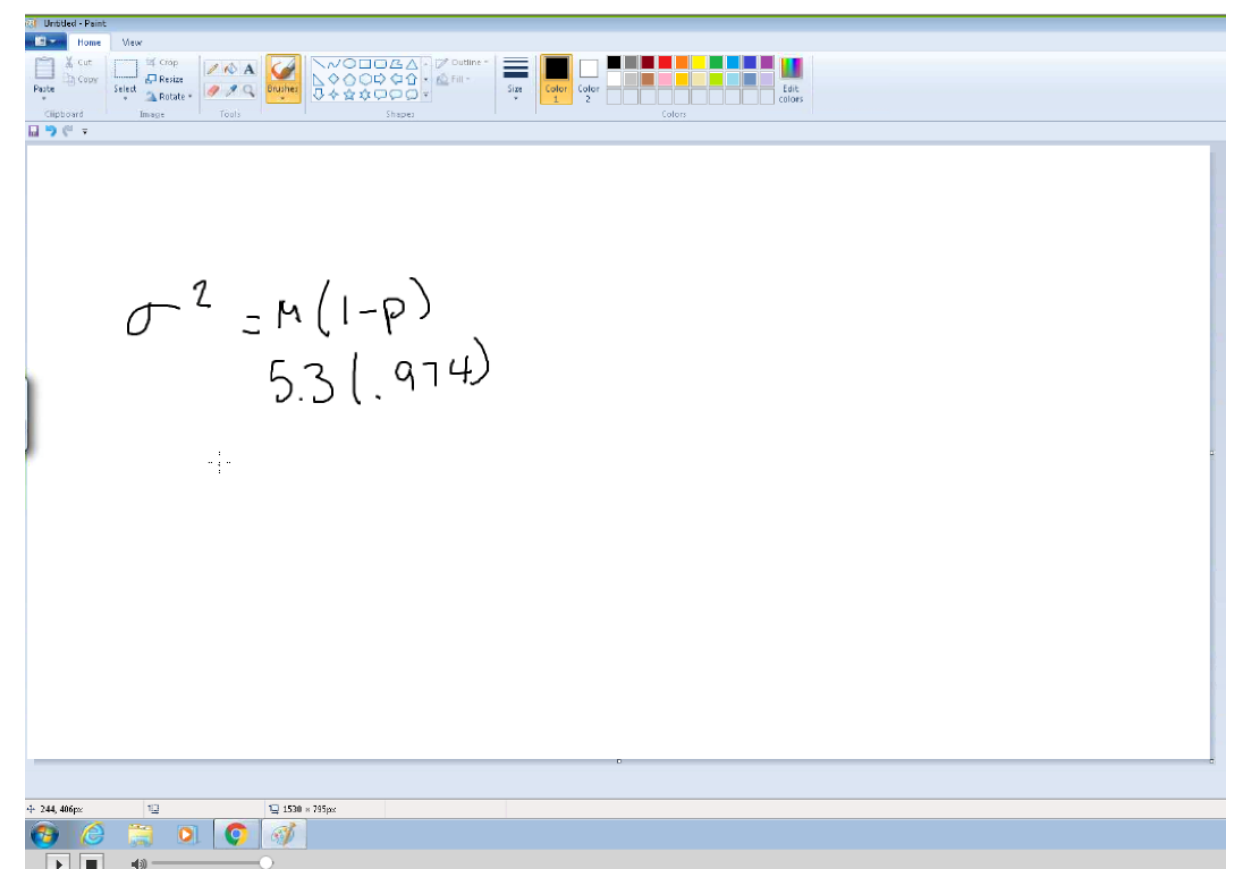

\section{Picture 9. Screenshot of Microsoft Paint Being Used as a Whiteboard by Hannah to Solve a Sample Proportion Problem}

Alice opened a blank untitled Microsoft Notepad window (Picture 10) to use as a whiteboard to demonstrate the main parts of the header, client, and implementation code for a computer program she was helping her tutee with. In the program they were working with, the header, client, and implementation codes were in three separate files that were programmed to communicate with each other to serve a single purpose. Peer tutor \#1 Alice typed out the basic elements of each individual code and separated them with dotted lines to demonstrate the parts of the code that connect the three files. She, like Mark, typed everything she shared using the keyboard and text rather than any writing or drawing tools. 


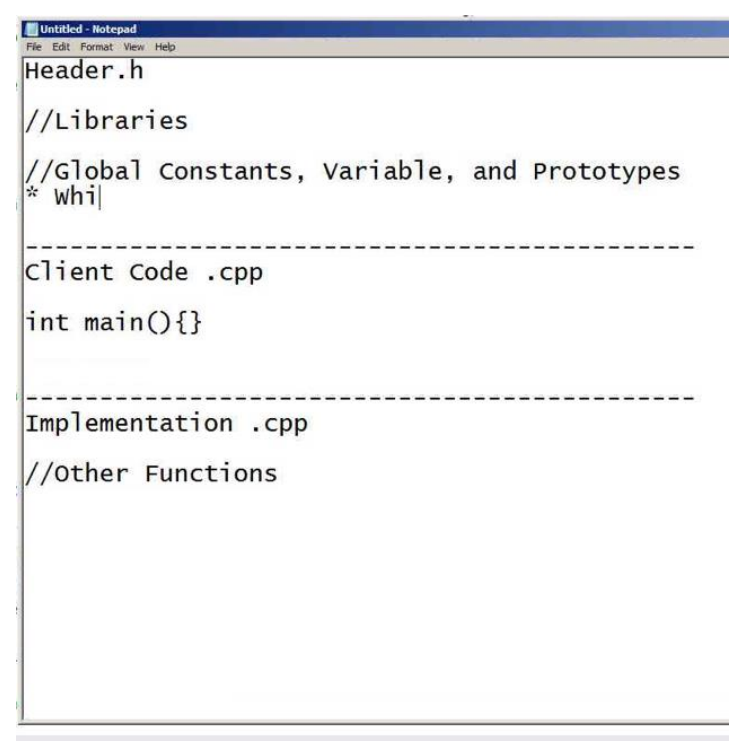

Picture 10. Screenshot of Microsoft Notepad being used as a whiteboard by Alice to Demonstrate the Connection Between the Header, Client, and Implementation Codes in a Computer Program.

Peer tutor \#9 Vince, the final peer tutor to use a whiteboard tool, used a physical whiteboard (Picture 12) that was mounted on the wall in the Distance Tutoring Room to hand write mathematical calculations for using the fminbnd function. He had it webcam turned on and pointed at the whiteboard throughout the entire online peer tutoring session that was observed. He did not show his face in front of the camera once throughout the entire session. Instead, the camera remained focused on the physical whiteboard. The camera zoomed in well on the writing on the whiteboard so that the contents were legible. There was a slight glare from the florescent lights in the room that covered part of the left side of the board, but the writing in that area was still readable. Vince's tutees were excited to see how he wrote the problem out as he solved it on the screen. Vince even drew a small diagram in the lower right corner of the whiteboard and used that to further explain what was going on in the problem. 


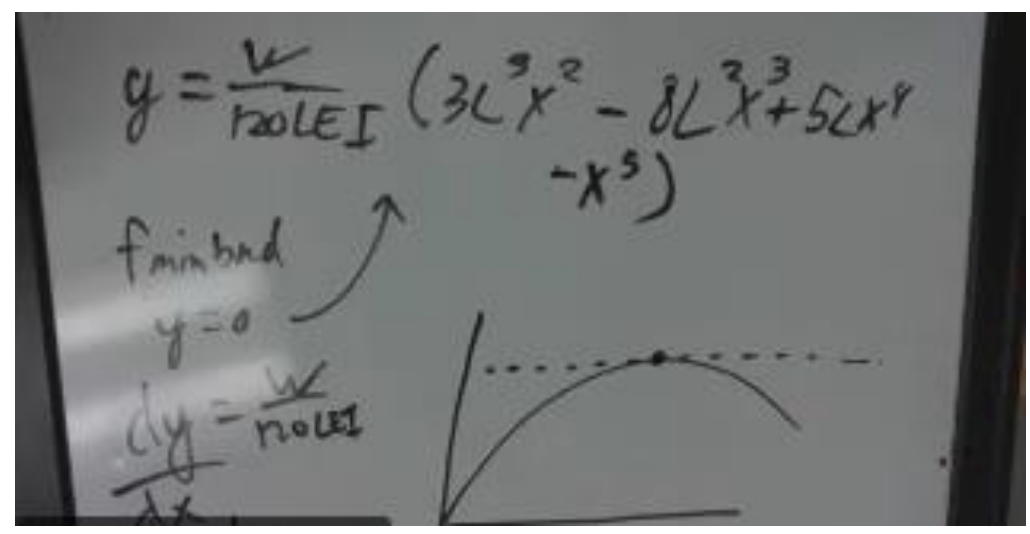

\section{Picture 11. Screenshot of a Physical Whiteboard Mounted on the Wall Being Used by Alice to explain the fminbnd function}

\section{$\underline{\text { Websites }}$}

Websites were also commonly used tools that peer tutors relied on during the online peer tutoring session. Four of the six peer tutors referred to one of three distinct types of websites during the online tutoring sessions that were observed. The three distinct types of websites used included Google search results, Old Dominion University course specific websites, and software tutorial resources. Peer tutor \#4 Hannah used Google to search results to locate information on the binomial distribution formula (Picture 13).

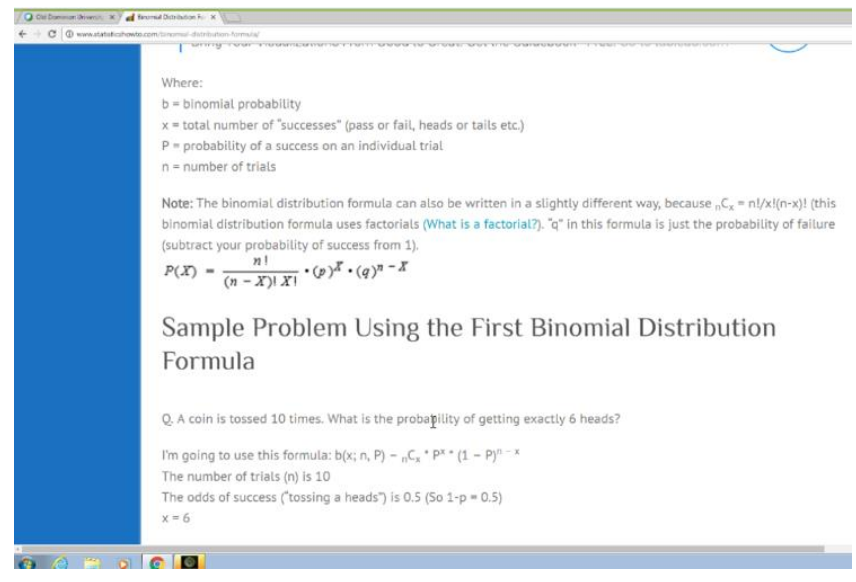

Picture 12. Screenshot of the Statistics How website used by Hannah to Explain the Binomial Distribution Formula. 
Throughout the tutoring session, Hannah referred to the contents on the page in Figure 8 while highlighting various content. She spoke to the tutee as she highlighted each specific item on the page assuming the tutee could see the highlights.

Mark used Google Image search results to show a Z-table, the formula for determining sample size, and the level of confidence formula (Picture 14).

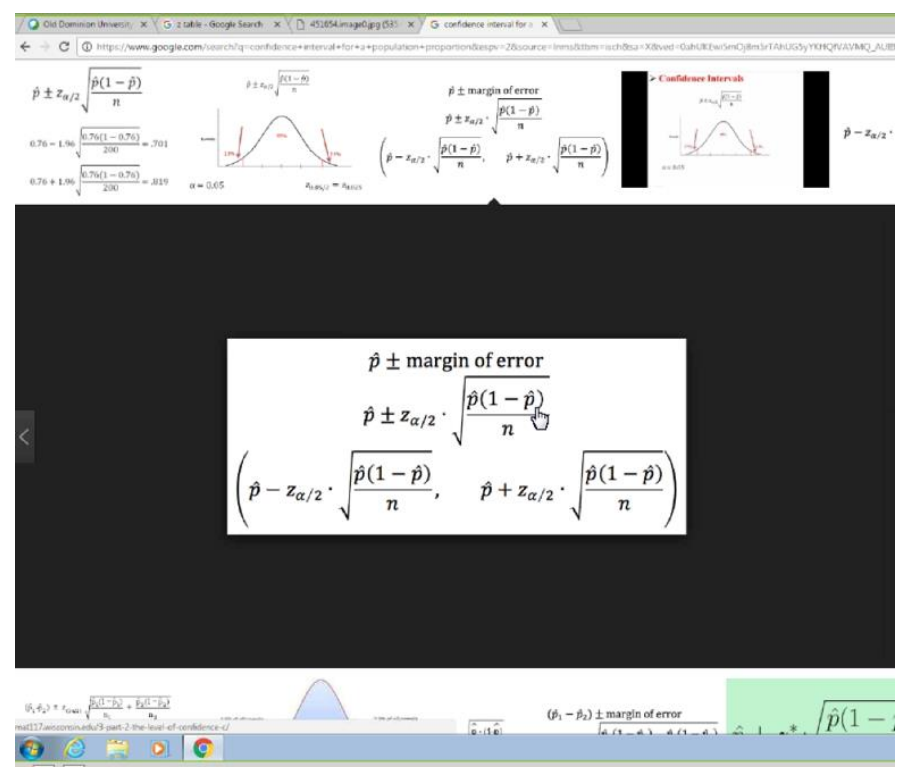

\section{Picture 13. Screenshot of a Google Image Used by Mark to Explain the Level of Confidence Formula}

Since Mark was working with images instead of web text, he did not attempt to highlight any content on the page. Instead, he used the three images he shared of the Ztable, sample size formula, and the level of confidence formula as guides to explain where the tutee should plug in each specific data point that was provided in the original problems. The tutee was very appreciative that Mark shared each of the formulas with her because she did not have either one written in her class notes.

Peer tutor \#5 Jessica used a website that appeared to be an internal resource that was available to Old Dominion University Computer Science students through the 
institution's website. She used the Command-F key sequence to find information about wild cards on the page (Picture 15).

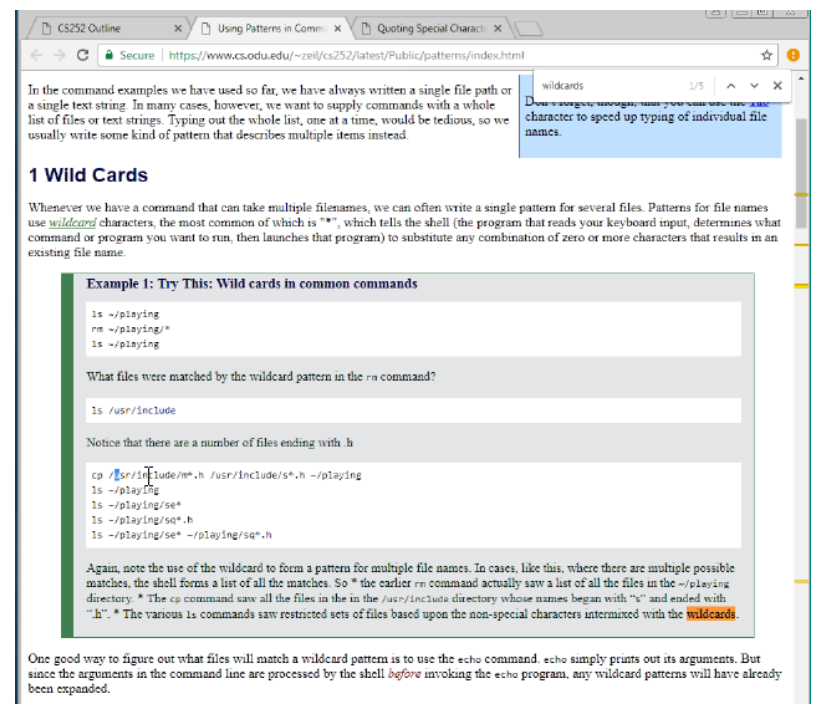

Picture 14. Screenshot of an Internal Page on the ODU Computer Science Website Used by Jessica to Explain Wild Cards in Computer Programming

As she highlighted each line of computer programming code on the page, she broke down the concepts and explained them to her tutee in detail. Once she finished explaining, she would ask her tutee to test the commands on his computer to see if he could successfully use a wildcard to identify the files he was searching for in the problem he and Jessica had been working with.

Peer tutor \#9 Vince used the tutorial guides on the MathWorks website to demonstrate how to use the fminbnd function in MATLab to solve a problem. MATLab is a course specific software used in engineering courses. The software is produced and distributed by the company MathWorks. MathWorks provides a series of compressive tutorial guides on how to use each of the various functions that are available in the software. Vince used the tutorial guides to teach his tutees the steps that needed to be taken to solve problems that involve the fminbnd function in MATLab. 


\section{$\underline{\text { Special Software }}$}

Two of the peer tutors, Alice and Vince, used special software as supplementary resources to help reinforce the concepts being taught. Once Alice determined that her tutee needed help understanding how classes, pointers, and link lists work in computer programming, she opened a computer program she had previously built in Microsoft Visual Studio (Picture 16). Visual Studio is a visual computer programing software that uses color coding to identify distinct types of coding in the program. It also comes with several built-in commands that are automatically pulled up on the computer screen in a floating drop-down menu as the computer programmer begins to type various codes into the program. Programmers can click the appropriate command rather than typing every individual command out. Once the program coding is complete, Visual Studio can be used to run the program and test for any errors. Alice never did run the demonstration program she was using, instead she just read through each line one at a time while explaining the information to her tutee.

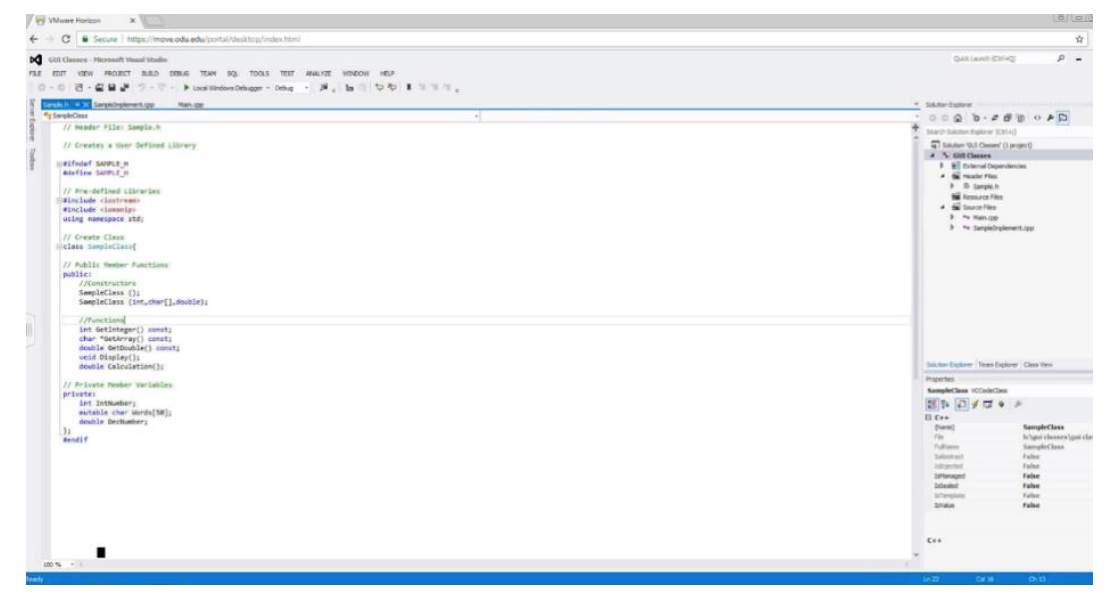

Picture 15. Screenshot of Computer Programming Code from a Sample Program that was Previously Developed by Alice to Explain Classes, Pointers, and link lists. 
Vince used a program called MATLab to work with his tutees. MATLab is a software program that is used by engineering students to analyze data, develop algorithms, and create models. The software uses a programming language to graphically display matrix and array mathematics. Vince's tutees were very excited to see MATLab appear on the screen (Picture 17) when Vince turned on the WebEx screen sharing feature at the beginning of the online tutoring session.

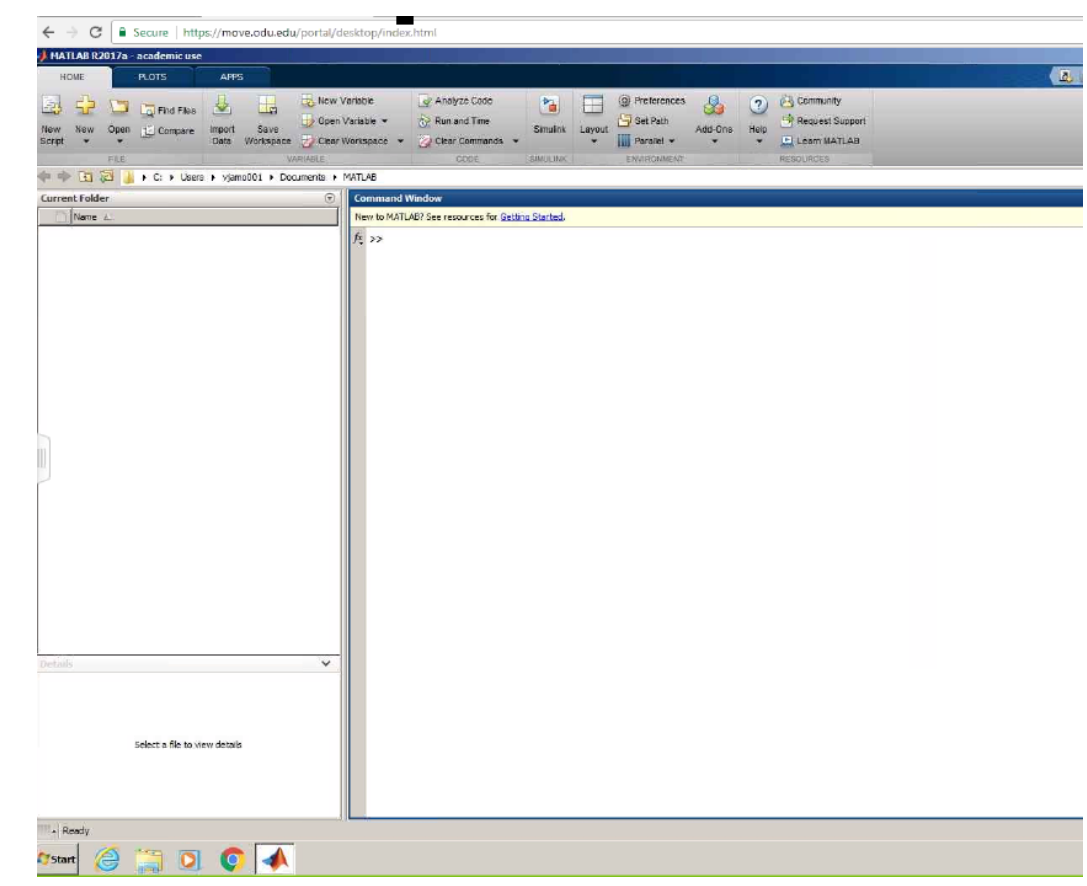

Picture 16. Screenshote of MATLab Software Vince Used to Explain the fminbnd Function

The first tutee said, "Oh look, he actually has MATLab up on the screen. I see that! That is awesome" (1:25). Vince responded by asking, "Do you guys have a specific question about MATLab?" (1:52). Over the course of the next fourteen minutes, Vince spent some time sharing the MathWorks website with his tutees while explaining how the fminbnd function works. Eventually, the first tutee asked Vince, "Can we actually do the problem? Can you actually type it in MATLab because I'm not understanding it? I need 
to see it. Can we type it in MATLab together?" (16:11). Vince agreed and then began to switch back and forth between the MathWorks website and MATLab software as he explained each step of the process to the tutees. Even after seeing how fminbnd works in the MATLab software, the tutees still did not fully grasp the concept and needed additional assistance with solving the problem. Eventually, Vince turned his webcam to a physical whiteboard which he used to write the mathematical calculations. Vince spent the entire fifty-minute session working on the same main problem with his tutees.

\section{$\underline{\text { Webcams }}$}

Peer tutor \# 6 Justin and Peer tutor \#9 Vince were the only two peer tutors out of the six that were observed who used their webcams during the online peer tutoring sessions. Rather than showing his face, Vince kept his webcam pointed at the whiteboard that was mounted on the wall in the Distance Tutoring Room throughout the entire tutoring session. Justin, on the other hand, utilized his webcam to share not only his face and physical actions, but also to share content with his tutee. Justin was the only peer tutor out of the six that were observed who did not share his computer screen with his tutees. Instead, he held pages from a textbook and printed PowerPoint slides up in front of the webcam for the tutee to see (Picture 18). 


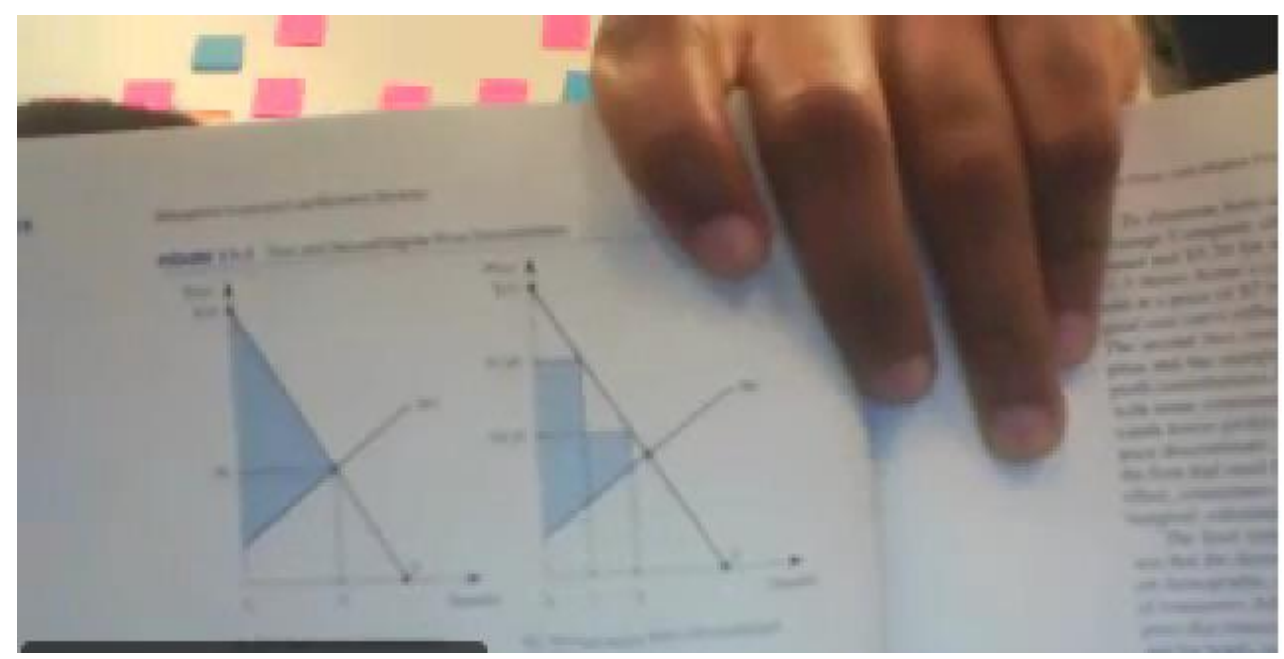

Picture 17. Screenshot of Justin Attempting to Share a Page from the Textbook with his Tutee by Holding the Gap in Place in Front of the Computer's Webcam

In Picture 18, Justin was simply trying to explain the two graphics that were being displayed on the left side of the image and was talking the tutee through what was going on in each image. Sharing content through the webcam worked for the tutee in this instance, however, there were several times when he or the tutee would try to share printed content with each other and were unsuccessful at doing so. There were three or four times throughout the observed sessions where the webcam video share option did not work well enough for either Vince or his tutee to be able to read the text on the page. So, Justin eventually resorted to sharing content by taking pictures with his phone and emailing it to the tutee. Several minutes were lost throughout the course of the entire session as the two worked together to find the best solution for sharing printed content back and forth with each other. 
Observation question \#4. What additional processes or concepts were observed that appear to be relevant to answering the research questions? What observations related to the research questions were surprising? What, if anything, appeared to be missing from the sessions?

The most surprising revelation that came out of the reviewing the recordings of the synchronous online peer tutoring sessions was the lack of understanding of how to take advantage of all the available features in the WebEx software to share content and communicate with the tutees and how much on-task tutoring time was lost as a result. Each of the six peer tutors who were observed were very prepared for the tutoring sessions in terms of having subject specific content and resources available prior to the tutoring sessions in terms of having subject specific content and resources available prior to the start of each session, however, only one of the six, Peer tutor \# 4 Jessica, knew how to help her tutee share his screen.

\section{Screen Sharing}

The peer tutor's lack of understanding of how to help their tutees use the screen share feature appeared to have the greatest impact on the online tutoring sessions in terms of time lost or time off task. At the very beginning of the observed online peer tutoring session, two of the tutees asked their peer tutor about a tutee option to share computer screens with the peer tutors. Peer tutor \#4 Hannah asked her, "Is there a screen share option in here?" $(1: 17)$ when trying to figure out a way to share the specific binomial distribution problem she was working on with Hannah. Hannah responded by saying, "I don't know for you. I don't know if there's a way for me to let you do it. Is there something on your computer you want to share?" (1:33). Peer tutor \#9 Vince's tutee said, 
"I wish I could share my screen with you because we have it as like a PDF form." (1:04). She was referring to a test review document that her instructor had given the class to use as a study guide for the upcoming test. In both examples, the tutees resorted to reading the actual problems out loud to the peer tutors. To be able to refer to the original problem throughout the remainder of the online tutoring sessions, the peer tutors had to write the problems down word-for-word as the tutees read them out loud or had to ask the tutees to repeat specific parts of each problem multiple times.

\section{Document Sharing}

Only one of the six peer tutors who were observed, Peer tutor \#9 Justin, attempted to share printed materials with his tutee. Instead of using a document camera to do so, he relied on holding the documents up in from of his computer's webcam and had his tutee try the same strategy when she wanted to share content. The two struggled constantly throughout the entire online tutoring session when trying to share content using this strategy. Eventually, Justin resorted to asking his tutee if he could just email her pictures of the printed materials from his phone. After multiple attempts to share a problem from the textbook with his tutee, Justin finally asked, "Want me to take a picture and send it to you? Can I just type in your phone number, so I can just text you? Actually, I can just email it to you if that is ok." (58:35). Overall, it took Justin over three minutes of the session to share that one problem with his tutee.

Justin also lost some additional time in his observed online tutoring session as he attempted to find a way to share digital content with his tutee. About forty minutes into the session, Justin had a supplementary PowerPoint presentation that had additional notes on the topic that he wanted to share with his tutee. Rather than using the WebEx screen 
sharing feature, he asked the tutee for her email address, so he could email her the presentation. Justin said, “I'm going to send you some other slides that I have that have the formula broken down, so we can talk about it. Maybe that will help you." (38:50). The entire process which involved the tutee spelling out each letter and symbol in her email address, composing and sending the email, opening and reading the email, and opening the presentation took approximately five minutes of tutoring time away from the online tutoring session. Had Justin known how to use WebEx to share his screen, those five minutes could have been spent going over additional subject matter content.

\section{$\underline{\text { Summary of Observation Results }}$}

Overall the observations revealed that peer tutors initially identify the topic to be discussed differently depending on if they know how to have their tutees use the WebEx screen share feature. The peer tutor who knew how to have her tutee share his screen could identify the initial problem and begin providing tutoring services in less than two minutes. Those who did not know how to help their tutees share the screen took anywhere from five to ten minutes to identify the initial problem. Peer tutors asked five main types of questions during the online peer tutoring session. The five types included general questions, checking for clarity, understanding a process, establishing a baseline, and defining a term. Tutee reactions to the peer tutor's questions varied from hesitation and confusion to answering with questions with questions and words of confirmation. To assess tutee understanding, the peer tutors relied on a variety of auditory and visual cues. Two different types of probing questions were used to help assess tutee understanding. They included questions that could have been answered with yes or no answers or 
questions that were open-ended. Finally, the peer tutors used a combination of screen and document sharing to reinforce points of tutee confusion.

\section{Synthesis of Results}

Data gathered through semi-structured interviews and observations were used to answer the three research sub-questions for this study. The nine peer tutors who were interviewed answered six specific open-ended questions. Four additional questions were developed to narrow down the focus of the synchronous online peer tutoring session recording reviewed. All ten questions were aligned to the research questions that guided this study (see Table 4.8).

Table 4.8 Alignment of Interview and Observation Questions to Research SubQuestions

\begin{tabular}{|c|c|c|}
\hline $\begin{array}{l}\text { Research } \\
\text { Sub-Question } \\
\text { (RSQ) }\end{array}$ & $\begin{array}{l}\text { Interview Question(s) } \\
\text { (IQ) }\end{array}$ & $\begin{array}{l}\text { Observation Question(s) } \\
\text { (OQ) }\end{array}$ \\
\hline RSQ \#1 & $\begin{array}{l}\text { IQ \#1: What did you decided } \\
\text { to become a peer tutor and did } \\
\text { you know you were going to } \\
\text { have to provide? }\end{array}$ & $\begin{array}{l}\text { OQ \#2: How do peer tutors } \\
\text { interact with their tutees in the } \\
\text { synchronous online } \\
\text { environment? How do peer } \\
\text { tutors determine if the tutee } \\
\text { comprehends the content being } \\
\text { discussed? }\end{array}$ \\
\hline RSQ \#2 & $\begin{array}{l}\text { IQ \#2: Please describe a time } \\
\text { when the synchronous tutoring } \\
\text { session went well and then a } \\
\text { time when it went bad. } \\
\text { IQ \#4: How do you know if } \\
\text { you are helping the students? }\end{array}$ & $\begin{array}{l}\text { OQ \#1: How did the peer tutor } \\
\text { initially identify the topic to be } \\
\text { discussed in the peer tutoring } \\
\text { session? What questions were } \\
\text { asked? }\end{array}$ \\
\hline RSQ \#3 & $\begin{array}{l}\text { IQ \#5: How do you adjust your } \\
\text { instructional practices when } \\
\text { you have determined that the } \\
\text { tutee is not comprehending the } \\
\text { subject matter? }\end{array}$ & $\begin{array}{l}\text { OQ \#3: How do peer tutors } \\
\text { determine if the tutee } \\
\text { comprehends the content being } \\
\text { discussed? How do peer tutors } \\
\text { change their instructional } \\
\text { practices when it is perceived } \\
\text { that the tutee does not }\end{array}$ \\
\hline
\end{tabular}


comprehend the content being discussed?

Two additional questions, observation question four and interview question six, were used to gather additional data that was used to answer the central research question for that sought to describe the lived experiences of peer tutors who use video conferencing technology to provide online tutoring services. The following section provides specific details on the findings that emerged from each of the three research subquestions that guided this study.

Research question \#1. How do peer tutors interact with their tutees in the synchronous online tutoring environment?

Peer tutors use a variety of communication tools and strategies to interact with their tutees in the synchronous online tutoring environment. The primary tool used by peer tutors to communicate with their tutees was WebEx, the official video conferencing software used by peer tutors at ODU; and with WebEx, they primarily used the audio communication tools. Peer tutors and their tutees relied on the audio capabilities of WebEx and external computer microphones to ask each other questions, answer each other's questions and describe specific concepts. The following section will provide some further insight into the types of communication the peer tutors had with their tutees and the communication issues that were described.

\section{Finding 1.1: Asking Questions}

Peer tutors communicated with their tutees by asking a variety of questions. After reviewing each of the six-synchronous online peer tutoring session recordings, video recording analysis question 2 revealed that peer tutors asked their tutees five main types 
of questions. There was a total of 231 individual questions asked throughout the course of the six synchronous online peer tutoring sessions that were observed. Those question were used to check for clarity, define terms, establish baseline knowledge, or understand a process. Nearly half of the questions that were asked were classified as general questions.

General questions varied from "What was answer D again? I am sorry, I can't remember." (3:55) asked by Peer tutor \#4 Hannah to "What do you mean? Are saying type in grep?" (7:27) asked by Peer tutor \#5 Jessica and "Ok, do you see the screen, or do I need to zoom?" (2:20) asked by Peer tutor \#1 Alice. The purpose for asking general questions varied from one session to the next, but the primary reason was to solicit feedback that was necessary to continue progressing through the session. Hannah could not remember what her tutee had said, hence she asked him to repeat specific information. Jessica had was confused by what her tutee had said, so she asked him a general question to provide additional clarification. Finally, Alice had just shared her screen and wanted to clarify with her tutee that the screen share had worked before moving forward with the session.

Aside from general questions, the peer tutors also asked their tutees questions to check for clarity. To check for clarity, Peer tutor \#7 Mark asked his tutee, "So with what you already know, can you get P hat from that? Can you solve the problem?” (6:15). Mark was trying to clarify whether his tutee knew how to properly insert the information that was given in the problem to solve for P hat. The tutee responded by saying, "Yes" and then began calculating the answer in the background. Peer tutor \#9 Vince had to ask his tutee a clarifying question to determine if the tutee had calculated the answer to a 
problem correctly. Vince asked, "What negative number did it give you?" (28:31). While Vince knew the eventual answer to the problem and that the answer would be a negative number he did not just simply give the answer to the tutee, instead, he used a clarifying question to verify his tutees calculations.

Other questions asked by the peer tutors were used to determine if the tutees understood a specific process. Peer tutor \#1 Alice asked her tutee, "Do you understand why I'm using the function here that I called GetArray ()? Can you explain that function to me?" (12:40) to determine if her tutee knew how a specific function worked. She was essentially asking her tutee if he could explain what the GetArray () function does and why it was necessary in the specific part of the computer program they were discussing at the time. To determine if her tutee understood a process, Peer tutor \# 4 Hannah asked her tutee, "Ok, so how would you put it into the formula? (16:18). Her tutee responded by saying, "I guess, I would put maybe $3 \% 28$ over N and I could put 1 in figure 2 but it's not going to change anything." (16:29). Based on the tutees hesitation and words like "I guess", "maybe", and "it's not going to change anything", Hannah knew right away that her tutee was still confused about the concept and immediately began breaking the formula down into more basic steps.

The remaining two question types were aimed at establishing baseline knowledge or defining a term. To establish baseline knowledge Peer tutor \#5 Jessica asked her tutee, "What in the name tells you whether it is a directory or file? (29:40) What is at the end of a file? (29:49) What is the recurring theme in all that?" (30:06). Jessica was trying to determine if her tutee understood the difference between a directory and a file and what specific characteristics set the two apart. Eventually, after asking a series of questions 
aimed at establishing baseline knowledge, Jessica's tutee was eventually able to explain that file names end with a dot and a file extension type like .h or .txt and directories do not. Rather than trying to establish baseline knowledge, Peer tutor \#1 Alice was trying to determine if her tutee could define character arrays when she asked, "Do you know what a character array is? Or an array in a program?" (11:20). Her tutee responded by saying, "Yea, I kind of understand that...so it would be a list of letters, right?" (11:30). The fact that he answered the question with a question and hesitated for a couple of seconds in the middle of his response alerted Alice to the fact that he did not fully grasp the concept of character arrays or arrays in programs. So, Alice began explaining each concept in more simplistic terms.

The final question category, definition question, only accounted for 10 of 231 (4.3\%) questions that were asked by the peer tutors in the synchronous online peer tutoring sessions. Alice asked her tutee, "Do you know what a character array is? Or an array in a program?" (11:20). Her tutee responded by saying, "Yea, I kind of understand that...so it would be a list of letters, right?" (11:30). The fact that he answered the question with a question and hesitated for a couple of seconds in the middle of his response alerted Alice to the fact that he did not fully grasp the concept of character arrays or arrays in programs. So, Alice began explaining each concept in more simplistic terms. Jessica asked her tutee, "What is a wildcard?" (2:07). Before her tutee could answer, Jessica asked a second question, "Do you know how to use a wildcard?" (2:11). Her tutee responded by saying, "No, I looked at it online and I was still confused." (2:19). Based on the tutees response, Jessica then shared her computer screen and began 
highlighting and discussion content on a Computer Science website that was internal to Old Dominion University.

\section{Finding 1.2: Answering tutee questions}

The peer tutors were not always the only ones asking questions. There were times, throughout the course of each observed session, where the peer tutors were answering the tutees questions. Two main types of situations occurred in the synchronous online peer tutoring session which require peer tutors to answer tutee questions. Sometimes, the tutees would respond a question posed by their peer tutor by asking the peer tutor a question. Other times, the tutees were asking leading questions that were not in response to a peer tutor question. One example of a situation where the tutee responded to a peer tutor's question with a question occurred in Peer tutor \#5 Jessica's online peer tutoring session. She asked her tutee, "So a wildcard is just like a placeholder for essentially anything. Does that make sense?" (3:33). Her tutee responded by asking the question, "So like...in the slash and like the dot, you can out anything... and it will search that?" $(3: 48)$. Jessica responded by answering her tutees question. She said,

"Yea, it's looking for all files inside this directory that start with the letter $\mathrm{M}$ and then it can have as many characters in-between because of the wildcard. It must end in .h. This is like hard coded essentially. The .h and the $m$ and then it's like anything in-between." (4:23)

Rather than simply defining a wildcard for her tutee, Jessica was attempting to explain how wildcards would work in the specific problem they had been working together to solve.

An example of a situation in which the tutee was asking a leading question that was not in response to a peer tutor question occurred in Peer tutor \#4 Hannah's online peer tutoring session. Hannah had presented her tutee with a hypothetical situation in 
which she had asked her tutee, "So, if I were to poll several people and ask them how much they liked rap music on a scale of 1 to 5 , does one person answering 5 affect the next person's answer?” (5:45). Hannah's tutee responded by saying, "I guess not. Unless for some reason they were influenced for some reason by the other person." (6:02). Jessica explained further, "Yea I guess through something like peer pressure, but for the most part, your answer is independent from the other person's answer." (6:26).

Eventually, the tutee responded with a leading question when she asked, "Can you tell me about an example when they wouldn't independent?" (6:43). Hannah immediately began responding to the tutees question by saying,

"Let's say you gave a student the possibility of picking 1-10, right? And if that person says 6 but then I ask the next person and they can't use the number six because it has already been used, then that's independent." (7:16).

Hannah's tutee confirmed her understanding of the sample problem by simply saying, "Oh, Ok!" (7:18). The two were then able to move on to the next problem which involved determining if the probability experiment represented a binomial experiment?" $(7: 32)$.

\section{Finding 1.3: Describing Specific Concepts}

When the peer tutors were not asking their tutees questions or answering their tutee's questions, they were describing specific concepts. One example of a situation in which the peer tutor was describing a specific concept that was unrelated to a question being asked or answered occurred during Jessica's observed synchronous online peer tutoring session. Peer tutor \#5 Jessica had just shared her computer screen, which was displaying a webpage on wildcards, that was internal to the Old Dominion University 
Computer Science program, with her tutee using the WebEx screen sharing feature. She said,

"So here he talks about wildcards. It's the start character. So, let's see. In this one (highlighting computer code on the website) when you give it the wildcard, you're going to copy all the files in this directory that start with the letter $\mathrm{M}$ and end with a ".h". So, the wildcard is a placeholder for essentially anything." (3:33).

Jessica's extra wildcard description came because of an earlier discussion that had occurred between Jessica and her tutee. She had already determined that her tutee did not understand wildcards, so she located an additional supplementary resource and used that information to help her tutee.

Peer tutor \# 7 Mark provided another example of a situation in which he was describing specific concepts that did not involve asking or responding to questions. He said,

"So, a confidence interval is basically a range of values that give you $95 \%$ certainty that something will happen. So, in the example the confidence interval is from 5 to 10 for heights. For example, you are $95 \%$ certain that all boys on the men's basketball team are between 5 and 6 foot tall." (12:45).

Mark could come up with the example confidence interval problem about the basketball players on the fly after previously determining that the tutee did not grasp the concept of confidence intervals. Once Mark talked his tutee through the example, he could verify his tutee understood the concept. His tutee said, 'Yea, I can see how confidence intervals work." (12:50).

\section{Finding 1.4: Communication Issues}

Most of the time, the peer tutors said the technology was reliable. However, when asked about a time when an online tutoring session did not go well (Interview question 2), the number one response involved some type of audio failure whether that trickled 
down from network connectivity issues or the fact that the tutee could not figure out how to get his or her audio working properly. Peer tutor \#1 Alice, Peer tutor \#2 Andrew, Peer tutor \#8 Tonya, and Peer tutor \#9 Vince all described different situations which had occurred previously that involved some sort of audio failure.

Alice described a situation in her interview when her microphone audio was not working, so she had to improvise by using Microsoft Notepad as a virtual whiteboard. She explained,

“The mic wasn't working on my part, so I had to improvise by using Microsoft Notepad to type everything she needed to say, so I'm not sure how well I conveyed the information to the student, but I did my best at it anyway."

After being asked the follow up question, "Do you find that there are often technical issues either on your side or on the student side?" Alice responded, "Yea, there were a couple of times that the video wasn't working, but beyond that there weren't any other technical issues." Alice explained that she relied on Microsoft Notepad as an alternative to audio communication instead of the WebEx chat feature because she felt the chat feature was more confusing when working with multiple lines of computer programming code.

Andrew described a situation that occurred where he couldn't get his computer's camera to turn on and connect. He was used to relying on the video camera to hold up pieces of paper that he had written various equations and other information on to share with his tutees, however, he was not able to use that method in the session he described. Rather than cancelling the session, he adapted by using the whiteboard feature that is built into Web Ex to type out everything he wanted to say to his tutee. There were a few times throughout that session where he attempted to use the mouse as a stylus to draw on 
the whiteboard, however, he ended up getting very frustrated with that process. Andrew said,

"There's a little whiteboard underneath or like on WebEx that we were using for the first half of the session. I used my mouse to draw on the whiteboard which was extremely painful. I tried the little pad with the pen but that was even worse. It was all but impossible to write anything on the whiteboard, so I just went back to using the mouse for drawing. It was a physics course that I was tutoring so we use a lot of numbers and a lot of weird equations, a lot of weird letters and so I can't get by with just typing everything out. So, it was extremely difficult to tutor with just the whiteboard on there."

In Andrew's situation, he could communicate through audio with his tutee even though his camera was not working, but he always relied heavily on the video camera to show his tutees visual aids. Without access to the camera, Andrew felt he failed to interact with his tutee in a meaningful way.

Peer tutor \#9 Vince described a different situation where he talked about how the computer in the Distance Tutoring Room experienced network failure. When asked about a time when an online peer tutoring session went bad or didn't go so good, he said,

"In my opinion, it was like this one time where I think it was a couple of sessions ago where we had hardware failure basically with the computer back there and it didn't work. It was something like networking. It was saying it could not connect to the network and the tablet was missing. With my own laptop and a whiteboard that I carried in front of me to physically write on, I held the session. That was uncomfortable, and the tutee had a hard time actually seeing what it was."

Again, like in the situations with Alice and Andrew, Vince relied on some alternative form of a whiteboard tool to interact with his tutee. Vince did not explain why he tried to use is computer's video camera and a physical whiteboard rather than using the whiteboard feature in WebEx. Regardless of the reasoning, he too struggled to interact effectively with his tutee when the technology did not work. 
Peer tutors relied on a variety audio and video technology that are built into and external to the WebEx video conferencing software to communicate and interact with their tutees. All peer tutors and their tutees are required to use audio tools like internal and external microphones during each peer tutoring session while video tools are optional. Interaction between peer tutors and their tutees involves asking each other questions, answering each other's questions, and describing specific concepts. According to all nine peer tutor interviews, the technology is generally reliable, however, when technology fails, and the audio or video connections are interrupted the peer tutors felt their interactions were not as effective. In those situations, the peer tutors could adapt and find alternative ways to interact with their tutees through text and a variety of whiteboard tools.

$\underline{\text { Research question \#2. How do peer tutors determine if the tutee comprehends the content }}$ being discussed?

Initially, the process of determining the level of tutee understanding of the material being discussed started with the use of specific questioning strategies that were previously discussed in the previous section on Research Question One. However, assessing understanding or comprehension of content in the synchronous online tutoring environment involves more than using basic questioning strategies. When asked the question in the interviews, "How do you know if you are actually helping students and if they are actually getting what you are sharing with them?" Each of the nine peer tutors responded by saying they either used probing questions including having the tutees explain certain concepts in their own words or they used a variety of auditory or visual 
clues to check for understanding. One unique response that stood out from the rest came from Hannah during her interview. She said,

"Usually, if they are asking questions and they are questions about the topic and understanding the concepts and if they come prepared with a lot of questions then I know that they are really ready to get help. I usually ask them (the tutees) do you understand this and then I'll try and ask them a question afterwards very similar and if they get it then they obviously understood the topic. If not, then not so much.”

Along with various questioning strategies, the peer tutors also relied on a variety of audio and video cues throughout each synchronous online peer tutoring session to assess tutee understanding. At times throughout each session, the tutees responded to their peer tutor's questions with hesitation and other times they responded with additional questions. In both instances, the hesitation and additional questions served as audio cues that alerted the peer tutors that a concept or concepts were not fully understood by the tutees. In the sessions where the video cameras were used, the peer tutors also relied on facial expressions and physical actions of the tutees to help assess tutee understanding. The following section will provide more in-depth descriptions of the questioning strategies that were used, how auditory cues were used when webcam videos were not visible, and how visual cues were used in sessions where the webcam video was visible to assess understanding in the synchronous online tutoring sessions.

\section{Finding 2.1: Probing Questions}

Peer tutors use a variety of probing questions as formative assessment tools to constantly assess what the tutee does and does not know. Two different questioning strategies were used by the peer tutors to assess understanding in the synchronous online peer tutoring sessions that were observed. Three of the six peer tutors primarily used questions that could essentially be answered with a simple yes or no response while the 
other three peer tutors asked more open-ended questions that require tutees to provide more detailed descriptions.

\section{Open-ended Questioning Approach}

Open-ended questions require students to explain certain concepts, terms, and processes in more specific detail. Peer tutor \#6 Justin talked about how he uses openended questions to help his assess each tutees level of understanding throughout the course of each online peer tutoring session. When Justin was asked how he knows if he is helping the tutee understand various concepts in the online tutoring sessions, he responded by saying, "Really, open ended questions. If they have an idea of what you are talking about they will be able to answer open ended questions." He then went on to provide a specific example of a time in which he successfully used this strategy in a synchronous online peer tutoring. After asking the tutee a series of open-ended questions and having the tutee explain several key concepts in his/her own words, Justin said he figured out that the tutee had been putting the percentages into the formula wrong. He said, "Instead of entering a .10 in the formula to represent $10 \%$, they (the tutee) were using the decimal .01 , which is $1 \%$ instead of $10 \%$. Once they figured that out, they successfully solved the problem." Justin was observed using a similar open-ended questioning strategy in his online peer tutoring session recording that was reviewed. After he had finished discussing what a label, label D, stood for on a graph or chart that they had been reviewing, Justin asked his tutee, "Can you tell me why that is? What do you think is going on there with the letter D?" While the first question Justin asked his tutee could have been answered with a yes or no response, he immediately followed up that question with an open-ended question that required his tutee to explain the concept in her 
own words. The tutee responded by saying, "D would be me?" Based on the tone and inflection of her voice, the tutee's response was phrased as a question back to Justin rather than as a detailed description of what letter D stood for on the chart. Justin instantly knew, based on his tutee's response, that she did not understand what was going on in the graph or chart, so he proceeded to break the graph or chart down into more basic parts and began explaining each one in greater detail.

Peer tutor \# 5 Jessica used several examples of open-ended questions throughout her online tutoring session. Rather than starting her questions with phrases such as "can you" or "do you know", she asked questions like, "So how can you just tell it you want to search for files?" (25:50), "What's the recurring theme of all those items you just described?" (30:06), and "So we want to search all files, so what would that look like?" (30:33). In all three instances, the tutee responded by asking the peer tutor some additional clarifying questions. Jessica's tutee responded to her first question by asking, "Do I just do ls (ls is a computer code that is used to list all the files and folders in a particular directory) and try to figure out how many files are in the project directory?" (28:57). The tutee responded to Jessica's second question by asking, "So, it's all a text file?" (30:08) While the wording of the response does not appear to be in the form of a question, Jessica could tell from the inflection in her tutee's voice that he was asking a question rather than making a statement. The tutee's response to Jessica's third question was, "So, can I just...would this work because it's looking for a dot?" (30:50). Other than the fact that the tutee responded to Jessica's original question with another question, the hesitation that was heard during the tutees response provided Jessica with auditory cues that the tutee did not fully understand what command to use to get the computer to search 
through all the files in the directory. The three examples of open-ended questions that Jessica was asking her tutee in the synchronous online tutoring session recording that was reviewed were part of a series of questions she used to help the tutee understand the difference between directories and files and how to search directories for a file type. Jessica continued to use a variety open-ended questions throughout the rest of the observed online tutoring session to assess understanding. Even at the end of the session, the tutee was still having trouble trying to find the right computer command to get the correct output for the problem. The tutee said, “Like I don't know what's going on. Like why is it coming up with No, that's not it?" (46:50). Jessica suggested, "You should test your commands in a separate terminal before you put them into the answer, so you can see what the output is." (46:59). She explained to the tutee that,

“Just typing in the command doesn't really help you figure out what the problem is with the command. None of the commands that you type in are going to break anything. He wouldn't give you anything to break. So, don't worry about that. You can just type it in your normal terminal. Grep whatever to see if it works. If not, keep going until you get it to work." (47:29).

At that point, time was running out for the session, so Jessica began wrapping up the session by saying, "I hope I helped somewhat at least." (47:30) and her tutee responded by saying, "Yea." Jessica then said, "Does it make more sense?" and the tutee responded with, "Yea, I kind of understand what wildcards ware not, so I guess it's gonna help." (47:42). While the open-ended questioning strategy used by Jessica did not give the tutee full confidence in understanding how to use the grep command, she was able to assist him with understanding how wildcards work in computer programming which is a major step in the process of being able to successfully use the grep command. 
Peer tutor \# 3 Charley and Peer tutor \#8 Tonya were interviewed; however, synchronous online tutoring session recordings were not able to be obtained for either due to a lack of response from request to participate emails that were distributed to the tutees they served. Although the two were not observed, in their interviews, they did specifically mention that they use similar open-ended questioning strategies to assess understanding.

Charley explained that he likes to write the initial problem on the whiteboard and then has the tutee try to describe each of the next steps in his/her own words. Initially, Charley kept wanting to explain how he handles the situation in his face-to-face peer tutoring sessions, so he had to be asked an additional question to solicit specific feedback on what strategy he uses in the online peer tutoring sessions to assess tutee understanding. He said, that sometimes he will bring up Microsoft Excel and screen share different spreadsheets with his tutees in order to have the tutees explain what is going on in each spreadsheet. Other times he said he might bring up a problem on a website and then ask the tutee to explain what is going on in the problem. If they do not initially get the concept, Charley provides a more broken-down explanation but then goes back at the end of the conversation and asks the tutee to teach the concept back to him.

Tonya described using a similar open-ended questioning approach. She said that she likes to give the tutees additional questions or problems that are like the concept she and her tutee had been working on together, she has the tutee try to answer the question or solve the problem independently. Once the tutee comes up with an answer, Tonya then had the tutee explain in detail how the problem was solved. Based on the tutees response, the peer tutor either moves forward in the session or talks through the problem areas with 
the tutee in more detail. Tonya only provided a generic description of the open-ended strategy she uses to assess tutee understanding. She did not elaborate on the question by providing a specific example of when she had used the strategy in an actual synchronous online peer tutoring session.

\section{$\underline{\text { Yes or No Questioning Approach }}$}

Peer tutors are often taught to use specific probing questing strategies during the training and are generally asked to refrain from using questions that can be answered with a simply yes or no response. This concept is especially important for peer tutors who provide synchronous online tutoring services because based on the technologies audio and video technologies that may or may not be used in each session, it can be difficult to determine if the tutee really grasps the concepts when they respond with the answer yes.

Although it is generally discouraged, four of the six tutees who were observed used yes or no type questions successfully in their synchronous online tutoring sessions. Once Vince was finally able to capture the entire problem his tutee was trying to read out loud to him, Vince asked her, ““'Do you know how to use the fminbnd function in MATLab?" (4:15). Rather than answering with a yes or a no, Vince's tutee responded by saying, "No, so what is that? What is fminbnd?" (4:30). After determining that the tutee did not understand what fminbnd was or how it works, Vince then brought up the MathWorks (the company that produces MATLab) website, and began walking the tutee through the tutorial on the site that explains how to use the fminbnd function in MATLab. As Vince was screen sharing and explaining the MathWorks tutorial he was also switching back over to MATLab on the shared screen to enter the commands to show his tutees how the information he was sharing transfers over into the MATLab software. In 
another observed tutoring session, Alice provided a detailed explanation of how a computer program was supposed to be divided into three different sections. One section was for the header file, the second section was for the client code, and the third section was for the implementation file. Once she was finished explaining the concept, she asked her tutee, "Do you understand what's happening here (referring to the actions taking place on the computer screen that is being screen shared)?" $(3: 45)$. Alice then beginning explaining what he understood about each of the three concepts but stated that he had completely forgotten what is supposed to be in the header file and that he would have to look back in his textbook and notes to find that information. Alice reacted by bringing up another sample computer program that already had the header file written out and explained each individual line of code in the example program.

There was one unique example in which Justin was observed using types of questioning approaches to solicit for understanding with his tutee. He began the interaction by asking, "See how much you owe on the dotted line?" (10:41) and received a single word response of, "Yes" (10:43) from the tutee. Justin then asked, "Ok, is there anything else that is sticking out to you?" (11:05) and received the response, "Well, the marginal is not a straight line. The marginal revenue down at the bottom." (11:18). The peer tutor then responded by asking, "Ok any idea of why that might be?" (11:26) While the tutee appeared to have finally understood the topic being discussed, Justin decided to use additional questions to identify any additional confusion that might be present. At the end of that interaction, the tutee was able to successfully answer each of Justin's questions and after receiving confirmation from the peer tutor that her assumptions were 
correct, she said with excitedly, "Oh yea!" In the video window of the recording, she could be seen shaking her head up and down while smiling.

\section{Finding 2.2: Interpreting Audio and Visual Cues}

Video conferencing technology, like WebEx, allows users to interact through text chat, audio chat, and even video chat. As a part of the synchronous online tutoring program at Old Dominion University, peer tutors are encouraged to turn their webcams on during each online tutoring session. While the choice to use the video feature is encouraged the decision is ultimately left up to each individual peer tutor, whereas the audio feature is required in every tutoring session. Peer tutors and their tutees are both asked to have a microphone available and active throughout the duration of each synchronous online tutoring session. Four of the six participants that were observed chose not to turn on their video cameras and subsequently, their tutees did not have active webcams showing in the video display either. The remaining two peer tutors that were observed did choose to activate their webcams and their tutees also had active webcams. The following sections will further describe how audio cues were used to check for understanding in synchronous online tutoring sessions where the tutee webcams were not active and visual cues were used when the tutee webcams were active.

\section{Tutoring Sessions with No Webcam Video}

Four of the six observed peer tutors chose not to activate their webcam video footage. Only two of those peer tutors, Peer tutor \#1 Alice and Peer tutor \# 4 Hannah, specifically mentioned in their individual interviews that they are not comfortable with displaying their own video during the online tutoring sessions. Of the four peer tutors that chose not to share their webcam footage, only one of the four was able to have her tutee share his 
screen during the synchronous online tutoring session. While it was unclear as to why the remaining two peer tutors chose not to activate their webcams for the tutoring sessions, the reasoning for not utilizing the screen sharing feature for the tutees came from a lack of understanding on how to guide the tutees to use that option in WebEx. In each of those four specific tutoring sessions the tutee webcam video footage was not active either. No explanation was available for why the video footage from the tutees who participated in those four sessions was not displayed.

Synchronous online tutoring sessions in which the webcam video footage was not displayed made it more difficult for peer tutors to determine whether the tutees were understanding the content. Therefore, those situations required the peer tutors to rely more heavily on specific audio clues and to use additional questions strategies to determine if their respective tutees were grasping the various concepts. The process of checking for tutee understanding in the sessions where the webcams were not active, and the tutees were not able to share their screen further complicated the issue. In those specific session, tutees could only rely on the audio cues and questioning techniques, because they were not able to see any actions taken by the tutees.

One specific example of when audio clues were used to determine tutee understanding occurred in the tutoring session that was observed between Hannah and her tutee. During the initial stages of the interaction, the two had been discussing the four answer choices provided for a multiple-choice question that was asking about binomial distributions. Hannah asked, "So you know it's not a binomial based on that, so, what's the closest answer to the question based on the meaning we just discussed?" (5:01). Her tutee responded by saying, "I guess it would be C...It says because there are more than 
two possible outcomes in that and leaves it there." $(5: 18)$ and then she further explained why she chose that specific answer. After hearing the words, "I guess..." Hannah realized that the tutee was still very confused, so she responded by asking, "Are the trials independent? What are your thoughts?" (5:28). During that session, the peer tutor used audio clues from the tutee to identify a specific area of confusion and then used additional example about a survey on rap music that Hannah thought of on her own to further clarify the concept. Hannah said, "So, if you asked a student if they liked rap music and they said 5 on a scale of one to 5 , does that person saying 5 affect the next person's answer?" (6:02). The two spent some time comparing the actual problem to the problem Hannah had made up and the tutee was eventually able to understand the concept of binomial distributions.

A second example of when audio clues were used to check for understanding was witnessed during an interaction that occurred in the online tutoring session that was observed between Alice and her tutee. During the interaction, Alice's tutee stated that he did not understand what was being discussed. After Alice asked, "So here are constructors (referring to specific text being displayed on the shared screen). Do you know what constructors do?" (18:38), Tutee responded by saying, "Na, like I said, the classes thing is a bit much for me. So, I have to look it up." (18:47). Unlike in the previous example where the peer tutor had to determine what the tutee meant by using the phrase, "I guess", in this example the tutee directly stated that he did not know enough about classes to accurately answer the peer tutors question. Alice reacted to her tutee's response by saying, 
"It's ok. I just wanted to make sure. In this case, I have two, but you only need one constructor. So this constructor does not have a data type before it and they are the name ask your class, so that's why it's SampleClass::SampleClass." (19:10).

She used the original question to help establish a baseline for what the tutee did and did not know, reassured him that it was ok he did not know how to explain constructors at the time, and then began to provide a more in-depth description of the concept.

In those two examples, the peer tutors had no visual cues available to use as measures for assessing tutee understanding. Due to the lack of visual cues, the two peer tutors had to be actively engaged in listening to every word their respective tutees spoke. Otherwise, they might have missed those important audio clues the tutees provided. One important note that was observed in all six of the synchronous online peer tutoring sessions that occurred is that at no time did the peer tutors ever appear to lose focus of the task at hand as they were providing tutoring services. Each of the six peer tutors remained actively engaged in listening to the tutees during the online tutoring sessions. The only time peer tutors had to have the tutees repeat certain items were in cases where the tutees were not able to share their screens and were trying to read complex problems or questions out loud to the peer tutors.

\section{Tutoring Sessions with Webcam Video}

The WebEx software provides a moveable and collapsible window where video from the participants is displayed during each online video conferencing session. As each participant in the virtual meeting speaks, WebEx automatically focuses video attention on the person who is speaking. So, if both the peer tutor and the tutee have their video 
showing, the video focus shifts back and forth as each peer tutor and tutee in the session speaks. Users do not have to do anything special to turn the auto switching of video focus feature on, it is something that is automatically enabled by WebEx by default.

In sessions where both the peer tutor and the tutee had their webcams turned on, visual cues such as facial expressions and physical actions of the tutees could be used to identify points were confusion was occurring. When the tutees webcam footage is displayed, the peer tutor can see every movement the tutee makes that is in front of the camera. There were only two of the six observed synchronous online tutoring sessions in which the tutees webcam video could be seen. Peer tutor \#6 Justin used his video camera to interact with his tutee throughout the duration of his online session. Peer tutor \#9 Vince, on the other hand, chose to show is webcam video, however, his camera was pointed at a physical whiteboard in the Distance Tutoring Room the entire time.

There were several instances throughout the synchronous online peer tutoring session that occurred between Justin and his tutee where it was easy to identify that the tutee was confused and did not understand the concept being presented. Nineteen minutes into the session, Justin's was seen holding her hand over her mouth and looking very confused while Justin was attempting to locate and share some additional supplementary resources on the Sweezy plot graph he had been discussing with his tutee. A few seconds later, when they transferred their attention to the next slide (Slide 7) in the presentation, Justin's tutee showed a very puzzled look on her face as she shuffled through her notes (19:40). Justin could tell by watching his tutee's actions that she was not understanding what they were talking about which is what led the peer tutor to begin looking for additional supplementary materials. There were a few times throughout the tutoring 
session where the tutee appeared to feel very defeated. In those instances, Justin remained very calm, and proceeded to break the more complicated problems into more simplistic examples. In one instance, he responded to his tutee's frustration by specifically giving her notes that should be written down. After noticing that his tutee appeared to be frustrated based on visual cues seen in the video feed, Justin said, "You might want to take a note of why the Sweezy model is criticized. I think that might be a possible test question." (26:32). The tutee appeared to feel a little more reassured as she responded by saying, "Well. Cause it offers no explanation of how the industry settles on the initial price that generates the kink." (27:18). Based off of both visual and audio cues, Justin was able to determine that he tutee finally understood the Sweezy Model, so he then changed the direction of the session to proceed on to the next topic of discussion on the Cournot Oligopoly.

The online tutoring session that was observed between Vince and his two tutees brought about a unique situation. This was the only session in which more than one tutee was present in the online tutoring session. The first tutee was the student who signed up for and scheduled the online tutoring session. The peer tutor had no up-front warning that there were going to be two tutees in the room, however, this did not change the way that he went about providing synchronous online tutoring services. The second tutee was never in the WebEx video feed, but you could hear her exchanging conversation with the first tutee throughout the session, and there were a couple of times in which she was the one asking the peer tutor questions.

Vince's first tutee was very stressed throughout the entire tutoring session. She scheduled the tutoring session about an hour and a half before she was scheduled to take 
a major test in the course for which she was seeking help. At the very beginning of the session, she informed Vince that she had a PDF of an old practice test and she wanted to go through each of the problems on the test because the test was going to be open book and open note. Unfortunately, they never really made it past problem two on the practice test before they ran out of time for the session and the tutees had to leave to take their test. There are at least two times when Vince's tutee used foul language out of frustration from not understanding the content. Along with the verbal frustration, she could also be seen rolling her eyes and dropping her pencil on the table out of frustration. In the first example, Vince had been discussing anonymous functions with the two tutees. When he asked the two, "Do you guys know how to make an anonymous function?" (7:46), the first tutee turned towards the second tutee and asked very hesitantly, "Do you know how to make an anonymous function?" (7:49). When the second tutee instantly could explain what anonymous functions were and that they use the "@” symbol, the first tutee appeared and sounded very frustrated as she said, "You were asking me to help you on this f---ing test, you are going to be helping me." (8:37) Her frustration was directed at the second tutee rather than towards Vince. Vince ignored the comment and began explaining a specific example of the anonymous function being used on the MathWorks website. Having the video feed turned on for this online session was very important, because it allowed Vince to see that the first tutee was directing her hostile and profane comment at the second tutee rather than at Vince. If Vince were only able to hear the audio in that example, there was a chance he could have thought that the comment was directed towards the services he was Overall, the session was not hostile, the first tutee was just very stressed due to the upcoming exam she was about to go take in class. The 
two appeared to be very satisfied with the services that Vince provided, because at the end of the session, they were talking through planning another session the following week.

After reviewing personal interview transcripts and the recorded tutoring sessions, it was determined that peer tutors use a variety of probing questions along with audio and visual cues to help determine whether their tutees comprehend the content being discussed in the synchronous online tutoring environment. Peer tutors receive in-depth training on how to properly ask questions in the tutoring sessions to determine the tutees level of understanding without specifically giving away answers. Those skills that were taught in the peer tutoring training sessions were prevalent throughout each of the observed synchronous online tutoring sessions. Depending on each peer tutors level of comfort with sharing their personal video feeds and their level of understanding for having the tutees share their screens, some peer tutors had to rely only on audio clues while others had the advantage of also being able to feed off facial expressions and physical actions from the tutees. The one thing that was evident throughout each of the observations is that the peer tutors must constantly be actively listening and reacting to the words and actions of their respective tutees throughout the duration of each synchronous online tutoring session to successfully provide meaningful and productive tutoring services.

$\underline{\text { Research question \#3. How do peer tutors change their instructional practice when it is }}$ perceived that the tutee does not comprehend the content being discussed?

Two key themes emerged from a review of the data for the third research question which were the use of supplementary materials and the use of scaffolding techniques. 
There were two main types of supplementary materials that were used by the peer tutors in the online tutoring sessions. The first type included all the content that each peer tutor had available from the previous courses he or she had previously completed and had been certified to tutor. The second type included all the additional digital resources such as websites that the peer tutors shared. The following sections will provide specific details on the two distinct types of supplementary materials.

\section{Finding 3.1: Supplementary Materials}

One of the benefits identified for building synchronous online peer tutoring programs internally from the host institutions own resources is that the peer tutors are more likely to be familiar with expectations and academic content for specific professors within each subject area and course. Peer tutor \#5 Jessica talked about this benefit during her interview. She said, "It helps that we have taken the classes so that we know usually the professors associated with them and the content that is taught in each course." Later in her interview she went even further by stating, "I usually start to recommend specific professors for my tutees during registration each semester based on past experiences."

The level of familiarity each peer tutor has with the professors in his or her major and minor areas of study is one benefit, but having access to specific academic content from those courses is also beneficial. One thing several of the peer tutors mentioned in their interviews was that since they have been hired as peer tutors, they now hold on to all their notes, files, and textbooks from each of the courses in which they are certified to tutor. The peer tutors then use the old resources as additional instructional support materials in the synchronous online tutoring sessions. 
The peer tutors appeared to have good systems in place for organizing all the resources from the courses in which they had previously completed. In the beginning of the synchronous online peer tutoring session that was observed for Peer tutor \#1 Alice, she asked her tutee, "Ok, so do you want to review classes, or do you want to just jump to pointers and link lists?" (1:30). Her tutee responded by saying, "We can review classes." (1:33). Following his response, Alice was immediately able to share her screen with her tutee using the WebEx screen sharing feature and she had a sample computer program that she had written in a previous course ready to use as an example to explain classes. Her tutee was excited that she had an example that she could share as a visual while they were discussing how classes work. He said, "Yea, it definitely would help if I could see something." (1:55). All together it took Alice less than 30 seconds to share her screen and load the previous program that she had written which gave the tutee more time to ask additional questions throughout the online peer tutoring session.

Peer tutors also maintained a list of specific websites that they liked to use to explain certain concepts. In the synchronous online tutoring session that occurred between Peer tutor \#9 Vince and his two tutees, Vince spent a lot of time guiding the tutees through the MathWorks Help pages. MathWorks is the company that produces MATLab, which is the software that is used in the course for which the tutees were seeking assistance. While sharing his screen, he would go to the MathWorks website to find a specific protocol for each step of the problem, explain it in detail to the tutees, and then he would go back into MATLab software to demonstrate how the coding would be transferred over. Vince knew exactly where to show his tutees to turn to when they did not how to work with specific functions in the MATLab software. He did not have to 
waste valuable tutoring time searching for supplementary resources to help his tutees understand anonymous functions.

Peer tutor \# 4 Hannah, Peer tutor \#5 Jessica, and Peer tutor \#7 Mark also shared at least one or more helpful web resources with their respective tutees. Peer tutor \#1 Alice and Peer tutor \#6 Justin were the only two tutors who did not share any outside web resources during their tutoring sessions. While Justin did not share a website with his tutee, he did email her an additional PowerPoint presentation on oligopolies that was more descriptive and provided more additional notes than the original version of the presentation. He did not give any indication either in his interview or during the session as to why he does not share his screen during the online tutoring sessions.

\section{Finding 3.2: Scaffolding}

Scaffolding is a process by which instructors or in this case peer tutors break complex concepts down into smaller more comprehensive tasks to build academic mastery. The process of scaffolding beings by assessing what the tutee already knows about the concept in question. Once the tutor identifies a baseline of understanding for each topic, he or she then begins to break the topic apart by asking additional probing questions and watching tutees complete various tasks. As each tutor moves through the process, the peer tutor makes mental or physical notes about areas of strengths and weaknesses. Tutees do not spend much time discussing concepts that fall into the strengths category, however, they do begin further to further explain the weaknesses through more in-depth conversations and sharing resources.

Peer tutor \#1 Alice provided a good example of the use of scaffolding at the very beginning of her synchronous online tutoring session. She began by simply asking the 
tutee, "Hello, what do you need help with today?" (0:10). Her tutee them stumbled through several words before he finally said, "Will, I'm having some issues with the GUI and what I'm having trouble with right now is pointers and link lists. So, I'm trying to have a better understanding of them and how they work." (0:50). Based on prior knowledge and experiences, Alice knew that the tutee would have to have a strong foundational understanding of classes before he could begin to understand pointers and link lists. So, she asked her tutee, "Ok, so do you want to review classes first or do you want to just jump to pointers and link lists?" (1:30). The peer tutor responded by saying, "We can review classes." (1:33). As then began using code in the program she was sharing and began adding new code to a Microsoft Notepad page. Alice explained how classes consisted of three specific section, the header, the client code, and the implementation. As she presented each section, she asked the tutee if he understood the code that was supposed to go in each area. When she asked her tutee about the header file, he responded by saying, "The header file? I have a little bit of a...I forgot what you put in the header file." (3:42). Based on her tutee's comments, Alice then had to switch gears again to create a new header file and explain each line of code in the file. From this point in the session, they began to build from one concept up to the next until the tutee eventually expressed that he was finally more comfortable with understanding how pointers and link lists work and how they are tied to classes.

Alice did not have to ask all of those clarifying questions along the way. She could have started with pointers and link lists and moved to the next concept. However, she knew from past experiences with specific classes and from tutoring other students in the same course that the tutee was first going to have to understand classes before 
anything could be discussed about pointers and link lists. This is a valuable skill that is taught during the peer tutoring training programs. While each of the six peer tutors that were observed used some form of this strategy, Alice was the tutor who appeared to dig down to the deepest level with her questioning strategies.

After reviewing personal interview transcripts and the recorded tutoring sessions, it was determined that peer tutors frequently rely on using probing question strategies to identify the main topics of discussion for each new synchronous online tutoring session and then based on the tutee responses to those questions the peer tutors use instructional scaffolding to build tutee confidence on each topic. Part of the instructional scaffolding process involves peer tutors introducing a variety of supplementary materials which included notes, files, and textbooks from previous courses as well as some outside web based content. Each of the six peer tutors that was observed used these strategies when it was perceived that the tutee was not comprehending the content being discussed in the synchronous online tutoring environment.

\section{Chapter Four Summary}

Chapter four provided deep explanations of the data collected for this study. The findings for this chapter derived from a review of interviews and observations that were transcribed verbatim. Observations occurred asynchronously through a review of previously recorded synchronous online peer tutoring sessions that took place in WebEx. Multiple themes emerged as the interviews and observations were transcribed and reviewed which included: peer tutoring training, technology training, asking probing questions, using auditory and visual cues, adaptation, preparation, and instructional scaffolding. 
The results for research question one showed that the peer tutors and tutees interacted in a variety of ways depending on each specific peer tutor's strengths and the type of content that was being discussed. An analysis of the data for question two revealed that peer tutors use a variety of questioning techniques along with auditory and visual cues to determine if the tutees comprehend the content. The data analysis for question three revealed that peer tutors effectively used instruction scaffolding techniques from the peer tutoring training to identify areas of confusion, build understanding in small chunks, and to ultimately guide the tutees to content mastery. There were a couple of additional findings that arose during the data analysis phase that did not necessarily fit under any of the three research questions. Those findings presented suggestions for how changes could be made to the online tutoring session scheduling form that would help to increase the level of preparation among the peer tutors for each new synchronous online tutoring session. The peer tutors continue to adapt and find new and better ways to share content and interact with the tutees. 


\section{CHAPTER FIVE: DISCUSSION}

The purpose of this exploratory case study was to gain further insight into experiences of peer tutors who provide synchronous online tutoring services, the types of interactions that occur during the tutoring sessions, the educational strategies the peer tutors use to check for understanding, and what instructional strategy adjustments are made by peer tutors when tutee comprehension appears to be lacking. Findings from this study were intended to provide guidance and support to other institutions of higher education who have developed, are currently developing, or plan to develop similar internal synchronous online peer tutoring programs that rely on the use of video conferencing software. Old Dominion University also hopes to use the findings from this study to improve their synchronous online peer tutoring program.

This study was based on the following central research question and three subquestions. The central research question that guided this study was, "How do peer tutors experience video-based synchronous online tutoring services?"

\section{$\underline{\text { Sub-Questions }}$}

a) How do peer tutors interact with their tutees in the synchronous online tutoring environment?

b) How do peer tutors determine if the tutee comprehends the content being discussed?

c) How do peer tutors change their instructional practices when it is perceived that the tutee does not comprehend the content being discussed? 
Participants in this study included nine current online peer tutors at Old Dominion University. All nine peer tutor participants participated in the semi-structured interviews, however, observational data was only available for six of the nine peer tutor who were interviewed. To preserve the authenticity of the interactions that occur between the peer tutors and their tutees in the synchronous online peer tutoring sessions, observational data was collected by reviewing screen recordings of previous online tutoring sessions. Since Old Dominion University already required all peer tutors to use the WebEx recording feature to record each peer tutoring session, previous recordings of online tutoring sessions between the peer tutors who agreed to participate in this study and their respective tutees were already available provided the tutees agreed to have their session recordings reviewed. The data was coded, analyzed, and organized first by data collection type and then categorically by research question.

Data for this study was collected, coded, analyzed, and organized first by data collection type and then categorically by research question. This chapter provides answers to the research questions in the form of assertions that emerged as the data was collected and analyzed throughout the duration of this study. Limitations for the study, recommendations for practice, and recommendations for future research are also presented in this chapter.

\section{Assertions}

Through a review of the literature and an analysis of the data collected over the course of this study, seven assertions were made. Those six assertions were then aligned to the three research questions that were used to guide this study (see Table 5.1). The 
following section provides more in-depth descriptions of the assertions, alignment to the research questions, and additional evidence to support them.

Table 5.1 Research Questions and Assertions

\begin{tabular}{|c|c|}
\hline Research Question & Assertion \\
\hline $\begin{array}{l}\text { Research Question \#1: How do } \\
\text { peer tutors interact with their tutees in the } \\
\text { synchronous online tutoring environment? }\end{array}$ & $\begin{array}{l}\text { Assertion \#1: Synchronous online } \\
\text { peer tutors communicate with tutees } \\
\text { verbally and visually. } \\
\text { Assertion \#2: Synchronous online } \\
\text { peer tutors interact with their tutees by } \\
\text { asking questions, answering questions, } \\
\text { and describing concepts. }\end{array}$ \\
\hline $\begin{array}{l}\text { Research Question \#2: How do } \\
\text { peer tutors determine if the tutee } \\
\text { comprehends the content being discussed? }\end{array}$ & $\begin{array}{l}\text { Assertion \#3: Synchronous online } \\
\text { peer tutors use various probing questions } \\
\text { to assess tutee understanding. } \\
\text { Assertion \#4: Synchronous online } \\
\text { peer tutors rely on verbal and visual cues } \\
\text { to assess tutee understanding. }\end{array}$ \\
\hline $\begin{array}{l}\text { Research Question \#3: How do } \\
\text { peer tutors change their instructional } \\
\text { practices when it is perceived that the } \\
\text { tutee does not comprehend the content } \\
\text { being discussed? }\end{array}$ & $\begin{array}{l}\text { Assertion \#5: Synchronous online } \\
\text { peer tutors use scaffolding techniques to } \\
\text { improve tutee comprehension. } \\
\text { Assertion \#6: Synchronous online } \\
\text { peer tutors use a variety of supplemental } \\
\text { resources to improve tutee } \\
\text { comprehension. }\end{array}$ \\
\hline
\end{tabular}

Research Question \#1: How do peer tutors interact with their tutees in the synchronous online tutoring environment?

Two assertions were made, based on the results of this study, to explain how peer tutors interact with their tutees in the synchronous online tutoring environment. First, synchronous online peer tutors communicate with their tutees verbally and visually. Second, synchronous online peer tutors interact with their tutees by asking questions, answering questions, and describing concepts. These two assertions are explained in more detail in the following sections. 
Assertion \#1: Synchronous online peer tutors communicate with tutees verbally and visually.

As the number of students taking online courses has continued to grow in recent years, several colleges have started to explore the idea of using internal peer tutors and video conferencing software to offer synchronous online tutoring services as an academic support strategy (Allen et al., 2016; Huang \& Liu, 2015). While online peer tutoring was originally developed to support the growing number of students enrolling in distance education courses and programs, students enrolled in blended and face-to-face courses have begun to take advantage of the services (Huang \& Liu, 2015; Jopling, 2012; Richardson, (2012). Flowers (2007) described online tutoring as a form of personal learning support that occurs between an e-tutor and an e-tutee over the Internet using audio, video, and/or text communication tools. Online peer tutoring that involves peer tutors and tutees communicating with each other in real-time is classified as synchronous peer tutoring. Finkelstein (2006) identified chat rooms, instant messaging, and video conferencing as three of the more common communication tools that are used to during synchronous online interactions.

The synchronous online peer tutoring program at Old Dominion University (ODU) is a good example of a program that was originally designed to support a growing population of students who were enrolling in distance education courses and programs. Although the program was originally intended for online students, since the fall of 2016 it has expanded to offer additional academic support to the entire student body at ODU. The online peer tutoring program at ODU operates through WebEx video conferencing 
technology which offers individual and group text chat features, audio communication, screen sharing capabilities, and video interaction.

All nine peer tutors who participated in the interview portion of this study explained that they rely heavily on the audio communication tools and screen sharing capabilities in WebEx to interact with their online tutees, however only two of the six peer tutors who were observed used the video tools to interact with their tutees and text chat communication was essentially non-existent. When the peer tutors can successfully connect with their online tutees and utilize the communication tools in WebEx, they explained the online peer tutoring sessions generally go well but each of the nine participants that were interviewed described the negative impact technical difficulties with connectivity and communication has had on their online tutoring sessions in the past.

One of the gaps identified by an analysis of the data collected during this study that impacts tutor and tutee interaction in synchronous online peer tutoring sessions involves technical difficulties that interfere with connectivity and communication. While both the peer tutors and their tutees have experienced a variety of connectivity and communication technical difficulties in the past, most of the issues come from the tutees rather than the peer tutors. Currently, tutees who participate in the synchronous online peer tutoring program receive little to no technical support on how to connect to the online tutoring sessions in WebEx or on how to test audio and video to ensure they are working properly before each session begins. The tutees also receive little direction or guidance on what to do when the audio and/or video tools are not working properly. Once a tutee registers for an online peer tutoring session through the MyTutor application in 
the ODU student portal, the tutee receives an auto generated email from WebEx that provides the session sign on information and some very basic directions for getting started. The email suggests that tutees should sign on to the session early to test their audio and video devices, however, the email does not provide any directions on what the tutee should do if their audio and/or video is not working. When connectivity and communication issues occur, the peer tutors are left to troubleshoot the audio and video issues, which is something that is outside of the initial ODU peer tutor training program. Peer tutor \#3 Charley described the negative impact that tutee technical issues have had on his past online peer tutoring sessions. He said,

"I don't know how to go about doing this, but the other problem is getting students online. When we have a 50-minute appointment and they can't get on let's say their appointment is from 10:00 to 10:50 and they can't get on until 10:15 because they are trying to figure out how to connect the audio and video. That's another big challenge."

Valuable tutoring time is lost when the peer tutors must spend time troubleshooting tutee WebEx audio and video connectivity issues. Sometimes, the peer tutors can successfully troubleshoot the connection issues and proceed with the session. Peer tutor \#6 Justin stated that he can fix the audio and video problems most of the time. He said, "You never know, there could be the audio might not work or video. I'm able to fix it every single time except for one time. I couldn't get the video to work." Justin did say that he has experienced audio and video connection issues on his end and on the tutee end in past synchronous online peer tutoring sessions but estimated that he is generally able to fix the issue within the first five minutes of the session. Peer tutor \#9 Vince was another peer tutor who had experienced technical issues during an online peer tutoring session. He described a situation in which the computer in the Distance Tutoring Room 
had technical issues and would not connect to the network. Vince said, "A couple of sessions ago where we had hardware failure. Basically, the computer back there didn't work and wouldn't connect to the network." Rather than spending valuable tutoring time to troubleshoot the network issue, he connected to the scheduled online tutoring session from his personal laptop and used the computer's webcam along with a physical whiteboard to conduct the tutoring session.

Unfortunately, there are other times when the peer tutors are not able to solve the connection problems. Peer tutor \#1 Alice described a situation she had experienced where she was not able to get her microphone to work. She said, "There was one session I didn't think went well only because the audio was on my part the mic was not working, so I had to improvise and use Notepad on the side to type in what I wanted to say." Alice further added, "I'm not sure how well I conveyed the information to the student, but did my best anyway." The technical issue caused Alice to question her own effectiveness during that synchronous online peer tutoring session.

Technical difficulties such as poor audio and video quality and limited bandwidth are two constraints that have been associated with online tutoring programs that rely on synchronous communication technologies (Knipe \& Lee, 2002; Wilkinson \& Hemby, 2000). These technical issues in the synchronous online tutoring environment have been known to cause peer tutors and their tutees increased anxiety (Develotte, Guichon, \& Vincent, 2010). The increased anxiety described by Develotte, Guichon, and Vincent (2010) was like the feelings that Alice described when her audio communication wouldn't work properly causing her to question her own effectiveness. To address the issue, Clancy (1995) and Guichon (2009) stressed the importance of including technical 
troubleshooting and adaptation strategies be a part of the initial peer tutoring training programs. This training described by Clancy (1995) and Guichon (2009) is more training on what to do when I know how to use the technology but some sort of glitch is preventing it from connecting or working.

Peer tutor \#3 Charley and Peer tutor \#8 Tonya offered possible suggestions for addressing connectivity and communication issues like the additional training support that Clancy (1995) and Guichon (20098) discussed. Tonya explained that she always plans to be logged into each online peer tutoring session two to three minutes early to test her own audio and video. She generally walks her tutees through the same processes she uses if audio or video technical issues occur. Charley thought it might be a good idea to develop a brief how-to guide to send to the tutees in the initial appointment notification email. He said,

"Maybe we create some little step-by-step sheet that goes to them (the tutees) in the appointment notification email that says, here's how you get on to WebEx and connect your audio and video real fast because that cuts out of their instructional time."

Implementing the two strategies suggested by Charley and Tonya would assist ODU with addressing the increased anxiety Develotte, Guichon and Vincent (2010) described. Charley felt that the current peer tutors could easily put together a tutorial document like the one he described to share with tutees when they receive confirmation of their scheduled online peer tutoring session.

The significance of this finding is the impact the additional technical support materials could have on increasing the amount of time the online peer tutors spend assisting their tutees with solving problems. In the session that Peer tutor \#3 Charley described, 15 of the 50 minutes allotted for the online peer tutoring session was spent just 
trying to get the tutee connected to the WebEx video conferencing software. Other peer tutors reported having spent up to approximately 10 minutes in previous sessions trying to assist tutees with connecting to WebEx or getting their audio and or video connected. Developing and providing additional technical support documentation like Charley described and recommending logging on and getting started early to test the audio and video connection as Tonya suggested would help to reduce the time lost on troubleshooting tutee technical issues. It would also increase the amount of time available for peer tutors to address their tutee's academic concerns in the synchronous online peer tutoring sessions.

Assertion \#2: Synchronous online peer tutors must receive specific training on how to communicate and interact with their tutees using video conferencing software.

Sansone, Ligorio, and Buglass (2016) studied twelve students who enrolled in a blended university course to determine how the role of e-tutor was performed and perceived. During the study, participants took turns playing the role of an online tutor. The participants identified monitoring and supporting discussions, encouraging everyone to participate, keeping discussions on topic, and guiding progress while reinforcing deadlines as key aspects for playing the role of peer tutor. For peer tutors to effective perform these tasks associated with the role of an online tutor, the peer tutors must be properly trained to actively listen, paraphrase, and communicate with their tutees (Falchikov, 2001).

All ODU peer tutors go through a rigorous peer tutoring program that was developed based on materials obtained from the College Reading and Learning 
Association (CRLA). CRLA, an internationally recognized organization, has led the way in providing guidelines for designing and evaluating peer tutor training programs. The three-tier peer tutor training program established by CRLA requires increasing levels of training and tutoring service. CRLA certifies colleges as Level I, Level II, or Level III based on the amount of training the peer tutors have received on specified topics and the amount of prior tutoring experience by the peer tutors. Level I of the program focuses primarily on communication skills such as active listening and paraphrasing, Level II provides suggestions on how to use probing questions and how to assess changes in study behavior, and Level III includes topics like self-regulated learning, structuring the learning experience, and training and supervising other tutors (Duffey \& Hodges, 2003). ODU has been classified as a Level III program which means that their peer tutors have received a minimum of 30 hours of classroom training and have also provided a minimum of 75 hours of face-to-face peer tutoring services.

While all six peer tutor participants who were observed provided strong, positive examples of the instructional strategies that were presented during the original peer tutoring training sessions, the interviews yielded different results about the peer tutoring training when asked how the program could be improved. Seven of the nine participants who were interviewed indicated that the peer tutoring instructional strategies training they had received was informative and beneficial, however, training on how to successfully tutor online through the WebEx video conferencing software was lacking. More specifically, they felt the portion of the peer tutoring training that was aimed at online tutoring fell short in the areas of understanding how to use the advanced features available in WebEx and how to use the supplemental hardware devices available in the 
Old Dominion University Distance Tutoring Room. Peer tutor \# 5 Jessica and Peer tutor \#8 Tonya were the only two peer tutors who did not specifically mention anything about the need for additional technology related training.

Peer tutor \#1 Alice, Peer tutor \#2 Andrew, Peer tutor \#3 Charley, Peer tutor \# 4 Hannah, and Peer tutor \# 7 Mark each expressed the need for additional WebEx training to be integrated into the peer tutor training program. Andrew, described the shortfalls of the portion of the training that was dedicated to tutoring online and how the lack of meaningful training personally impacted his first online peer tutoring experience when he said,

"We went through a PowerPoint where they had screen shots that said click on this and then click on that and you will have it open (referring to the WebEx video conferencing software). I didn't really ever get my hands on it until my first online peer tutoring session. So, when I went to do it myself, it took me five or six minutes to get into WebEx and so my tutee was just sitting there waiting for me. Then when I got on, I didn't even have a camera, so it was just, it just took so much time to get set up."

Charley provided a similar comment when he said, "They walked us through how to connect to it (WebEx) and stuff like that. A couple little features of it, but it was brief." He further explained, "I think it should have been more emphasized more. I think more time needs to be spent on how to communicate over online and help the students getting connected all of those kinds of issues that we have to tackle."

Justin and Vince discussed the need for additional training support on how to use the supplemental hardware that is provided by Old Dominion University in the Distance Tutoring Room. Justin suggested that, "Maybe some instruction for some of the equipment could be provided, because I just go in there maybe a couple of times a semester which is not enough time to get used to the equipment." Rather than requesting 
training on how to use the supplemental hardware, Vince wanted more training on how to troubleshoot technical issues with the computer or additional hardware that are available.

The need for additional technical training for tutors who use video conferencing software to provide synchronous online tutoring services was also presented in a review of the literature. Kear et al. (2012) described similar comments to those made by Andrew and Charley when reporting the results of a study that was conducted on the same type of synchronous online tutoring program. The program analyzed by Kear et al. (2012) relied utilized the Elluminate video conferencing software rather than WebEx which was used for this study. The study found that while tutors were provided with training videos and handouts on how to interact with tutees via the Elluminate software, several tutors reported that they had to conduct practices sessions with friends or family members before they felt comfortable interacting in the synchronous online tutoring environment. Angelova and Zhao (2016) found that interacting in the synchronous online tutoring environment requires the tutors to possess a new skill set to provide tutees with emotional and technical support along with content knowledge.

The significance of this finding is the impact the additional training could have on increasing the amount of time the online peer tutors spend assisting their tutees with solving problems. More specifically, time on task was lost throughout the five online peer tutoring sessions in which the peer tutors did not know how to help their tutees use the screen share feature on the tutee end. Additional time was lost in other sessions like Peer tutor \#5 Justin's session where he struggled to share printed resources with his tutees. He first attempted to hold the printed materials up in front of his computer's web cam and when that was unsuccessful, he eventually resorted to taking pictures of the content with 
his phone and emailed it to his tutee. Of the six online peer tutoring sessions that were observed, online one of the five peer tutors who conducted those sessions was able to answer all his tutee's questions. Peer tutor \# 7 Mark was the only peer tutor who answered all his tutee's questions. The other five peer tutors each ran out of time before they could address all their tutees needs. Additional training on how to communicate and interact within the WebEx video conferencing software would help to reduce the time off task in the synchronous online peer tutoring sessions.

Research Question \#2: How do peer tutors determine if the tutee comprehends the content being discussed?

Two additional assertions emerged, based on the results of this study, to explain how peer tutors determine if the tutee comprehends the content being discussed in the synchronous online tutoring environment. First, synchronous online peer tutors use various probing questions to assess tutee understanding. Second, synchronous online peer tutors rely on verbal and visual cues to assess tutee understanding. These three assertions are explained in more detail in the following sections.

Assertion \#3: Synchronous online peer tutors use various probing questions to assess tutee understanding.

Herppich, Wittwer, Nuckles, and Renkl (2014) identified using various forms of formative and summative assessment strategies to assess tutee understanding to adapt instruction and enhance learning as an expectation of peer tutors. Formative assessment data is collected by peer tutors throughout the duration of each peer tutoring session and used to adapt instructional practices along the way (Shepard, Hammerness, DarlingHammond, \& Rust, 2005). Unlike formative assessment which is used to improve 
learning as the material is being taught, summative assessment is used to measure student learning at the end of instruction (e.g. Shavelson et al., 2008). As peer tutors interact with their tutees, they ask their tutees questions to determine what is and what is not known (Cromley \& Azevedo, 2005). Responses obtained for the questions asked are used throughout each tutoring session and later after the session has ended to assess tutee understanding.

The six online peer tutors who were observed during this study did not use summative assessment strategies, however, they frequently used five different types of questions throughout each session to formatively assess their tutees. Peer tutors asked a total of 207 questions during the six online peer tutoring sessions that were reviewed. Those 207 questions were broken down into five categories: general questions (103), checking for clarity (73), understanding a process (29), establishing a baseline (16), and defining terms (10).

ODU peer tutors are trained to use a variety of probing questions throughout the tutoring sessions because the peer tutors are supposed to help guide their tutees through understanding concepts rather than simply giving away answers. Peer tutor \#5 Jessica provided a good example of this during her observed synchronous online peer tutoring session. Although her tutee was really struggling to understand what line of code to use to search a computer directory for a certain type of file, Jessica continued to ask a plethora of questions instead of spelling out the line of code that was needed. After asking several questions, she finally said,

"Yes. You're going to have to. You gotta do it (appears to be struggling with what to say). I don't wanna... It's gonna be all in one line, but you're going to have to do two separate things. Does that help? That's as much as I can say (really struggling with trying to help without just giving the tutee the answer)" (38:49). 
Jessica was the only peer tutor out of the six that were observed who had to constantly remind her tutee that she could not simply just give him the answer or tell him what to do step-by-step. While the other five peer tutor participants did not specifically have to remind their tutees that peer tutors are not allowed to give out answers to question or problems, they were all observed using different tactics to assess tutee level of understanding.

As Peer tutor \#4 Hannah and her tutee worked their way through a multiplechoice question on binomial distributions, Hannah's tutee kept throwing out different answers hoping Hannah would verify the correct answer. Instead of giving away the answer, Hannah asked her tutee additional questions when the wrong answer was given. When her tutee said, "I was thinking the answer was D, because it says, no, because the probability of success does not remain the same in all..." (3:58), Hannah responded by asking, "Ok, so what are the rules of a binomial? As far as you understand?" (4:04). The discussion went on for another three minutes before the tutee finally narrowed the answers down to a final answer of $\mathrm{C}$. The tutee entered her answer into the computerbased assignment and began to read the next problem out loud to Hannah. Before Hannah began assisting her tutee with the next problem, she asked, "Ok. Was the answer right by the way?" (7:35) and her tutee responded by saying, "Yea, it was." (7:37).

The significance of this finding is that the training the peer tutors have received on using formative assessment strategies and probing questions appears to have been very successful. During the interviews, Peer tutor \#6 Justin discussed how he uses open-ended questions to assess each tutees level of understanding throughout the course of each peer tutoring session. Peer tutor \#8 Tonya discussed how she asks her tutees additional 
questions to have then explain how each problem was solved rather than simply verifying correct answers. Peer tutor \#3 Charley also described how he uses Excel spreadsheets as a teaching tool and has his tutee explain what is going on in each spreadsheet used. Peer tutor \#5 Jessica was observed using several examples of open-ended questions throughout her online tutoring sessions. Other peer tutors such as Peer tutor \#1 Alice and Peer tutor \#9 Vince effectively used yes or no answer questions to formatively assess tutee understanding. Based on these results, the instructional strategies portion of the current peer tutor training program at ODU yielded positive results.

Assertion \#4: Synchronous online peer tutors rely on verbal and visual cues to assess tutee understanding.

Online peer tutoring can be presented either asynchronously, meaning there is a delay in time between the interactions that occur between peer tutors and their tutees, or synchronously, meaning the interactions occur in real-time. Childs (2012) identified three main drawbacks that have been associated with asynchronous peer tutoring which included added difficulty with explaining certain concepts using only text communication, time delay between when work was submitted, reviewed, and feedback was provided made it difficult to measure progression, and often additional time was needed to further clarify concepts. One strategy for addressing the drawbacks that have been associated with asynchronous online peer tutoring is to use synchronous online communication tools and strategies. Park and Bonk (2007) specifically addressed the benefits of using synchronous video conferencing software such as, the ability to provide immediate feedback, exchange different prospective in real-time, more dynamic 
interactions between peer tutors and their tutees, strengthened social presence, and increased emotional support.

The peer tutors who were observed during this study, took advantage of the audio and video tools that are available in the WebEx video conferencing software to communicate with their tutees in real time. One of the advantages of doing so that emerged from an analysis of the data that was collected for this study was how well the peer tutors could put the active listening and paraphrasing training they had received during the ODU peer tutor training program into action. All nine peer tutors discussed the importance of having a good audio connection during their interviews. When that synchronous audio connection was not available due to technical difficulties like those that were described by Peer tutor \#1 Alice, the peer tutors had to result to text chat or typing out text on some form of a digital whiteboard. While text chat is a synchronous tool, there is a delay between when an initial message is typed, when it is read, and when a response is received. That delay, along with a lack of auditory cues to go off caused Alice to question her own effectiveness at the end of the session where she could not get her audio to work.

Alice was not the only peer tutor who discussed or was observed using audio and video cues to assess tutee understanding. In the two sessions where the web cameras were turned on and active, Peer tutor \#6 Justin and Peer tutor \#9 could not only hear the frustration in their tutees voices when the tutees were struggling to understand concepts, they could see the tutees eyes rolling, hair being pulled, pencils being dropped, and other actions that occurred out of tutee frustration. The peer tutor's ability to not only hear 
audio cues of frustration but to see them as well, helped the two peer tutors know that additional academic support was needed on specific topics.

Unfortunately, not all peer tutors and not all tutees use the video feature available in WebEx. ODU only requires that tutees have access to a computer microphone for communicating and interacting with the peer tutors and the tutees are told they can use the video feature if so desired. Peer tutors are also only required to use the audio communication tools, however, ODU highly recommends that peer tutors try to use the video tools as much as possible to make the synchronous online peer tutoring sessions more personalized. Alice and Peer tutor \# 4 Hannah both explained that they do not feel comfortable with using the video tools, therefore, they both choose not to use that option. Peer tutor \#3 Charley did not specifically state if he uses the video tools or not, but he did mention that he still struggles to determine if his online tutees understand the content he presents through verbal communication.

The significance of this assertion is that audio communication played a vital role in the peer tutors being able to assess tutee understanding in the synchronous online tutoring environment. It is important for institutions who choose to implement a similar synchronous online peer tutoring program to ensure the technology provided for peer tutors to use to provide online peer tutoring services is kept in working order and that some form of technical support is available to assist the peer tutors with the audio is not working. While video communication did add some additional benefits for assessing tutee understanding and ODU makes the technology tools available for the peer tutors to use the video feature available, tutees might not always have access to video communication tools. Video communication tools are not as cheap and easy to obtain as a 
computer microphone is, which is why ODU continues to only require peer tutors and their tutees to have access to audio tools.

Research Question \#3: How do peer tutors change their instructional practices when it is perceived that the tutee does not comprehend the content being discussed?

Two final assertions were made, based on the results of this study, to explain how peer tutors change their instructional practices when it is perceived that the tutee does not comprehend the content being discussed in the synchronous online tutoring environment. First, synchronous online peer tutors use scaffolding techniques to improve tutee comprehension. Second, synchronous online peer tutors use a variety of supplemental resources to improve tutee comprehension. These three assertions are explained in more detail in the following sections.

Assertion \#5: Synchronous online peer tutors use scaffolding techniques to improve tutee comprehension.

MacDonald (2000) found that peer tutors should be equipped and prepared with a variety of effective instructional strategies for peer tutoring sessions to be successful. One example of the instructional strategies that MacDonald (2000) described is scaffolding. Scaffolding is a process where peer tutors assess their tutees prior knowledge, remove more difficult tasks, and incrementally provide more challenging information until tutee understanding increases and independent mastery is achieved (Wood, Bruner, \& Ross, 1976; Vygotsky, 1978). Chi and Roscoe (2008) found that tutors who are generally more knowledgeable about the academic content being discussed support and direct the learning process through active scaffolding, questioning, and explaining during the tutoring sessions. 
Peer tutor \#1 Alice, Peer tutor \#2 Andrew, Peer tutor \#4 Hannah, Peer tutor \#6, and Peer tutor \#9 were all discussed using various scaffolding techniques during their interviews. Alice uses staggered if/then statements to improve tutee comprehension. She transforms more difficult topics into a series of if statements and as her tutees successfully address each statement she moves on to more difficult topics and tasks. Andrew explained how he talks to his tutees to establish what information is known and what is unknown in the beginning to walk his tutees through the unknown step by step. He usually asks the tutees to try and explain each step in their own words before offering additional academic assistance. Hannah starts by having her tutees try to self-identify what specific steps he or she is having trouble with. Justin talked about how he begins reviewing each topic by having his tutees recall and explain what they can remember was presented in class for each topic. Once Justin's tutees have shared all they can recall from class, he then has then gives them practice problems based on the topics discussed and asks his tutees to apply the concept and explain their approach. Tonya also gives her tutees practice problems and has her tutees talk through the problems until they achieve mastery. However, Tonya likes to take it a step further by giving a second similar practice problem to ensure each concept discussed is understood by her tutees.

Scaffolding, like the use of probing questions previously presented in Assertion \#3, is something that is presented in the ODU peer tutor training program. While scaffolding is a strategy that is use by peer tutors to provide in-person and/or online tutoring services, identifying academic gaps in the synchronous online tutoring environment can bring about additional difficulties and complications. The main difficulty that emerged from an analysis of the interview and observation data collected 
for this study was the challenges that came about when peer tutor did not know how to help their tutees use the WebEx screen sharing feature. Peer tutor \#5 Jessica was the only peer tutor who knew how to help her tutee share his screen. As a result, she could observe her tutee as he entered different lines of computer programming code into a software tool he was using to solve coding problems. Rather than telling her tutee if his approach was right or wrong, she would tell him to test out his theory to see what the response would be. When an invalid or incorrect response was returned, she would give him additional information to consider and test.

The other five peer tutors who were observed did not know how to help their tutees use the WebEx screen sharing feature. Therefore, they could not visually assess if their tutees were following the correct process to solve the problems being discussed. Peer tutor \#6 Justin attempted to have his tutee use her computers web cam to share her work via the WebEx video feature, however, he and his tutee both struggled to comprehend information that was share through that process.

The significance of this finding is that the training the peer tutors have received on scaffolding as an instructional strategy for improving comprehension appears to have been successful, however, the process could be improved by providing the peer tutors with additional WebEx training on how to have tutees share their screens. Wu, Lin, and Yang (2013) found the ability to support real-time interaction and feedback along with social presence that involves audio, video, and text to be a benefit of synchronous online tutoring sessions that are conducted using video conferencing software. Unfortunately, some of that benefit is lost when the peer tutors do not know how to help their tutees use the screen sharing features that are available through video conferencing software. 
Valuable tutoring time was lost throughout the course of Justin's observed online peer tutoring session as he and his tutee struggled to find a good way to share information with each other. Providing the peer tutors with some additional training on how to take advantage of all the screen sharing features in WebEx would allow peer tutors to spend more time helping their tutees to solve academic problems rather than losing time trying to figure out how to share and receive information.

Assertion \#6: Synchronous online peer tutors use a variety of supplemental resources to improve tutee comprehension.

Three main criteria are most commonly used for selecting students to serve as peer tutors ("International Tutoring Training Program Certification Requirements", 2015). First, the student must currently be a student at the same academic institution for which he or she is applying to be a peer tutor. Second, the peer tutors must have already successfully completed the academic courses for which they will be providing tutoring services. Third, the student must be recommended by a campus faculty or staff member. Additionally, the College Learning and Readiness Association (CRLA) guidelines also state that the peer tutors should have at least a 3.0 Grade Point Average (GPA) and that they must go through an interview or application process with the coordinator or supervisor of the peer tutoring program (Deese-Roberts, 2003). All nine peer tutors who participated in this study met these criteria.

The importance of these criteria was that the students who serve as peer tutors were students at the same college as their tutees and had already completed the same courses with many of the same professors that the tutees were seeking help with. As a result, peer tutors had access to a plethora of supplemental resources from the previous 
courses such as textbooks, handouts, released test questions and external websites along with additional insight into each specific professor's teaching habits and expectations. Peer tutor \#8 talked about the benefits that come from using internal students as peer tutors in an online peer tutoring program when she said,

"I do like what ODU has done, because a lot of times the tutors have taken that course here, at this school, so they kind of understand how the test might be formatted or what are certain professors looking for. So, for the classes that I am helping them (referring to the tutees) with, I mean, obviously, I've been through it, so it's like I kind of understand like you know some information they'll introduce to them and then like I see some tutees are like stressing over it and I'm like it's not that they're really gonna focus on that, so that's like something you don't really like need to pay too much attention to. Whereas, if I am tutoring someone from outside of ODU, I would not know what their professor is looking for and would not know what to really expect."

Tonya was not the only peer tutor who talked about the benefits of using internal peer tutors in the program. Peer tutor \#4 Hannah said, "it would be difficult to have an outside tutor who was not familiar with ODU." She continued to say that, "A lot of the time in know the professiors and then if not, I learn about those professors because a lot of students come in to get help for the same course with the same professors, so you learn a lot about their teaching styles."

Peer tutor \#2 Andrew also talked about the benefits of using internal peer tutors in the synchronous online peer tutoring program. Andrew said, "It definitely puts some familiarity in there and makes you relatable kind of like oh, you go to ODU and I go to ODU and you go through the same classes I have gone through." He went on to say, "If I had some random tutor not from ODU they could help me with physics, but they don't know ODU physics specifically, so there is definitely a sense of comfort for the tutees."

The comfort that Andrew described is one of the benefits associated with peer tutoring that has been documented in previous research. Poellhuber, Chomienne, and 
Karsenti (2008) found that relationships are formed as peer tutors begin to interact with their tutees and those relationships are initially responsible for determining the success of peer tutoring sessions. Cobb (2000) explained that those relationships that have been built upon trust and mutual respect have resulted in higher levels of cooperation and ultimately have been linked to overall success of peer tutoring programs. When those close relationships between peer tutors and their tutees are not formed, Lazerson (1980) found that there is an increased chance that the tutees will fail to progress.

The significance of this finding is that while the peer tutors had all received training on topics such as role modeling, communication skills, active listening and paraphrasing, and identifying and using resources, ultimately a lot of what was responsible for the formation of the relationships discussed in the literature came from each individual peer tutors' unique personality and lived experiences. the training the peer tutors have received on using formative assessment strategies and probing questions appears to have been very successful. Connections that were forged between the peer tutors and their tutees stemmed from the fact that both parties were students at the same institution of higher education taking the same classes with the same instructors. As a result, the peer tutors could help their tutees identify possible test questions, course specific supplementary resources such as websites, old textbooks, and previous course notes, along with some specific study habits that might be beneficial. Based on these results, the students who have been selected by ODU to serve as peer tutors have succeeded in forming the initial relationships which have been presented in the literature. 


\section{Limitations}

Four main limitations emerged over the course of this study. According to Leedy and Ormrod (2010), limitations are potential weaknesses in a study that cannot be controlled by the researcher. The limitations which were encountered during this study were the number of online peer tutoring sessions that are scheduled and that occur, the number of peer tutors who provide online peer tutoring services, the willingness of tutees to participate in the study, and issues with WebEx recordings of each online peer tutoring session.

$\underline{\text { Scheduled Synchronous Online Peer Tutoring Sessions That Occur }}$

According to statistical data that was compiled and released by Old Dominion University Peer Educator Program administrators, out 62 online peer tutoring sessions that were scheduled during the Spring 2017 semester, only 28 or $45 \%$ of those sessions occurred. The number of scheduled online peer tutoring sessions grew to 197 in the fall of 2017 and of those 197 sessions that were scheduled only 32 or $16 \%$ occurred. There is no clear data available that explains why so many students take time to register for online peer tutoring sessions but to not bother to show up for the scheduled appointments. Old Dominion University does have a no-show policy in place to try to reduce the number of no shows that occur each semester. According to the Peer Educator Program Tutoring Guidelines, Policies, and Procedures document that is posted on the Old Dominion University Peer Educator Program website, students who do not show up at all for the scheduled sessions or who are more than 15 minutes late are considered no-shows. Session cancellations that are made less than two hours before the scheduled appointment are also considered no-shows. If students miss more than two MyTutor scheduled 
appointments within 30 days, they are barred from registering for future appointments. If scheduling privileges have been suspended, then those students are required to contact and meet with the Director or Assistant Director of the Peer Educator Program before the privileges can be reinstated.

Although Old Dominion University has instituted the strict no-show policy, students continue to register for synchronous online peer tutoring appointments but fail to show up for the scheduled sessions. Based on the data previously shared for the Spring and Fall 2017 semesters, only 60 total online peer tutoring sessions occurred during that time-span. IRB approval for this study was not granted until April of 2017, which was two weeks before the last day students were able to schedule online peer tutoring appointments for the Spring 2017 academic semester. Therefore, of the 60 online sessions that occurred, approximately 28 of them were not eligible to be included in this study, which left only about 32 sessions that were available. That number was further reduced when repeat customers were accounted for in the statistical data. During the Spring 2017 semester, online tutoring services were provided to 16 unique students. There were 26 unique students who were participated in online peer tutoring services during the Fall 2017 semester. That means that of the 28 online tutoring sessions that occurred in Spring 2017, 12 of those were repeat customers and of the 32 that occurred in Fall 2017, six of those were repeat customers. After accounting for the date in which IRB approval was granted, when that date fell in line with the Old Dominion University Peer Educator Program Academic Calendar, and eliminating the repeat customers, approximately only 26 online tutoring sessions were available to possibly use as observations. 


\section{The Number of Peer Tutors Who Provide Online Peer Tutoring Services}

According to the same statistical report that was described in the previous limitation section on scheduled online peer tutoring sessions that occur, a total of nine different peer tutors provided online peer tutoring services in the spring of 2017. That number grew to thirteen different peer tutors who provided online peer tutoring services in the fall of 2017. All nine peer tutors who provided online tutoring services in the spring of 2017 agreed to participate in this study and were interviewed in April 2017.

Since the semi-structured interview occurred in April 2017, two of the original nine participants have left the peer tutoring program to pursue other employments in their fields of study. One of those peer tutors, Andrew, had just started providing online peer tutoring services at the beginning of January 2017. During the Spring 2017 semester, he only conducted one online peer tutoring session, which had occurred prior to the interview in April. So, that session was not eligible. Andrew did not provide peer tutoring services during the summer of 2017 and he later decided to leave the peer tutoring program at the beginning of the semester in the fall of 2017. So, he only provided one single online peer tutoring session throughout his tenure as a peer tutor at Old Dominion University. As a result, an online peer tutoring session recording was not able to be obtained for Andrew. Alice was the other tutee who decided to leave the program in the fall of 2017. Although the window of time was short between then the interviews occurred and when Alice left the program, one of her tutees gave his permission to participate in this study. So a recording was able to be analyzed for Alice.

Six new peer tutors were added to the online peer tutoring program at Old Dominion University in the fall of 2017. Two of those six filled the positions that were 
previously left vacant by Alice and Andrew and the other four expanded the total number of online peer tutors from the original nine to thirteen. The additional six peer tutors who were added to the program between the spring and fall of 2017 were not asked to participate in this study. The primary reason the additional peer tutors were not asked to participate is because peer tutoring training occurs during the summer semesters at Old Dominion University. That means the new peer tutors were trained after the original interviews took place in April 2017. The peer tutoring training had also been modified for improvements from what the original nine participants had received. Therefore, to maintain integrity of the study, the new peer tutors were not added. The Willingness of Tutees to Participate in The Study

The third limitation for this study was the willingness of tutees to participate in the study. Recordings could be obtained for six of the nine peer tutors that were initially interviewed at the beginning of this study. Permission for recordings from one of Hannah's and one of Mark's tutees was granted in May 2017, permission was granted from Alice's tutee in July 2017, permission was granted from Justin's tutee in September 2017, permission from one of Jessica's tutees and one of Vince's tutees was granted in October 2017. As of the end of October 2017, permission to view recordings for Andrew, Charley, and Tonya had not been granted. By that time, Andrew had already resigned from his peer tutoring position having only conducted one online per tutoring session. While Charley and Tonya both continued to conduct online peer tutoring sessions throughout the Fall 2017 semester multiple attempts to recruit their tutees for the study fell short. Despite bi-weekly request for participation emails that were sent out directly to tutees that Charley and Tonya by the Director of the Peer Educator Program at Old 
Dominion University yielded zero results. Those email messages were sent to the tutees @ odu.edu email account. Unfortunately, there is no way of knowing if the tutees who were emailed check their official student email accounts on a regular basis.

Issues with Webex Recordings of Online Peer Tutoring Sessions

The Old Dominion University Peer Educator Program administrators require peer tutors to record all synchronous online peer tutoring sessions using the recording feature that is available through the WebEx video conferencing software. However, the peer tutors must remember to manually click on the record button at the beginning of each online tutoring session in order for the session to be recorded and archived. Sometimes the peer tutors forget to push the record button until part way through the tutoring and sometimes the record button does not get pushed at all. Once the WebEx software finalizes each recording, the system automatically sends an email to the peer tutor with a URL that is used to access the recording. The peer tutors then must remember to forward the email messages that contain the access information for the WebEx recordings to the Peer Educator Program administrators. No data was provided by Old Dominion University on the number of online peer tutoring sessions that occurred but were not recorded. At least four students from Old Dominion University completed the electronic request for participation form, however, the Peer Educator Administrators were not able to find any recordings from those four students.

\section{Recommendations for Practice}

Overall, the peer tutors who chose to participate in this study were excited to know that additional research was being done to see how the current online peer tutoring program at Old Dominion University might be improved. They were also excited to know 
that this research would be shared with other intuitions that might be considering starting a similar synchronous online peer tutoring program or who have already implemented a similar program and might be looking to improve their current practices. All nine peer tutors were anxious to hear more about the results of this study to help improve their own tutoring practices.

While the researcher who conducted this study had no direct contact with the tutees who were observed, at the end of each synchronous online peer tutoring session that was reviewed, the tutees could be heard thinking the peer tutors for their time and verbally expressing their satisfaction for the services that were provided. At the end of all but one session, the tutees discussed setting up future appointments with the same peer tutors they received tutoring services from. The tutees expressions of gratitude and desire to seek out additional services in the future came even when the peer tutors were not able to address every concept or topic the tutees were seeking help with. This further demonstrates the importance of the early forming of personal connections and relationships between the peer tutors and their tutees in the synchronous online peer tutoring environment.

Two main findings were identified because of this study that need to be taken into consideration when developing or revising similar synchronous online peer tutoring programs. First, additional technical training is needed for both the peer tutors and their tutees. The peer tutors need to be trained on how to take advantage of the more advanced features available through the WebEx software such as how to have tutees use the screen sharing feature, how to use the supplementary hardware tools that are provided, and what virtual whiteboard options exist. The tutees need additional technical tutorials to provide 
extra assistance when trying to log into WebEx and getting their computer audio connected. Second, additional technical support options are needed for peer tutors who experience problems with hardware tools not working properly. Addressing these two main concerns would decrease peer tutor and tutee frustration and allow for more time to be spend on addressing and solving academic needs as opposed to troubleshooting communication and technology issues.

\section{Recommendations for Future Research}

Recommendations for future research related to the information presented in this study are based upon a review of the literature in Chapter two, limitations that were presented in Chapter three, and the results of the data analysis from Chapter four. The following section provides ideas for suggestions for additional studies on the topic of synchronous online peer tutoring programs that use video conferencing technology.

a) Based on suggestions provided by the peer tutor participants in this study, additional studies could be developed to further explore how synchronous online peer tutoring sessions require different approaches from one subject area to the next. For example, a similar study could be developed to compare and contrast different approaches computer science or engineering majors take when providing synchronous online peer tutoring.

b) Another suggestion would be to integrate the online peer tutoring satisfaction survey data that is currently being collected by the Peer Educator Program administrators at Old Dominion University to transform this qualitative study into a mixed methods approach. 
c) A final recommendation would to make the suggested changes to the online portion of the online portion of the peer tutor training program, have the current peer tutors complete the revised version of the training program, and then re-interview and conduction additional observations to how the changes impact peer tutor and tutee communication and interaction.

\section{Summary and Conclusion}

The purpose of this study was to describe the lived experiences of peer tutors who provide synchronous online peer tutoring services via video conferencing technology. Using an exploratory case study approach, this qualitative study sought to answer three research sub-questions aimed at describing how peer tutors interact with their tutees, how the peer tutors assess tutee understanding, and how the peer tutors address perceived areas of confusion with their tutees in the synchronous online peer tutoring environment.

\section{Perceptions Associated with Peer Tutor Training}

The first major finding of this study was that peer tutor communication and interaction with tutees differs based on individual peer tutor academic and technical skill sets. Through lived-experiences, each of the six peer tutors who were observed in this study have learned to adapt to make up for shortcomings that were identified in the online portion of the peer tutor training program. While there are some improvements that can be made to the current peer tutoring training program like showing the peer tutors the different options that are available for sharing printed materials, digital whiteboards, and tutee screen sharing, no two peer tutors are going to tutor the same way. Like college professors who teach the same courses in higher education, every teacher has his or her unique way of communicating, interacting, instructing, reinforcing, and remediating 
students. Peer tutors have their own personal preferences for carrying out the responsibility of tutoring other students. Personality influences and adaptations are not something that can be taught. Instead, they are developed over the course of a peer tutors entire school career. The primary goal for the online portion of the peer tutoring program should be to demonstrate all the feature that are available inside of the WebEx software and from the external hardware devices that are available in the Distance Tutoring Room and then have the peer tutor use their personal preferences to determine what tools to use and how they want to use them.

Increasing Technical Support for Peer Tutors and Their Tutees

The second major finding was the need for additional technical support for peer tutors and their tutees to be provided. All too often, the peer tutors find themselves having to troubleshoot technical issues with their own technology or with the audio and video technology of their tutees. Rather than spending valuable tutoring time trying to solve hardware connection issues, peer tutors and tutees need to be provided with additional technical support such as step-by-step how to guides on how to address the frequent connectivity problems and possibly a technical support hotline. This would allow the peer tutors to focus the teaching aspect of online tutoring rather than how to fix broken issues. A conclusion that can be drawn from this finding is that any higher education who already has or plans to institute a similar online peer tutoring program in the coming years needs to have some sort of plan in place for addressing technical issues that occur with peer tutors and their tutees. 


\section{$\underline{\text { Improving Scheduling and Preparation for Peer Tutors }}$}

The third and final major finding was that the peer tutors are spending a good deal of time in the beginning of each peer tutoring session just trying to figure out exactly what each tutee needs assistance with. Like the conclusion that was drawn from the technical support section above, institutions implementing synchronous online peer tutoring programs need to find ways to better assist the peer tutors with being prepared for each tutoring session. Students are required to register for each peer tutoring session many hours in advance. Rarely do programs who offer online peer tutoring services allow their students to register for immediate tutoring sessions. Generally, there is at least a two hour or more delay between the time a student registers for an online peer tutoring session. During that time, the peer tutors could spend time preparing a plan and organizing resources for their upcoming tutoring session. Requiring potential tutees to complete the additional information on the online peer tutoring session registration form and allowing for the attachment of images, documents, and other files would be a step in the right direction.

While the results of this study identified changes that need to be made in the online portion of the peer tutor training program, increased technical support, and improved scheduling and preparation for peer tutors as possible areas of improvement, ultimately the synchronous online peer tutoring sessions appeared to be successful. In all six synchronous online peer tutoring sessions that were reviewed, the tutees who participated in those sessions were heard thinking the peer tutors for their time and the help that was provided. All the tutees were also heard discussing the scheduling of additional online peer tutoring sessions soon. Data collected during the interviews and the 
observations revealed that all nine peer tutors were very passionate about the role they serve in as peer tutors and helping other achieve academic success was a common passion shared by all participants in this study. 


\section{REFERENCES}

ACT Inc. (2011). The condition of college and career readiness. Iowa City, IA: ACT.

Adelman, C. (2005). Educational "anticipations" of traditional age community college students: A prolegomea to any future accountability indicators. Journal of Applied Research in the Community College, 12(1), 93-107.

Agar, M. A. (1980). The professional stranger. New York, NY: Academic Press.

Allen, H. B. (1971). Principles of informant selection. American Speech, 46, 47-51.

Allen, I. E., Seaman, J., Poulin, R., \& Straut, T. T. (2016). Online report card. Tracking Online Education in the United States. Babson Survey Research Group and Quahog Research Group.

Almarzouqi, I., \& Mynard, J. (2006). Investigating peer tutoring. ELT Journal, 60(1), 1322. doi: $10.1093 /$ elt/cci077

Amos, J. (2011). Saving now and saving later: How high school reform can reduce the nation's wasted remediation dollars. Alliance for Excellent Education, 11(10), 110.

Anderson, C. (1997). Enabling and shaping understanding through tutorials. The Experience of Learning, 2, 184-197.

Anderson, T. (2008). Is videoconferencing the killer app for $\mathrm{k} 12$ distance education?. International Journal of E-Learning \& Distance Education, 22(2), 109-124.

Angelova, M., \& Zhao, Y. (2016). Using an online collaborative project between American and Chinese students to develop ESL teaching skills, cross-cultural awareness and language skills. Computer Assisted Language Learning, 29(1), 167-185. 
Angrosino, M. V. (2007). Doing ethnographic and observational research. Thousand Oaks, CA: Sage.

Annis, L. F. (1983). The processes and effects of peer tutoring. Human Learning, 2(1), $39-47$.

Arendale, D. (1994). Understanding the supplemental instruction model. In D. Martin \& D. Arendale (Eds.), Supplemental instruction: Increasing achievement and retention (pp. 11-21). San Fransisco, CA: Jossey-Bass.

Armstrong, K. J., Arnold, K. D., \& Lu, E. C. (2012). The ecology of college readiness: ASHE Higher Education Report. New York, NY: Wiley.

Ashman, A. F., \& Elkins, J. (1990). Co-operative learning among special students, In H.C. Foot, M. J. Morgan, \& R. H. Schute (Eds.), Children helping children. London: John Wiley.

Astin, A. (1993). What matters in college? Four critical years revisited. San Fransisco, CA: Jossey-Bass.

Astin, A. (1998). The changing American college students: Thirty-year trends, 19661996. Review of Higher Education, 21, 115-135.

Bailey, T. (2009). Challenge and opportunity: Rethinking the role and function of developmental education in community college. New Directions for Community Colleges, 2009(145), 11-30.

Bailey, T., Jeong, D. W., \& Cho, S. W.(2010). Referral, enrollment, and completion in developmental education sequences in community colleges. Economics of Education Review, 29(2), 255-270.

Bandura, A. (1977). Self-efficacy: Toward a unifying theory of behavioral change, Psychological Review, 84, 191-215.

Bandura, A. (1986). Social foundations of thought and action: A social cognitive theory. Englewood Cliffs, NJ: Prentice-Hall.

Bandura, A. (1988). Self-efficacy conception of anxiety. Anxiety Research, 1(2), 77-98.

Bandura, A. (1997). Self-efficacy: The exercise of control. New York, NY: Freeman. 
Barefoot, B. O., Gardner, J. N., \& Upcraft, M. L. (2004). Challenging and supporting the first-year student: A handbook for improving the first year of college. Indianapolis, IN: Jose-Bass.

Barron, A., Barros, C.,Hilbelink, A., Hogarty, M. V., Hohlfeld, T., Kromrey, J., Loggie, K., \& Schullo, S. (2005). Synchronous E-Learning: Analyzing teaching strategies. In C. Crawford, R. Carlsen, I. Gibson, K. McFerrin, J. Price, R. Webeer, \& D.A. Willis (Eds.) Proceedings of Society for Information Technology \& Teacher Education International Conference, 2005, 3060-3067. Chesapeake, VA: AACE.

Barton-Arwood, S., Jolivette, K., \& Massey, N. (2000). Mentoring with elementary-age students. Intervention in School \& Clinic, 36(1), 36-39.

Baxter, P., \& Jack, S. (2008). Qualitative case study methodology: Study design and implementation for novice researchers. The Qualitative Report, 13(4), 544-559.

Bean, J., \& Eaton, B. S. (2001). The psychology underlying successful retention practices. Journal of College Student Retention: Research, Theory and Practice, 3, 73-89.

Bell, A. (1797). An experiment in education, made at the Male Asylum of Madras. Edinburgh: Cadell \& Davies.

Bell, A. (1808). The Madras School or elements of tuition: Comprising the analysis of an experimental in education, Made at the Asylum, Madras. London: T. Bensley, Bolt Court.

Berg, G. A. (2009). Cases on online tutoring, mentoring, and educational services: Practices and Applications. Hershey, NY: Information Science Reference.

Berliner, D. C. (2001). Learning about and learning from expert teachers. International Journal of Educational Research, 35(5), 463-482.

Berliner, D. C. (2004). Describing the behavior and documenting the accomplishments of expert teachers. Bulletin of Science, Technology \& Society, 24(3), 200-212.

Bernard, H. R. (2002). Research methods in anthropology: Qualitative and quantitative methods. (3rd ed.). Walnut Creek, CA: AltaMira Press. 
Beth-Marom, R., Saporta, K., \& Caspi, A. (2005). Synchronous vs. asynchronous tutorials: Factors affecting students' preferences and choices. Journal of Research on Technology in Education, 37(3), 245-262.

Bettinger, E. P., \& Long, B. T. (2009). Addressing the needs of underprepared students in higher education does college remediation work?. Journal of Human Resources, 44(3), 736-771.

Bettinger, E. P., Boatman, A., \& Long, B. T. (2013). Student supports: Developmental education and other academic programs. The Future of Children, 23(1), 93-115.

Biddle, B. J. (1986). Recent developments in role theory. Annual Review of Sociology, 12(1), 67-92.

Biddle, B. J. (2013). Role theory: Expectations, identities, and behaviors. New York, NY: Academic Press.

Biggs, J. B. (2011). Teaching for quality learning at university: What the student does. United Kingdom: McGraw-Hill Education.

Black, P., \& Williams, D. (2009). Developing the theory of formative assessment. Educaitonal Assesstmen, Evaluation and Accountability, 21, 5031. Doi: 10.1080/0969595980050102

Blackie, J. (2004). Bell, Andrew (1753-1832). In R. Fox (Ed.), Oxford dictionary of national biography (pp. 900-905). United Kingdom: Oxford University Press.

Blanc, R. A., DeBuhr, L. E., \& Martin, D. C. (1983). Breaking the attrition cycle: The effects of supplemental instruction on undergraduate performance and attrition. Journal of Higher Education, 54(1), 80-90.

Bloom, B. S. (1984). The 2 Sigma problem: The search for methods of group instruction as effective as one-to-one tutoring. Educational Researcher, 13(6), 4-16.

Bonk, C.J., \& King, K. S. (1998). Computer conferencing and collaborative writing tools: Starting a dialogue about student dialogue. In C. J. Bonk, \& K. S. King (Eds.), Electric collaborators: Learner-centered technologies for literacy, apprenticeship, and discourse (pp. 3-23). Mahwah, NJ: Erlbaum. 
Bowman-Perrott, L., Davis, H., Greenwood, C., Parker, R., Vannest, K., \& Williams, L. (2013). Academic benefits of peer tutoring: A meta-analytic review of single case research. School Psychology Review, 42(1), 39-55.

Bowyer-Bower, F. B. (1954). A pioneer of army education: The Royal Military Asylum, Chelsea, 1801-1821. British Journal of Educational Studies, 2(2), 122-132. doi: 10.1080/00071005.1954.9972916

Boyatzis, R. E. (1998). Transforming qualitative information: Thematic analysis and code development. Thousand Oaks, CA: Sage.

Boylan, H. (2002). What works: Research-based best practices in developmental education. Boone, NC: Apalachian State University. National Center for Developmental Education.

Boylan, H. R., Bliss, L. B., \& Bonham, B. S. (1997). Program components and their relationship to student performance. Journal of Developmental Education, 20(3), $2-8$.

Branon, R. F., \& Essex, C. (2001). Synchronous and asynchronous communication tools in distance education: A survey of instructors. TechTrends, 45(1), 36-42.

Bray, M., Farlowe, A., \& Shumow, L. (2002). Tutoring- higher education. Retrieved from http://education.stateuniversity.com/pages/2516/Tutoring.html

Breuch, L. A. M. K., \& Racine, S. J. (2000). Developing sound tutor training for online writing centers: Creating productive peer reviewers. Computers and Composition, 17(3), 245-263.

Bridges, B. K., Buckley, J. A., Hayek, J. C., Kinzie, J., \& Kuh, G. D. (2011). Piecing together the student success puzzle: Research, propositions, and recommendations, ASHE Higher Education Report, 116. Hoboken, NJ: John Wiley \& Sons.

Britto, M., \& Rush, S. (2013). Developing and implementing comprehensive studeny support services for online students. Journal of Asynchronous Learning Networks, $17(1), 29-42$. 
Burmeister, S. (1995). The challenges of supplemental instruction (SI): Improving student grades and retention in high risk courses. In M. Maxwell (Ed.), From access to success: A book of readings on college developmental eduaction and learning assistance programs (pp. 209-214). Clearwater, FL: H \& H Publishing.

Burns, M. (2006). Improving student writing through e-mail mentoring. Learning \& Leading with Technology, 33, 38-43.

Burns, S., Cunningham, J., \& Foran-Mulcahy, K. (2014). Asynchronous online instruction: creative collaboration for virtual student support. CEA Critic, 76(1), 114-131.

Cao, Q., Griffin, T. E., \& Bai, X. (2009). The importance of synchronous interaction for student Satisfaction with course web sites. Journal of Information Systems Education, 20(3), 331-339.

Chaney, B. W. (2010). National evaluation of student support services: Examination of student outcomes after six years. Final Report. Office of Planning, Evaluation and Policy Development, US Departmetn of Education.

Charmaz, K. (2006). Constructing grounded theory: A potential guide through qualitative analysis. Thousand Oaks, CA: Sage.

Chediak, M. (2005). Online tutoring part of growing trend market for web education matures. Washington Post. Retrieved from http://www.smarthinking.com/static/aboutUs/newsAndEvents/articles/prestart104 .$c f m$.

Chen, N., Chen, Y., \& Tsai, C. (2009). The use of online synchronous discussion for web-based professional development for teachers. Computers \& Education, 53, 1155-1166.

Chen, N. S., Wang, Y., Wu, P. J., \& Levy, M. (2008). Developing a pedagogically meaningful e-tutor training program for cyber face-to-face language teaching. In 2008 Eighth IEEE International Conference on Advanced Learning Technologies (pp. 361-365). IEEE. 
Chen, X. (2016). Remedial coursetaking at US public 2-and 4-year institutions: Scope, experiencing, and outcomes. Statistical Analysis Report. NCES 2016-405. National Center for Education Statistics.

Chen, X., Tasoff, S., \& Wu, J. (2010). Academic preparation for college in the high school senior class of 2003-04, (NCES 2010-169). Washington, DC: US Department of Education.

Chi, M. T. H. (2006). Two approaches to the study of experts' characteristics. In A. Ericsson, N. Charness, P. Feltovich, \& R. Hoffman (Eds.) The Cambridge handbook of expertise and expert performance (pp. 21-30). New York, NY: Cambridge University Press.

Chi, M., \& Roscoe, R. D. (2007). Understanding tutor learning: Knowledge-building and knowledge-telling in peer tutors' explanations and questions. Review of Educational Research, 77, 334-374.

Chi, M., \& Roscoe, R. D. (2008). Tutor learning: The role of explaining and responding to questions. Instructional Science, 36, 321-350.

Childs, M. (2012). E-tutoring in synchronous and asynchronous environments. Interactions Journal, 20(3). Retrieved from: https://www2.warwick.ac.uk/services/ldc/resource/interactions/issues/issue20/chil ds/

Clancey, W. J. (1995). A tutorial on situated learning. In: J. S. (Ed.), Proceedings of the International Conference on computers and education (pp. 49-70). Charlottesville, VA; AACE

Cobb, J. B. (2000). Listening within the social contexts of tutoring: Essential component of the mentoring relationship. International Journal of Listening, 14(1), 94-108.

Cohen, P. A., Kulik, J. A., \& Kulik, C. C. (1982). Educational outcomes of tutoring: A meta-analysis of findings. American Educational Research Journal, 19(2), 237248.

Corrigan, J. A. (2012). The implementation of e-tutoring in secondary schools: A diffusion study. Computers \& Education, 59(3), 925-936. 
Creswell, J. W. (2012). Qualitative inquiry and research design: Choosing among five approaches. Los Angeles, CA: Sage.

Creswell, J. W. (2013). Qualitative inquiry and research design (3rd ed.). Thousand Oaks, CA: Sage.

Creswell, J. W., \& Clark, V. L. P. (2011). Designing and conducting mixed method research (2nd ed.). Thousand Oaks, CA: Sage.

Cromley, J. G., \& Azevedo, R. (2005). What do reading tutors do? A naturalistic study of more and les experienced tutors in reading. Discourse Processes, 40, 83-113. doi: 10.1207/s15326950dp4002_1

Dabkowski, B. (2000). The history of peer tutoring. Retrieved from http://wrtintertext.syr.edu/VIII/dabkowski.html

Davenport, O., Good-Majah, C., Johnson, J., Schollaet, A., \& Visor, J. (1995).

Supplemental instruction's impact on affect: A follow-up and expansion. In Proceedings from the 20th Century Annual Conference on Developmental Education (pp. 36-37). Chicago, IL: National Association for Developmental Education.

Dawson, P., van der Meer, J., Skalicky, J., \& Cowley, K. (2014). On the effectiveness of supplemental instruction: A systematic review of supplemental instruction and peer-assisted study sessions literature between 2001 and 2010. Review of Educational Research, 84(4), 609-639.

De Backer, L., Van Keer, H., \& Valcke, M. (2012). Exploring the potential impact of recoprocal peer tutoring on higher education students' metacognitive knowledge and regulation. Instructional Science, 40(3), 559-588.

Deese-Roberts, S. (2003). Tutor training handbook. Lenexa, Kansas: College Reading and Learning Association.

De Fazio, T., \& Ketenon, A. (2012). Quality assurance in a consortium: Open universities Australia. In I. Jung \& C. Latchem (Eds.) Quality assurance and accreditation in distance education: Models, policies, and research. (pp. 124-135). New York, NY: Routledge. 
de Freitas, S., \& Neumann, T. (2009). Pedagogic strategies supporting the use of synchronous audio conferencing: a review of the literature. British Journal of Educational Technology, 40(6), 980-998.

Denzin, N. K., \& Lincoln, Y. S. (2011). The SAGE handbook of qualitative research. Thousand Oaks, CA: Sage.

Develotte, C., Guichon, N., \& Vincent, C. (2010). The use of the webcam for teaching a foreign language in a desktop videoconferencing environment. $\operatorname{Re} C A L L, 22(3)$, 293-312.

Doherty, B. \& Atkinson, M. (2004). A pilot study of online tutoring using Smarthinking. PowerPoint presentation. Retrieved from http://www.smarthinking.com

Duffey, T. \& Hodges, R. (2003). Establishing a helping relationship: Facilitating verbal and non-verbal communication. Tutor Training Handbook, 65-75.

Duffy, T.M., Dueber, B., \& Hawley, C.L. (1998). Critical thinking in a distributed environment: A pedagogical base for the design of conferencing systems. In C.H. Bonk \& K.S. Kind (Eds.), Electronic collaborators: Learner-centered techniques for literacy, apprenticeship, and discourse (pp. 51-79). Mahwah, NJ: Erlbaum.

Ehly, S., \& Larsen, C. (1980). Peer tutoring for individualized instruction. Boston, MA: Ally and Bacon.

Eig, J. (1997). Supplemental instructional programs: An effective way to increase student academic success? Journal of the Indiana University Student Personnel Association, 1997, 11-15.

Einon, G. (2010). Managing computer-supported collaboration. In A. Brechin, H. Brown, \& M. A. Eby (Eds.), Online communication and collaboration: A reader. (pp. 2629). Abingdon, England: Routledge.

Evans, M. J., \& Moore, J. S. (2013). Peer tutoring with the aid of the Internet. British Journal of Educational Technology, 44(1), 144-155.

Falchikov, N. (2001). Learning together. Peer tutoring in higher education. London, England: Routledge Falmer. 
Fantuzzo, J. W., Dimeff, L. A., \& Fox, S. L. (1989). Reciprocal peer tutoring: A multimodal assessment of effectiveness with college students. Teaching of Psychology, 16(3), 133-135.

Fantuzzo, J. W., Riggio, R. E., Connelly, S., \& Dimeff, L. A. (1989). Effects of reciprocal peer tutoring on academic achievement and psychological adjustment: A component analysis. Journal of Educational Psychology, 81(2), 173-177.

Fields, R. (2014). Towards the National Assessment of Educational Progress (NAEP) as an indicator of academic preparedness for college and job training. Washington, DC: National Assessment Governing Board.

Finkelstein, J. (2006). Learning in real time. San Francisco, CA: Jossey Bass.

Flowers, A. T. (2007). NCLB spurs growth in online tutoring options. School Reform News. Chicago, IL: The Heartland Institute Retrieved from http://www.heartland.org/Article.cfm?artId=20426.

Fowler, F. J. (2002). Survey research methods. Thousand Oaks, CA: Sage.

Furr, P. F., \& Ragsdale, R. G. (2002). Desktop video conferencing. Education and Information Technologies, 7(4), 295-302.

Gabriel, K. F. (2008). Teaching unprepared students: Strategies for promoting success and retention in higher education. Sterling, VA: Stylus.

Gardner, R., Nobel, M., Hessler, T., Yawn, C., \& Heron, T. (2007). Tutoring system innovations: Past practice and future prototypes. Intervention in School and Clinic, 43(2), 71-81.

Gaustad, J. (1993). Peer and cross-age tutoring. ERIC, 1-5. retrieved from https://scholarsbank.uoregon.edu/xmlui/bitstream/handle/1794/3300/digest079.pd $\mathrm{f}$ ? sequence $=1$ \&is Allowed $=\mathrm{y}$

Gerlaugh, K., Thompson, L., Boylan, H., \& Davis, H. (2007). National study of developmental education II: Baseline data for community colleges. Research in Developmental Education, 20(4), 1-4. 
Glaser, B. G. (1978). Theoretical sensitivity: Advances in the methodology of grounded theory. Mill Valley, CA: Sociology Press.

Goldstein, M. T., \& Perin, D. (2008). Predicting performance in a community college content-area course from academic skill level. Community College Review, 36(2), 89-115.

Goodlad, S. (1998). Mentoring and tutoring by students. London, England: Kogan Page Limited.

Gordon, E. E., \& Gordon, E. H. (1990). Centuries of tutoring- a history of alternative education in America and western Europe. Lanham, MD: University Press of America.

Grbich, C. (2007). Qualitative data analysis: An introduction. Thousand Oaks, CA: Sage.

Greene, B., Lewis, L., \& Parsad, B. (2003). Remedial education at degree-granting postsecondary institutions in fall 2000. Washington, DC: National Center for Educational Statistics, U.S. Department of Education, Institution of Education Sciences

Greene, J. P., \& Winters, M. A. (2005). Public high school graduation and collegereadiness rates: 1991-2001. (Education Working Paper No. 8). New York: Center for Civic Innovation at the Manahattan Institute.

Guichon, N. (2009). Training future language teachers to develop online tutors' competence through reflective analysis. ReCALL, 21(02), 166-185.

Halcomb, E. J. \& Davidson, P. M. (2006). Is verbatim transcription of interview data always necessary? Applied Nursing Research, 19, 38-42.

Hara, N., Bonk, C. J., \& Angeli, C. (2000). Content analysis of online discussion in an applied educational psychology course. Instructional science, 28(2), 115-152.

Harrell, M. C. \& Bradley, M. A. (2009). Data collection methods: Semi-structuctured interviews and focus groups. Santa Monica, CA: RAND Corporation.

Have, P. T. (2004). Understanding qualitative research and ethnomethodology. London: Sage. 
Hawkins, T. (1980). Intimacy and audience: The relationship between revision and the social dimension of peer tutoring. College English, 42(1), 64-68.

Hellstrom, M., Johannesson, C., Karlsson, G., \& Thorbiornson, J. (2007). Net based examination: Small group tutoring, home assignments, and large group automatic and peer assessment. International Journal of Emerging Technologies in Learning, 2(3), 16-20.

Herppich, S., Wittwer, J., Nuckles, M., \& Renkl, A. (2014). Addressing knowledge deficits in tutoring and the role of teaching experience: Benefits for learning and summative assessment. Journal of Educational Psychology, 106(4), 935-945. doi: $10.1037 / \mathrm{a} 0036076$

Hiltz, S.R., Coppola, N., Rotter, N., Turoff, M., \& Benbunan-Fich, R. (1999). Measuring the importance of collaborative learning for the effectiveness of ALN: A multimeasure, multi-method approach. Journal of Asynchronous Learning Networks, $4(2), 103-125$.

Hizer, S. E., Schultz, P. W., \& Bray, R. (2017). Supplemental instruction online: As effective as the traditional face-to-face model?. Journal of Science Education and Technology, 26(1), 100-115.

Hodges, R., \& White, W. G. (2001). Encouraging high-risk student participation in tutoring and supplemental instruction. Journal of Developmental Education, 24(3), 2-10.

Horton, W. (2006). e-Learning by design. San Francisco, CA: Pfeiffer.

Hou, H. T., Wu, S. Y. (2011). Analyzing the social knowledge construction behavioral patterns of a synchronous collaborative discussion instructional activity using an instant messanging tool: a case study. Computers \& Education, 57(2), 1459-1468.

Hrastinski, S. (2008). The potential of synchronous communication ot enhance participation in online discussions: A case study of two e-learning courses. Information \& Management, 45, 499-506. 
Hsiao, E. \& Huang, X. (2012). Synchronous and asynchronous communication in an online environment: Faculty experiences and perceptions. Quarterly Review of Distance Education, 13(1), 15-30.

Huang, C.W., \& Liu, E.Z.F. (2015). The learning satisfaction, attitudes, and grades of etutees receiving online English tutoring. International Journal of Online Pedagogy and Course Design, 5(3), 17-30.

Hughes, A. N., Gibbons, M. M., \& Mynatt, B. (2013). Using narrative career counseling with the underprepared college student. The Career Development Quarterly, 61(1), 40-49.

International Tutor Training Program Certification Requirements-ITTPC. (2015, March). Retrieved from https://www.crla.net/index.php/certifications/ittpcinternational-tutor-training-program.

Jenkins, D. (2011). Get with the program: Accelerating community college students' entry into and completion of programs of study. CCRC Working Paper No. 32. Community College Research Center, Columbia University.

Jennings, M., \& Bronack, S. C. (2001). The use of desktop video conferencing as a medium for collaboration between beginning instructional designers and intern teachers. International Journal of Educational Telecommunications, 7(2), 91-107.

Johns, C. (2009). Becoming a reflective practitioner (3rd ed.). San Francisco, CA: Wiley. Jopling, M. (2012). 1: 1 online tuition: a review of the literature from a pedagogical perspective. Journal of Computer Assisted Learning, 28(4), 310-321.

Jung, L. A., Gaylon-Keramidas, C., Collins, B., \& Ludlow, B. (2006). Distance education strategies to support practica in rural settings. Rural Special Education Quarterly, 25(2), 18-24.

Kaplan, G. (2014). MIA: Accuplacer prep. New England Journal of Higher Education. Retrieved from http://www.nebhe.org/thejournal/mia-accuplacer-prep. 
Kear, K., Chetwynd, F., Williams, J., \& Donelan, H. (2012). Web conferencing for synchronous online tutorials: Perspectives of tutors using a new medium. Computers \& Education, 58(3), 953-963.

Kellogg, D. L., \& Smith, M. A. (2009). Student-to-student interaction revisited: A case study of working adult business students in online courses. Decision Sciences Journal of Innovative Education, 7(2), 433-456.

Kisker, C. B. (2015). What can we learn from the Sixth Edition of "The American Community College": CSCC Awards Luncheon Address. Community College Journal of Research and Practice, 39(4), 308-313.

Knapp, L. G., Kelly-Reid, J. E., \& Ginder, S. A. (2011). Postsecondary Institutions and Price of Attendance in the United States: 2010-11, Degrees and Other Awards Conferred: 2009-10, and 12- Month Enrollment: 2009-10 (NCES 2011-250). Institute of Education Sciences, U.S. Department of Education. Washington, DC: National Center for Education Statistics

Knipe, D., \& Lee, M. (2002). The quality of teaching and learning via videoconferencing. British Journal of Educational Technology, 33(3), 301-311.

Krefting, L. (1991). Rigor in qualitative research: The assessment of trustworthiness. American Journal of Occupational Therapy, 45(3), 214-222.

LaPointe, D. K., Greysen, K. R. B., \& Barrett, K. A. (2004). Speak2Me: Using synchronous audio for ESL teaching in Taiwan. The International Review of Research in Open and Distance Learning, 5(1). Retrieved from: http://www.irrodl.org/index.php/irrodl/article/view/166/386

Lau, L. K. (2003). Institutional factors affecting student retention. Education, 124, 126136. Retrieved from http//www.projectinnovation.biz/index.html.

Lazerson, D. B. (1980). I must be good if I can teach! Peer-tutoring with aggressive and withdrawn children. Journal of Learning Disabilities, 13(3), 152-157. doi: 10.1177/002221948001300309

Lederman, N. G., \& Lederman, J. S. (2015). What is theoretical framework? A practical answer, Journal of Science Teacher Education, 26(7), 593-597. 
Leech, N. L.\& Onwuegbuzie, A. J. (2007). An array of qualitative data analysis tools: A call for data analysis triangulation. School Psychology Quarterly, 22(4), 557-584).

Leedy, P. D. \& Ormrod, J. E. (2010). Practical research: Planning and design. Upper Saddle River, NJ: Merrill.

Leone, M., \& Tian, R. G. (2009). Push vs pull: Factors influence student retention. American Journal of Economics and Business Administration, 1(2), 122-132.

Lewins, A., \& Silver, C. (2007). Using software in qualitative research: A step-by-step guide. London: Sage.

Lewis, J. L. \& Sheppard, S. R. J. (2006). Culture and communication: Can landscape visualization improve forest management consultation with indigenous communities? Landscape and Urban Planning, 77, 291-313.

Lincoln, Y. S., \& Guba, E. G. (1985). Naturalistic inquiry. Beverly Hills, CA: Sage.

Linton, R. (1945). The cultural background of personality. New York, NY: AppletonCentury.

Loch, B., \& Reushle, S. (2008). The practice of web conferencing: Where are we now? In Proceedings of the $25^{\text {th }}$ Annual Conference of the Australasian Society for Computers in Learning Tertiary Education (ASCILITE 2008), (pp. 562-571). Proceedings of the $25^{\text {th }}$ Annual Conference of the Australian Society for Computers in Learning in Tertiary Education. (ASCILITE).

Luszczynska, A., \& Schwarzer, R. (2005). Social cognitive theory. Predicting Health Behaviour, 2, 127-169.

MacDonald, R. B. (2000). The master tutor: A guidebook for more effective tutoring ( $2^{\text {nd }}$ ed.). Williamsville, NY: Cambridge Stanford, Limited.

Mack, N., Woodsong, C., MacQueen, K. M., Guest, G., \& Namey, E. (2005). Qualitative research methods: A data collector's field guide. Raleigh, NC: Family Health International.

Mariano, C. (1990). Qualitative research: Instructional strategies and curricular considerations. Nursing and Health Care, 11(7), 354-359. 
Martin, D. C., Lorton, M., Blanc, R. A., \& Evans, C. (1977). The learning center: A comprehensive model for colleges and universities. Kansas City, MO: University of Missouri.

Martin, F., \& Parker, M.A. (2014). Use of synchronous virtual classrooms: Why, who, and how? Journal of Online Learning and Teaching, 10(2), 192-210.

Martin, F., Parker, M.A., \& Deale, D.F. (2012). Examining interactivity in synchronous virtual classrooms. The International Review of Research in Open and Distributed Learning, 13(3), 228-261.

Martin, J. \& Zajchowski, R. (1993). Differences in the problem solving of stronger and weaker novices in physics: Knowledge, strategies, or knowledge structure?. Journal of Research in Science Teaching, 30(5), 459-470.

Marshall, C. \& Roseman, G. (1995). Designing qualitative research. London: Sage. Maruyama, G. (2012). Assessing college readiness should we be satisfied with ACT or other threshold scores? Educational Researcher, 41(7), 252-261.

McBrien, J. L., Cheng, R., \& Jones, P. (2009). Virtual spaces: Employing a synchronous online classroom to facilitate student engagement in online learning. The International Review of Research in Open and Distributed Learning, 10(3). Retrieved from http://www.irrodl.org/index.php/irrodl/article/ view/605/1264

McClarty, K. L., \& Gaertner, M. N. (2015). Measuring mastery: Best practices for assessment in competency-based education. Washington DC: American Enterprise Institute for Public Policy Research.

Mead, G. H. (1935). Mind, self, and society, In C. W. Morris (Ed.), Works of Mead (pp. 223-234). Chicago, IL: University of Chicago Press.

Merriam, S. B. (2009). Qualitative research: A guide to design and implementation. San Francisco, CA: John Wiley \& Sons.

Meyer, C. B. (2001). A case in case study methodology. Field Methods, 13(4), 329-352.

Miles, M. B., \& Huberman, A. M. (1994). Qualitative data analysis: An expanded sourcebook. Thousand Oaks, CA: Sage. 
Mize, C.D. (1996). Desktop video communication. TechTrends, 41(6), 44-47.

Moore, M. G. (1989). Editorial: Three types of interaction. American Journal of Distance Education, 3(2), 1-7.

Moore, M. G., \& Kearsley, G. (1996). Distance education: A systems approach. Boston, MA: Wadsworth.

Moust, J. H. C., \& Schmidt, H. G. (1995). Facilitating small-group learning: A comparison of student and staff tutors' behavior. Instructional Science, 22, 287301.

National Center for Supplemental Instruction. (1997). Supplemental Instruction (SI): Review of research concerning the effectiveness of SI from the University of Missouri-Kansas City and other institutions across the United States. Kansas City, MI: University of Missouri-Kansas City, Center for Academic Development.

Nelson-Royes, A. M. (2015). Why tutoring?: A way to achieve success in school. Lanham, MD: Rowman \& Littlefield.

Okilwa, N. S., \& Shelby, L. (2010). The effects of peer tutoring on academic performance of students with disabilities in grades 6 through 12: A synthesis of the literature. Remedial and Special Education, 31(6), 450-463.

Ory, J. C., \& Bullock, C. (1997). Student use and attitudes about On-Campus ALN. In Proceedings of the 1997 27th Annual Conference on Frontiers in Education (pp. 416-431). Piscataway, NJ: IEEE.

Palinkas, L. A., Horwitz, S. M., Green, C. A., Wisdom, J. P., Duan, N., \& Hoagwood, K. (2015). Purposeful sampling for qualitative data collection and analysis in mixed method implementation research. Administration and Policy in Mental Health and Mental Health Services Research, 42(5), 533-544.

Palmquist, M. (2003). A brief history of computer support for writing centers and writing-across-the-curriculum programs. Computers and Composition, 20(4), 395-413. Doi: 10.1016/j.compcom.2003.08.013. 
Paquette, K. R. (2008). Study of elementary students' attitudes about writing after a cross-age tutoring experience. Reading Improvement, 45(4), 181-191.

Park, S. W., \& Kim, C. (2016). The effects of a virtual tutee system on academic reading engagement in a college classroom. Education Technology Research Development, 64, 1995-218. doi: 10.1007/s11423-015-9416-3.

Park, Y. J., \& Bonk, C. J. (2007). Synchronous learning experiences: Distance and residential learners' perspectives in a blended graduate course. Journal of Interactive Online Learning, 6(3), 245-264.

Parker, M. A., \& Martin, F. (2010). Using virtual classrooms: Student perceptions of features and characteristics in an online and blended course. Journal of Online Learning and Teaching, 6(1), 135-147.

Parker, T., L., Barrett, M. S., \& Bustillos, L. T. (2014). Developmental education as a strategy toward state and institutional goals. In T. L. Parker, M. S. Barrett, and L. T. Bustillos (Eds.) The State of Developmental Education (pp. 33-39). New York, NY: Palgrave Macmilli3an.

Pascarella, E. T., \& Terenzini, P. T. (2005). How college affects students (Vol. 2): A third decade of research. San Francisco, CA: Jossey-Bass.

Pattillo, R. E. (2007). Decreasing transactional distance in a Web-based course. Nurse educator, 32(3), 109-112.

Patton, M. Q. (2002). Qualitative evaluation and research methods. Thousand Oaks, CA: Sage.

Perin, D. (2004). Remediation beyond developmental education: The use of learning assistance centers to increase academic preparedness in community colleges. Community College Journal of Research \& Practice, 28(7), 559-582.

Perin, D. (2005). Institutional decision making for increasing academic preparedness in community colleges. New Directions for Community Colleges, 2005(129), 27-38.

Persad, B., \& Lewis, L. (2008). Distance education at degree-granting postsecondary institutions: 2006-2007 (NCES2009-044). Washington, DC: National Center for 
Education Statistics, Institute of Education Sciences, U.S. Department of Education.

Pettigrew, A. M., (1990). Longitudinal field research on change: Theory and practice. Organizational Science, 1(3), 267-292.

Poellhuber, B., Chomienne, M., \& Karsenti, T. (2008). The effect of peer collaboration and collaborative learning on self-efficacy and persistence in a learner-paced continuous intake model. Journal of Distance Education, 22(3), 41-62.

Porter, A. C., \& Polikoff, M. S. (2012). Measuring academic readiness for college. Educational Policy, 26(3), 394-417.

Powell, M. A. (1997). Peer tutoring and mentoring services for disadvantaged secondary school students. Project Summaries, 4(2), 33-43.

Price, L., Richardson, J. T. E., \& Jelfs, A. (2007). Face-to-face versus online tutoring support in distance education. Studies in Higher Education, 32(1), 1-20.

Radford, A. W., Berkner, L., Wheeless, S. C., \& Shepherd, B. (2010). Persistence and attainment of 2003-04 beginning postsecondary students: After 6 years. Jessup, MD: National Center for Educational Statistics.

Rapoport, T., Yair, G., \& Kahane, R. (1989). Tutorial relations: The dynamics of social contract and personal trust. Interchange 20, 14-26.

Rehn, N., Maor, D., \& McConney, A. (2016). Investigating teacher presence in courses using synchronous videoconferencing. Distance Education, 37(3), 302-316.

Reid, M. J. \& Moore, J. L. (2008). College readiness and academic preparation for postsecondary education: Oral histories of first-generation urban college students. Urban Education, 43(2), 240-261.

Rheinheimer, D. C., Grace-Odeleye, B., Francois, G. E., \& Kusorgbor, C., (2010). Tutoring: A support strategy for at-risk students. Learning Assistance Review, 15(1), 23-34.

Richards, L., \& Morse, J. M. (2007). Readme first for a user's guide to qualitative methods (2nd ed.). Thousand Oaks, CA: Sage. 
Richardson, J. T. E. (2012). Face-to-face versus online tuition: Preference, performance and pass rates in white and ethcic minority students. British Journal of Educational Technology, 43(1), 17-27.

Rippa, S. A. (1997). Education in a free society: An American history. White Plains, NY: Addison Wesley Longman.

Rivas, C. (2012). Coding and analyzing qualitative data, In C. Steele (Ed.), Researching society and culture. (pp. 368-386). Thousand Oaks, CA: Sage.

Robinson, D. R., Schofield, J. W., \& Steers-Wentzell, K. L. (2005). Peer and cross-age tutoring in math: Outcomes and their design implications. Educational Psychology Review, 17(4), 327-362.

Rockinson-Szapkiw, A.J., \& Walker, V. L. (2009). Web 2.0 technologies: Facilitating interaction in an online human services counseling skills course. Journal of Technology in Human Services, 27(3), 175-193.

Roscoe, R. D., \& Chi, M. T. (2007). Understanding tutor learning: Knowledge-building and knowledge-telling in peer tutors' explanations and questions. Review of Educational Research, 77(4), 534-574.

Rose, A. M. (1962). A systematic summary of symbolic interaction theory. In A. M. Rose (Ed.), Human behavior and social processes: An interactionist approach (pp. 317) Boston, MA: Houghton Mifflin.

Rothbell, G. (1991). Just as housewife: Role-image and the stigma of the single role. In J. R. Blau, R. L. Coser, \& N. Goodman (Eds.) Social Roles and Social Institutions: Essays in Honor of Rose Laub Coser (pp. 21-26). Piscataway, NJ: Transaction Publishers.

Rovai, A. P. (2001). Classroom community at a distance: A comparative analysis of two ALN-based university programs. The Internet and Higher Education, 4(2), 105118.

Rubin, H. J., \& Rubin, I. S. (1995). Qualitative interviewing: The art of hearing data. Thousand Oaks, CA: Sage. 
Rutschow, E. Z., \& Schneider, E. (2012). Unlocking the gate: What we know about improving developmental education. MDRC Paper, 1-116. Retrieved from https://papers.ssrn.com/sol3/papers2.cfm?abstract_id=2019763. Doi: $10.2139 /$ ssrn.2019763

Saldana, J. (2009). The coding manual for qualitative researchers. Thousand Oaks, CA: Sage.

Saldana, J. (2015). The coding manual for qualitative researchers. Thousand Oaks, CA: Sage.

Salmon, G. (2012). E-moderating: The key to teaching and learning. New York, NY: Routledge.

Sansone, N., Ligorio, M. B., \& Buglass S. L. (2016). Peer e-tutoring: Effects on students' participation and interaction style in online courses. Innovations in Education and Teaching International, O(0), 1-10. Doi: 10.1080/14703297.2016.1190296

Sarbin, T. R., \& Vernon, L. A. (1968). Role Theory. In G. Lindzey \& E. Aronson (Eds.), The Handbook of Social Psychology (Vol. 1) (pp. 488-559). Reading, MA: Addison-Wesley.

Saunders, D. (1992). Peer tutoring in higher education. Studies in Higher Education, 17(2), 211-218. doi: 10.1080/03075079212331382677

Schuster, J. H., \& Finkelstein, M. J. (2006). The American faculty: The restructuring of academic work and careers. Baltimore, MD: Johns Hopkins University Press.

Scruggs, T. E., \& Osguthorpe, R. T. (1986). Tutoring interventions within special education settings: a comparison of cross-age and peer tutoring, Psychology in the Schools, 23(2), 187-193.

Schavelson, R. J., Young, D. B., Ayala, C. C., Brandon, P. R., Furtak, E. M., Ruiz-Primo, M. A., ... Yin, Y. (2008). On the impact of curriculum-embedded formative assessment on learning: A collaboration between curriculum and assessment developers. Applied Measurement in Education, 21, 295-314. Doi:

$10.1080 / 08957340802347647$ 
Shaw, S. T. \& Skomsvold, P. L. (2015). Pit stops and pitfalls of the Yellow Brick Road: Demographics and characteristics of community college students along the path of degree completion. RTI International, 1-19. doi: 10.13140/RG.2.1.2850.8004

Shepard, L. A., Hammerness, K., Darling, Hammond, L., \& Rust, F. (with BaratzSnowden, J., Gordon, E., Gutierrez, C., \& Pacheco, A.). (2005). Assessment. In L. Darling-Hammond \& J. Bransford (Eds.), Preparing teachers for a changing world: What teachers should learn and be able to do (pp. 275-326). San Francisco, CA: Josey-Bass.

Slavin, R.E. (1987). Making chapter 1 makes a difference. Phi Delta Kappan, 69(2), 110119.

Snedecor, G. W. (1939). Design of sampling experiments in the social sciences. Journal of Farm Economics, 21, 846-855.

Solomon, M. R., Surprenant, C., Czepiel, J. A., \& Gutman, E. G. (1985). A role theory perspective on dyadic interactions: The service encounter, 49(1), 99-111.

Southern Association of Colleges and Schools Commission on Colleges. (2011). Handbook for institutions seeking reaffirmation. Decator, GA: Southern Association of Colelges and Schools Commission on Colleges.

Stake, R. E. (1995). The art of case study research. Thousand Oaks, CA: Sage.

Stephen, D. E., O'Connell, P., \& Hall, M. (2008). Going the extra mile, fire-fighting, or laissez faire? Re-evaluating personal tutoring relationships within mass higher education. Teaching in Higher Education, 13(4), 449-460.

Stern, S. (2001). Learning assistance centers: Helping students through. ERIC Digest ED 45901. Los Angeles, CA: ERIC Clearinghouse for Community Colleges.

Sternberg, R. J. (1985). Beyond IQ: A triarchic theory of human intelligence. New York, NY: Cambridge University Press.

Stickler, U., \& Hampel, R. (2002). Designing online tutor training for language courses: A case study. Open Learning, 22(1), 75-85. 
Strauss, A. L. (1987). Qualitative analysis for social scientists. Cambridge: Cambridge University Press.

Sullivan, M. (2011). Behind America's tutor boom. MarketWatch Inc. Retrieved from http://www.marketwatch.com/story/behind-americas-tutor-boom1318016970246.

Swan, K. (2003). Learning effectiveness: What the research tells us. In J. Bourne \& J. Moore (Eds.), Elements of quality online education: Practice and direction (pp. 13-46). Needham, MA: The Sloan Consortium.

Swann, J. (2010). A dialogic approach to online facilitation. Australian Journal of Educational Technology, 26(1), 50-62.

Swanson, R. A. \& Chermack, T. J. (2013). Theory building in applied disciplines. San Francisco, CA: Berrett-Koehler.

Tan, P. J. B. (2013). Students' adoptions and attitudes towards electronic placement tests: A UTAUT analysis. American Journal of Computer Technology and Applications, 1(1), 14-24.

Tansy, M., \& de Barona, M. (1996). Peer and cross-age tutoring programs. Guidance \& Counseling, 12(1), 21-25.

Thomas, E., \& Magilvy, J. K. (2011). Qualitative rigor or research validity in qualitative research. Journal for Specialists in Pediatric Nursing, 16(2), 151-155.

Thurston, A., Duran, D., Cunningham, E. Blanch, S., \& Topping, K. (2009). International on-line reciprocal peer tutoring to promote modern language development in primary schools. Computers \& Education, 53(2), 462-472.

Tinto, V. (2000). Linking learning and leaving: Exploring the role of college classroom in student departure. In J. Braxton (Ed.), Reworking the student departure puzzle (pp. 81-94). Nashville, TN: Vanderbilt University Press.

Tongco M. D. C. (2007). Purposeful sampling as a tool for informant selection. Ethnobotany Research \& Applications, 5, 147-158. 
Topping, K. J. (1988). The peer tutoring handbook: Promoting co-operative learning. London: Routledge.

Topping, K. J. (1996). The effectiveness of peer tutoring in further and higher education: A topology and review of the literature. Higher Education, 32, 321-345.

Topping, K. J. (1998). The effectiveness of peer tutoring in further and higher education: A typology and review of the literature. In S. Goodlad (Ed.), Mentoring and tutoring by students, (pp. 49-69). London: Kogan Page.

Topping, K. J. (2005). Trends in peer learning. Educational Psychology, 25, 631-645.

Topping, K. J., \& Bryce, A. (2004). Cross-age peer-tutoring of reading and thinking: Influence on thinking skills. Educational Psychology, 24(5), 595-621. doi: 10.1080/0144341042000262935

Topping, K. J., Campbell, J., Douglas, W., \& Smith, A. (2003). Cross-age peer-tutoring in mathematics with seven- and 11-year-olds: Influence on mathematical vocabulary, strategic dialogue and self-concept. Educational Research, 45(3), 287-308. doi: 10.1080/0013188032000137274

Topping, K. J., Peter, C. Stephen, P., \& Whale, M. (2004). Cross-age peer tutoring of science in the primary school: Influence on scientific language and thinking. Educational Psychology, 24(1), 57-75. doi: 10.1080/0144341032000146449

Tsuei, M. (2012). Using synchronous peer tutoring system to promote elementary students' learning in mathematics. Computers \& Education, 58(4), 1171-1182.

Turner, R. H. (1990). Role change. Annual Review of Sociology, 16(1), 87-110.

Turrentine, P., \& MacDonald, L. (2006). Tutoring online: Increasing effectiveness with best practices. National Association for Developmental Education, 2(2), 9-18.

University of North Dakota Learning Center. (2004). Smarthinking. Retrieved from http://www.und.edu/dept/ULC/smarthinking.html

Utley, C. A., Mortweek, S. L., \& Greenwood, C. R. (1997). Peer-mediated instruction and instructions. Focus on Exceptional Children, 29(5), 1-23. 
VanLehn, K. (2011). The relative effectiveness of human tutoring, intelligent tutoring systems, and other tutoring systems. Educational Psychologist, 46(4), 197-221. doi: 10.1080/00461520.2011.611369

Vasquez, E., \& Slocum, T. A. (2012). Evaluation of synchronous online tutoring for students at risk of reading failure. Exceptional Children, 78(2), 221-235.

Vasquez, E., Forbush, D. E., Mason, L. L., Lockwood, A. R., \& Gleed, L. (2011). Delivery and evaluation of synchronous online reading tutoring to students at-risk of reading failure. Rural Special Education Quarterly, 30(3), 16-26.

Vogt, W. P., Gardner, D. C., Haeffele, L. M., \& Vogt, E. R. (2014). Selecting the right analyses for your data: Quantitative, qualitative, and mixed methods. New York, NY: Guilford Publications.

Vonderwell, S. (2003). An examination of asynchronous communication experiences and perspectives of students in an online course. A case study. The Internet and Higher Education, 6(1), 77-90.

Vygotsky, L. S. (1978). Mind in society: The development of higher psychological processes. Cambridge, MA: Harvard University Press.

Wagner, L. (1990). Social and historical perspectives on peer teaching in education. In H.C. Foot, M.J. Morgan, and R.H. Schute (Eds.), Children helping children (pp. 21-42). Chichester, England: Wiley.

Wang, Y. (2004). Supporting synchronous distance language learning with desktop videoconferencing. Language Learning \& Technology, 8(3), 90-121.

Weitz, B. A. (1981). Effectiveness in sales interactions: A contingency framework, Journal of Marketing, 45(Winter), 85-103.

Wengraf, T. (2001). Qualitative research interviewing: Biographic narrative and semi structured methods. Thousand Oaks, CA: Sage

Wilkinson, K. L., \& Hemby, K. V. (2000). An examination of perceptions of the use of virtual conferences in organizations: The Organizational Systems Research Association (OSRA) and the Association for Business Communication (ABC) 
members speak out. Information Technology, Learning, and Performance Journal, 18(2), 13-23.

Williams, E. A., Duray, R., \& Reddy, V. (2006). Teamwork orientation, group cohesiveness, and student learning: A study of the use of teams in on-line distance education. Journal of Management Education, 30(4), 592-616.

Wood, D., Bruner, J. S., \& Ross, G. (1976). The role of tutoring in problem solving. Journal of Child Psychiatry and Psychology, 17, 89-100.

Wright, J., \& Cleary, K. S. (2006). Kids in the tutor seat: Building schools' capacity to help struggling readers through a cross-age peer-tutoring program. Psychology in the Schools, 43(1), 99-107. doi: 10.1002/pits.20133.

Wu, E., Lin, W. C., \& Yang, S. C. (2013). An experimental study of cyber face-to-face vs. cyber text-based English tutorial programs for low-achieving university students. Computers \& Education, 63(1), 52-61.

Wu, W. V., \& Marek, M. (2010). Making English a "habit": Increasing confidence, motivation, and ability of EFL students through cross-cultural, computer-assisted interaction. Turkish Online Journal of Educational Technology, 9(4), 100-112.

Xenos, M., Avouris, N., Stravinoudis, D., \& Margaritis, M. (2009). Introduction of synchronous peer collaboration activities in a distance learning course. IEEE Transactions on Education, 52(3), 305-311.

Yin, R. K. (2003). Case study research: Design and methods (3rd ed.). Thousand Oaks, CA: Sage.

Yin, R. K. (2012). Applications of case study research ( $3^{\text {rd }}$ ed.). Thousand Oaks, CA: Sage.

Yin, R. K. (2014). Case Study research design and methods ( $5^{\text {th }}$ ed.). Thousand Oaks, CA: Sage 